\title{
Synthesis of 2,4-Disubstituted Piperidines via Radical Cyclization: Unexpected Enhancement in Diastereoselectivity with Tris(trimethylsilyl)silane
}

Lucile A. Gandon, Alexander G. Russell, Tatyana Güveli, Angela E. Brodwolf, Benson M. Kariuki, Neil Spencer and John S. Snaith*

Spectral Data

S8
S9
S10
S11
S12
S13
S14
S15
S16
S17
S18
S19
S20
S21
S22
S23

${ }^{1} \mathrm{H}$ NMR Spectrum $(300 \mathrm{MHz})$ of 1 in $\mathrm{CDCl}_{3}$

${ }^{13} \mathrm{C}$ NMR Spectrum $(75 \mathrm{MHz})$ of $\mathbf{1}$ in $\mathrm{CDCl}_{3}$

${ }^{1} \mathrm{H}$ NMR Spectrum $(300 \mathrm{MHz})$ of 2 in $\mathrm{CDCl}_{3}$

${ }^{13} \mathrm{C}$ NMR Spectrum $(75 \mathrm{MHz})$ of 2 in $\mathrm{CDCl}_{3}$

${ }^{1} \mathrm{H}$ NMR Spectrum $(500 \mathrm{MHz})$ of $\mathbf{3}$ in $\mathrm{CDCl}_{3}$

${ }^{13} \mathrm{C}$ NMR Spectrum $(125 \mathrm{MHz})$ of $\mathbf{3}$ in $\mathrm{CDCl}_{3}$

${ }^{1} \mathrm{H}$ NMR Spectrum $(500 \mathrm{MHz})$ of 4 in $\mathrm{CDCl}_{3}$

${ }^{13} \mathrm{C}$ NMR Spectrum $(125 \mathrm{MHz})$ of 4 in $\mathrm{CDCl}_{3}$

${ }^{1} \mathrm{H}$ NMR Spectrum (300 MHz) of $N$-tosyl alaninol in $\mathrm{CDCl}_{3}$

${ }^{13} \mathrm{C}$ NMR Spectrum $(75 \mathrm{MHz})$ of $N$-tosyl alaninol in $\mathrm{CDCl}_{3}$

${ }^{1} \mathrm{H}$ NMR Spectrum (300 MHz) of $N$-tosyl phenylalaninol in $\mathrm{CDCl}_{3}$

${ }^{13} \mathrm{C}$ NMR Spectrum $\left(75 \mathrm{MHz}\right.$ ) of $N$-tosyl phenylalaninol in $\mathrm{CDCl}_{3}$

${ }^{1} \mathrm{H}$ NMR Spectrum $(300 \mathrm{MHz})$ of $N$-tosyl valinol in $\mathrm{CDCl}_{3}$

${ }^{13} \mathrm{C}$ NMR Spectrum $\left(75 \mathrm{MHz}\right.$ ) of $N$-tosyl valinol in $\mathrm{CDCl}_{3}$

${ }^{1} \mathrm{H}$ NMR Spectrum (300 MHz) of N-tosylleucinol in $\mathrm{CDCl}_{3}$

${ }^{13} \mathrm{C}$ NMR Spectrum $\left(75 \mathrm{MHz}\right.$ ) of N-tosylleucinol in $\mathrm{CDCl}_{3}$ 
${ }^{1} \mathrm{H}$ NMR Spectrum (300 MHz) of N-tosylisoleucinol in $\mathrm{CDCl}_{3}$

${ }^{13} \mathrm{C}$ NMR Spectrum $(75 \mathrm{MHz})$ of $\mathrm{N}$-tosylisoleucinol in $\mathrm{CDCl}_{3}$

${ }^{1} \mathrm{H}$ NMR Spectrum (300 MHz) of $N$-tosyl phenylglycinol in $\mathrm{CDCl}_{3}$

${ }^{13} \mathrm{C}$ NMR Spectrum $\left(75 \mathrm{MHz}\right.$ ) of $N$-tosyl phenylglycinol in $\mathrm{CDCl}_{3}$

${ }^{1} \mathrm{H}$ NMR Spectrum $\left(300 \mathrm{MHz}\right.$ ) of $N$-tosyl tert-leucinol in $\mathrm{CDCl}_{3}$

${ }^{13} \mathrm{C}$ NMR Spectrum $(75 \mathrm{MHz})$ of $N$-tosyl tert-leucinol in $\mathrm{CDCl}_{3}-$ ts-tleu

${ }^{1} \mathrm{H}$ NMR Spectrum (300 MHz) of $\mathbf{8 a}$ in $\mathrm{CDCl}_{3}$

${ }^{13} \mathrm{C}$ NMR Spectrum $(75 \mathrm{MHz})$ of $\mathbf{8 a}$ in $\mathrm{CDCl}_{3}$

${ }^{1} \mathrm{H}$ NMR Spectrum (300 MHz) of $\mathbf{8 b}$ in $\mathrm{CDCl}_{3}$

${ }^{13} \mathrm{C}$ NMR Spectrum $(75 \mathrm{MHz})$ of $\mathbf{8 b}$ in $\mathrm{CDCl}_{3}$

${ }^{1} \mathrm{H}$ NMR Spectrum (300 MHz) of $8 \mathbf{c}$ in $\mathrm{CDCl}_{3}$

${ }^{13} \mathrm{C}$ NMR Spectrum $(75 \mathrm{MHz})$ of $\mathbf{8 c}$ in $\mathrm{CDCl}_{3}$

${ }^{1} \mathrm{H}$ NMR Spectrum $\left(300 \mathrm{MHz}\right.$ ) of $\mathbf{8 d}$ in $\mathrm{CDCl}_{3}$

${ }^{13} \mathrm{C}$ NMR Spectrum $\left(75 \mathrm{MHz}\right.$ ) of $\mathbf{8 d}$ in $\mathrm{CDCl}_{3}$

${ }^{1} \mathrm{H}$ NMR Spectrum $\left(300 \mathrm{MHz}\right.$ ) of $8 \mathbf{e}$ in $\mathrm{CDCl}_{3}$

${ }^{13} \mathrm{C}$ NMR Spectrum $(75 \mathrm{MHz})$ of $\mathbf{8 e}$ in $\mathrm{CDCl}_{3}$

${ }^{1} \mathrm{H}$ NMR Spectrum (300 MHz) of $\mathbf{8 f}$ in $\mathrm{CDCl}_{3}$

${ }^{13} \mathrm{C}$ NMR Spectrum $\left(75 \mathrm{MHz}\right.$ ) of $\mathbf{8 f}$ in $\mathrm{CDCl}_{3}$

${ }^{1} \mathrm{H}$ NMR Spectrum $\left(300 \mathrm{MHz}\right.$ ) of $\mathbf{8 g}$ in $\mathrm{CDCl}_{3}$

${ }^{13} \mathrm{C}$ NMR Spectrum $(75 \mathrm{MHz})$ of $\mathbf{8 g}$ in $\mathrm{CDCl}_{3}$

${ }^{1} \mathrm{H}$ NMR Spectrum (300 MHz) of $\mathbf{9 a}$ in $\mathrm{CDCl}_{3}$

${ }^{13} \mathrm{C}$ NMR Spectrum $\left(75 \mathrm{MHz}\right.$ ) of $\mathbf{9 a}$ in $\mathrm{CDCl}_{3}$

${ }^{1} \mathrm{H}$ NMR Spectrum (300 MHz) of $\mathbf{9 b}$ in $\mathrm{CDCl}_{3}$

${ }^{13} \mathrm{C}$ NMR Spectrum $(75 \mathrm{MHz})$ of $9 \mathbf{b}$ in $\mathrm{CDCl}_{3}$

${ }^{1} \mathrm{H}$ NMR Spectrum (300 MHz) of $9 \mathrm{c}$ in $\mathrm{CDCl}_{3}$

${ }^{13} \mathrm{C}$ JMOD NMR Spectrum $\left(75 \mathrm{MHz}\right.$ ) of $9 \mathrm{c}$ in $\mathrm{CDCl}_{3}$

${ }^{1} \mathrm{H}$ NMR Spectrum $(300 \mathrm{MHz})$ of $9 d$ in $\mathrm{CDCl}_{3}$

${ }^{13} \mathrm{C}$ NMR Spectrum $\left(75 \mathrm{MHz}\right.$ ) of $\mathbf{9 d}$ in $\mathrm{CDCl}_{3}$

${ }^{1} \mathrm{H}$ NMR Spectrum $\left(300 \mathrm{MHz}\right.$ ) of $9 \mathrm{e}$ in $\mathrm{CDCl}_{3}$

${ }^{13} \mathrm{C}$ NMR Spectrum $(75 \mathrm{MHz})$ of $9 \mathrm{e}$ in $\mathrm{CDCl}_{3}$

${ }^{1} \mathrm{H}$ NMR spectrum $(300 \mathrm{MHz})$ of 9 f in $\mathrm{CDCl}_{3}$

${ }^{13} \mathrm{C}$ NMR Spectrum $(75 \mathrm{MHz})$ of 9 f in $\mathrm{CDCl}_{3}$ 
${ }^{1} \mathrm{H}$ NMR Spectrum (300 MHz) of $\mathbf{9 g}$ in $\mathrm{CDCl}_{3}$

${ }^{13} \mathrm{C}$ NMR Spectrum $\left(75 \mathrm{MHz}\right.$ ) of $\mathbf{9 g}$ in $\mathrm{CDCl}_{3}$

${ }^{1} \mathrm{H}$ NMR Spectrum (300 MHz) of 10a in $\mathrm{CDCl}_{3}$

${ }^{13} \mathrm{C}$ NMR Spectrum $(75 \mathrm{MHz})$ of 10a in $\mathrm{CDCl}_{3}$

${ }^{1} \mathrm{H}$ NMR Spectrum $\left(300 \mathrm{MHz}\right.$ ) of $\mathbf{1 0 b}$ in $\mathrm{CDCl}_{3}$

${ }^{13} \mathrm{C}$ NMR Spectrum (75 MHz) of $\mathbf{1 0 b}$ in $\mathrm{CDCl}_{3}$

${ }^{1} \mathrm{H}$ NMR Spectrum $(300 \mathrm{MHz})$ of $\mathbf{1 0 c}$ in $\mathrm{CDCl}_{3}$

${ }^{13} \mathrm{C}$ NMR Spectrum $\left(75 \mathrm{MHz}\right.$ ) of $\mathbf{1 0 c}$ in $\mathrm{CDCl}_{3}$

${ }^{1} \mathrm{H}$ NMR Spectrum $(300 \mathrm{MHz})$ of $\mathbf{1 0 d}$ in $\mathrm{CDCl}_{3}$

${ }^{13} \mathrm{C}$ NMR Spectrum $(75 \mathrm{MHz})$ of $\mathbf{1 0 d}$ in $\mathrm{CDCl}_{3}$

${ }^{1} \mathrm{H}$ NMR Spectrum $\left(300 \mathrm{MHz}\right.$ ) of $\mathbf{1 0 e}$ in $\mathrm{CDCl}_{3}$

${ }^{13} \mathrm{C}$ NMR Spectrum $(75 \mathrm{MHz})$ of $\mathbf{1 0 e}$ in $\mathrm{CDCl}_{3}$

${ }^{1} \mathrm{H}$ NMR Spectrum $\left(300 \mathrm{MHz}\right.$ ) of $\mathbf{1 0 f}$ in $\mathrm{CDCl}_{3}$

${ }^{13} \mathrm{C}$ NMR Spectrum $(75 \mathrm{MHz})$ of $\mathbf{1 0 f}$ in $\mathrm{CDCl}_{3}$

${ }^{1} \mathrm{H}$ NMR Spectrum $\left(300 \mathrm{MHz}\right.$ ) of $\mathbf{1 0 g}$ in $\mathrm{CDCl}_{3}$

${ }^{13} \mathrm{C}$ NMR Spectrum $(75 \mathrm{MHz})$ of $\mathbf{1 0 g}$ in $\mathrm{CDCl}_{3}$

${ }^{1} \mathrm{H}$ NMR Spectrum $(300 \mathrm{MHz})$ of 11a in $\mathrm{CDCl}_{3}$

${ }^{13} \mathrm{C}$ NMR Spectrum $(75 \mathrm{MHz})$ of $11 \mathrm{a}$ in $\mathrm{CDCl}_{3}$

${ }^{1} \mathrm{H}$ NMR Spectrum $(300 \mathrm{MHz})$ of $\mathbf{1 1} \mathbf{b}$ in $\mathrm{CDCl}_{3}$

${ }^{13} \mathrm{C}$ NMR Spectrum $(75 \mathrm{MHz})$ of $\mathbf{1 1 b}$ in $\mathrm{CDCl}_{3}$

${ }^{1} \mathrm{H}$ NMR Spectrum $\left(300 \mathrm{MHz}\right.$ ) of $11 \mathrm{c}$ in $\mathrm{CDCl}_{3}$

${ }^{13} \mathrm{C}$ NMR Spectrum $(75 \mathrm{MHz})$ of $11 \mathrm{c}$ in $\mathrm{CDCl}_{3}$

${ }^{1} \mathrm{H}$ NMR Spectrum $\left(300 \mathrm{MHz}\right.$ ) of $\mathbf{1 1 d}$ in $\mathrm{CDCl}_{3}$

${ }^{13} \mathrm{C}$ NMR Spectrum (75 MHz) of $\mathbf{1 1 d}$ in $\mathrm{CDCl}_{3}$

${ }^{1} \mathrm{H}$ NMR Spectrum $(300 \mathrm{MHz})$ of $11 \mathrm{e}$ in $\mathrm{CDCl}_{3}$

${ }^{13} \mathrm{C}$ NMR Spectrum $\left(75 \mathrm{MHz}\right.$ ) of 11e in $\mathrm{CDCl}_{3}$

${ }^{1} \mathrm{H}$ NMR Spectrum (300 MHz) of $\mathbf{1 1 f}$ in $\mathrm{CDCl}_{3}$

${ }^{13} \mathrm{C}$ NMR Spectrum (75 MHz) of $\mathbf{1 1 f}$ in $\mathrm{CDCl}_{3}$

${ }^{1} \mathrm{H}$ NMR Spectrum $\left(300 \mathrm{MHz}\right.$ ) of $\mathbf{1 1 g}$ in $\mathrm{CDCl}_{3}$

${ }^{13} \mathrm{C}$ NMR Spectrum $\left(75 \mathrm{MHz}\right.$ ) of $\mathbf{1 1 g}$ in $\mathrm{CDCl}_{3}$

${ }^{1} \mathrm{H}$ NMR Spectrum $(300 \mathrm{MHz})$ of $\mathbf{1 1 h}$ in $\mathrm{CDCl}_{3}$

${ }^{13} \mathrm{C}$ NMR Spectrum (75 MHz) of $\mathbf{1 1 h}$ in $\mathrm{CDCl}_{3}$ 
${ }^{1} \mathrm{H}$ NMR Spectrum (300 MHz) of $\mathbf{1 1 i}$ in $\mathrm{CDCl}_{3}$

${ }^{13} \mathrm{C}$ NMR Spectrum $\left(75 \mathrm{MHz}\right.$ ) of $\mathbf{1 1 i}$ in $\mathrm{CDCl}_{3}$

${ }^{1} \mathrm{H}$ NMR Spectrum $(300 \mathrm{MHz})$ of $\mathbf{1 1} \mathbf{j}$ in $\mathrm{CDCl}_{3}$

${ }^{13} \mathrm{C}$ NMR Spectrum $\left(75 \mathrm{MHz}\right.$ ) of $\mathbf{1 1} \mathbf{j}$ in $\mathrm{CDCl}_{3}$

${ }^{1} \mathrm{H}$ NMR Spectrum $(300 \mathrm{MHz})$ of $\mathbf{1 1 k}$ in $\mathrm{CDCl}_{3}-$ cis trans mix

${ }^{13} \mathrm{C}$ NMR Spectrum $(75 \mathrm{MHz})$ of $11 \mathrm{k}$ in $\mathrm{CDCl}_{3}$ - cis trans mix

${ }^{1} \mathrm{H}$ NMR Spectrum $(300 \mathrm{MHz})$ of 111 in $\mathrm{CDCl}_{3}$

${ }^{13} \mathrm{C}$ NMR Spectrum $(75 \mathrm{MHz})$ of 111 in $\mathrm{CDCl}_{3}$

${ }^{1} \mathrm{H}$ NMR Spectrum $(300 \mathrm{MHz})$ of $\mathbf{1 1} \mathbf{m}$ in $\mathrm{CDCl}_{3}$

${ }^{13} \mathrm{C}$ NMR Spectrum (75 MHz) of $\mathbf{1 1 m}$ in $\mathrm{CDCl}_{3}$

${ }^{1} \mathrm{H}$ NMR Spectrum $(300 \mathrm{MHz})$ of $\mathbf{1 1 n}$ in $\mathrm{CDCl}_{3}$

${ }^{13} \mathrm{C}$ NMR Spectrum $(75 \mathrm{MHz})$ of $\mathbf{1 1 n}$ in $\mathrm{CDCl}_{3}$

${ }^{1} \mathrm{H}$ NMR Spectrum $(300 \mathrm{MHz})$ of $\mathbf{1 2 a}$ in $\mathrm{CDCl}_{3}$

${ }^{13} \mathrm{C}$ NMR Spectrum $(75 \mathrm{MHz})$ of 12a in $\mathrm{CDCl}_{3}$

${ }^{1} \mathrm{H}$ NMR Spectrum (300 MHz) of $\mathbf{1 2} \mathbf{b}$ in $\mathrm{CDCl}_{3}$

${ }^{13} \mathrm{C}$ NMR Spectrum $(75 \mathrm{MHz})$ of $\mathbf{1 2 b}$ in $\mathrm{CDCl}_{3}$

${ }^{1} \mathrm{H}$ NMR Spectrum $(300 \mathrm{MHz})$ of $\mathbf{1 2 c}$ in $\mathrm{CDCl}_{3}$

${ }^{13} \mathrm{C}$ NMR Spectrum $(75 \mathrm{MHz})$ of $\mathbf{1 2 c}$ in $\mathrm{CDCl}_{3}$

${ }^{1} \mathrm{H}$ NMR Spectrum $(300 \mathrm{MHz})$ of $\mathbf{1 2 d}$ in $\mathrm{CDCl}_{3}$

${ }^{13} \mathrm{C}$ NMR Spectrum $(75 \mathrm{MHz})$ of $\mathbf{1 2 d}$ in $\mathrm{CDCl}_{3}$

${ }^{1} \mathrm{H}$ NMR Spectrum $\left(300 \mathrm{MHz}\right.$ ) of $\mathbf{1 2 e}$ in $\mathrm{CDCl}_{3}$

${ }^{13} \mathrm{C}$ NMR Spectrum $(75 \mathrm{MHz})$ of $\mathbf{1 2 e}$ in $\mathrm{CDCl}_{3}$

${ }^{1} \mathrm{H}$ NMR Spectrum $\left(300 \mathrm{MHz}\right.$ ) of $\mathbf{1 2 f}$ in $\mathrm{CDCl}_{3}$

${ }^{13} \mathrm{C}$ NMR Spectrum $(75 \mathrm{MHz})$ of $\mathbf{1 2 f}$ in $\mathrm{CDCl}_{3}$

${ }^{1} \mathrm{H}$ NMR Spectrum (300 MHz) of $\mathbf{1 2} \mathbf{g}$ in $\mathrm{CDCl}_{3}$

${ }^{13} \mathrm{C}$ NMR Spectrum $\left(75 \mathrm{MHz}\right.$ ) of $\mathbf{1 2 g}$ in $\mathrm{CDCl}_{3}$

${ }^{1} \mathrm{H}$ NMR Spectrum $(300 \mathrm{MHz})$ of $\mathbf{1 2 h}$ in $\mathrm{CDCl}_{3}$

${ }^{13} \mathrm{C}$ NMR Spectrum (75 MHz) of $\mathbf{1 2 h}$ in $\mathrm{CDCl}_{3}$

${ }^{1} \mathrm{H}$ NMR Spectrum $(300 \mathrm{MHz})$ of $\mathbf{1 2 i}$ in $\mathrm{CDCl}_{3}$

${ }^{13} \mathrm{C}$ NMR Spectrum $\left(75 \mathrm{MHz}\right.$ ) of $\mathbf{1 2 i}$ in $\mathrm{CDCl}_{3}$

${ }^{1} \mathrm{H}$ NMR Spectrum $\left(300 \mathrm{MHz}\right.$ ) of $\mathbf{1 2} \mathbf{j}$ in $\mathrm{CDCl}_{3}$

${ }^{13} \mathrm{C}$ NMR Spectrum $\left(75 \mathrm{MHz}\right.$ ) of $\mathbf{1 2} \mathbf{j}$ in $\mathrm{CDCl}_{3}$ 
${ }^{1} \mathrm{H}$ NMR Spectrum $(300 \mathrm{MHz})$ of $\mathbf{1 2} \mathbf{k}$ in $\mathrm{CDCl}_{3}$

${ }^{13} \mathrm{C}$ NMR Spectrum $(75 \mathrm{MHz})$ of $\mathbf{1 2} \mathbf{k}$ in $\mathrm{CDCl}_{3}$

${ }^{1} \mathrm{H}$ NMR Spectrum (300 MHz) of $\mathbf{1 2 l}$ in $\mathrm{CDCl}_{3}$

${ }^{13} \mathrm{C}$ NMR Spectrum $\left(75 \mathrm{MHz}\right.$ ) of $\mathbf{1 2 l}$ in $\mathrm{CDCl}_{3}$

${ }^{1} \mathrm{H}$ NMR Spectrum (300 MHz) of $\mathbf{1 2} \mathbf{m}$ in $\mathrm{CDCl}_{3}$

${ }^{13} \mathrm{C}$ NMR Spectrum (75 MHz) of $\mathbf{1 2 m}$ in $\mathrm{CDCl}_{3}$

${ }^{1} \mathrm{H}$ NMR Spectrum $\left(300 \mathrm{MHz}\right.$ ) of $\mathbf{1 2 n}$ in $\mathrm{CDCl}_{3}$

${ }^{13} \mathrm{C}$ NMR Spectrum $(75 \mathrm{MHz})$ of $\mathbf{1 2 n}$ in $\mathrm{CDCl}_{3}$

${ }^{1} \mathrm{H}$ NMR Spectrum $\left(300 \mathrm{MHz}\right.$ ) of 14a in $\mathrm{CDCl}_{3}$

${ }^{13} \mathrm{C}$ NMR Spectrum $(75 \mathrm{MHz})$ of $\mathbf{1 4 a}$ in $\mathrm{CDCl}_{3}$

${ }^{1} \mathrm{H}$ NMR Spectrum $(300 \mathrm{MHz})$ of $\mathbf{1 4 b}$ in $\mathrm{CDCl}_{3}$

${ }^{13} \mathrm{C}$ NMR Spectrum $(75 \mathrm{MHz})$ of $\mathbf{1 4} \mathbf{b}$ in $\mathrm{CDCl}_{3}$

${ }^{1} \mathrm{H}$ NMR Spectrum $\left(300 \mathrm{MHz}\right.$ ) of $\mathbf{1 4 c}$ in $\mathrm{CDCl}_{3}$

${ }^{13} \mathrm{C}$ NMR Spectrum $(75 \mathrm{MHz})$ of $\mathbf{1 4 c}$ in $\mathrm{CDCl}_{3}$

${ }^{1} \mathrm{H}$ NMR Spectrum $\left(300 \mathrm{MHz}\right.$ ) of $\mathbf{1 4 d}$ in $\mathrm{CDCl}_{3}$

${ }^{13} \mathrm{C}$ NMR Spectrum $(75 \mathrm{MHz})$ of $\mathbf{1 4 d}$ in $\mathrm{CDCl}_{3}$

${ }^{1} \mathrm{H}$ NMR Spectrum $\left(300 \mathrm{MHz}\right.$ ) of $14 \mathrm{e}$ in $\mathrm{CDCl}_{3}$

${ }^{13} \mathrm{C}$ NMR Spectrum $(75 \mathrm{MHz})$ of $14 \mathrm{e}$ in $\mathrm{CDCl}_{3}$

${ }^{1} \mathrm{H}$ NMR Spectrum $(300 \mathrm{MHz})$ of $\mathbf{1 4 f}$ in $\mathrm{CDCl}_{3}$

${ }^{13} \mathrm{C}$ NMR Spectrum $\left(75 \mathrm{MHz}\right.$ ) of $\mathbf{1 4 f}$ in $\mathrm{CDCl}_{3}$

${ }^{1} \mathrm{H}$ NMR Spectrum (300 MHz) of 15a in $\mathrm{CDCl}_{3}$

${ }^{13} \mathrm{C}$ NMR Spectrum (75 MHz) of $\mathbf{1 5 a}$ in $\mathrm{CDCl}_{3}$

${ }^{1} \mathrm{H}$ NMR Spectrum $(300 \mathrm{MHz})$ of $\mathbf{1 5} \mathbf{b}$ in $\mathrm{CDCl}_{3}$

${ }^{13} \mathrm{C}$ NMR Spectrum $(75 \mathrm{MHz})$ of $\mathbf{1 5 b}$ in $\mathrm{CDCl}_{3}$

${ }^{1} \mathrm{H}$ NMR Spectrum (300 MHz) of $\mathbf{1 5 c}$ in $\mathrm{CDCl}_{3}$

${ }^{13} \mathrm{C}$ NMR Spectrum $\left(75 \mathrm{MHz}\right.$ ) of $\mathbf{1 5 c}$ in $\mathrm{CDCl}_{3}$

${ }^{1} \mathrm{H}$ NMR Spectrum $\left(300 \mathrm{MHz}\right.$ ) of $\mathbf{1 5 d}$ in $\mathrm{CDCl}_{3}$

${ }^{13} \mathrm{C}$ NMR Spectrum (75 MHz) of $\mathbf{1 5 d}$ in $\mathrm{CDCl}_{3}$

${ }^{1} \mathrm{H}$ NMR spectrum $(300 \mathrm{MHz})$ of $\mathbf{1 5 e}$ in $\mathrm{CDCl}_{3}$

${ }^{13} \mathrm{C}$ NMR Spectrum $(75 \mathrm{MHz})$ of $\mathbf{1 5 e}$ in $\mathrm{CDCl}_{3}$

${ }^{1} \mathrm{H}$ NMR Spectrum $\left(300 \mathrm{MHz}\right.$ ) of $\mathbf{1 5 f}$ in $\mathrm{CDCl}_{3}$

${ }^{13} \mathrm{C}$ NMR Spectrum $\left(75 \mathrm{MHz}\right.$ ) of $\mathbf{1 5 f}$ in $\mathrm{CDCl}_{3}$ 
${ }^{1} \mathrm{H}$ NMR Spectrum $(300 \mathrm{MHz})$ of a mixture of $16 \mathbf{a}$ and $17 \mathbf{a}$ in $\mathrm{CDCl}_{3}$

${ }^{13} \mathrm{C}$ NMR Spectrum $(75 \mathrm{MHz})$ of a mixture of 16a and 17a in $\mathrm{CDCl}_{3}$

Spectrum (300 MHz) of a mixture of $\mathbf{1 6} \mathbf{b}$ and $\mathbf{1 7} \mathbf{b}$ in $\mathrm{CDCl}_{3}$

${ }^{13} \mathrm{C}$ NMR Spectrum $(75 \mathrm{MHz})$ of a mixture of $\mathbf{1 6} \mathbf{b}$ and $\mathbf{1 7} \mathbf{b}$ in $\mathrm{CDCl}_{3}$

${ }^{1} \mathrm{H}$ NMR Spectrum $\left(300 \mathrm{MHz}\right.$ ) of a mixture of $16 \mathbf{c}$ and $17 \mathbf{c}$ in $\mathrm{CDCl}_{3}$

${ }^{13} \mathrm{C}$ NMR Spectrum $(75 \mathrm{MHz})$ of a mixture of $\mathbf{1 6 c}$ and $17 \mathbf{c}$ in $\mathrm{CDCl}_{3}$

${ }^{1} \mathrm{H}$ NMR Spectrum (300 MHz) of $\mathbf{1 6 d}$ in $\mathrm{CDCl}_{3}$

${ }^{13} \mathrm{C}$ NMR Spectrum $(125 \mathrm{MHz})$ of $\mathbf{1 6 d}$ in $\mathrm{CDCl}_{3}$

${ }^{1} \mathrm{H}$ NMR Spectrum $(300 \mathrm{MHz})$ of $\mathbf{1 7} \mathbf{d}$ in $\mathrm{CDCl}_{3}$

${ }^{13} \mathrm{C}$ NMR Spectrum $(125 \mathrm{MHz})$ of $\mathbf{1 7} \mathbf{d}$ in $\mathrm{CDCl}_{3}$

${ }^{1} \mathrm{H}$ NMR Spectrum $(300 \mathrm{MHz})$ of $\mathbf{1 6 e}$ in $\mathrm{CDCl}_{3}$

${ }^{13} \mathrm{C}$ NMR Spectrum $(75 \mathrm{MHz})$ of $\mathbf{1 6 e}$ in $\mathrm{CDCl}_{3}$

${ }^{1} \mathrm{H}$ NMR Spectrum (300 MHz) of $\mathbf{1 6 f}$ in $\mathrm{CDCl}_{3}$

${ }^{13} \mathrm{C}$ NMR Spectrum $\left(75 \mathrm{MHz}\right.$ ) of $\mathbf{1 6} \mathbf{f}$ in $\mathrm{CDCl}_{3}$

${ }^{1} \mathrm{H}$ NMR Spectrum $(500 \mathrm{MHz})$ of $\mathbf{1 7 f}$ in $\mathrm{CDCl}_{3}$

${ }^{13} \mathrm{C}$ NMR Spectrum $(125 \mathrm{MHz})$ of $\mathbf{1 7 f}$ in $\mathrm{CDCl}_{3}$

${ }^{1} \mathrm{H}$ NMR Spectrum (300 MHz) of $\mathbf{1 6 g}$ and $\mathbf{1 7 g}(77: 23)$ in $\mathrm{CDCl}_{3}$

${ }^{13} \mathrm{C}$ NMR Spectrum $(75 \mathrm{MHz})$ of $\mathbf{1 6 g}$ and $\mathbf{1 7} \mathbf{g}(77: 23)$ in $\mathrm{CDCl}_{3}$

${ }^{1} \mathrm{H}$ NMR Spectrum (300 MHz) of $\mathbf{1 6 g}$ and $\mathbf{1 7 g}(85: 15)$ in $\mathrm{CDCl}_{3}$

${ }^{13} \mathrm{C}$ NMR Spectrum $(75 \mathrm{MHz})$ of $\mathbf{1 6 g}$ and $\mathbf{1 7 g}(85: 15)$ in $\mathrm{CDCl}_{3}$

${ }^{1} \mathrm{H}$ NMR Spectrum $\left(300 \mathrm{MHz}\right.$ ) of $\mathbf{1 6 h}$ and $\mathbf{1 7 h}$ from TTMSS cyclization in $\mathrm{CDCl}_{3}$

${ }^{13} \mathrm{C}$ NMR Spectrum $\left(75 \mathrm{MHz}\right.$ ) of $\mathbf{1 6 h}$ and $\mathbf{1 7} \mathbf{h}$ from TTMSS cyclization in $\mathrm{CDCl}_{3}$

${ }^{1} \mathrm{H}$ NMR Spectrum $\left(300 \mathrm{MHz}\right.$ ) of $\mathbf{1 6} \mathbf{h}$ and $\mathbf{1 7} \mathbf{h}$ from TBTH cyclization in $\mathrm{CDCl}_{3}$

${ }^{1} \mathrm{H}$ NMR Spectrum $(300 \mathrm{MHz})$ of $\mathbf{1 6 h}$ in $\mathrm{CDCl}_{3}$

${ }^{13} \mathrm{C}$ NMR Spectrum $(75 \mathrm{MHz})$ of $\mathbf{1 6 h}$ in $\mathrm{CDCl}_{3}$

${ }^{1} \mathrm{H}$ NMR Spectrum $(300 \mathrm{MHz})$ of $\mathbf{1 7} \mathbf{h}$ in $\mathrm{CDCl}_{3}$

${ }^{13} \mathrm{C}$ NMR Spectrum $(75 \mathrm{MHz})$ of $\mathbf{1 7 h}$ in $\mathrm{CDCl}_{3}$

${ }^{1} \mathrm{H}$ NMR Spectrum $(300 \mathrm{MHz})$ of $\mathbf{1 6 i}$ and $\mathbf{1 7} \mathbf{i}(85: 15)$ in $\mathrm{CDCl}_{3}$

${ }^{13} \mathrm{C}$ NMR Spectrum $(75 \mathrm{MHz})$ of $\mathbf{1 6 i}$ and $\mathbf{1 7} \mathbf{i}(85: 15)$ in $\mathrm{CDCl}_{3}$

${ }^{1} \mathrm{H}$ NMR Spectrum (300 MHz) of $\mathbf{1 6} \mathbf{i}$ in $\mathrm{CDCl}_{3}$

${ }^{13} \mathrm{C}$ NMR Spectrum $(75 \mathrm{MHz})$ of $\mathbf{1 6} \mathbf{i}$ in $\mathrm{CDCl}_{3}$

${ }^{1} \mathrm{H}$ NMR Spectrum (300 MHz) of 16j and $\mathbf{1 7} \mathbf{j}$ (97:3) in $\mathrm{CDCl}_{3}$ 
${ }^{13} \mathrm{C}$ NMR Spectrum (75 MHz) of $\mathbf{1 6} \mathbf{j}$ and $\mathbf{1 7} \mathbf{j}$ (97:3) in $\mathrm{CDCl}_{3}$

${ }^{1} \mathrm{H}$ NMR Spectrum $(300 \mathrm{MHz})$ of $\mathbf{1 6} \mathbf{j}$ from TTMSS cyclization in $\mathrm{CDCl}_{3}$

${ }^{13} \mathrm{C}$ NMR Spectrum (75 MHz) of $\mathbf{1 6 j}$ from TTMSS cyclization in $\mathrm{CDCl}_{3}$

${ }^{1} \mathrm{H}$ NMR Spectrum $(300 \mathrm{MHz})$ of $\mathbf{1 6} \mathbf{k}$ in $\mathrm{CDCl}_{3}$

${ }^{13} \mathrm{C}$ NMR Spectrum $(75 \mathrm{MHz})$ of $\mathbf{1 6 k}$ in $\mathrm{CDCl}_{3}$

${ }^{1} \mathrm{H}$ NMR Spectrum $(300 \mathrm{MHz})$ of $\mathbf{1 7} \mathbf{k}$ in $\mathrm{CDCl}_{3}$

${ }^{13} \mathrm{C}$ NMR Spectrum $(100 \mathrm{MHz})$ of $\mathbf{1 7} \mathbf{k}$ in $\mathrm{CDCl}_{3}$

${ }^{1} \mathrm{H}$ NMR Spectrum $\left(300 \mathrm{MHz}\right.$ ) of $\mathbf{1 6 1}$ in $\mathrm{CDCl}_{3}$

${ }^{13} \mathrm{C}$ NMR Spectrum $(75 \mathrm{MHz})$ of 161 in $\mathrm{CDCl}_{3}$

${ }^{1} \mathrm{H}$ NMR Spectrum $\left(300 \mathrm{MHz}\right.$ ) of $\mathbf{1 7 1}$ in $\mathrm{CDCl}_{3}$

${ }^{13} \mathrm{C}$ NMR Spectrum $(125 \mathrm{MHz})$ of $\mathbf{1 7 1}$ in $\mathrm{CDCl}_{3}$

${ }^{1} \mathrm{H}$ NMR Spectrum $(300 \mathrm{MHz})$ of $\mathbf{1 6} \mathbf{m}$ and $\mathbf{1 7} \mathbf{m}$ in $\mathrm{CDCl}_{3}$

${ }^{13} \mathrm{C}$ NMR Spectrum $\left(75 \mathrm{MHz}\right.$ ) of $\mathbf{1 6} \mathbf{m}$ and $\mathbf{1 7} \mathbf{m}$ in $\mathrm{CDCl}_{3}$

${ }^{1} \mathrm{H}$ NMR Spectrum $\left(300 \mathrm{MHz}\right.$ ) of $\mathbf{1 6 n}$ and $\mathbf{1 7 n}$ in $\mathrm{CDCl}_{3}$

${ }^{13} \mathrm{C}$ NMR Spectrum $\left(75 \mathrm{MHz}\right.$ ) of $\mathbf{1 6} \mathbf{n}$ and $\mathbf{1 7} \mathbf{n}$ in $\mathrm{CDCl}_{3}$

${ }^{1} \mathrm{H}$ NMR Spectrum $(500 \mathrm{MHz})$ of $\mathbf{2 4 f}$ in $\mathrm{CDCl}_{3}$

${ }^{13} \mathrm{C}$ NMR Spectrum $(125 \mathrm{MHz})$ of $\mathbf{2 4 f}$ in $\mathrm{CDCl}_{3}$

${ }^{1} \mathrm{H}$ NMR Spectrum $\left(300 \mathrm{MHz}\right.$ ) of $24 \mathbf{i}$ in $\mathrm{CDCl}_{3}$

${ }^{13} \mathrm{C}$ NMR Spectrum (75 MHz) of 24i in $\mathrm{CDCl}_{3}$

${ }^{1} \mathrm{H}$ NMR Spectrum $(300 \mathrm{MHz})$ of $25 \mathrm{a}$ in $\mathrm{D}_{2} \mathrm{O}$

${ }^{13} \mathrm{C}$ NMR Spectrum $(100 \mathrm{MHz})$ of 25a in $\mathrm{D}_{2} \mathrm{O}$ NB trifluoroacetate counterion peaks also visible

${ }^{1} \mathrm{H}$ NMR Spectrum $(300 \mathrm{MHz})$ of $\mathbf{2 5} \mathbf{b}$ in $\mathrm{D}_{2} \mathrm{O}$

${ }^{13} \mathrm{C}$ NMR Spectrum $(100 \mathrm{MHz})$ of $\mathbf{2 5 b}$ in $\mathrm{D}_{2} \mathrm{O}$

${ }^{1} \mathrm{H}$ NMR Spectrum $(300 \mathrm{MHz})$ of $\mathbf{2 5 c}$ in $\mathrm{D}_{2} \mathrm{O}$

${ }^{13} \mathrm{C}$ NMR Spectrum (100 MHz) of 25c in $\mathrm{D}_{2} \mathrm{O}$ (2 second relaxation delay)

${ }^{13} \mathrm{C}$ NMR Spectrum $(100 \mathrm{MHz})$ of $25 \mathrm{c}$ in $\mathrm{D}_{2} \mathrm{O}$ (1 second relaxation delay)

${ }^{13} \mathrm{C}$ NMR Spectrum $(75 \mathrm{MHz})$ of $\mathbf{2 5 d}$ in $\mathrm{D}_{2} \mathrm{O}$

${ }^{13} \mathrm{C}$ NMR Spectrum $(75 \mathrm{MHz})$ of $\mathbf{2 5 d}$ in $\mathrm{D}_{2} \mathrm{O}$ 


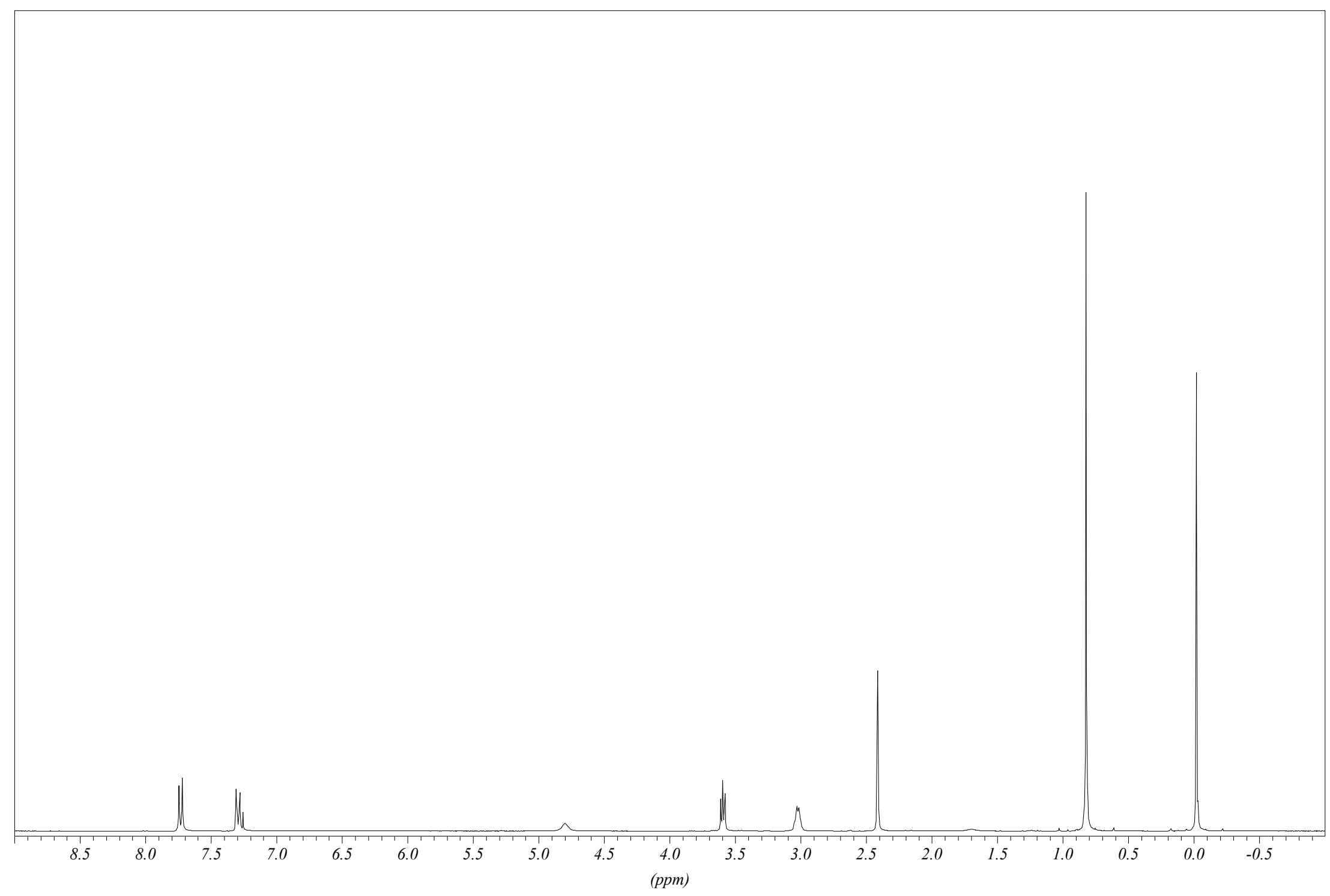

${ }^{1} \mathrm{H}$ NMR Spectrum (300 MHz) of 1 in $\mathrm{CDCl}_{3}$ 


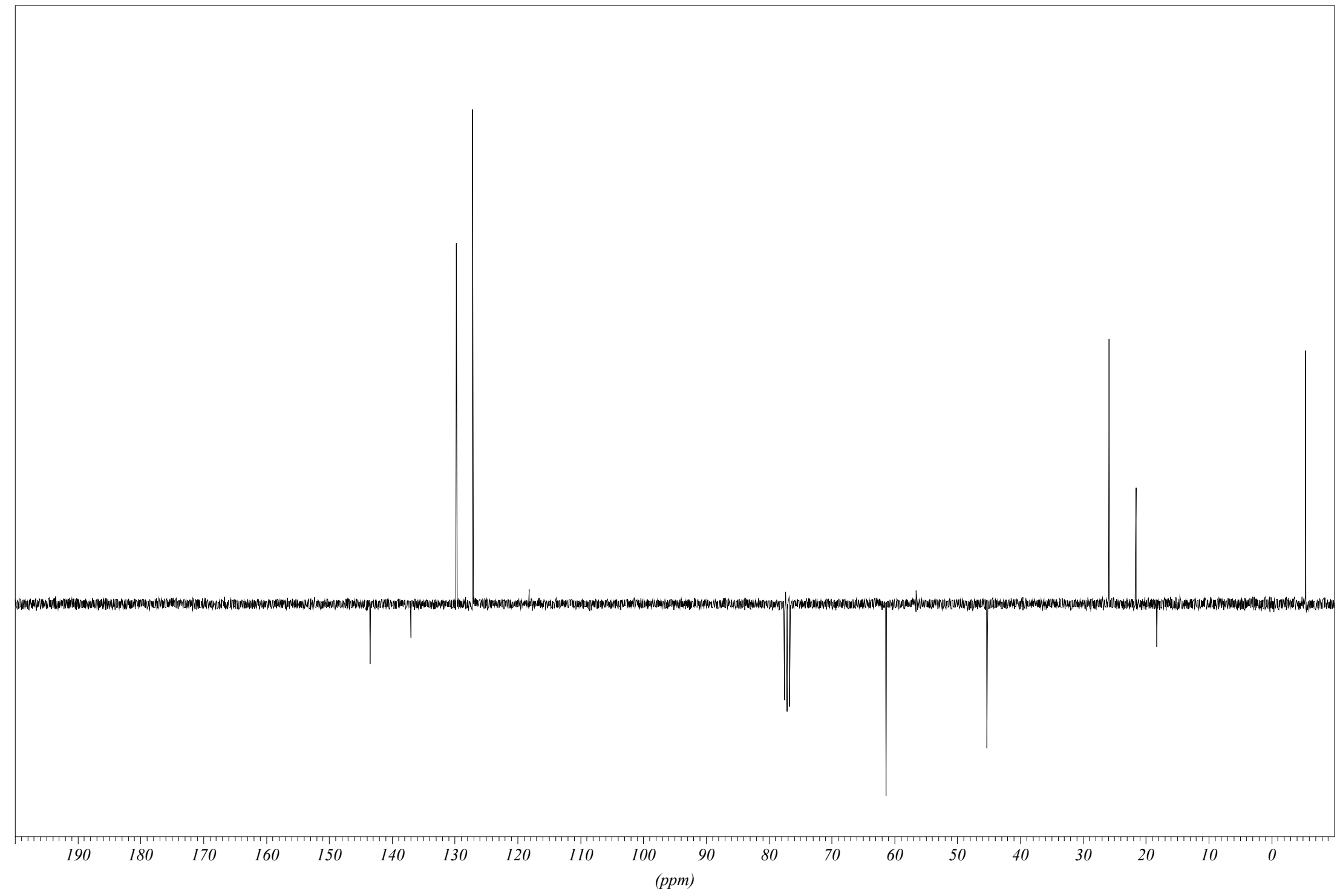

${ }^{13} \mathrm{C}$ NMR Spectrum $(75 \mathrm{MHz})$ of $\mathbf{1}$ in $\mathrm{CDCl}_{3}$ 


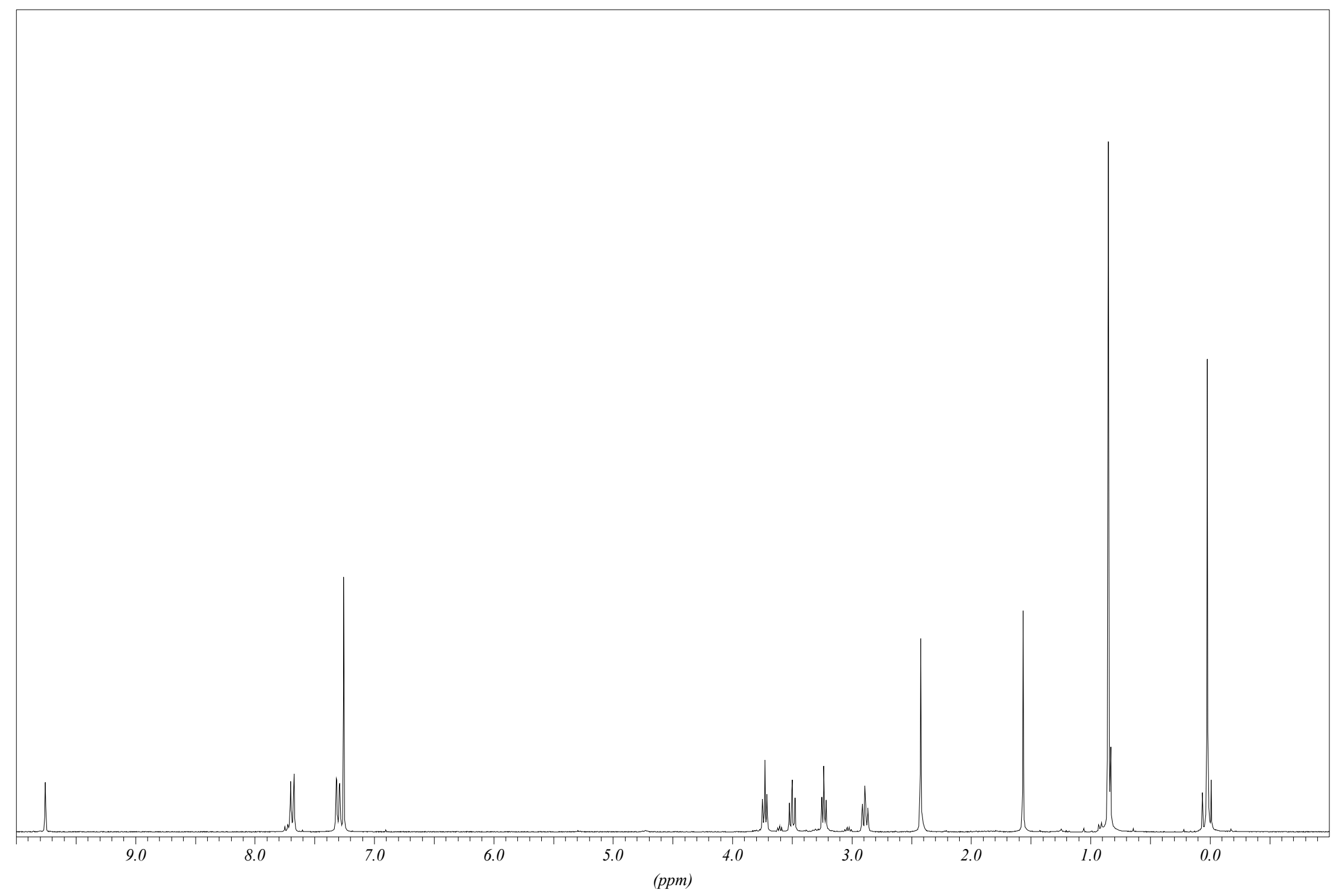

${ }^{1} \mathrm{H}$ NMR Spectrum $(300 \mathrm{MHz})$ of 2 in $\mathrm{CDCl}_{3}$ 


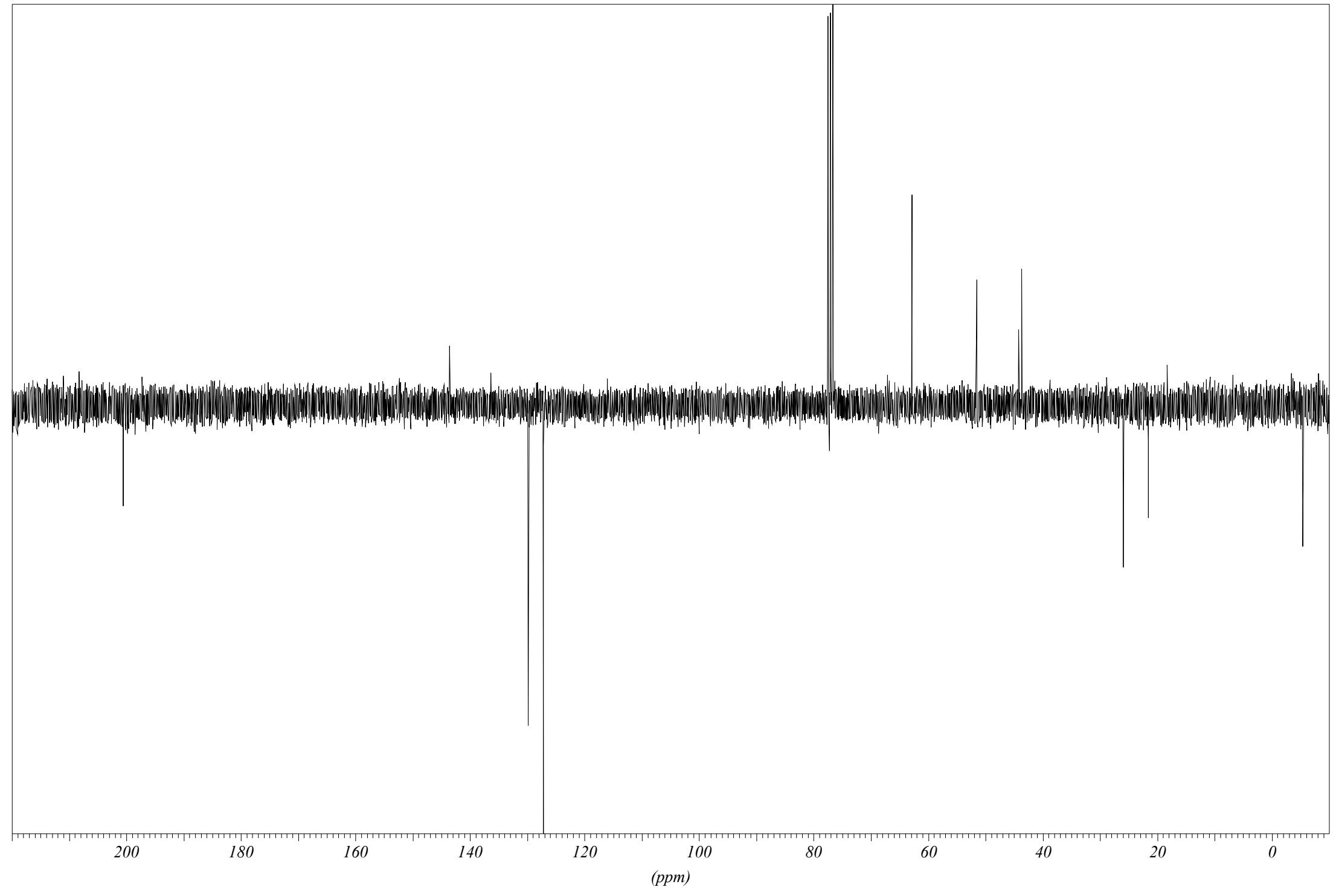

${ }^{13} \mathrm{C}$ NMR Spectrum (75 MHz) of 2 in $\mathrm{CDCl}_{3}$ 


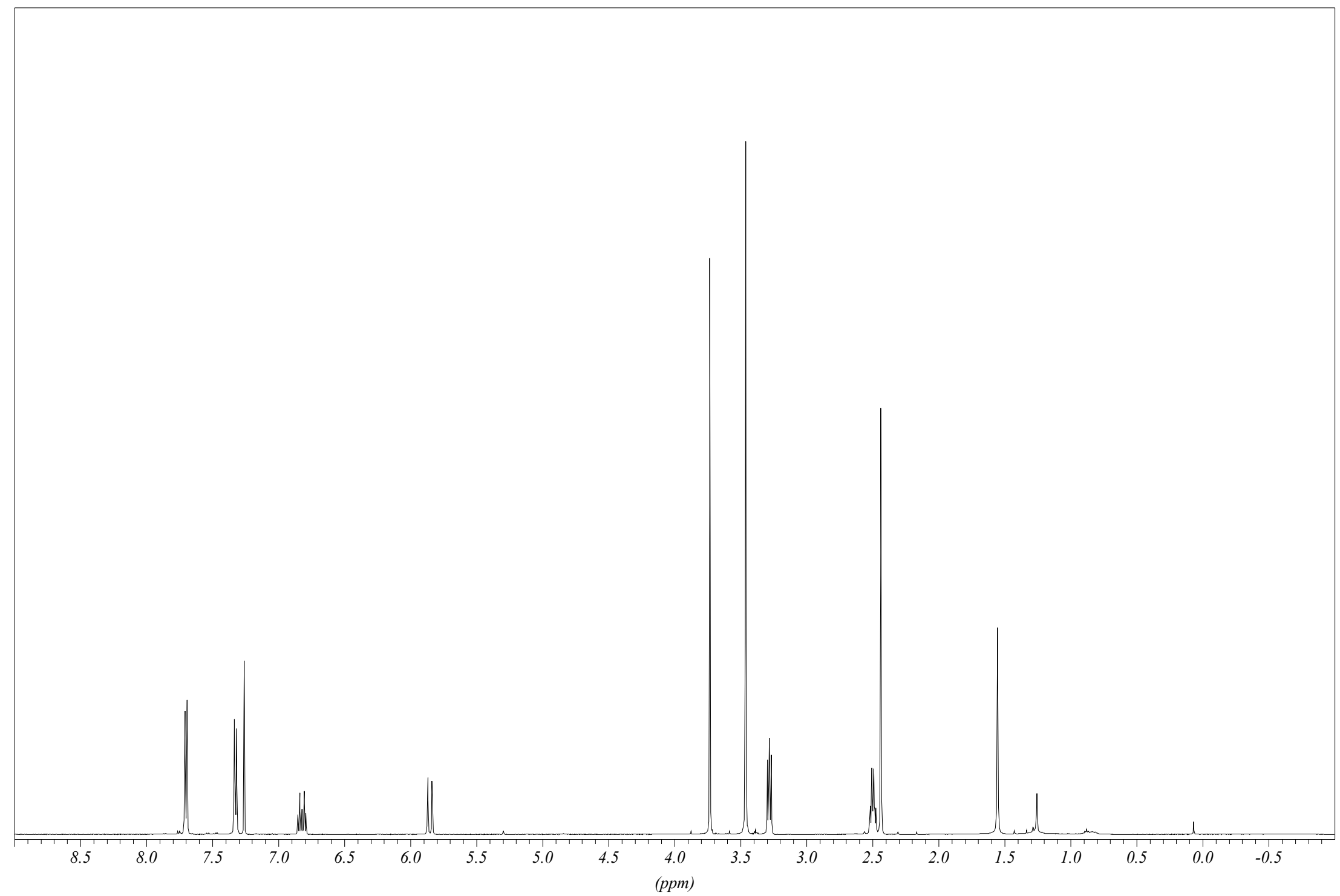

${ }^{1} \mathrm{H}$ NMR Spectrum $(500 \mathrm{MHz})$ of $\mathbf{3}$ in $\mathrm{CDCl}_{3}$ 


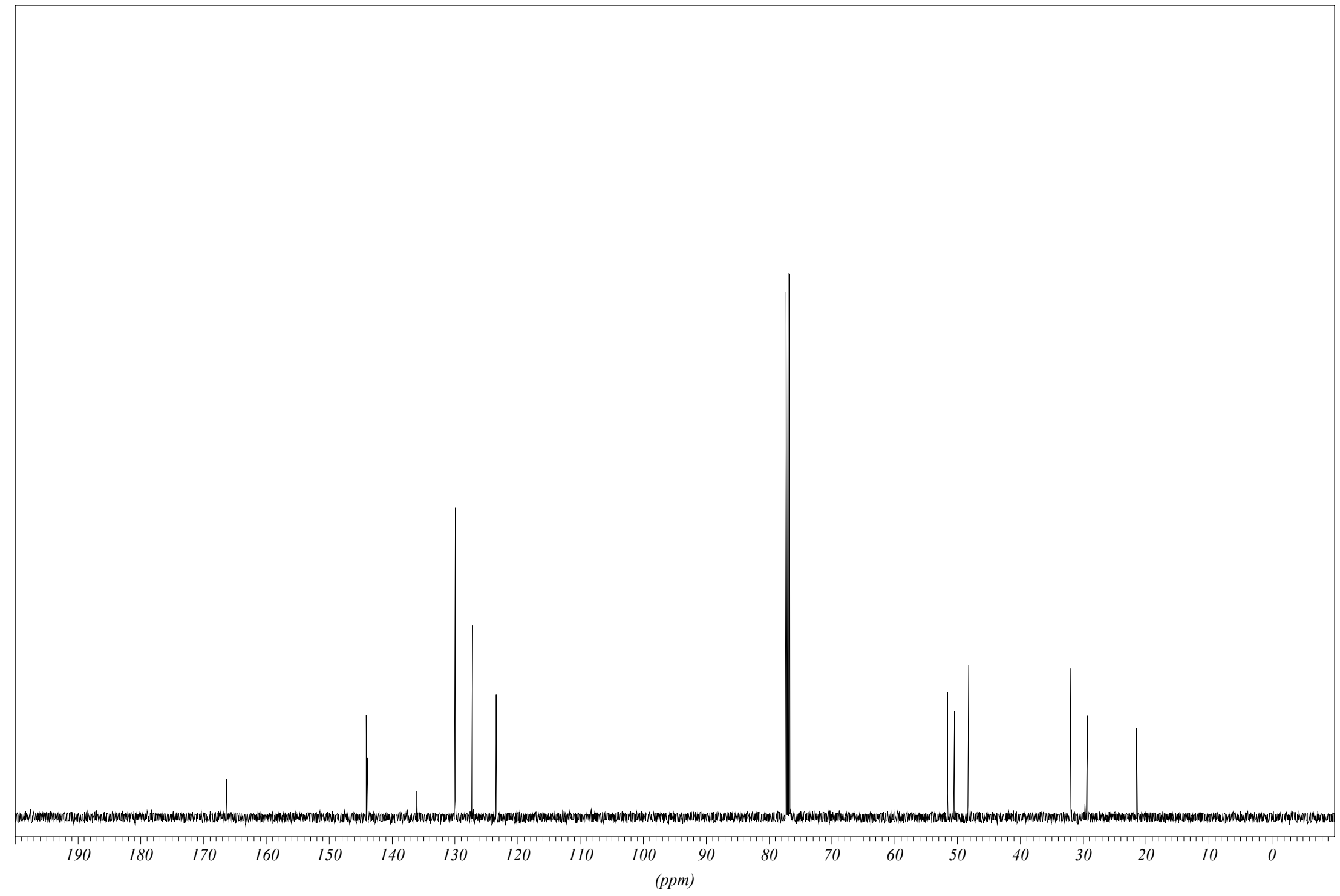

${ }^{13} \mathrm{C}$ NMR Spectrum (125 MHz) of 3 in $\mathrm{CDCl}_{3}$ 


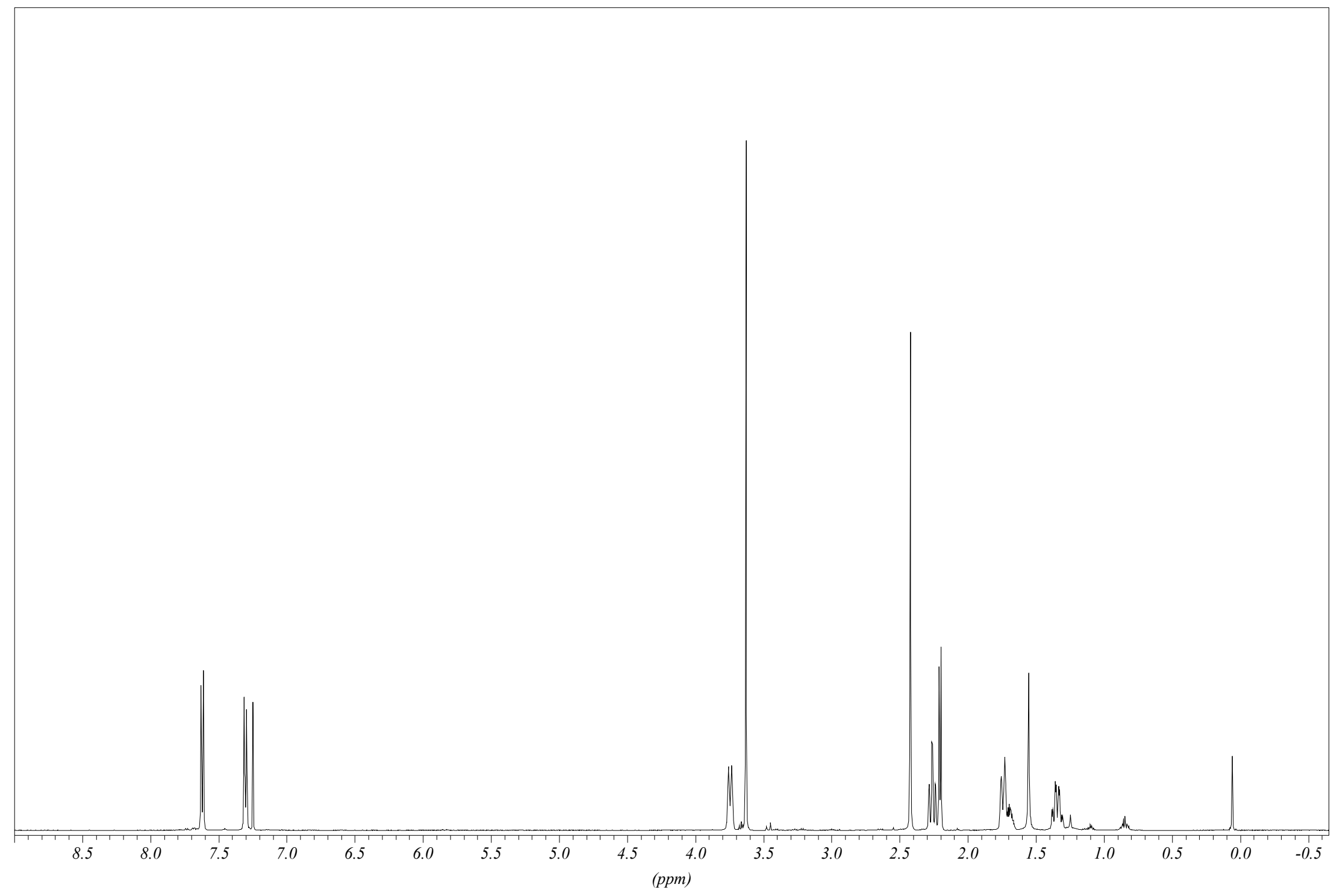

${ }^{1} \mathrm{H}$ NMR Spectrum $(500 \mathrm{MHz})$ of 4 in $\mathrm{CDCl}_{3}$ 


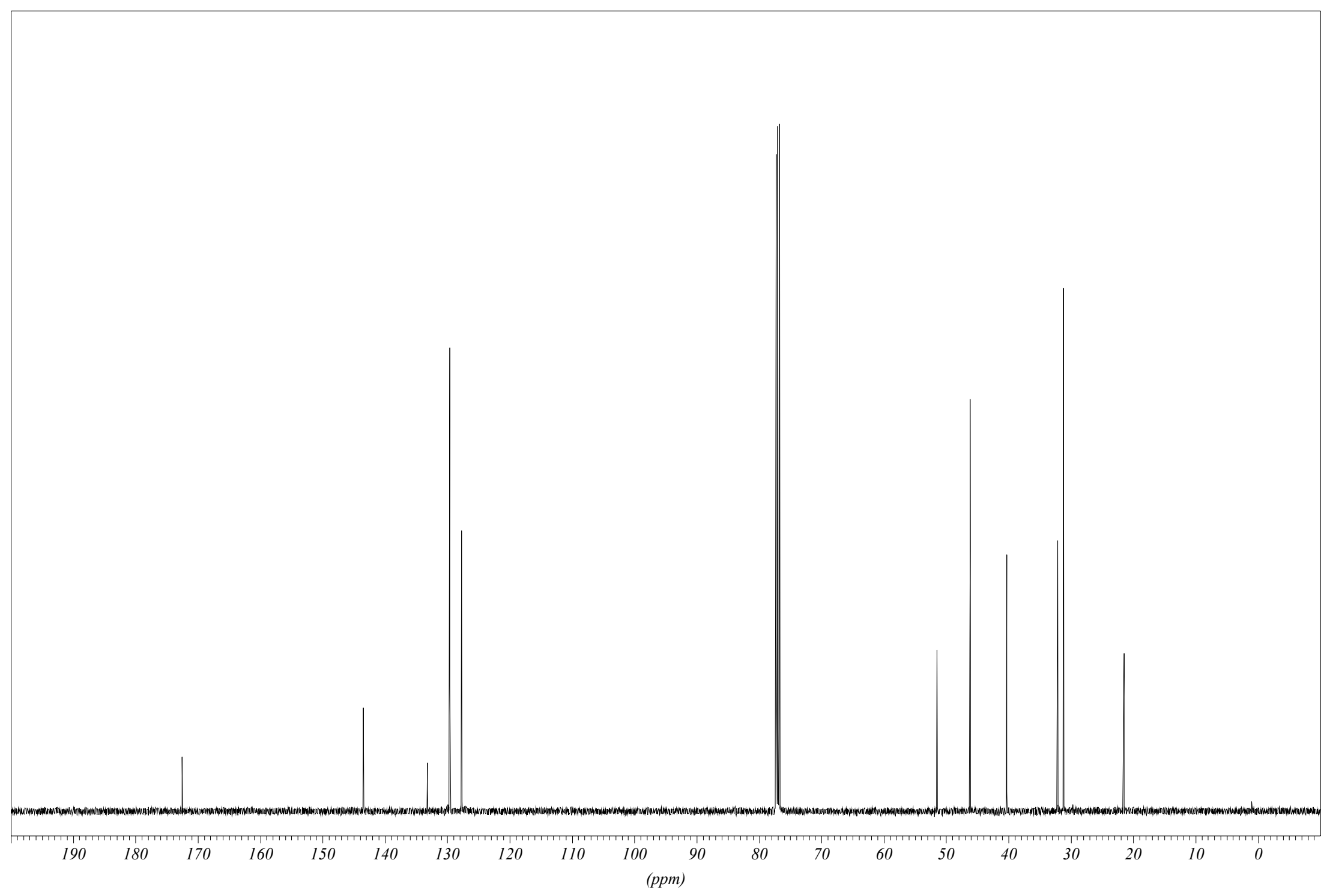

${ }^{13} \mathrm{C}$ NMR Spectrum $(125 \mathrm{MHz})$ of 4 in $\mathrm{CDCl}_{3}$ 


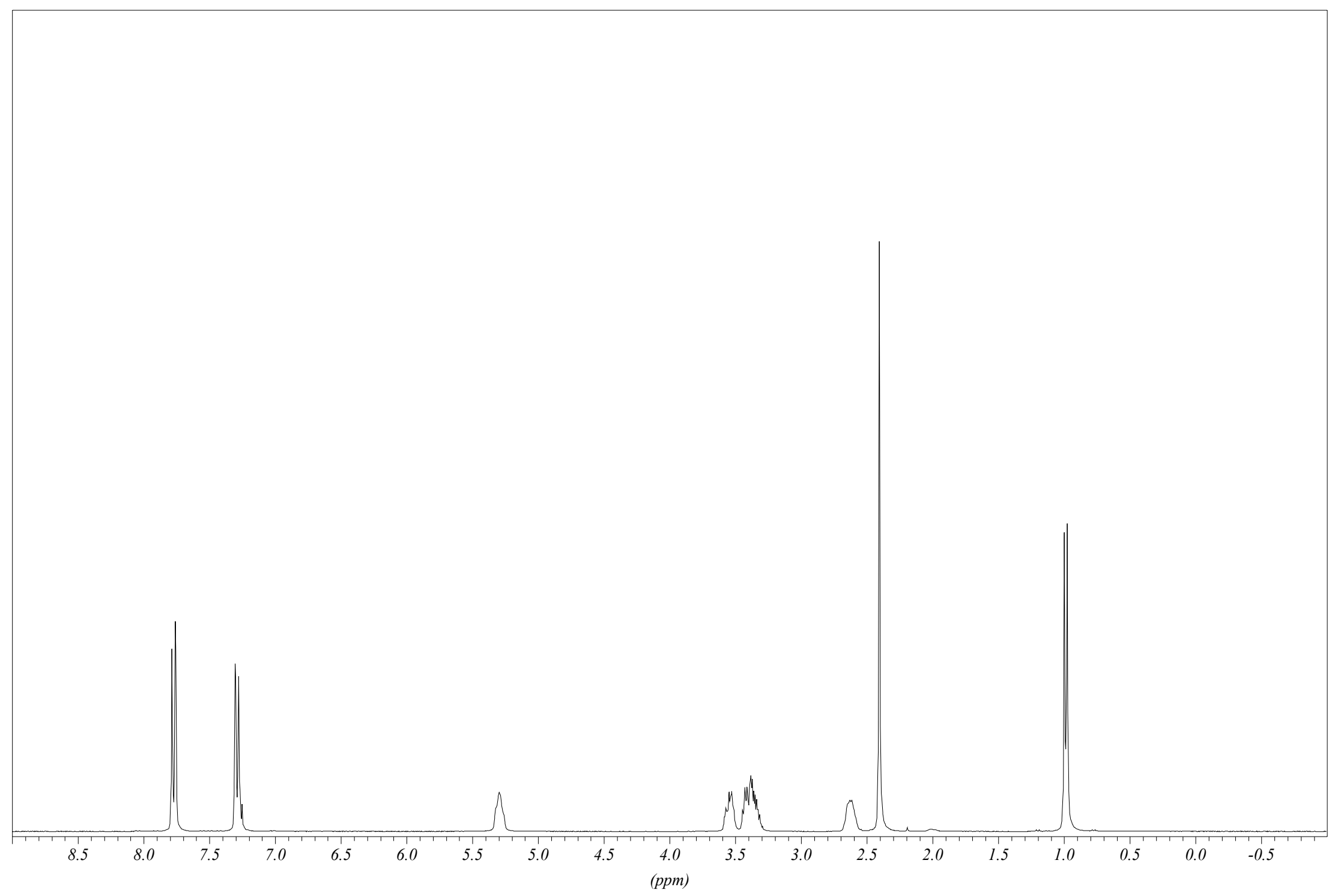

${ }^{1} \mathrm{H}$ NMR Spectrum $\left(300 \mathrm{MHz}\right.$ ) of $N$-tosyl alaninol in $\mathrm{CDCl}_{3}$ 


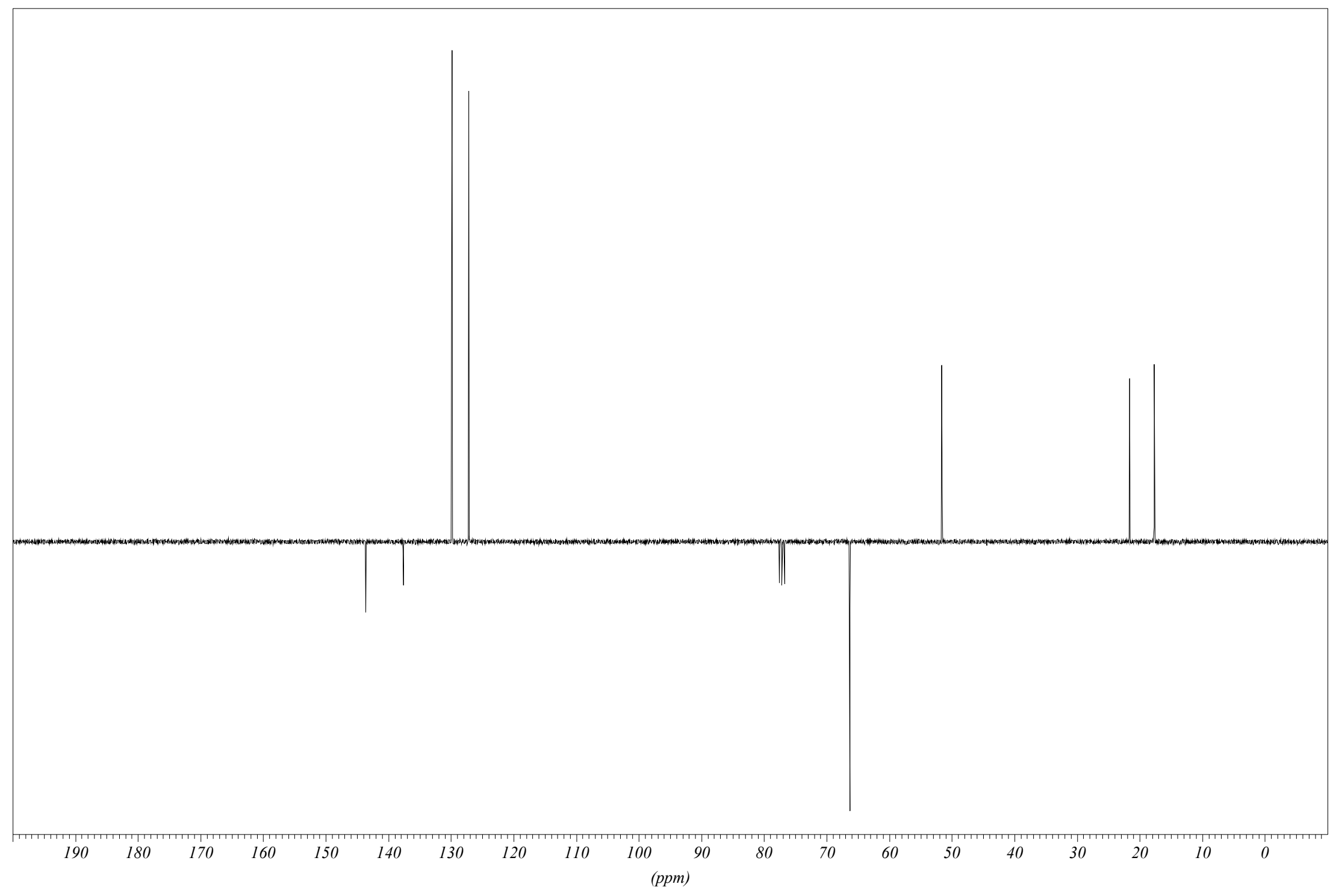

${ }^{13} \mathrm{C}$ NMR Spectrum (75 MHz) of $N$-tosyl alaninol in $\mathrm{CDCl}_{3}$ 


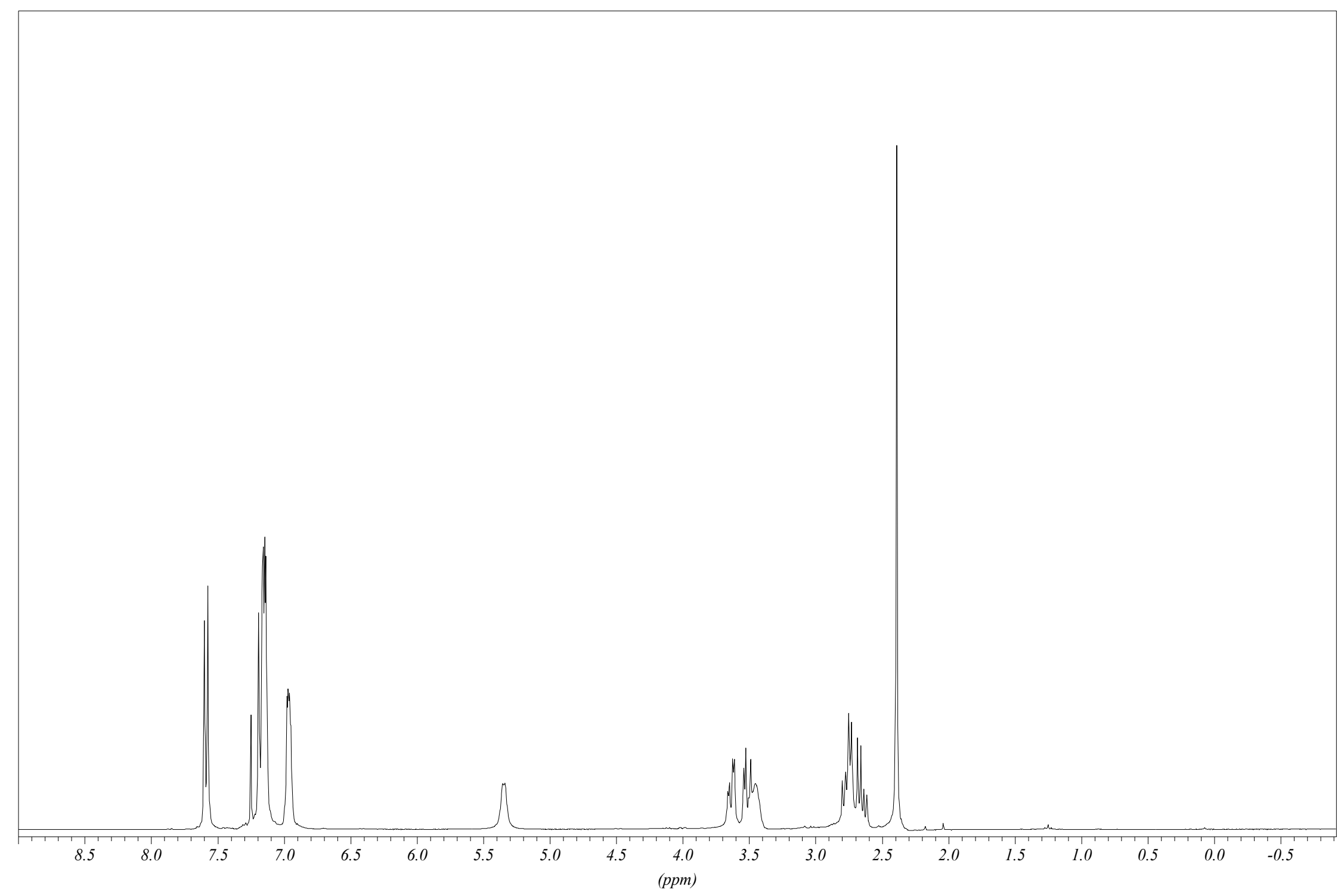

${ }^{1} \mathrm{H}$ NMR Spectrum (300 MHz) of $N$-tosyl phenylalaninol in $\mathrm{CDCl}_{3}$ 


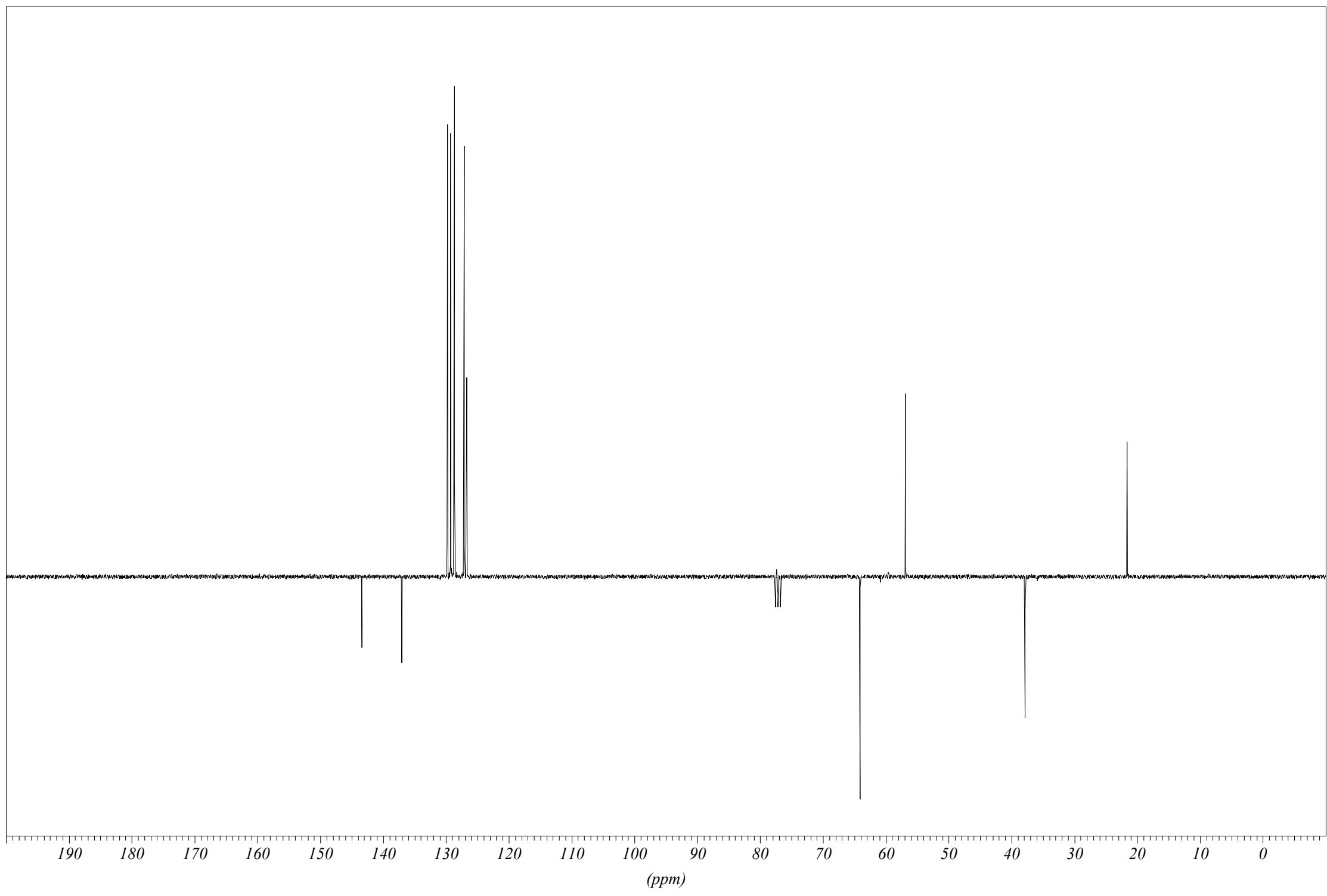

${ }^{13} \mathrm{C}$ NMR Spectrum (75 MHz) of $N$-tosyl phenylalaninol in $\mathrm{CDCl}_{3}$ 


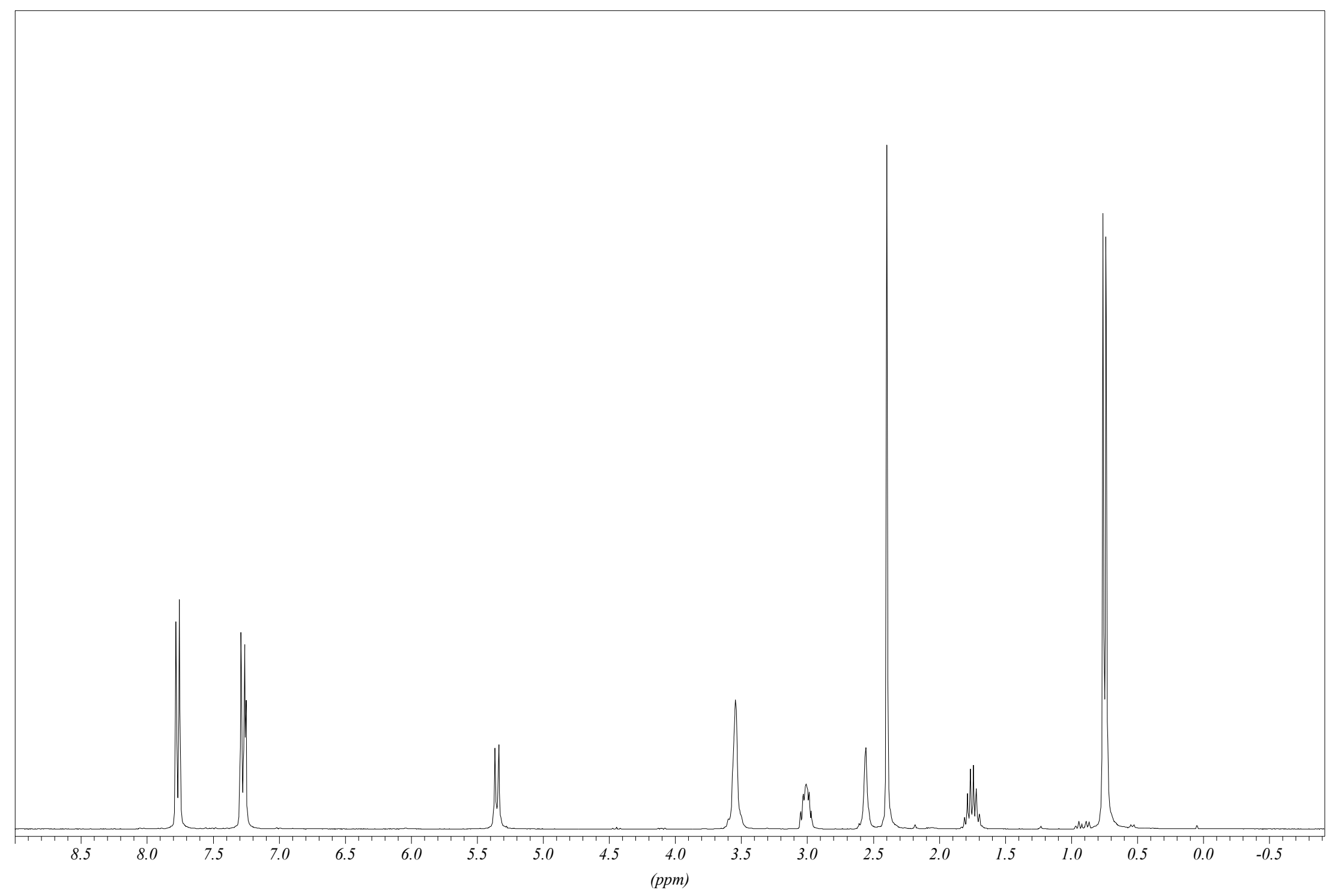

${ }^{1} \mathrm{H}$ NMR Spectrum (300 MHz) of $\mathrm{N}$-tosyl valinol in $\mathrm{CDCl}_{3}$ 


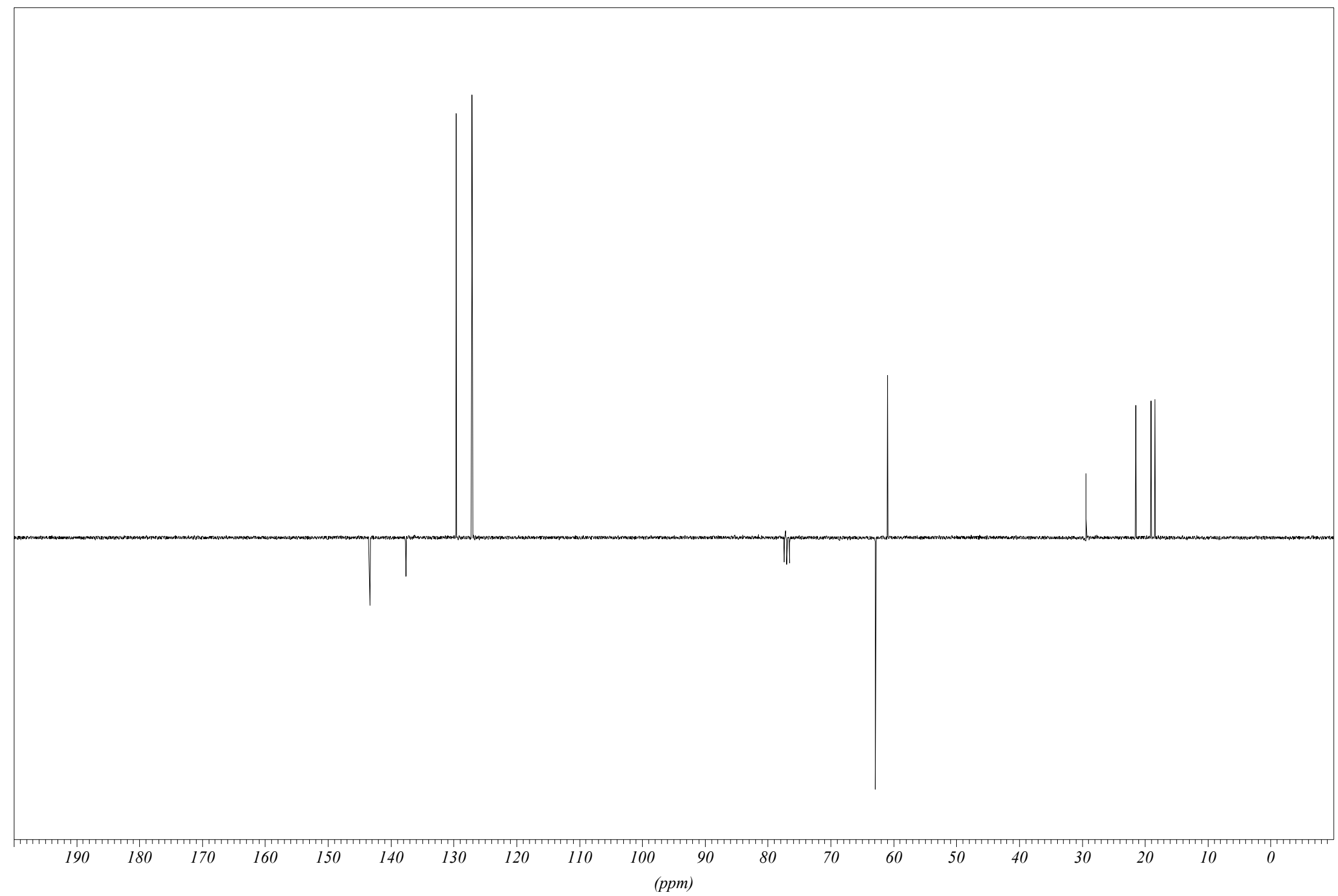

${ }^{13} \mathrm{C}$ NMR Spectrum (75 MHz) of $N$-tosyl valinol in $\mathrm{CDCl}_{3}$ 


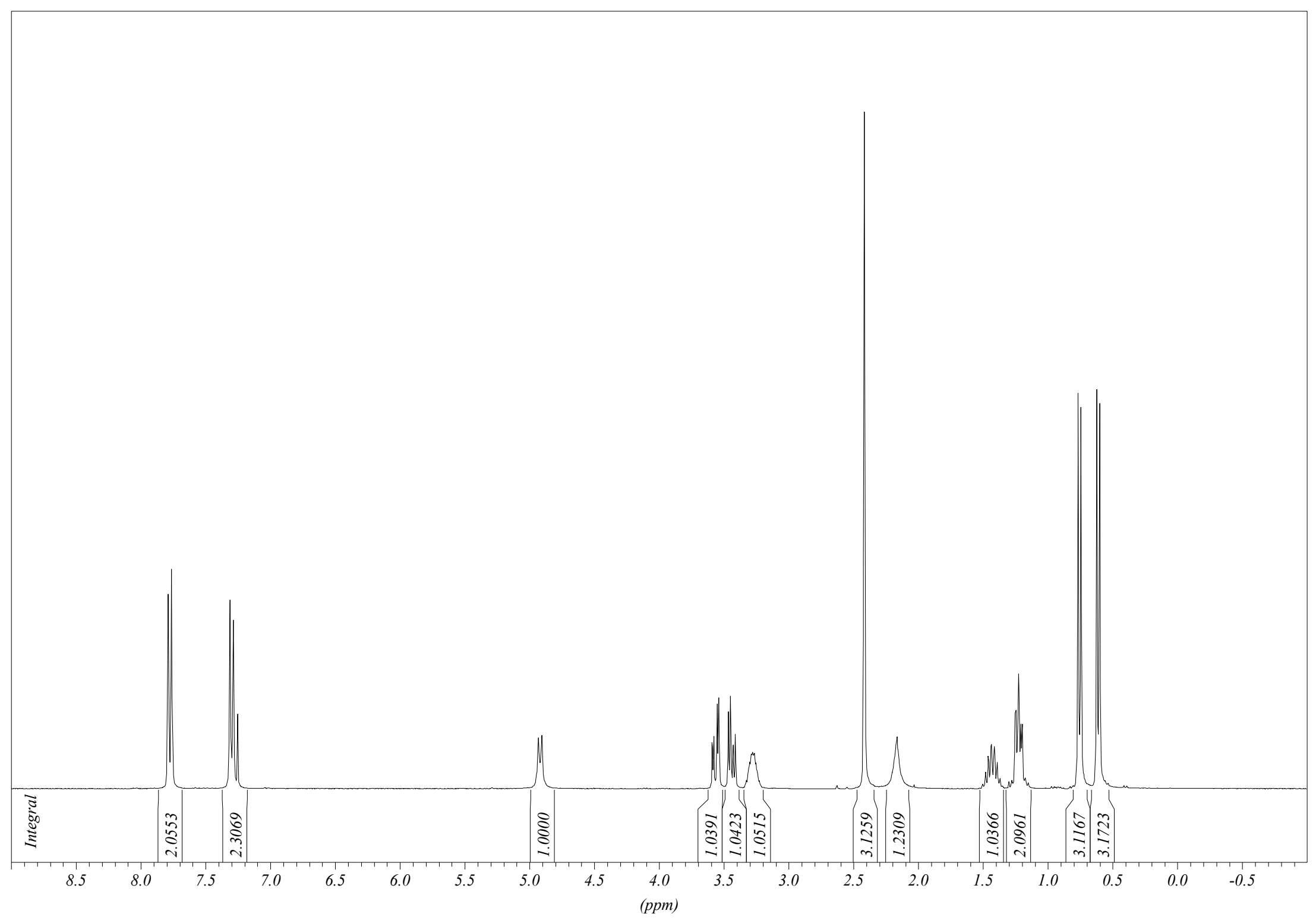

${ }^{1} \mathrm{H}$ NMR Spectrum $(300 \mathrm{MHz})$ of N-tosylleucinol in $\mathrm{CDCl}_{3}$ 


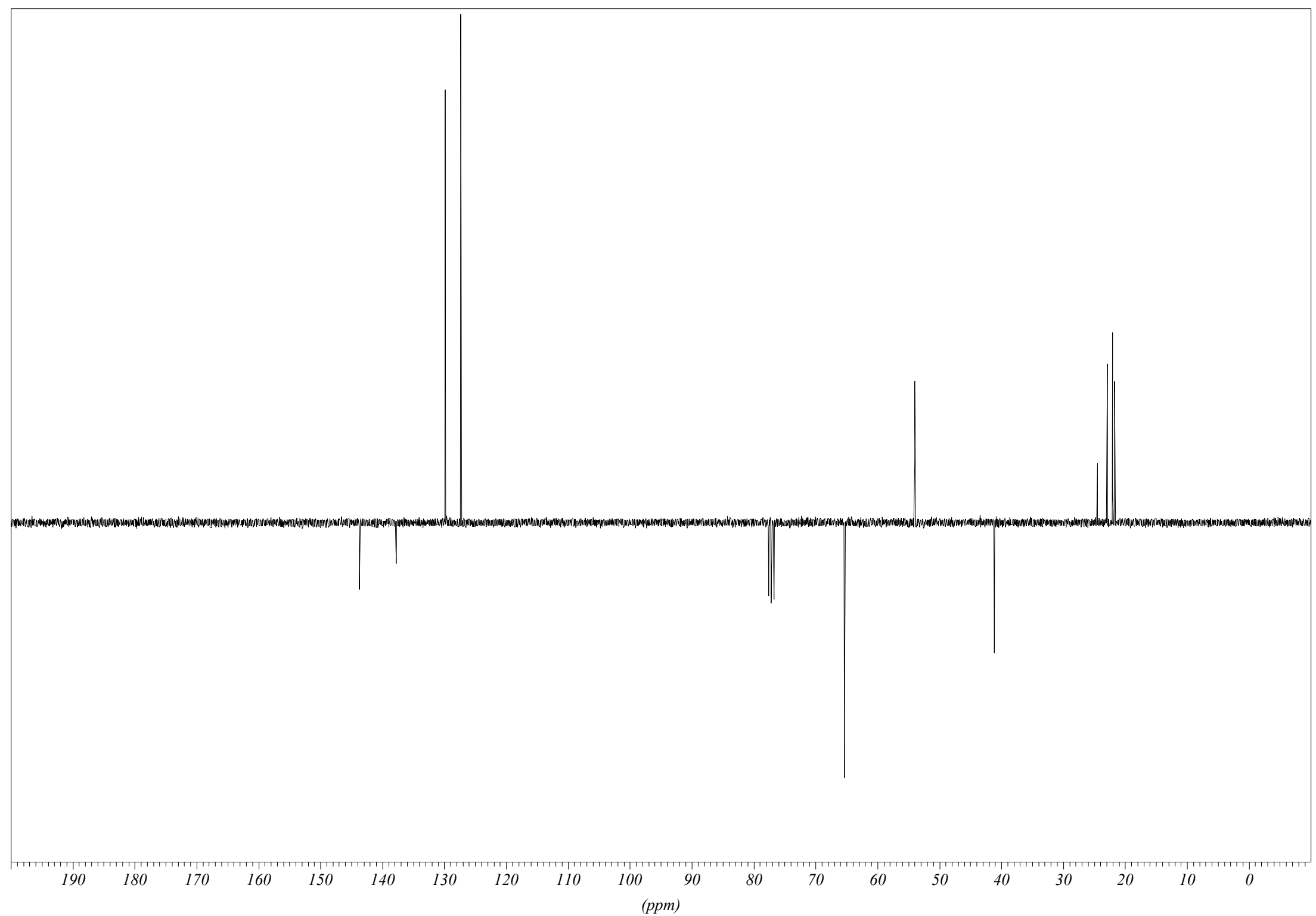

${ }^{13} \mathrm{C}$ NMR Spectrum $(75 \mathrm{MHz})$ of N-tosylleucinol in $\mathrm{CDCl}_{3}$ 


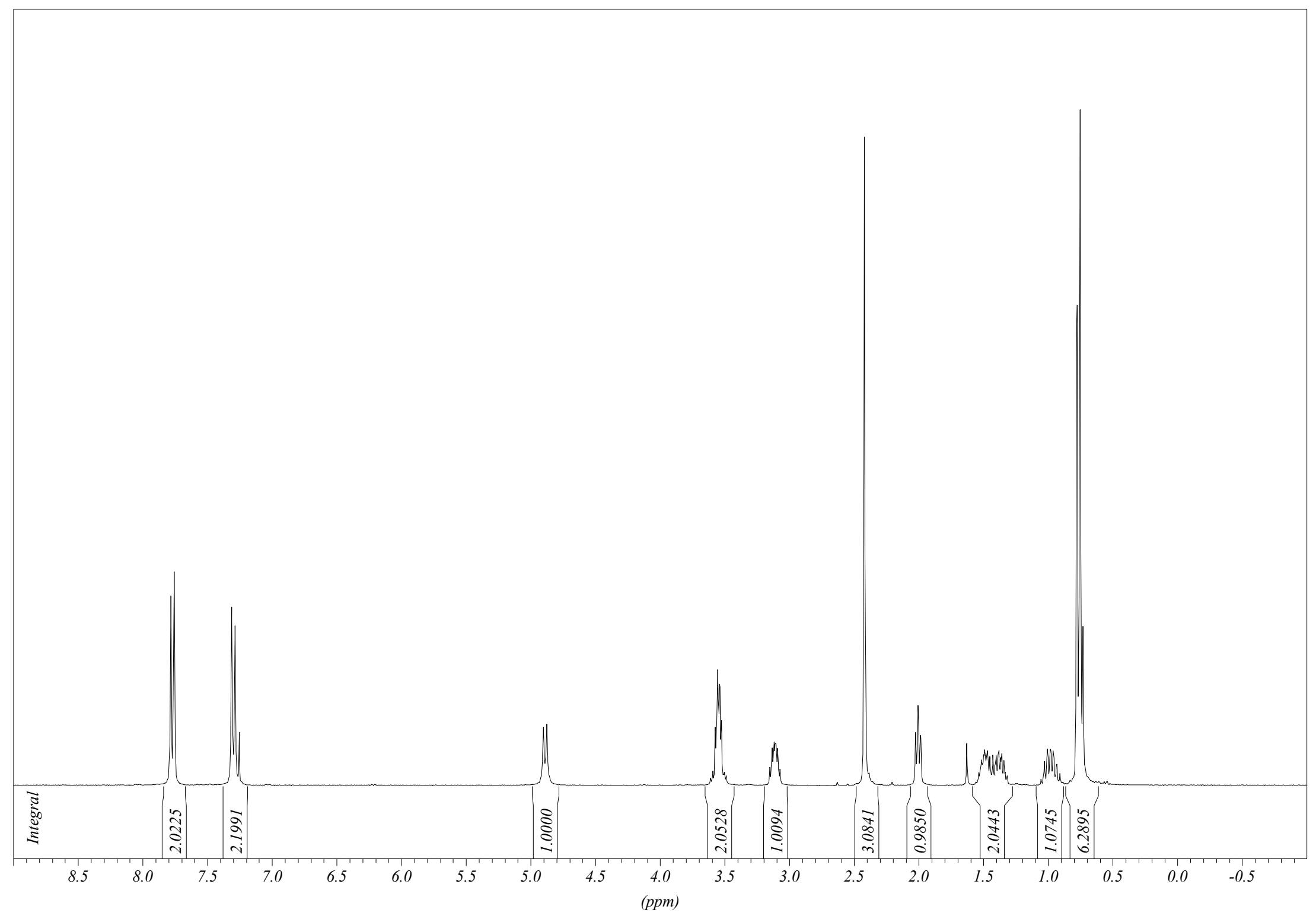

${ }^{1} \mathrm{H}$ NMR Spectrum (300 MHz) of N-tosylisoleucinol in $\mathrm{CDCl}_{3}$ 


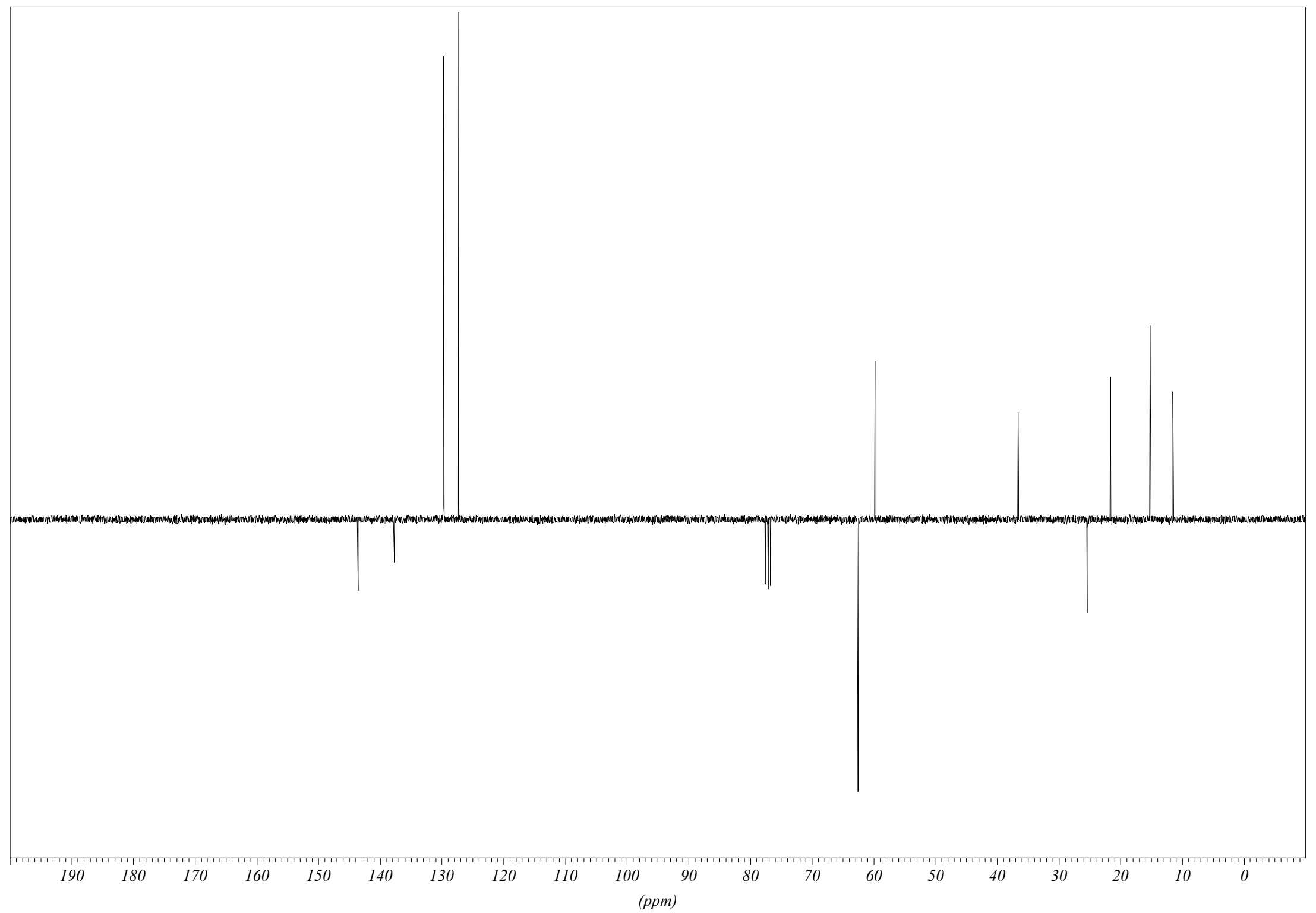

${ }^{13} \mathrm{C}$ NMR Spectrum $\left(75 \mathrm{MHz}\right.$ ) of $\mathrm{N}$-tosylisoleucinol in $\mathrm{CDCl}_{3}$ 


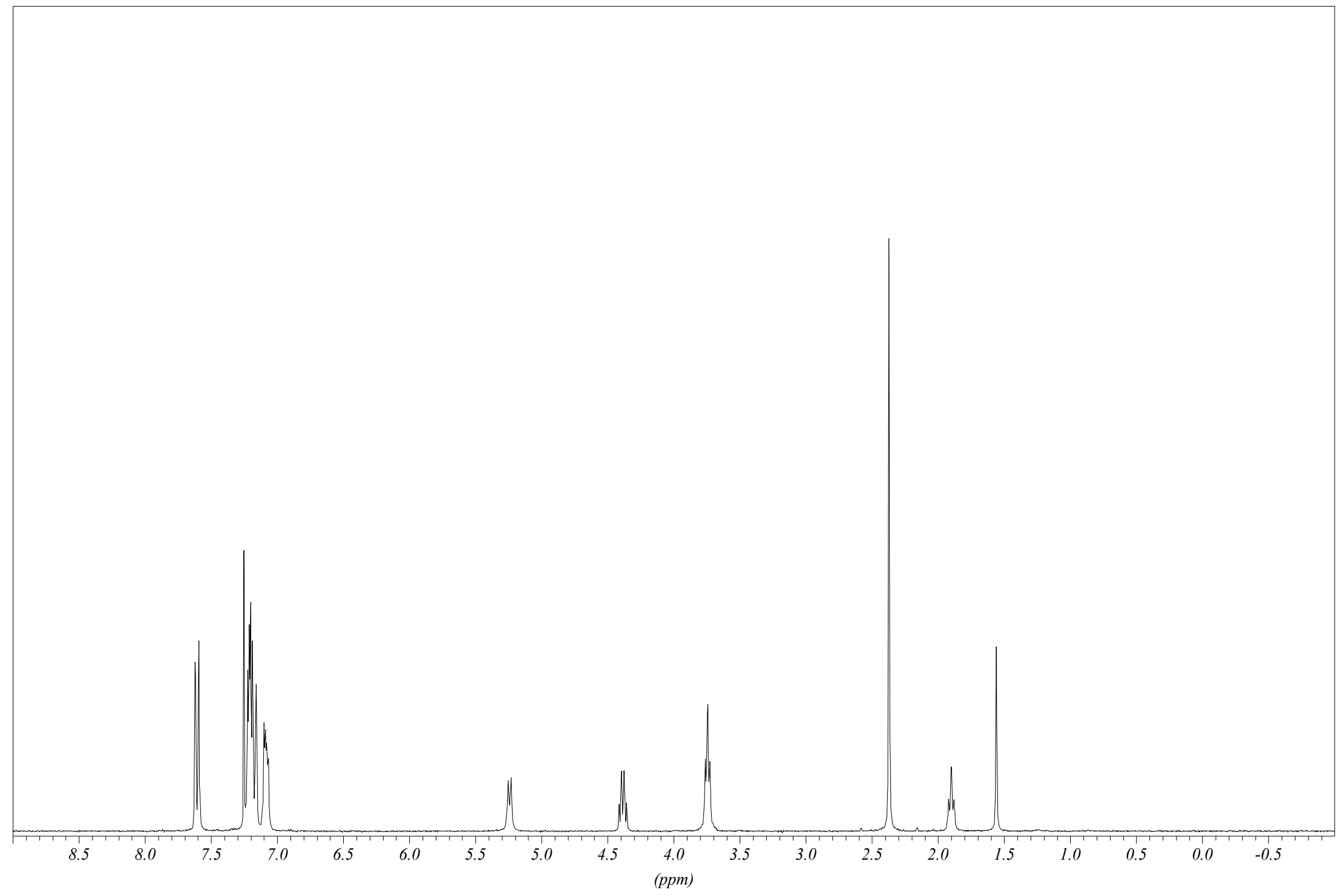

${ }^{1} \mathrm{H}$ NMR Spectrum (300 MHz) of $N$-tosyl phenylglycinol in $\mathrm{CDCl}_{3}$ 


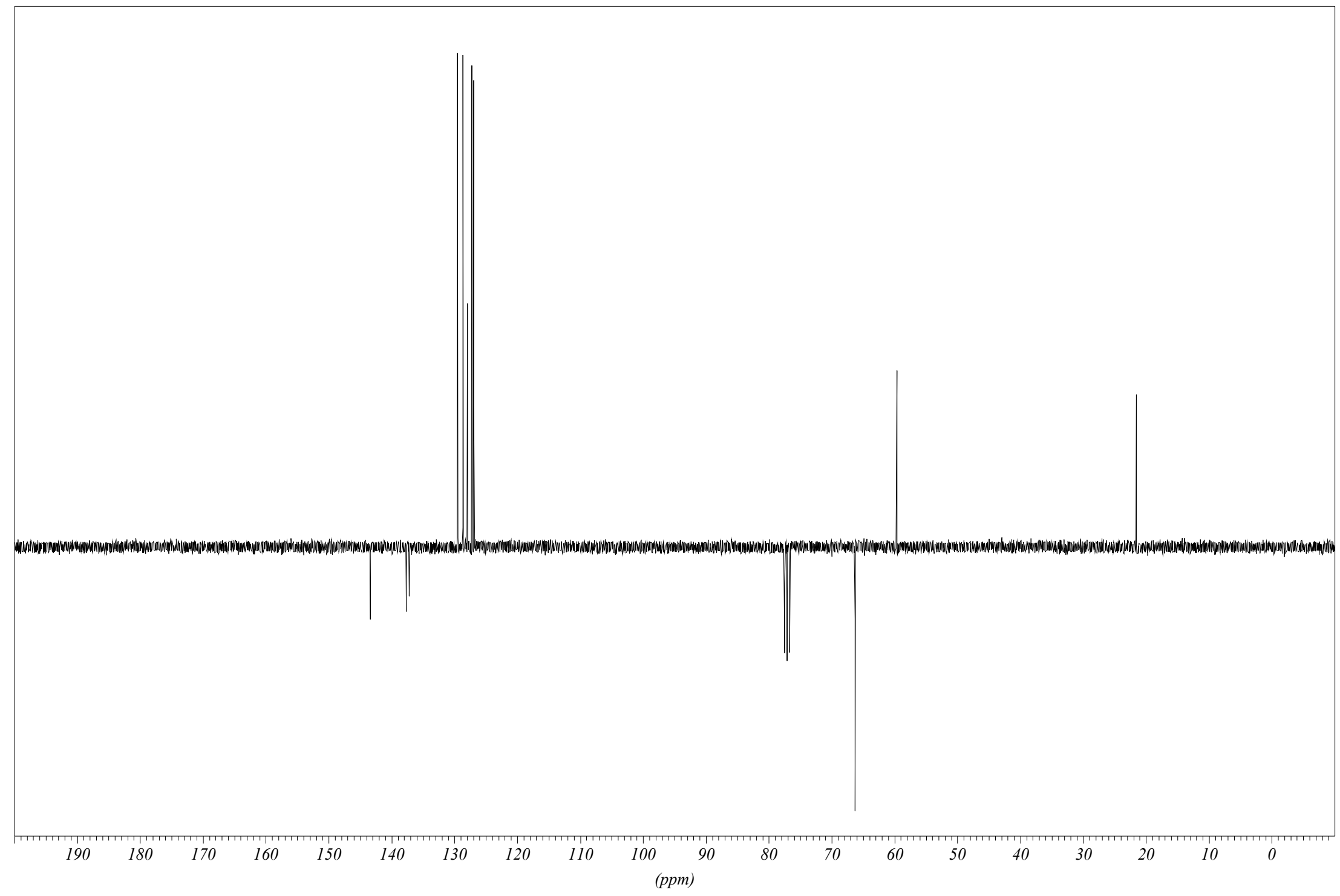

${ }^{13} \mathrm{C}$ NMR Spectrum (75 MHz) of $N$-tosyl phenylglycinol in $\mathrm{CDCl}_{3}$ 


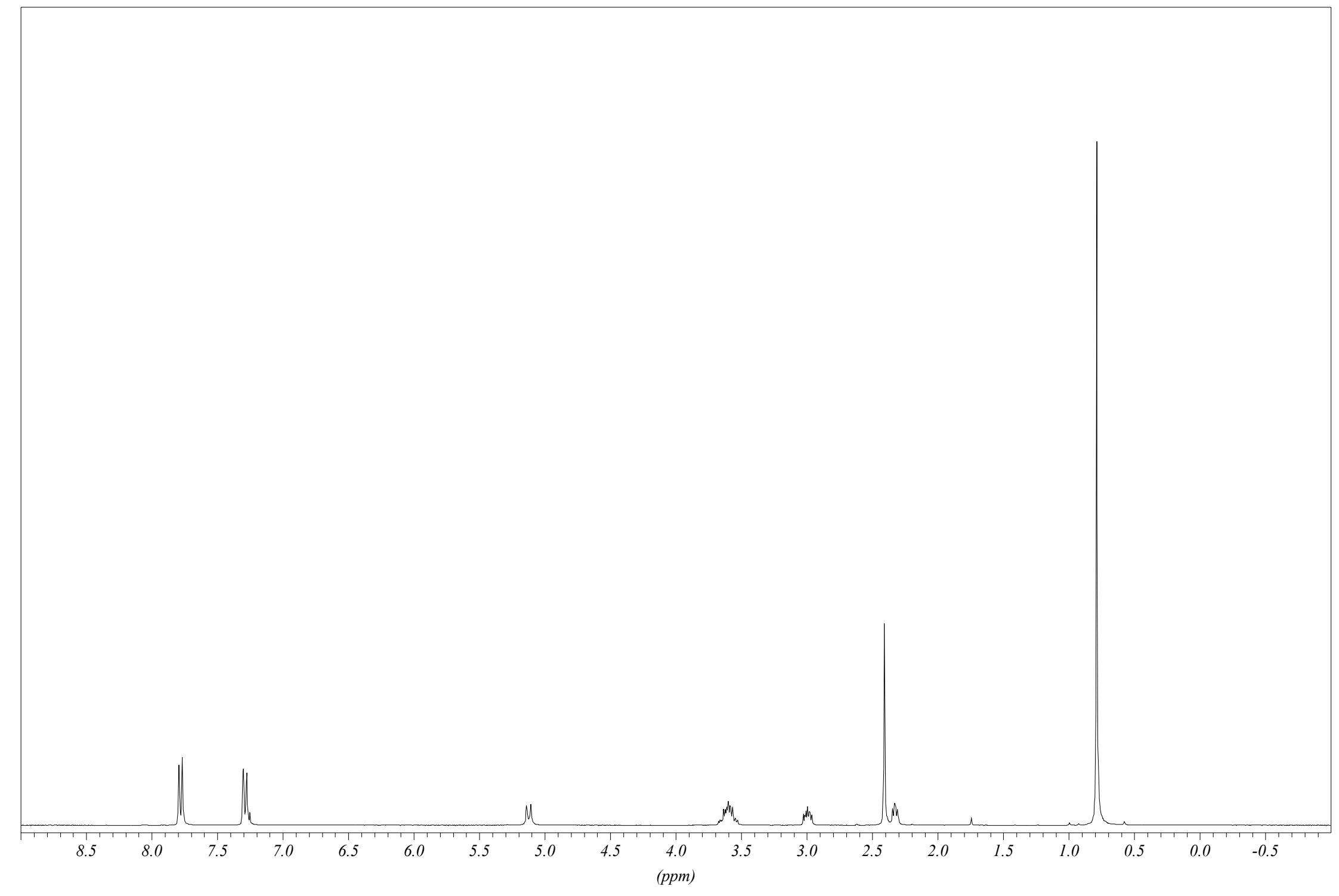

${ }^{1} \mathrm{H}$ NMR Spectrum $(300 \mathrm{MHz})$ of $N$-tosyl tert-leucinol in $\mathrm{CDCl}_{3}$ 


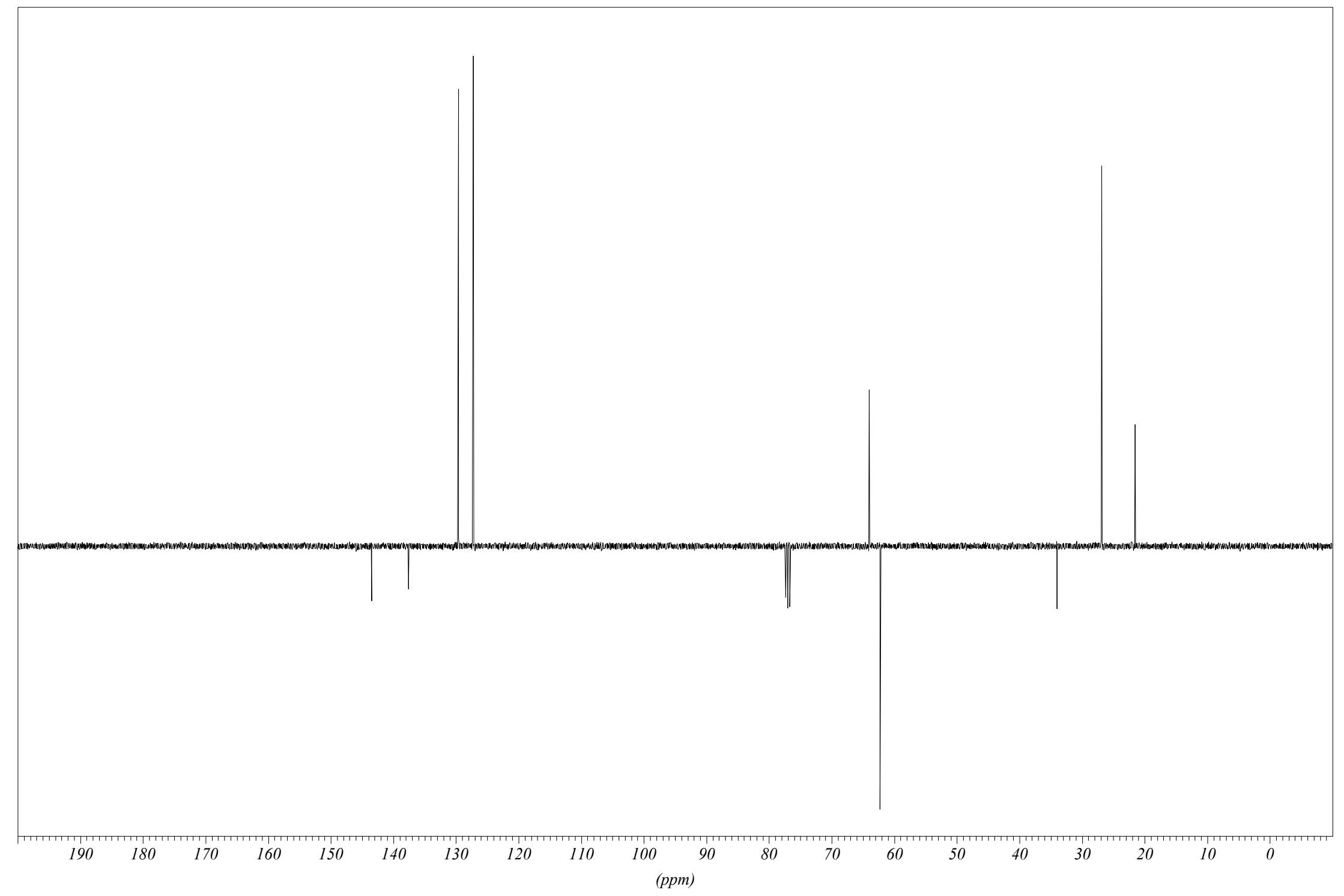

${ }^{13} \mathrm{C}$ NMR Spectrum $(75 \mathrm{MHz})$ of $N$-tosyl tert-leucinol in $\mathrm{CDCl}_{3}$ - ts-tleu 


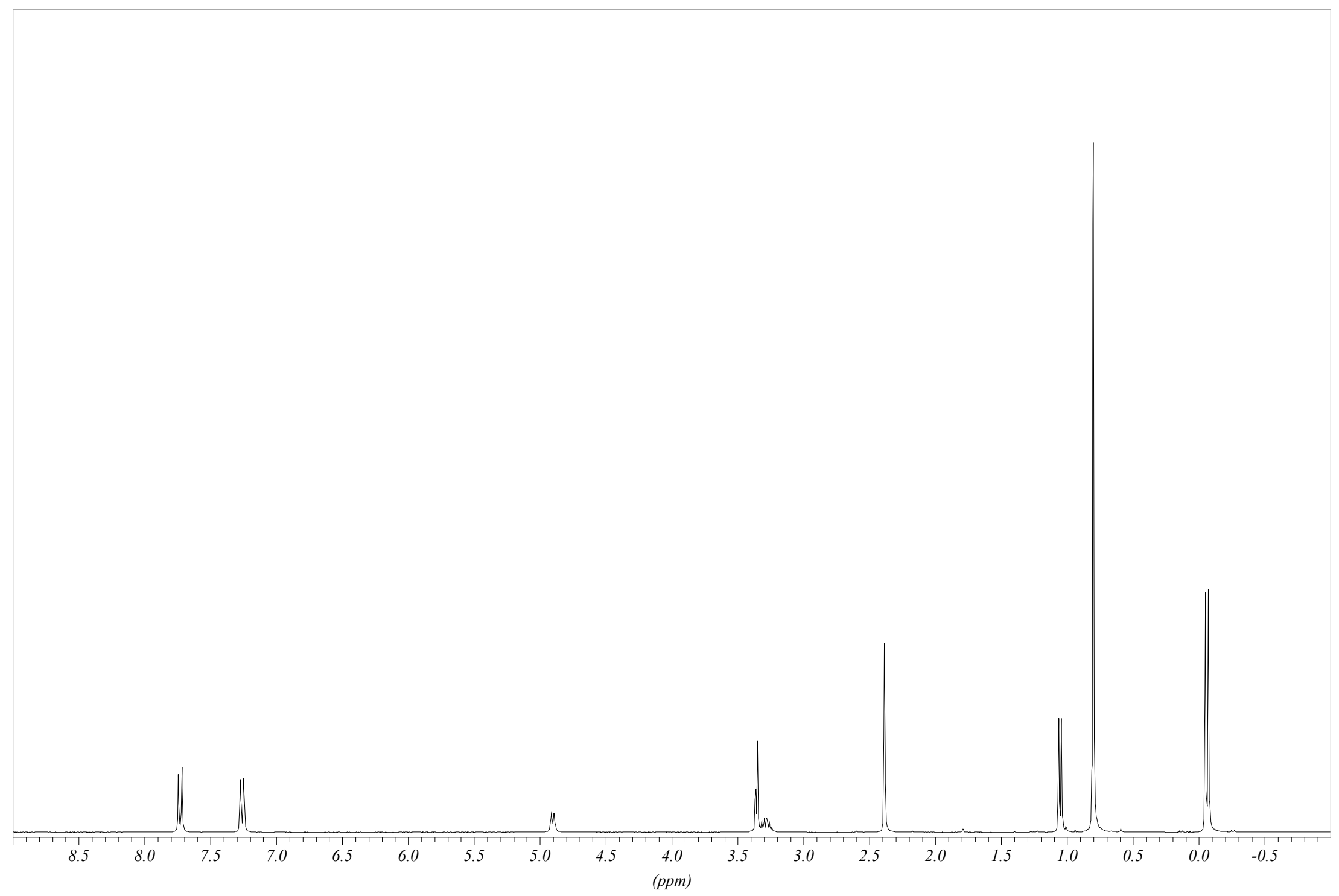

${ }^{1} \mathrm{H}$ NMR Spectrum $\left(300 \mathrm{MHz}\right.$ ) of $\mathbf{8 a}$ in $\mathrm{CDCl}_{3}$ 


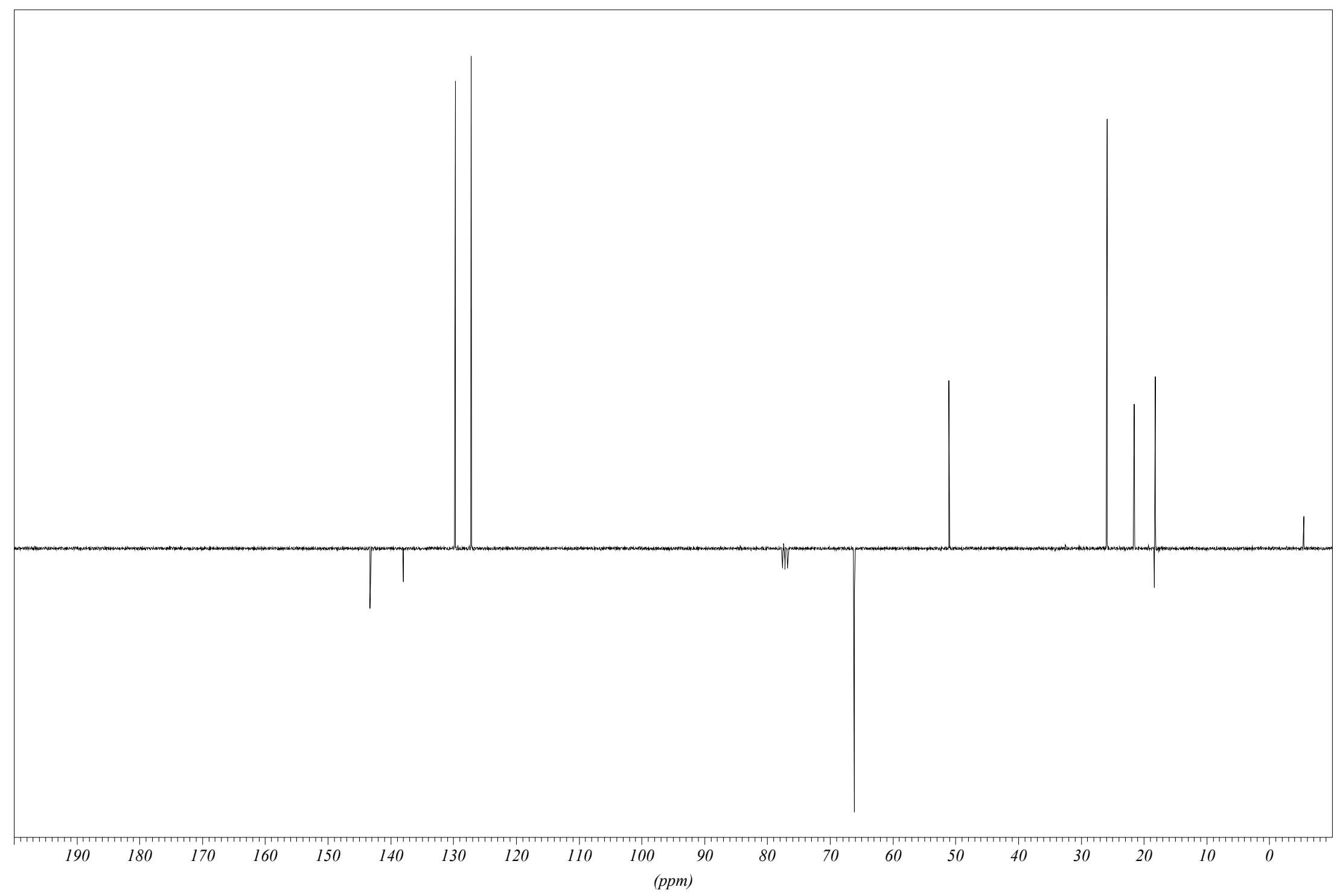

${ }^{13} \mathrm{C}$ NMR Spectrum (75 MHz) of $\mathbf{8 a}$ in $\mathrm{CDCl}_{3}$ 


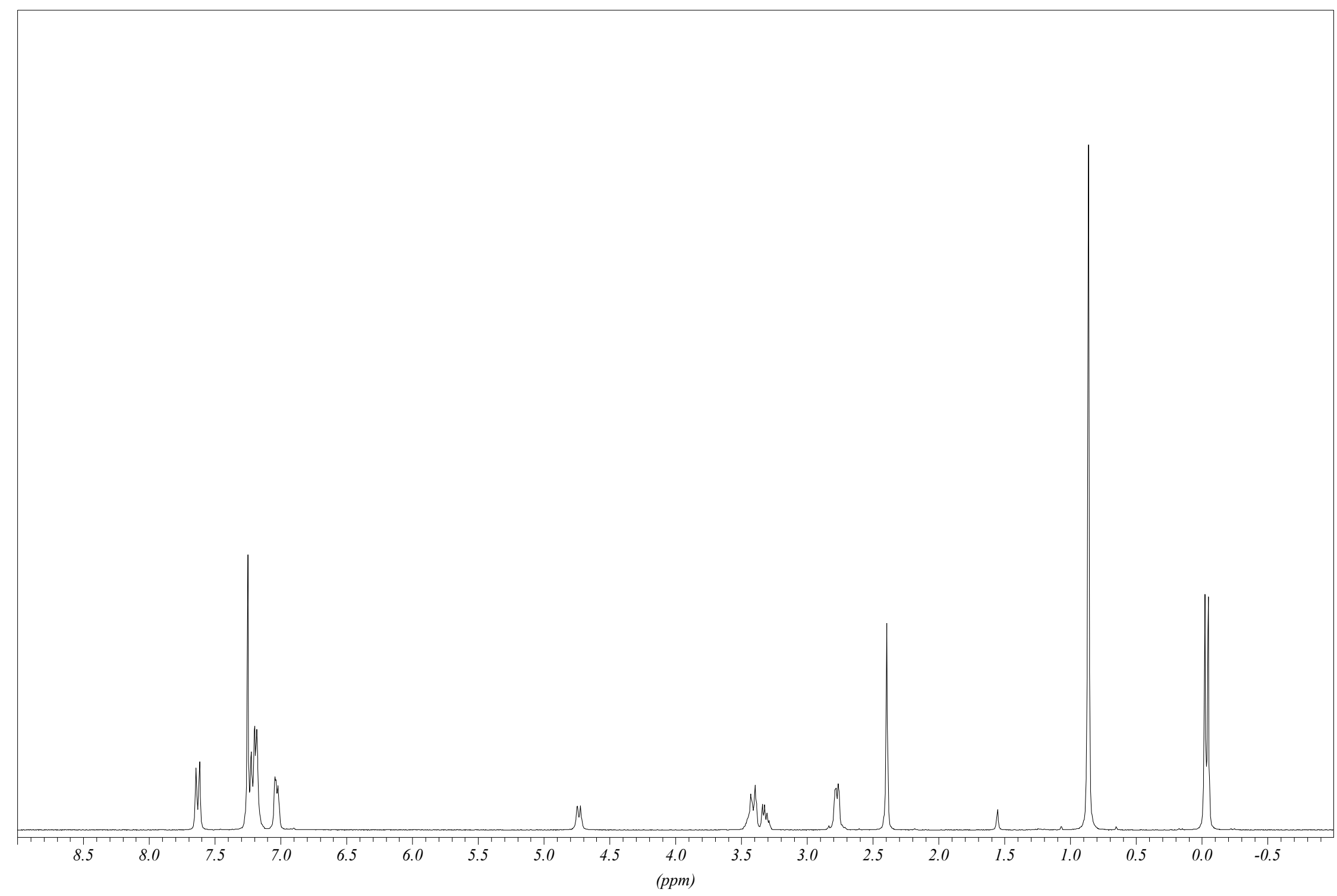

${ }^{1} \mathrm{H}$ NMR Spectrum (300 MHz) of $\mathbf{8 b}$ in $\mathrm{CDCl}_{3}$ 


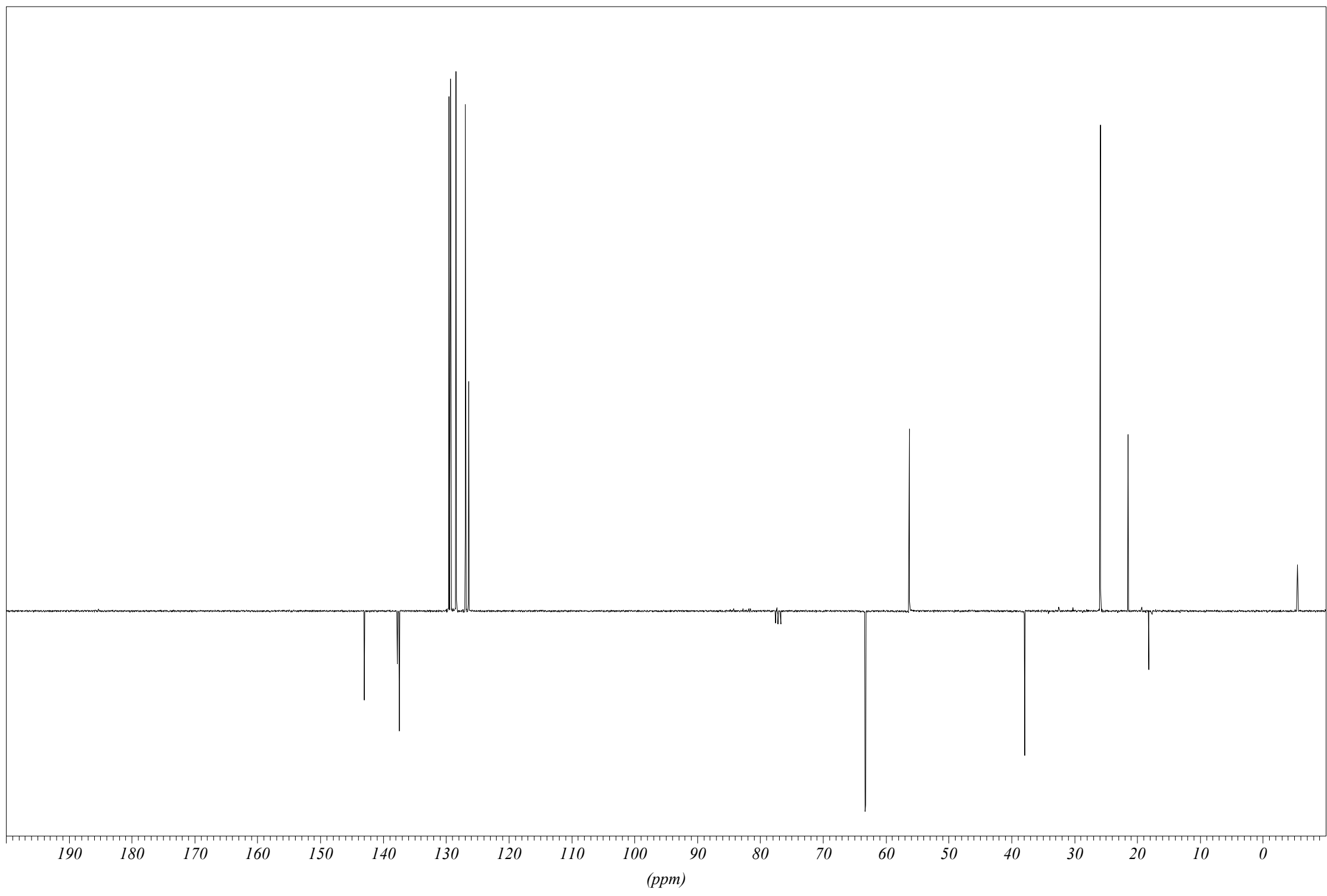

${ }^{13} \mathrm{C}$ NMR Spectrum (75 MHz) of $\mathbf{8 b}$ in $\mathrm{CDCl}_{3}$ 


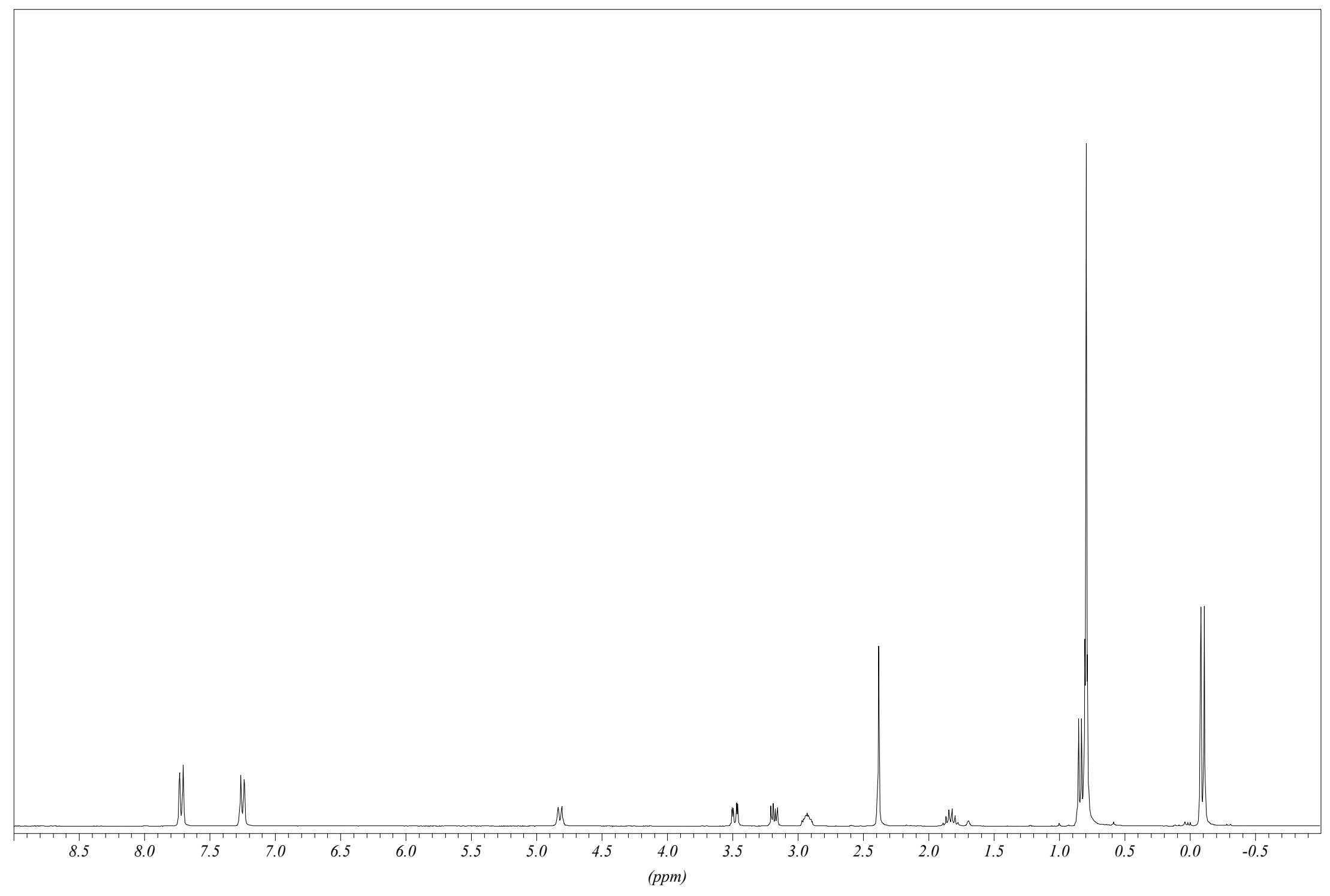

${ }^{1} \mathrm{H}$ NMR Spectrum $\left(300 \mathrm{MHz}\right.$ ) of $\mathbf{8 c}$ in $\mathrm{CDCl}_{3}$ 


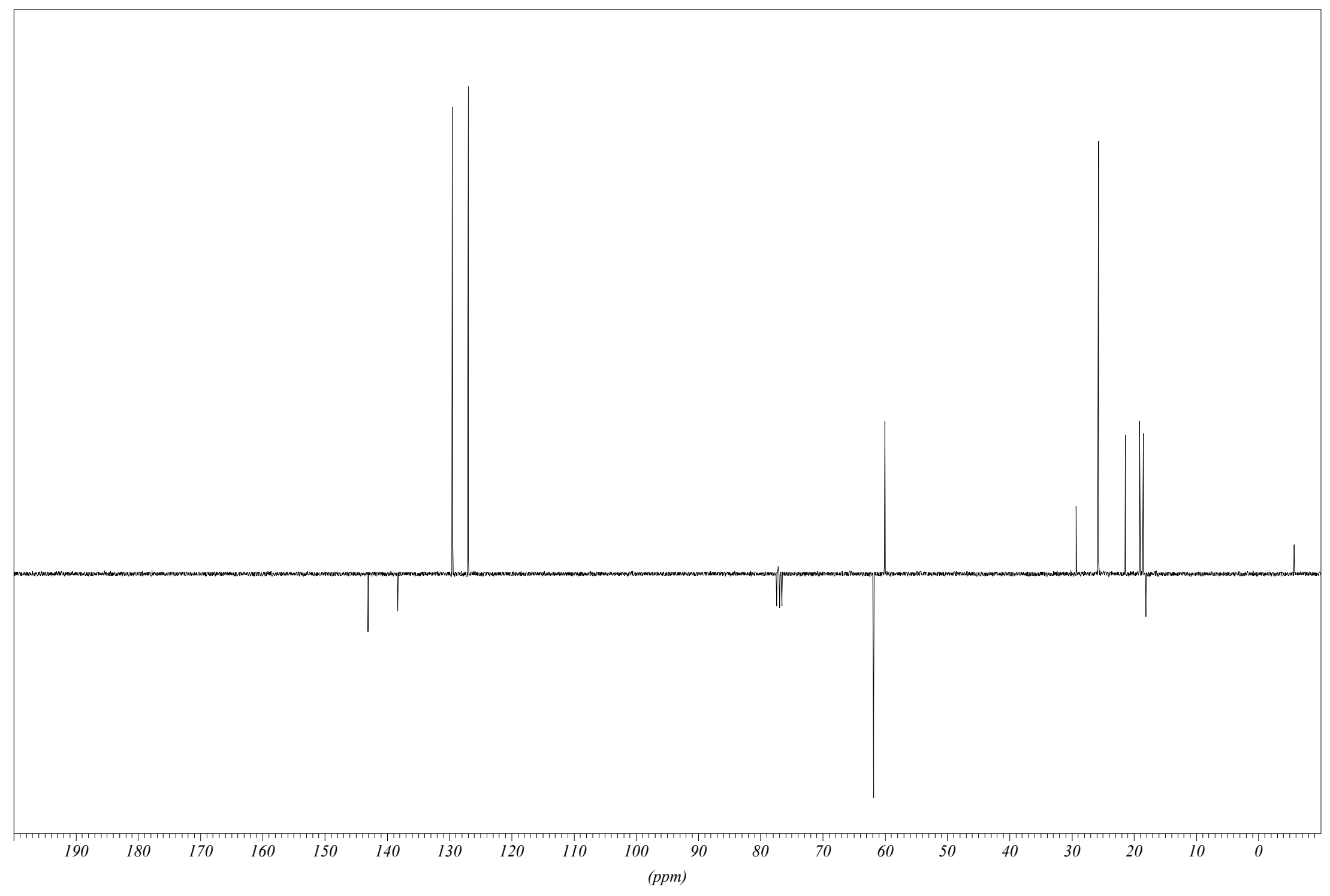

${ }^{13} \mathrm{C}$ NMR Spectrum $(75 \mathrm{MHz})$ of $\mathbf{8 c}$ in $\mathrm{CDCl}_{3}$ 


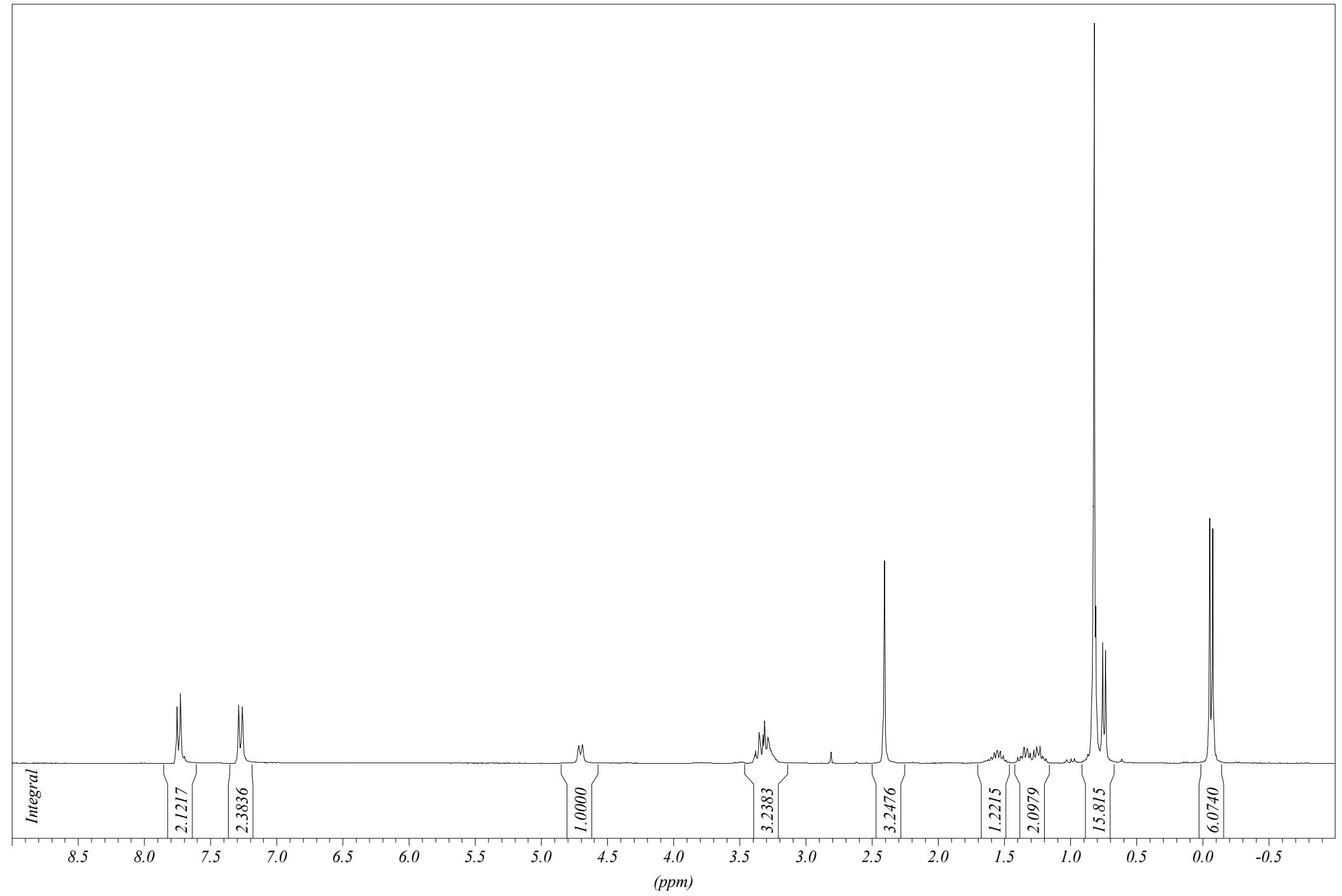

${ }^{1} \mathrm{H}$ NMR Spectrum $(300 \mathrm{MHz})$ of $\mathbf{8 d}$ in $\mathrm{CDCl}_{3}$ 


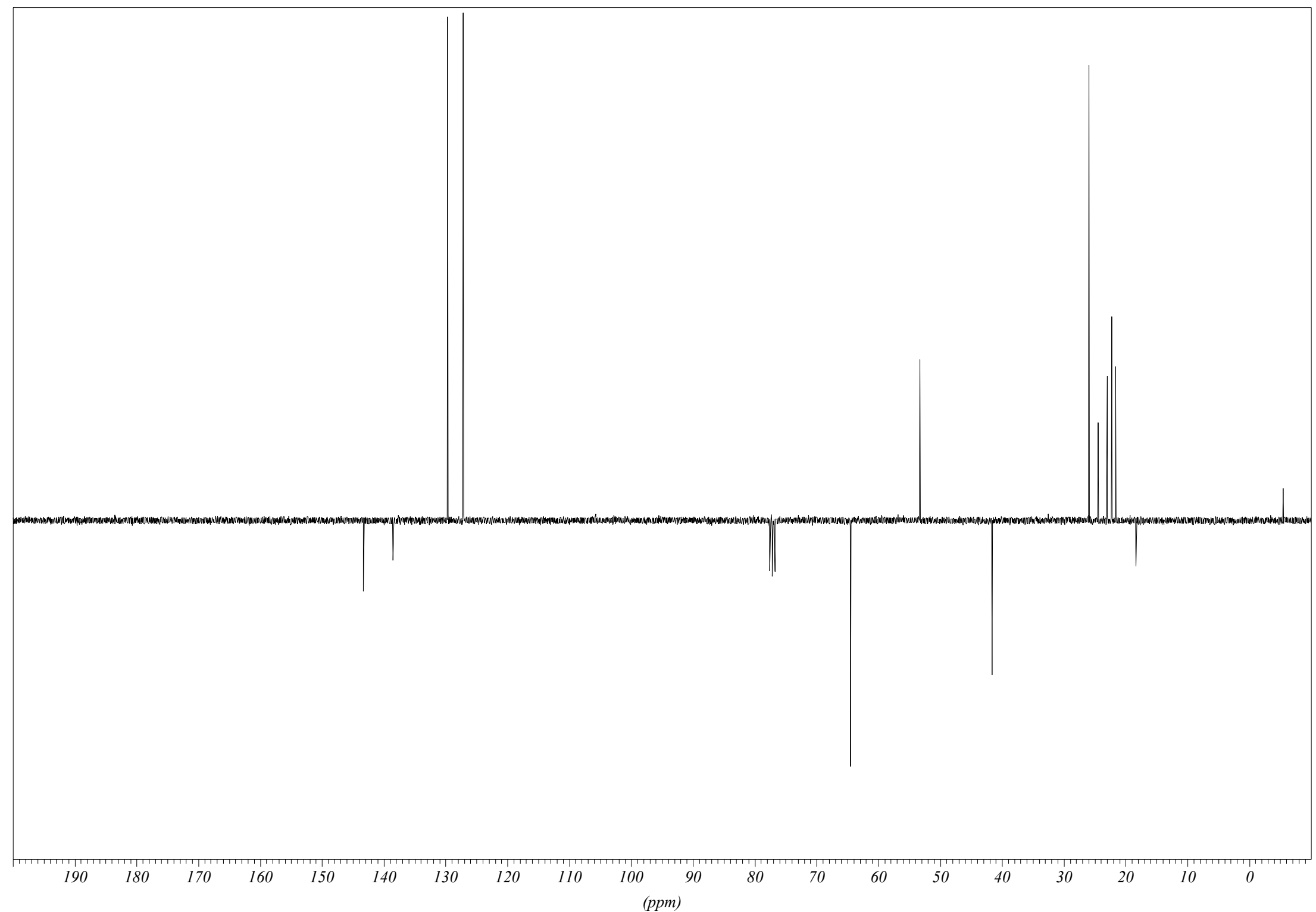

${ }^{13} \mathrm{C}$ NMR Spectrum (75 MHz) of $8 \mathbf{d}$ in $\mathrm{CDCl}_{3}$ 


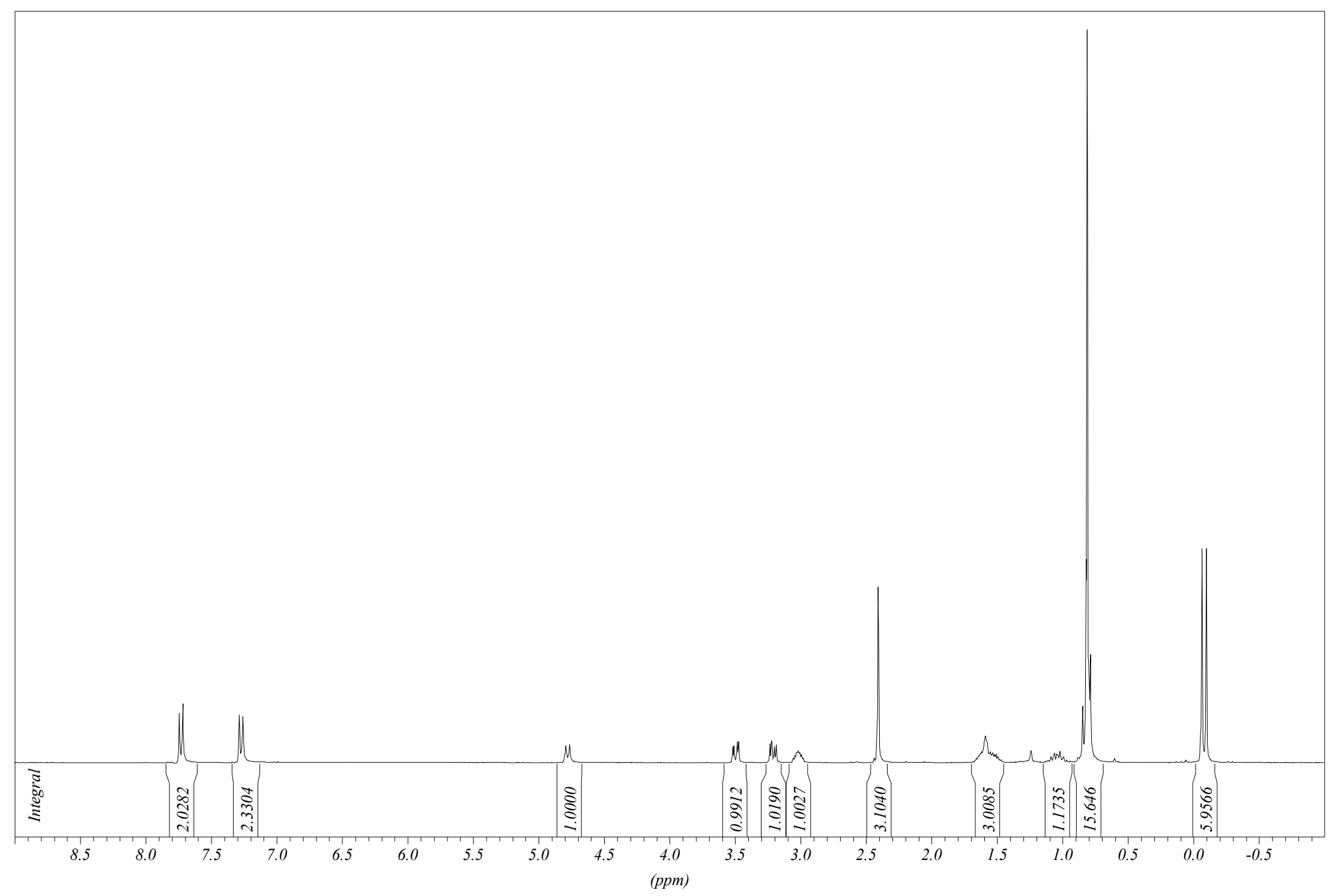

${ }^{1} \mathrm{H}$ NMR Spectrum (300 MHz) of $\mathbf{8 e}$ in $\mathrm{CDCl}_{3}$ 


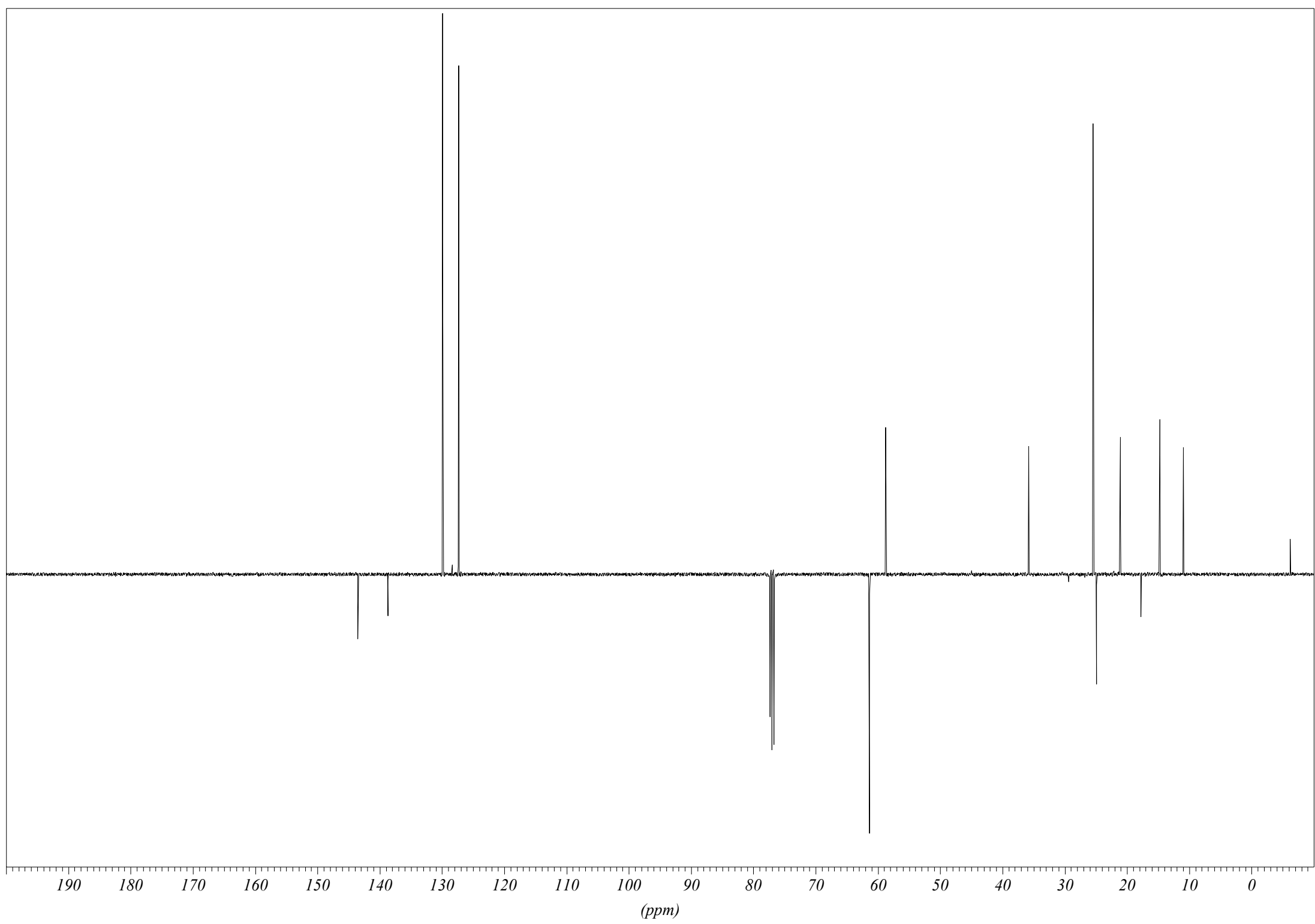

${ }^{13} \mathrm{C}$ NMR Spectrum $(75 \mathrm{MHz})$ of $\mathbf{8 e}$ in $\mathrm{CDCl}_{3}$ 


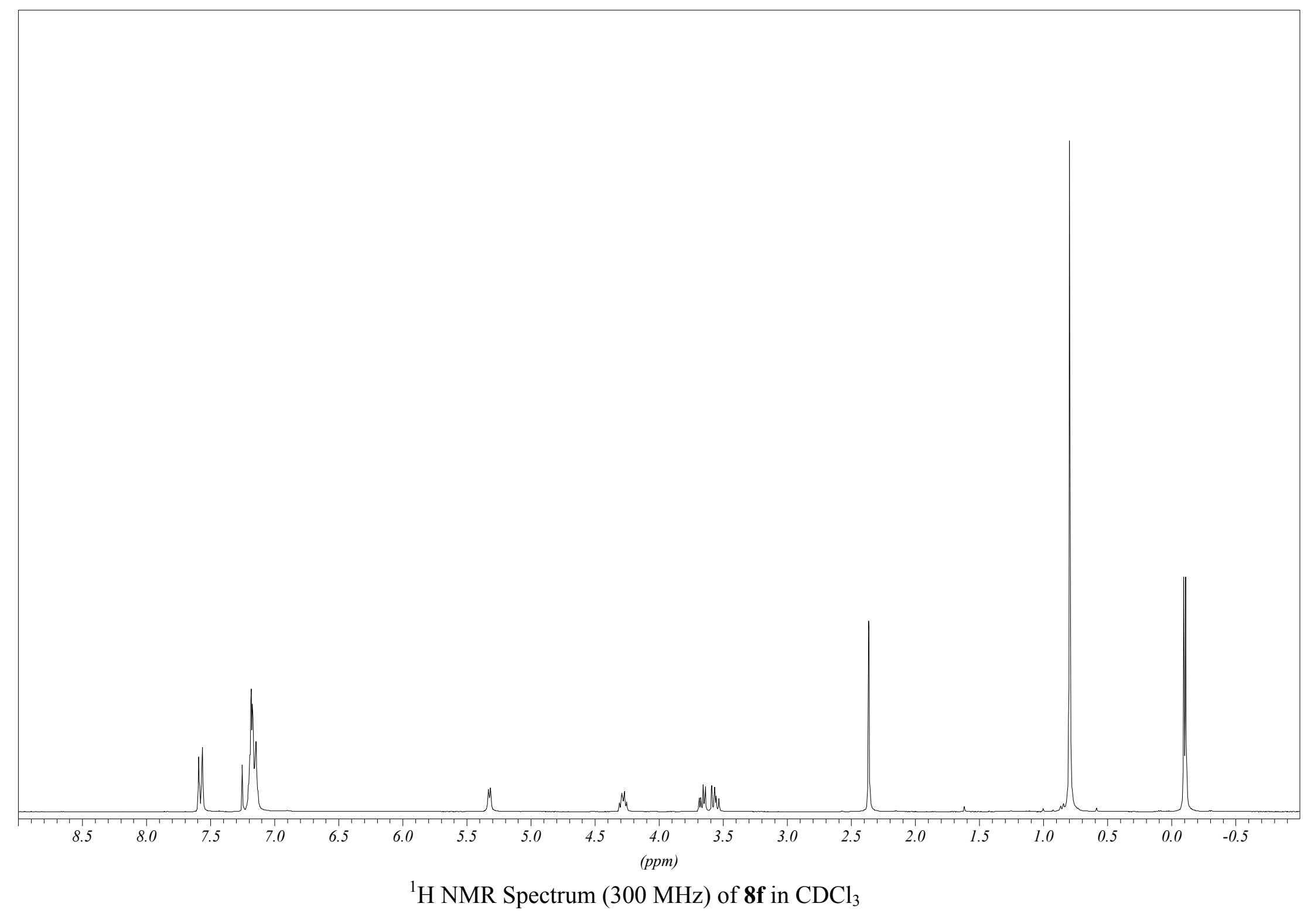




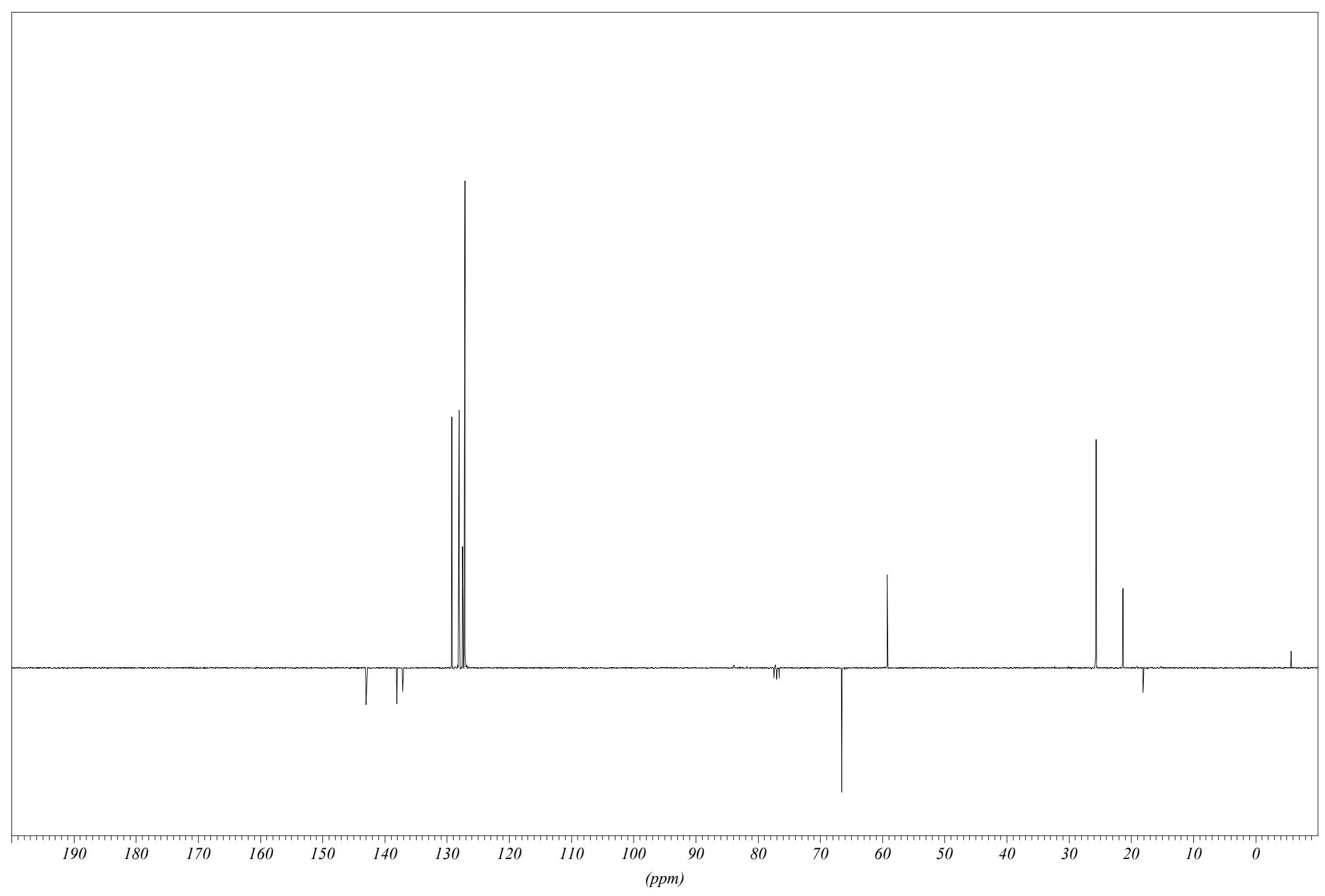

${ }^{13} \mathrm{C}$ NMR Spectrum $(75 \mathrm{MHz})$ of $\mathbf{8 f}$ in $\mathrm{CDCl}_{3}$ 


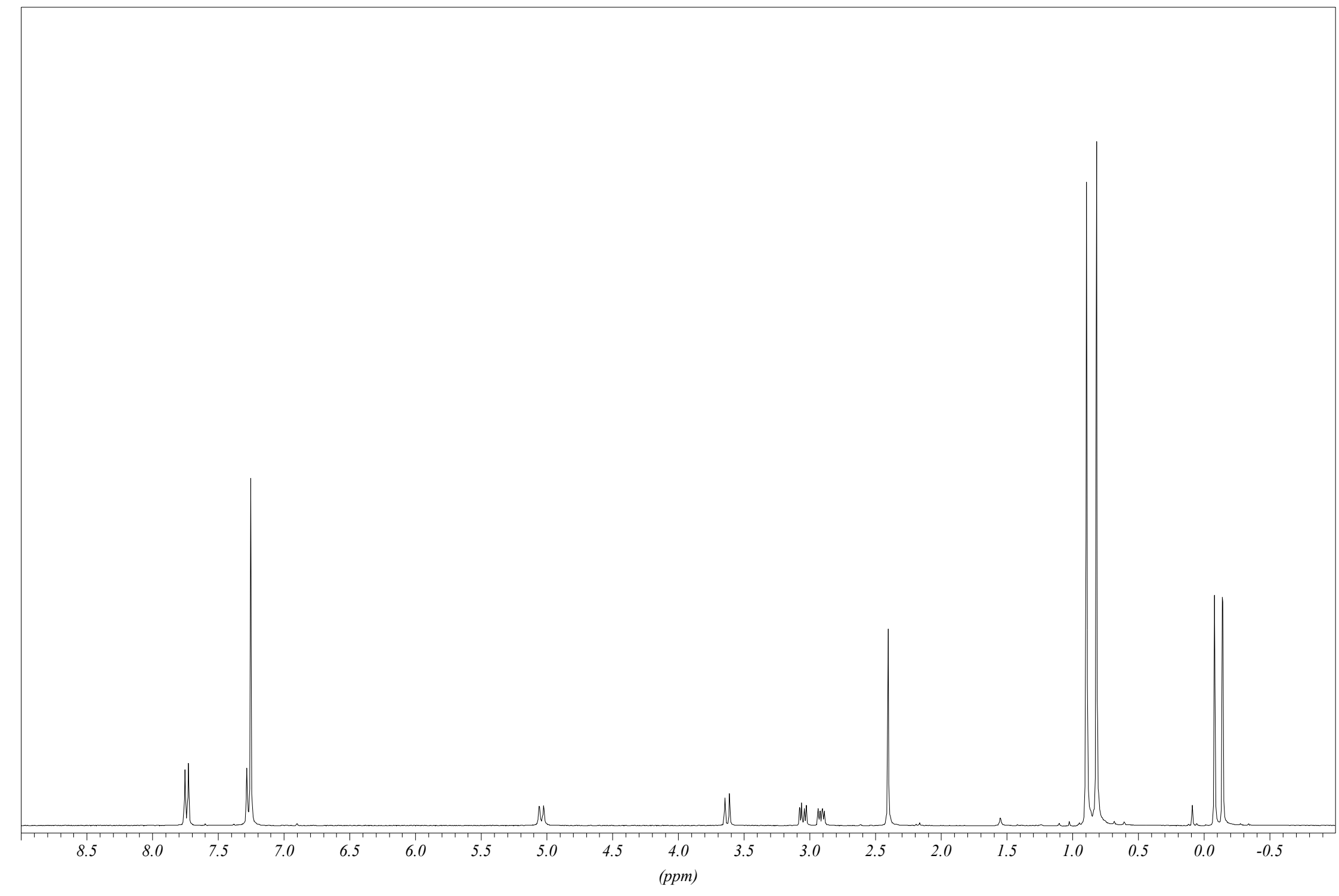

${ }^{1} \mathrm{H}$ NMR Spectrum (300 MHz) of $\mathbf{8 g}$ in $\mathrm{CDCl}_{3}$ 


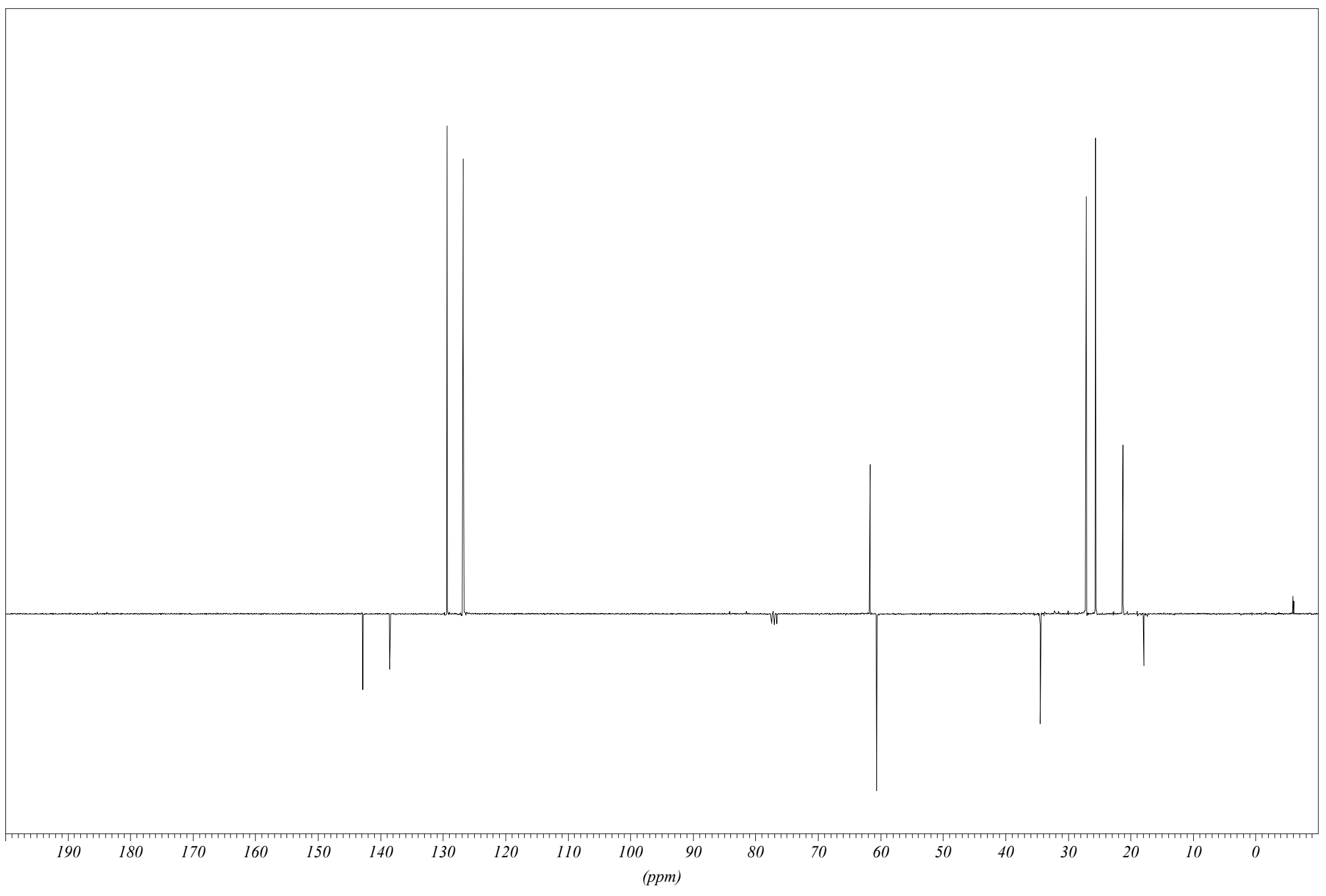

${ }^{13} \mathrm{C}$ NMR Spectrum $(75 \mathrm{MHz})$ of $\mathbf{8 g}$ in $\mathrm{CDCl}_{3}$ 


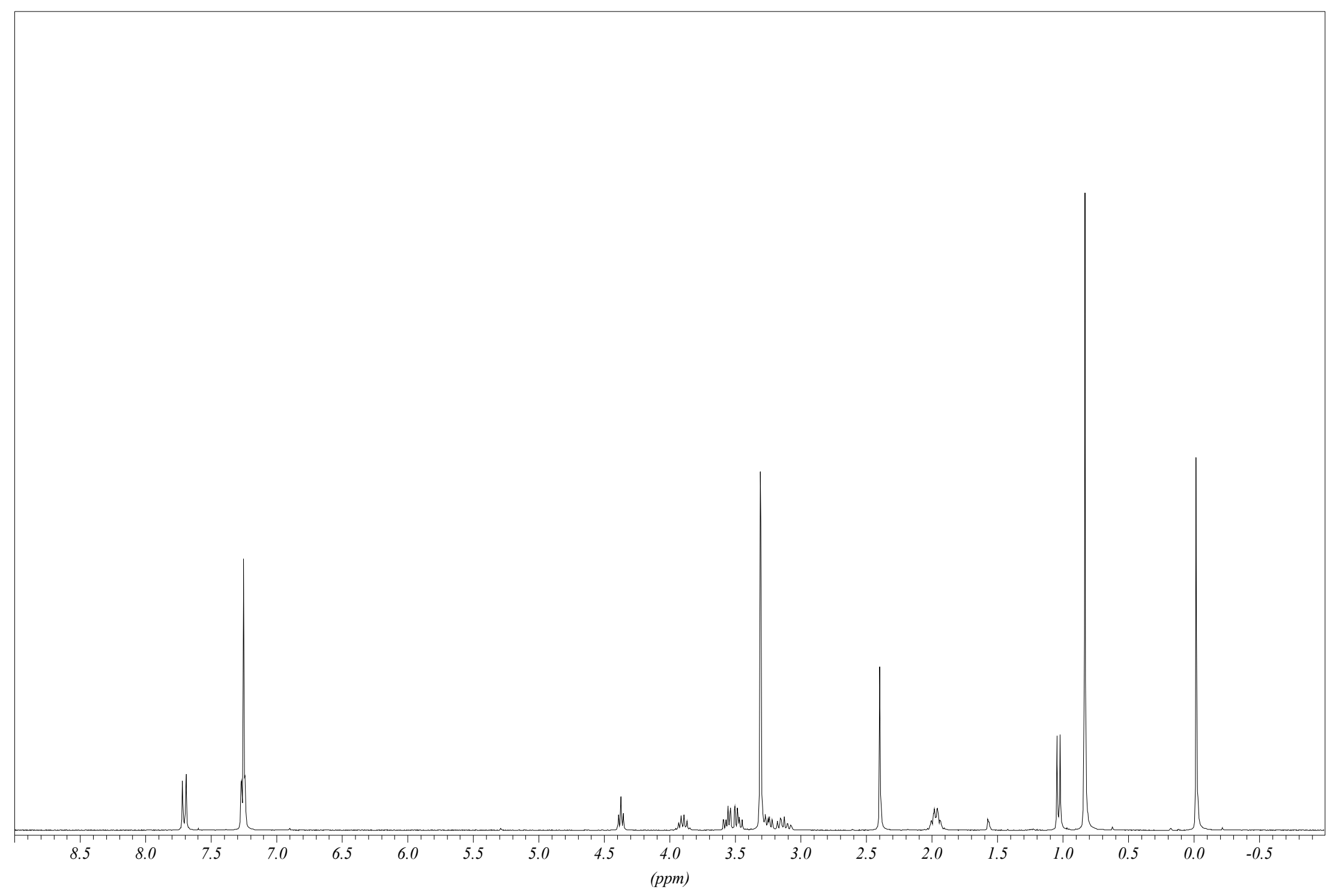

${ }^{1} \mathrm{H}$ NMR Spectrum (300 MHz) of 9a in $\mathrm{CDCl}_{3}$ 


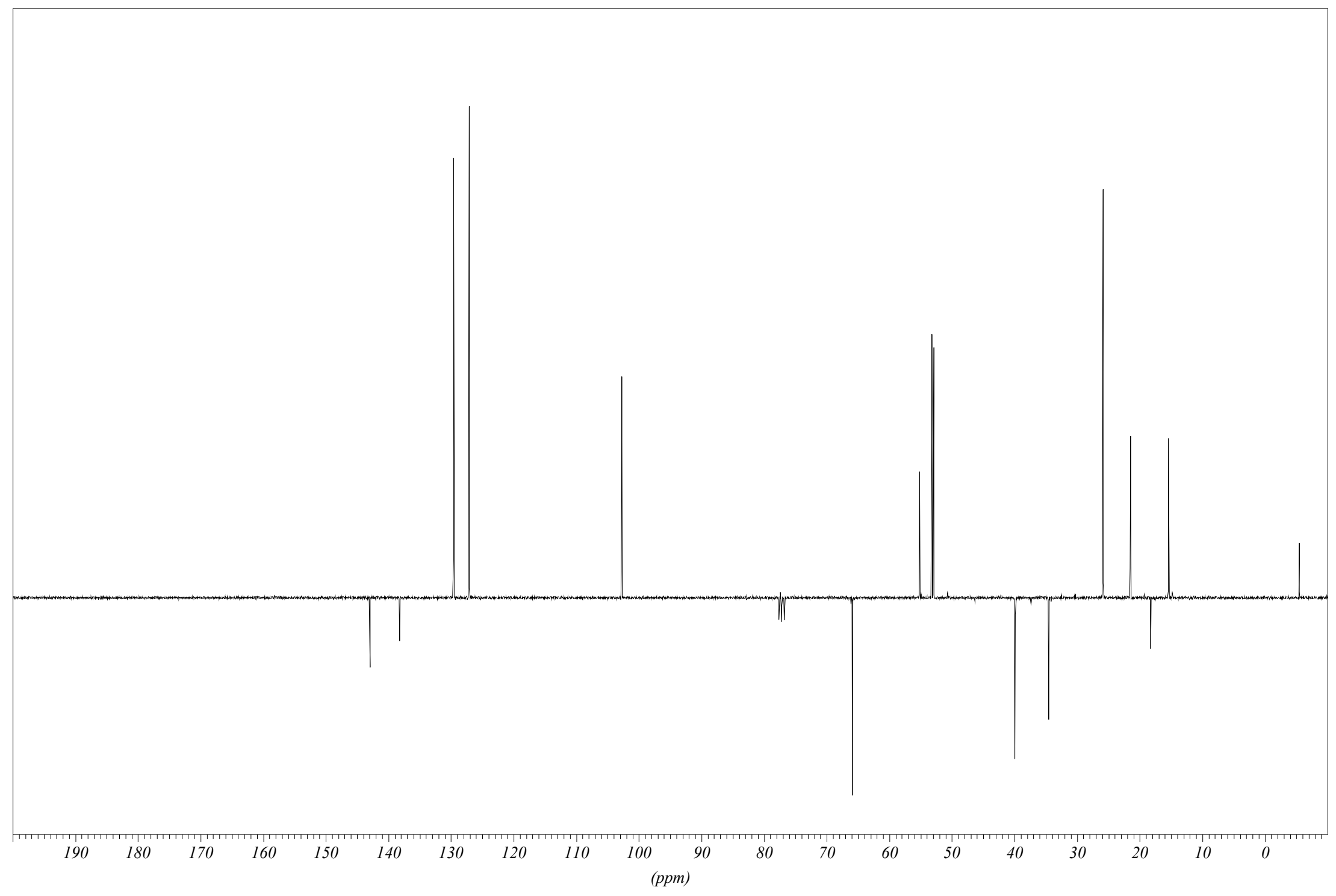

${ }^{13} \mathrm{C}$ NMR Spectrum (75 MHz) of $\mathbf{9 a}$ in $\mathrm{CDCl}_{3}$ 


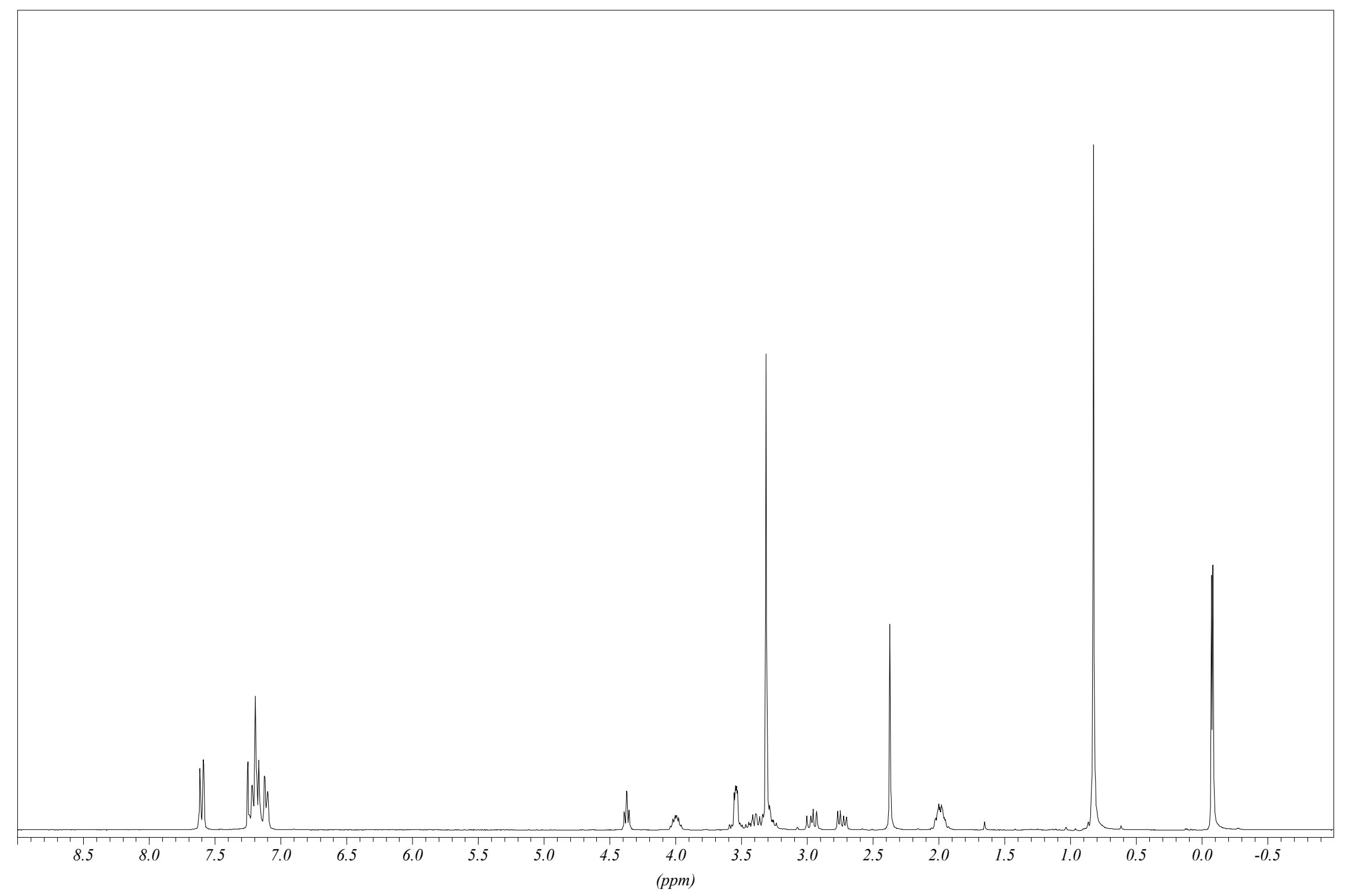

${ }^{1} \mathrm{H}$ NMR Spectrum (300 MHz) of $\mathbf{9 b}$ in $\mathrm{CDCl}_{3}$ 


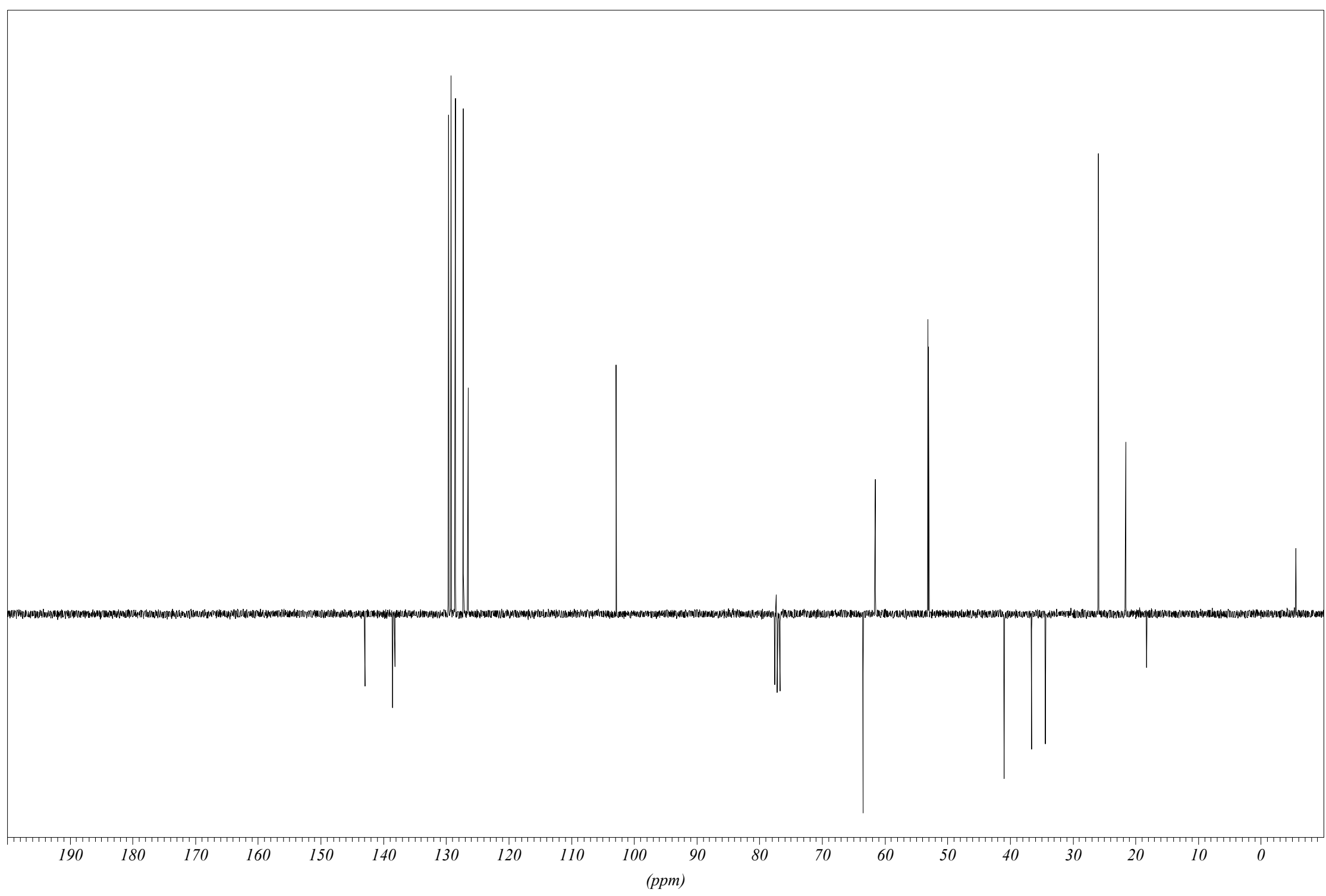

${ }^{13} \mathrm{C}$ NMR Spectrum $\left(75 \mathrm{MHz}\right.$ ) of $\mathbf{9 b}$ in $\mathrm{CDCl}_{3}$ 


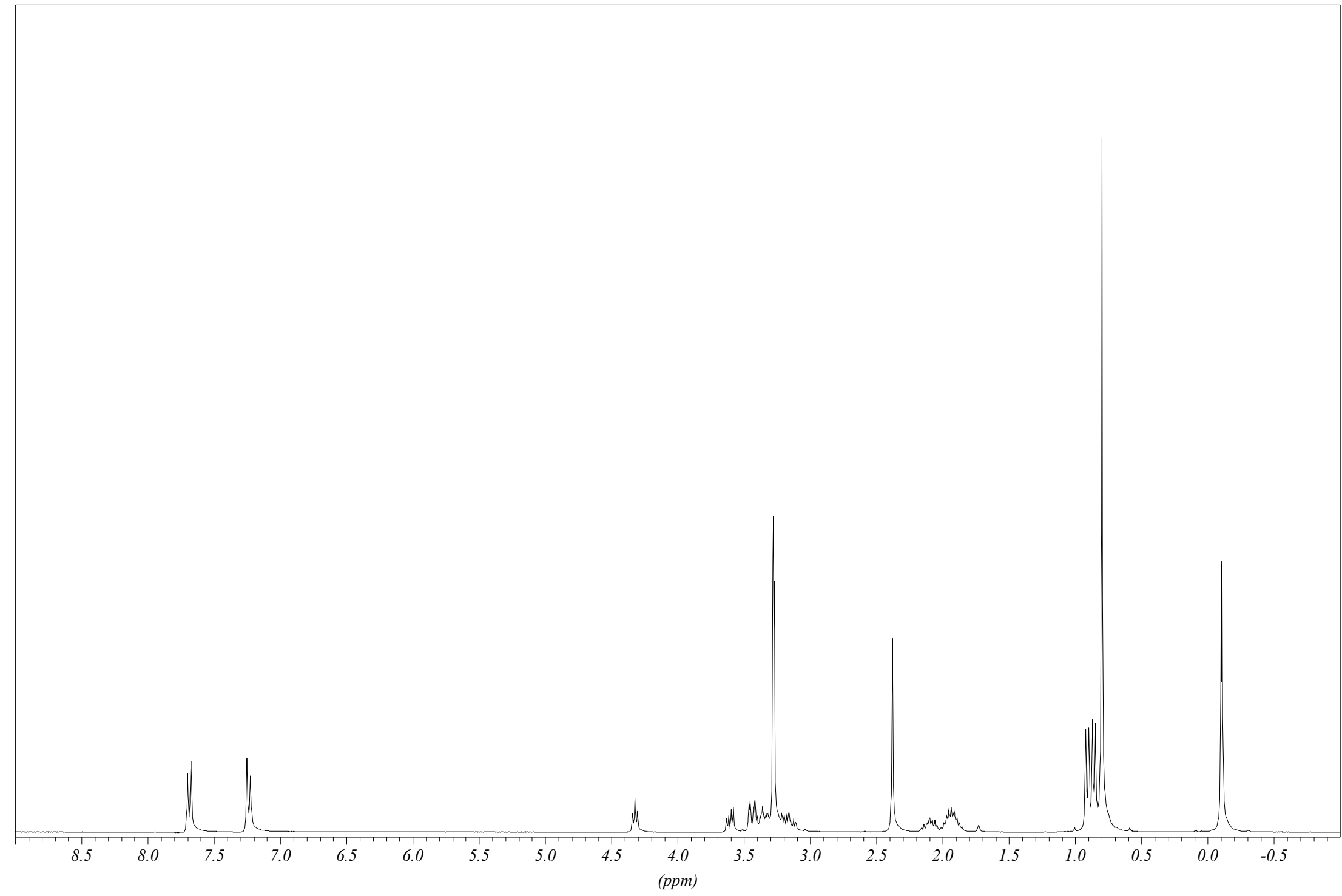

${ }^{1} \mathrm{H}$ NMR Spectrum $(300 \mathrm{MHz})$ of $9 \mathrm{c}$ in $\mathrm{CDCl}_{3}$ 


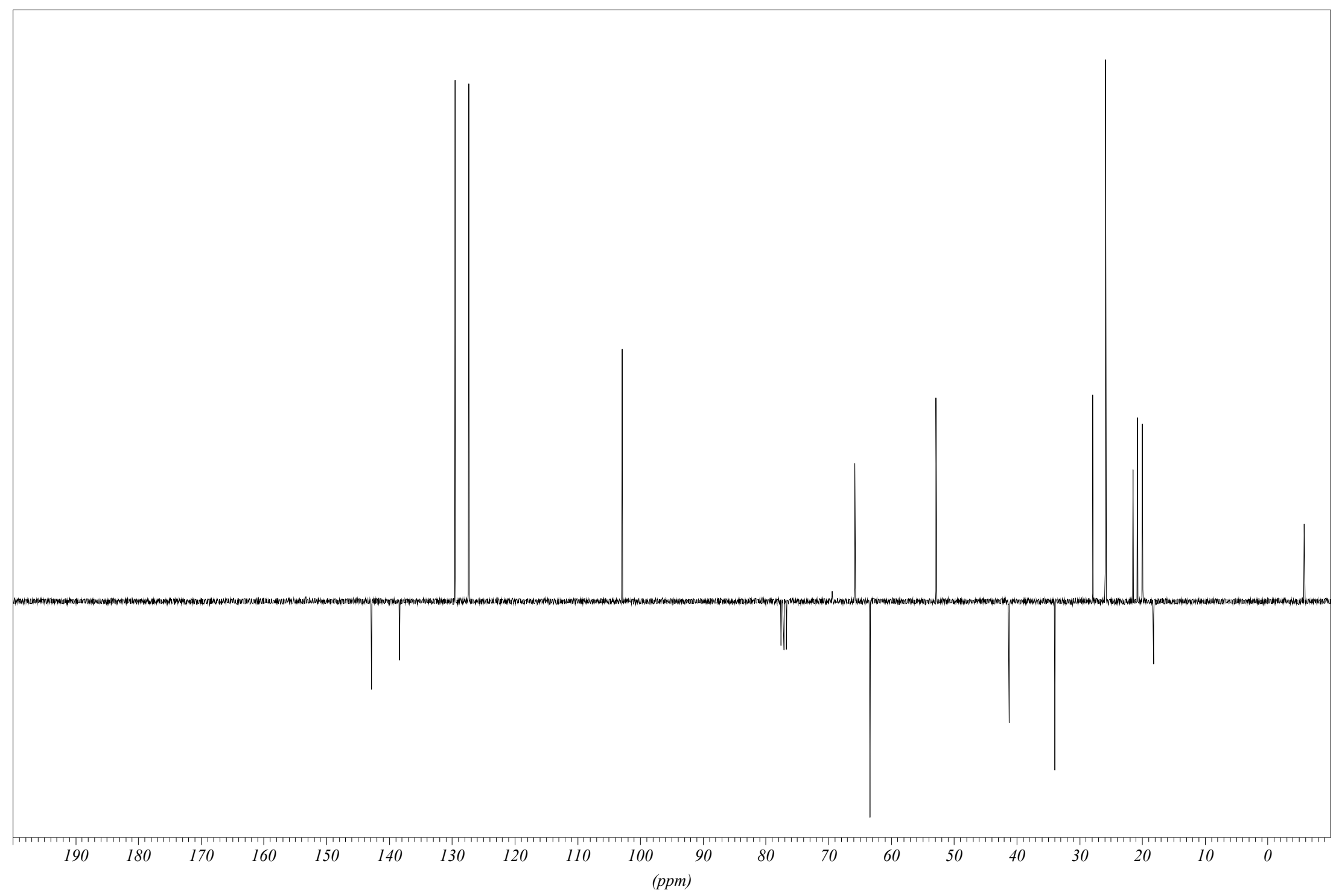

${ }^{13} \mathrm{C}$ JMOD NMR Spectrum $\left(75 \mathrm{MHz}\right.$ ) of $\mathbf{9 c}$ in $\mathrm{CDCl}_{3}$ 


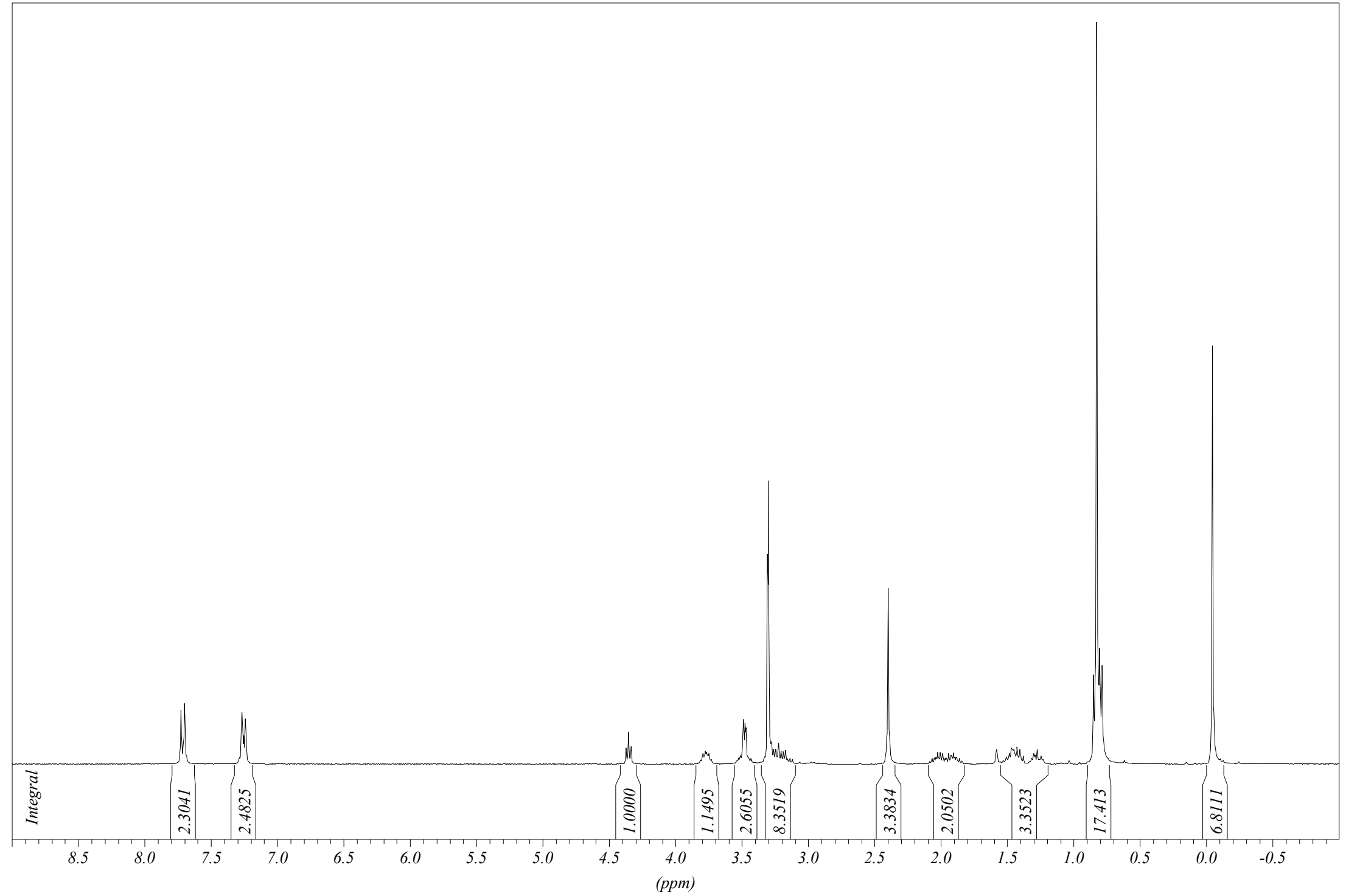

${ }^{1} \mathrm{H}$ NMR Spectrum (300 MHz) of $\mathbf{9 d}$ in $\mathrm{CDCl}_{3}$ 


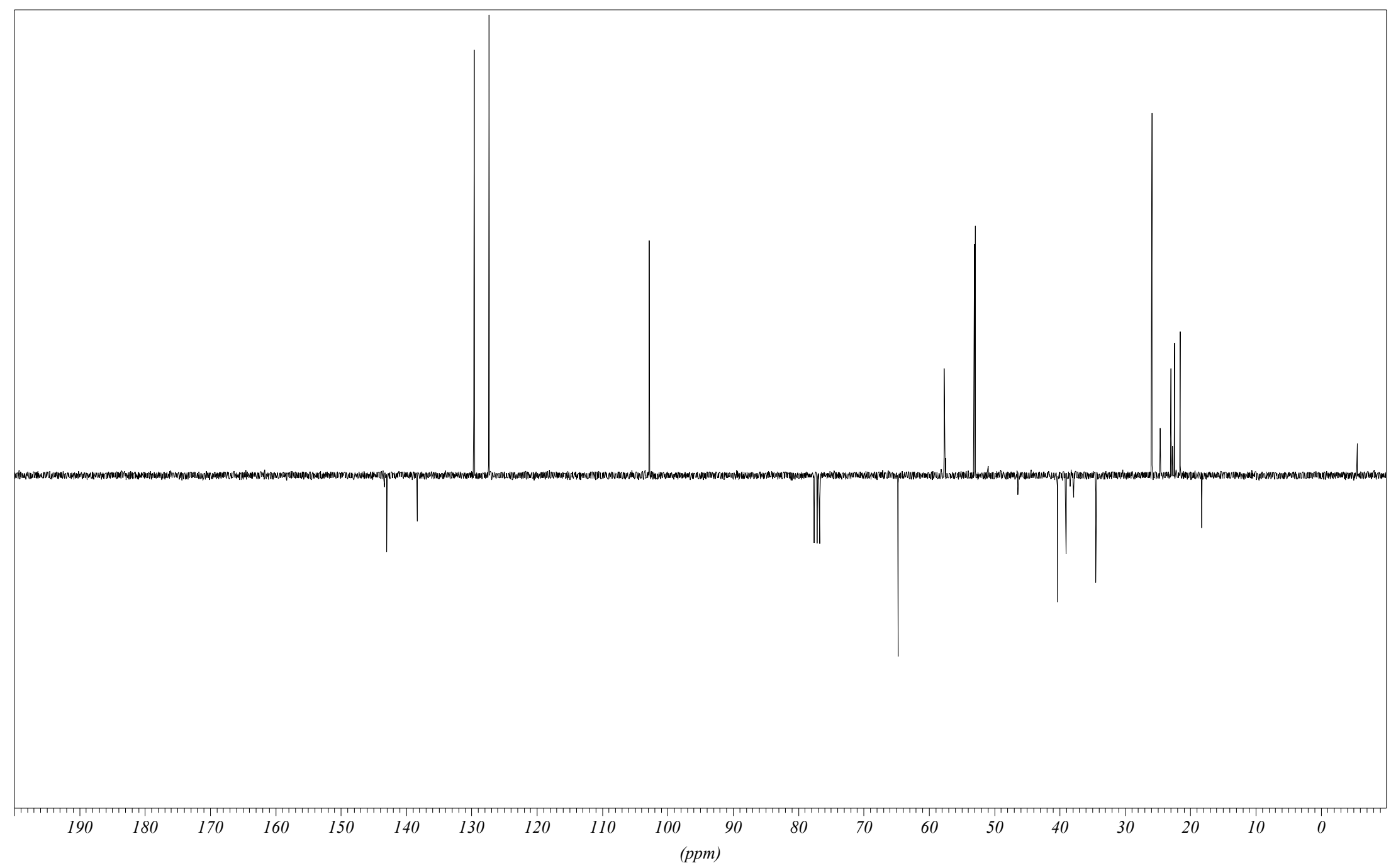

${ }^{13} \mathrm{C}$ NMR Spectrum (75 MHz) of $\mathbf{9 d}$ in $\mathrm{CDCl}_{3}$ 


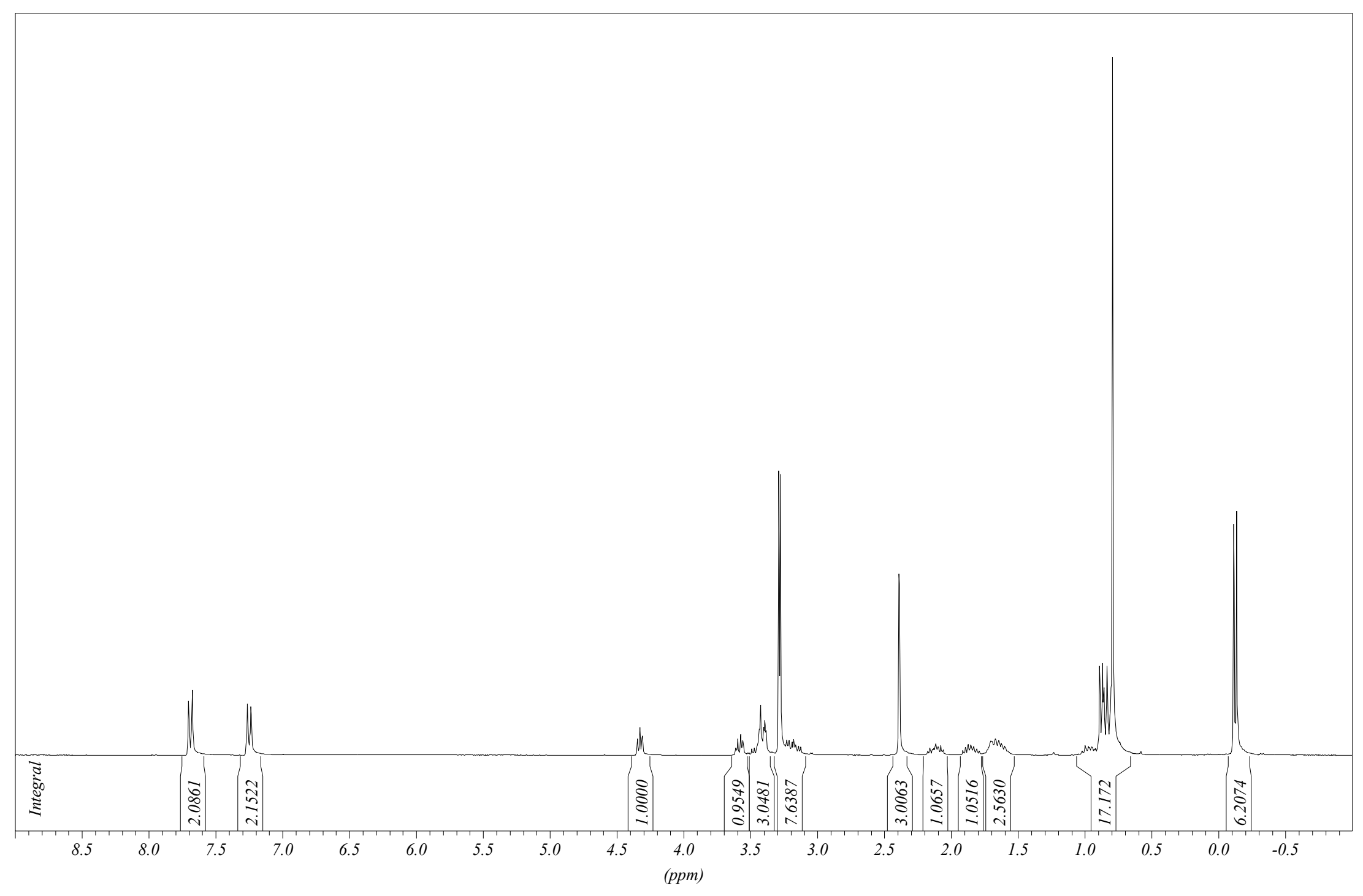

${ }^{1} \mathrm{H}$ NMR Spectrum (300 MHz) of $9 \mathrm{e}$ in $\mathrm{CDCl}_{3}$ 


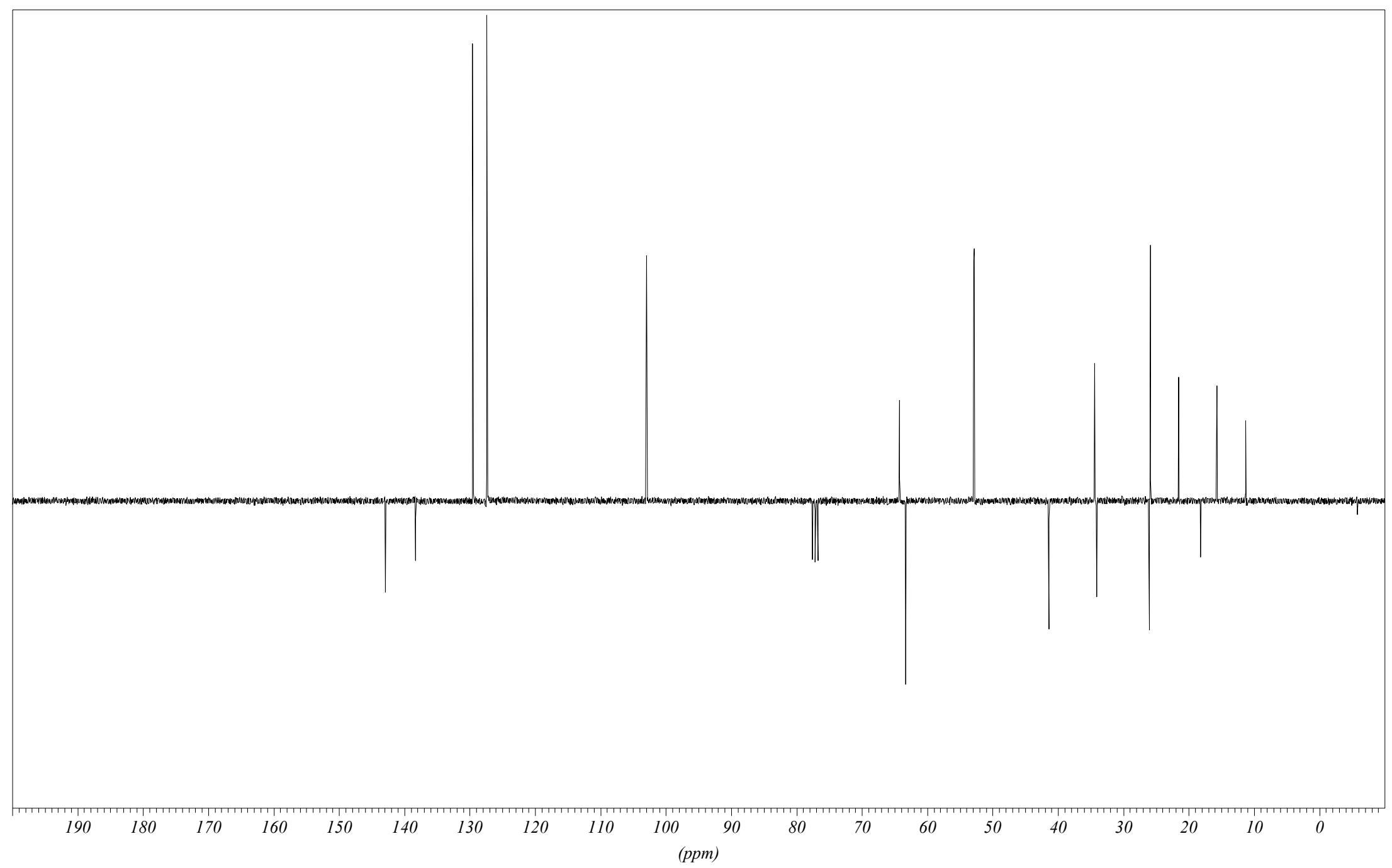

${ }^{13} \mathrm{C}$ NMR Spectrum (75 MHz) of $\mathbf{9 e}$ in $\mathrm{CDCl}_{3}$ 


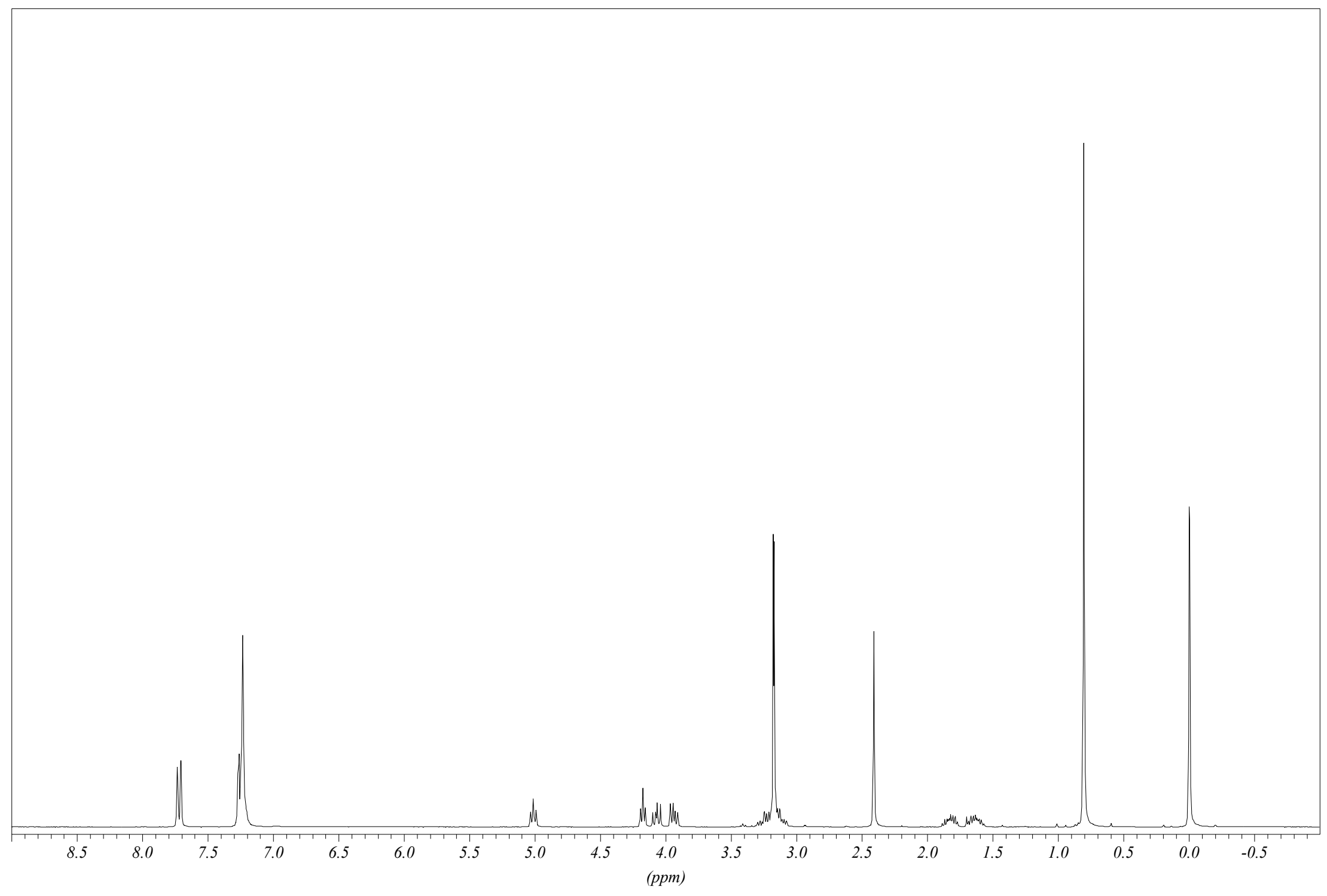

${ }^{1} \mathrm{H}$ NMR spectrum $(300 \mathrm{MHz})$ of $9 f$ in $\mathrm{CDCl}_{3}$ 


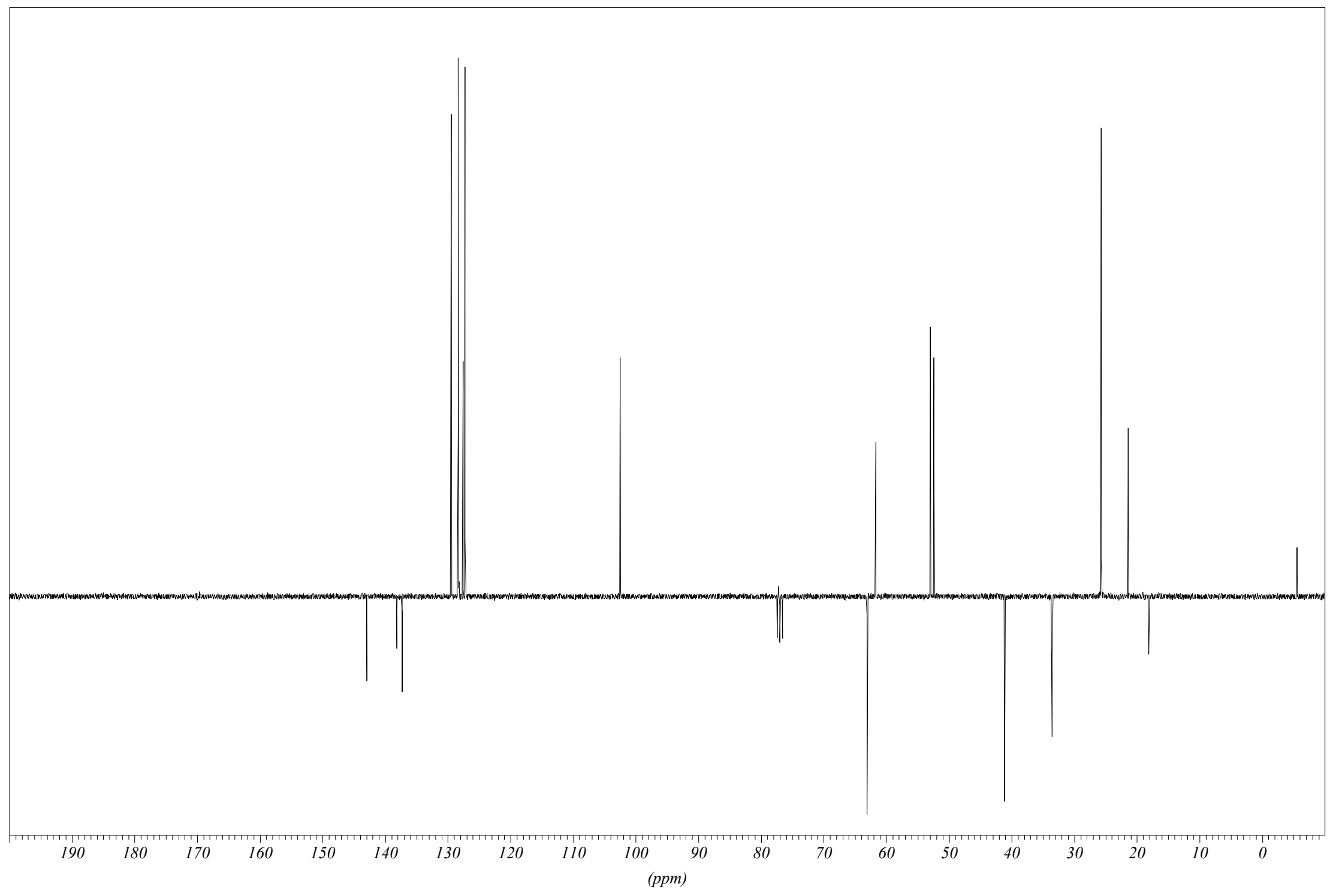

${ }^{13} \mathrm{C}$ NMR Spectrum $\left(75 \mathrm{MHz}\right.$ ) of $9 \mathrm{f}$ in $\mathrm{CDCl}_{3}$ 


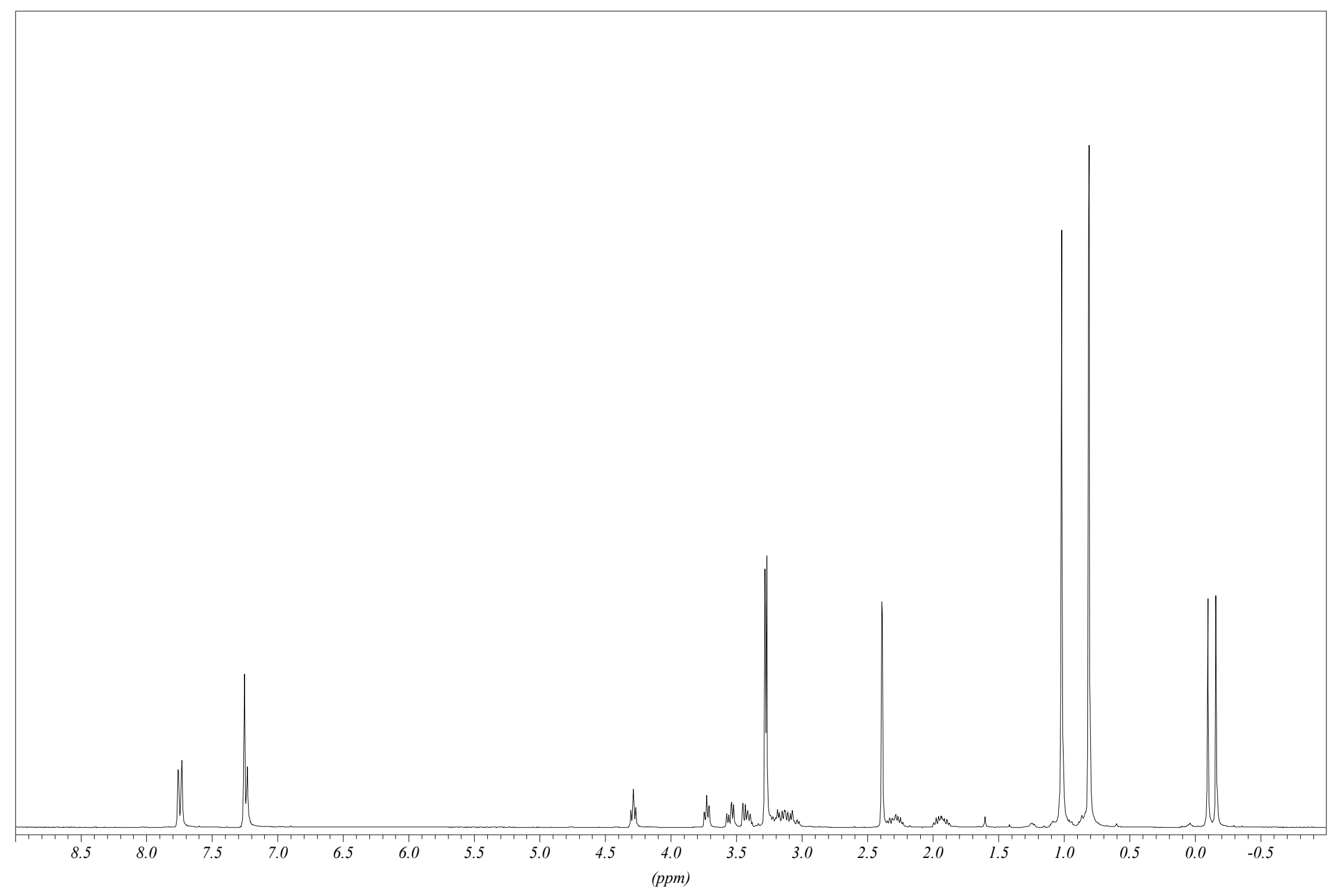

${ }^{1} \mathrm{H}$ NMR Spectrum $\left(300 \mathrm{MHz}\right.$ ) of $\mathbf{9 g}$ in $\mathrm{CDCl}_{3}$ 


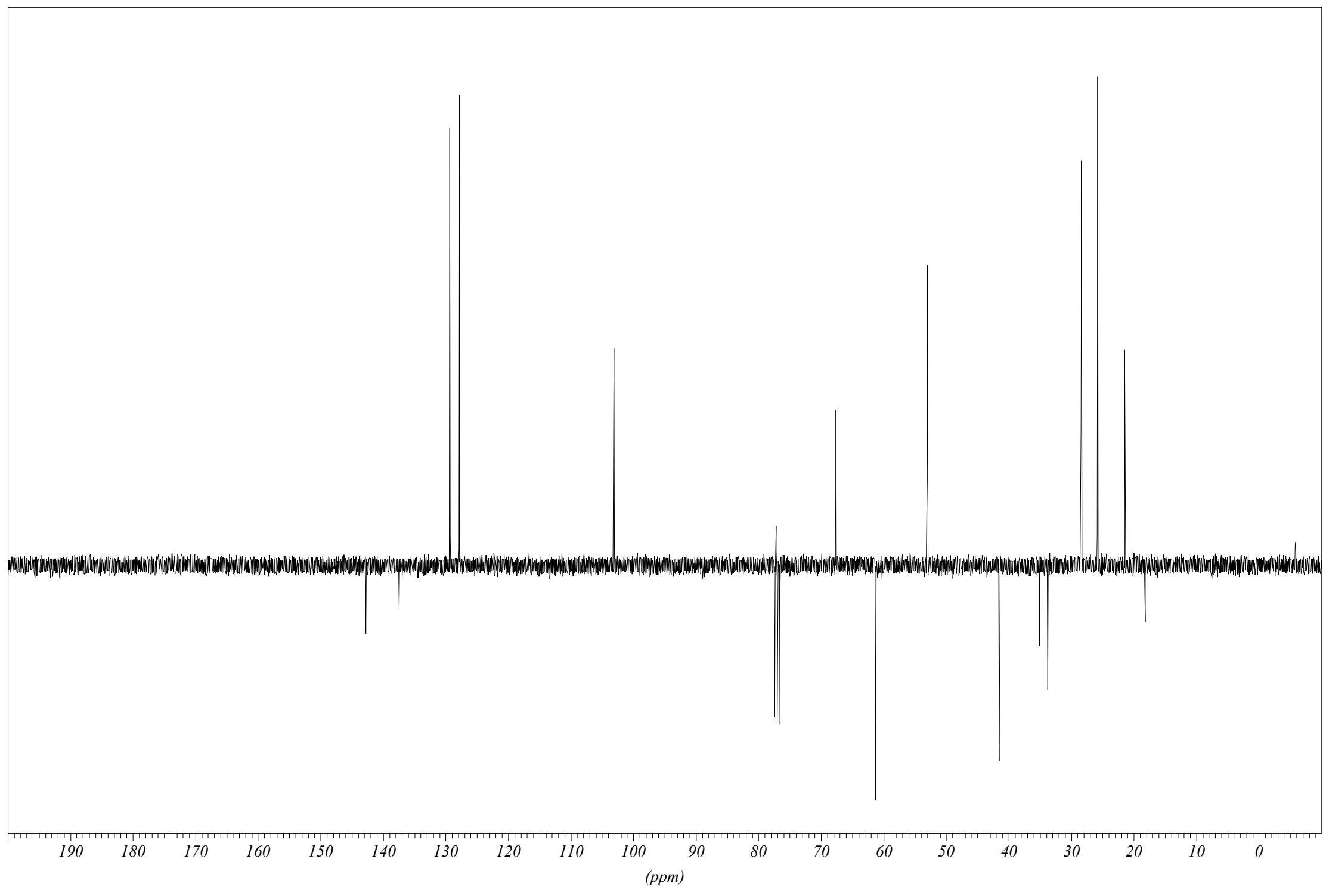

${ }^{13} \mathrm{C}$ NMR Spectrum $\left(75 \mathrm{MHz}\right.$ ) of $\mathbf{9 g}$ in $\mathrm{CDCl}_{3}$ 


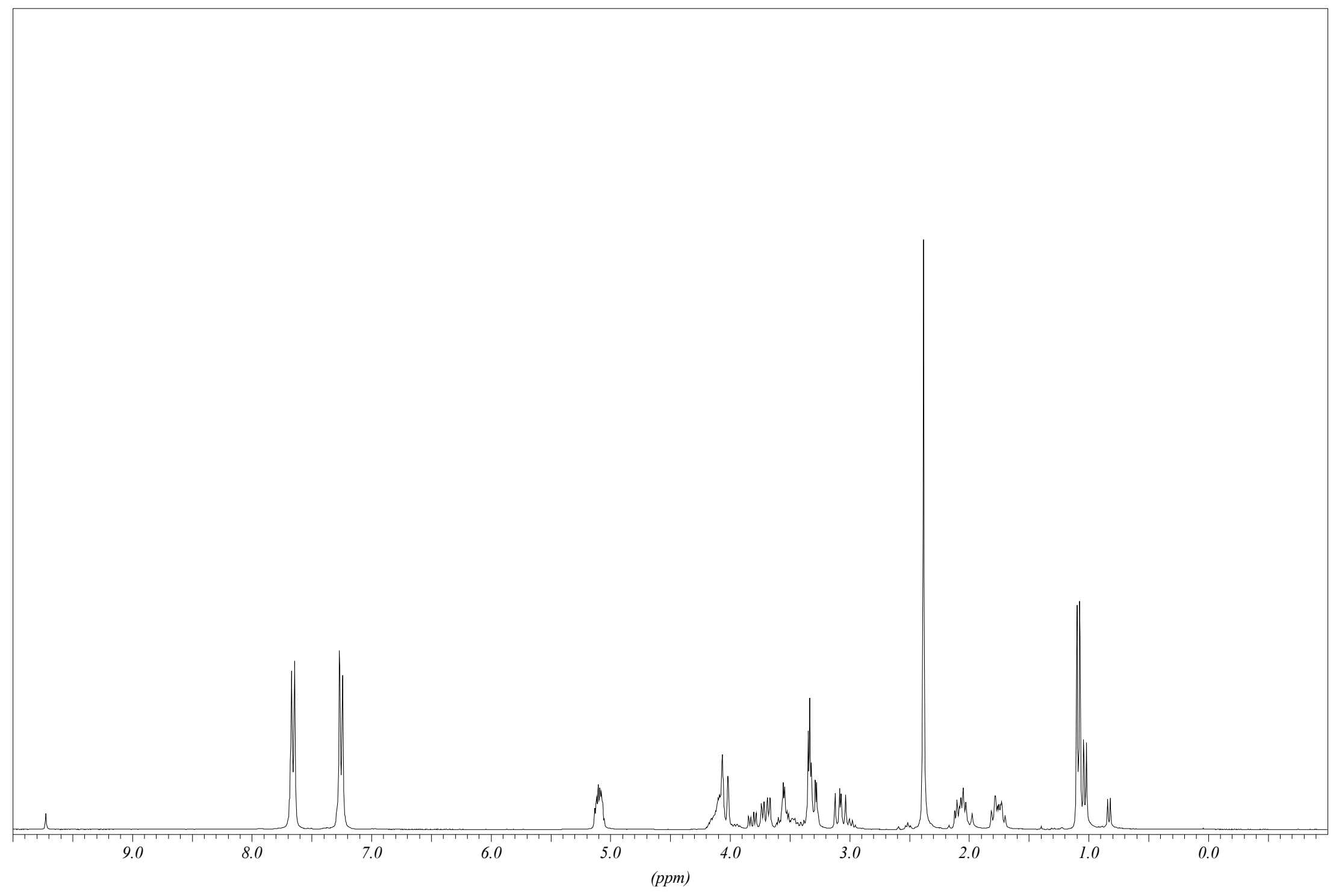

${ }^{1} \mathrm{H}$ NMR Spectrum (300 MHz) of $\mathbf{1 0 a}$ in $\mathrm{CDCl}_{3}$ 


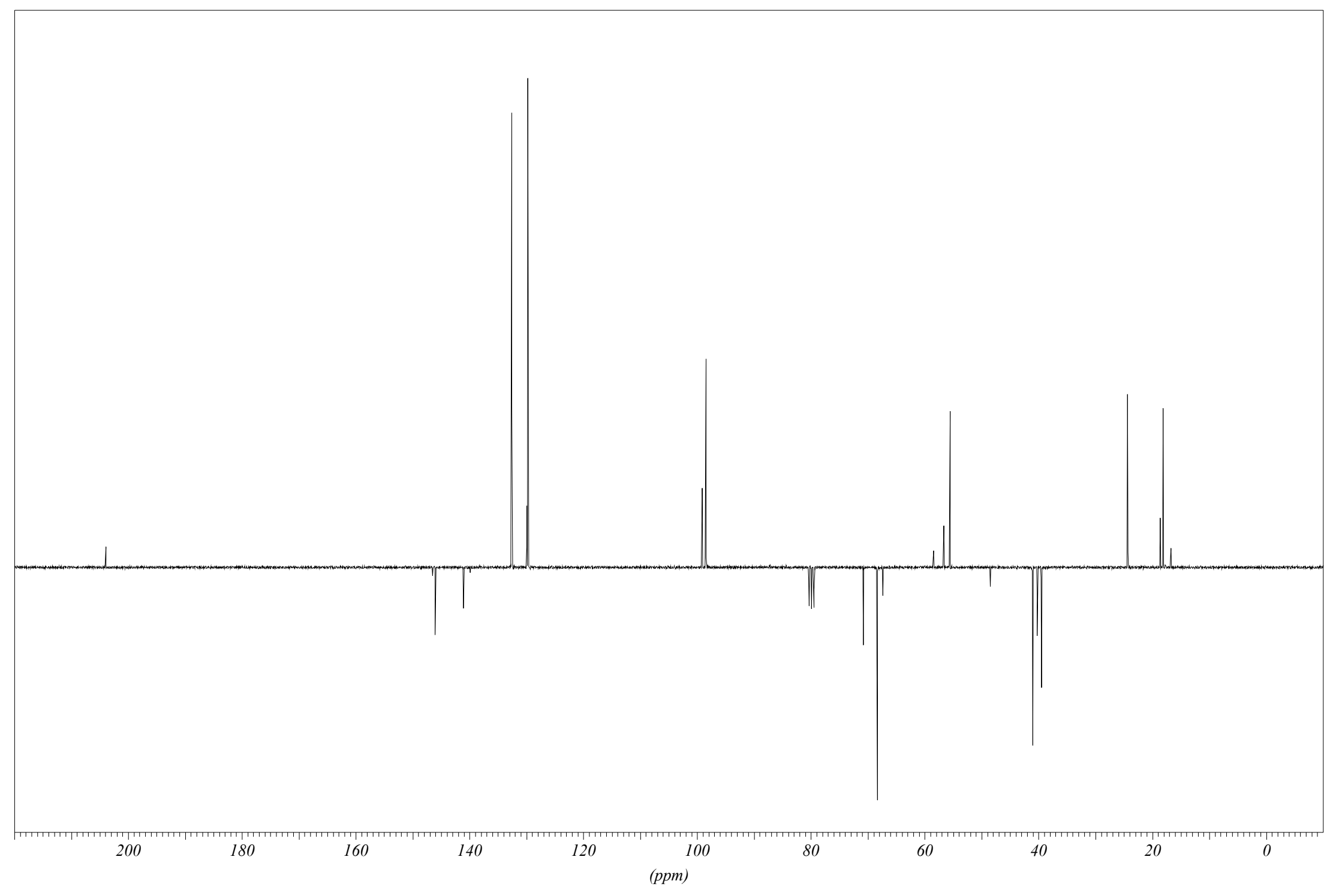

${ }^{13} \mathrm{C}$ NMR Spectrum (75 MHz) of 10a in $\mathrm{CDCl}_{3}$ 


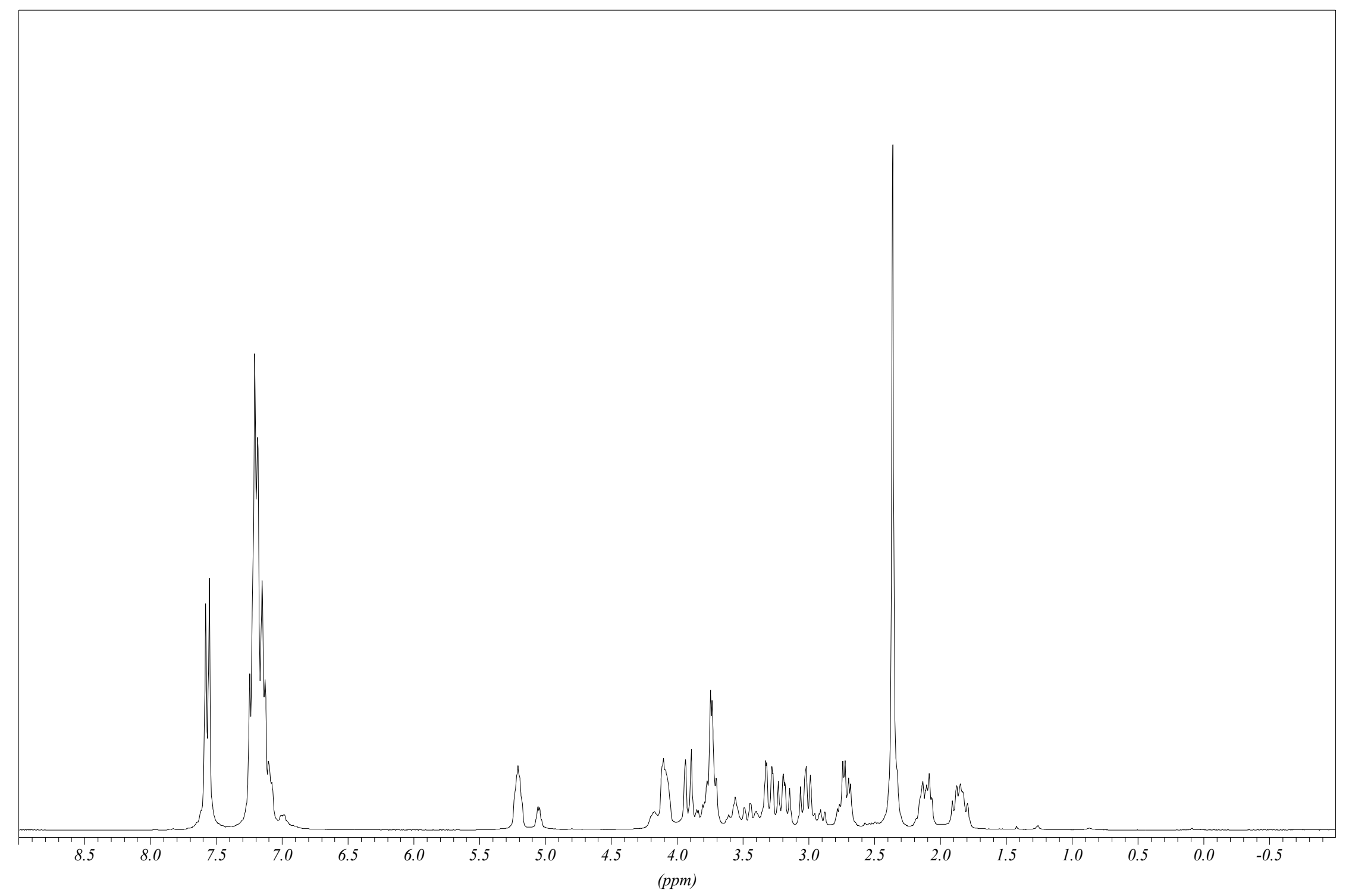

${ }^{1} \mathrm{H}$ NMR Spectrum (300 MHz) of $\mathbf{1 0 b}$ in $\mathrm{CDCl}_{3}$ 


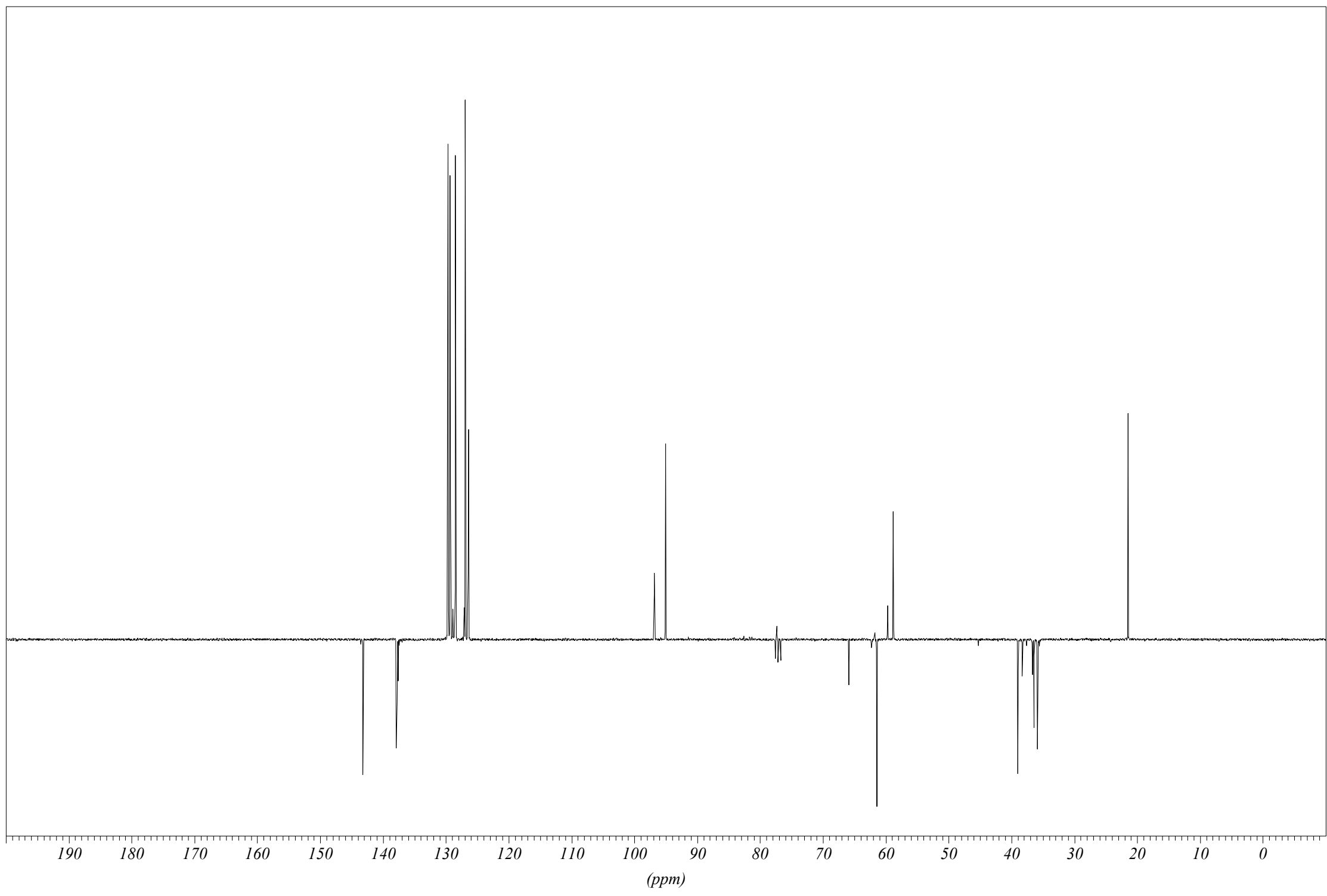

${ }^{13} \mathrm{C}$ NMR Spectrum $(75 \mathrm{MHz})$ of $\mathbf{1 0 b}$ in $\mathrm{CDCl}_{3}$ 


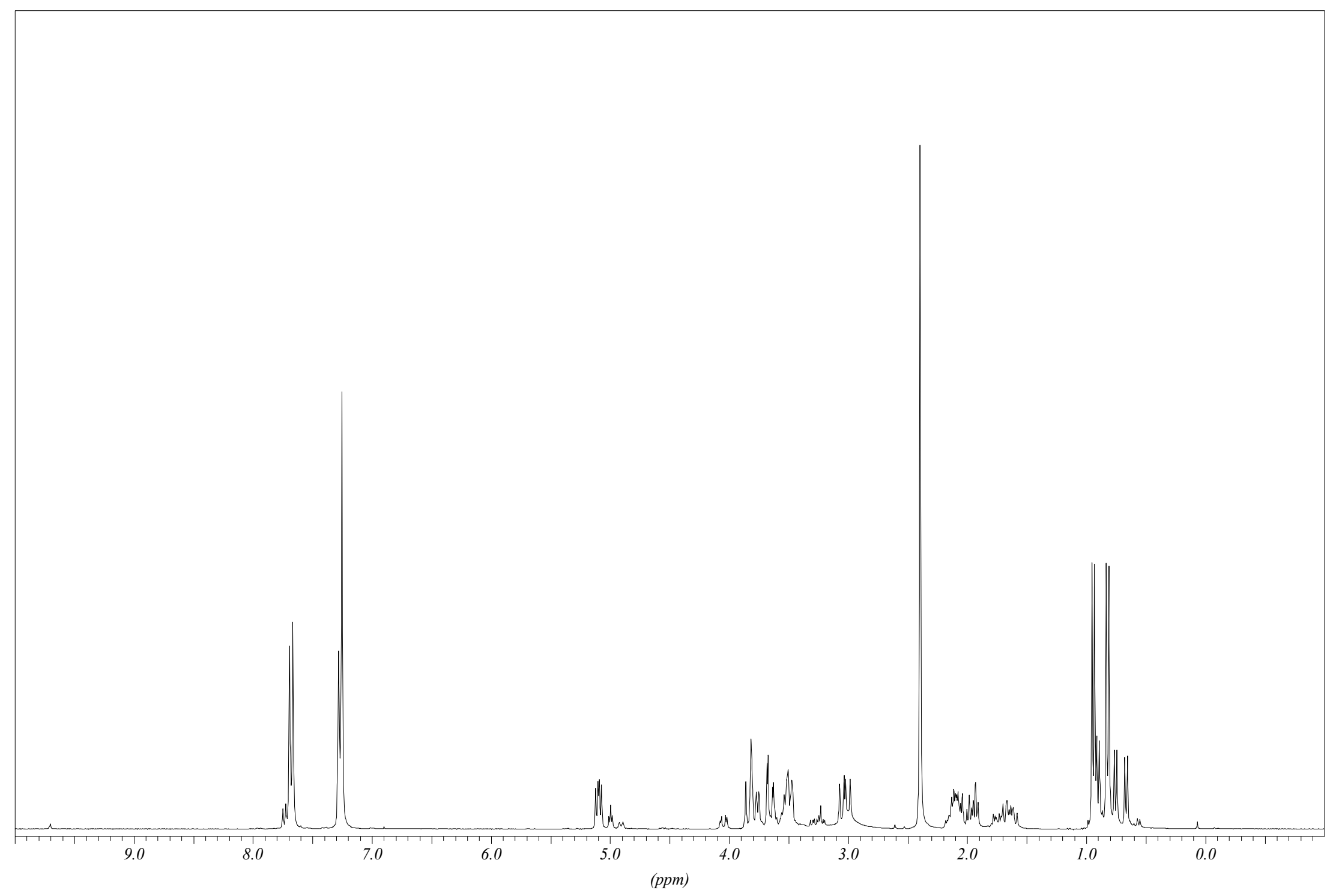

${ }^{1} \mathrm{H}$ NMR Spectrum (300 MHz) of $\mathbf{1 0 c}$ in $\mathrm{CDCl}_{3}$ 


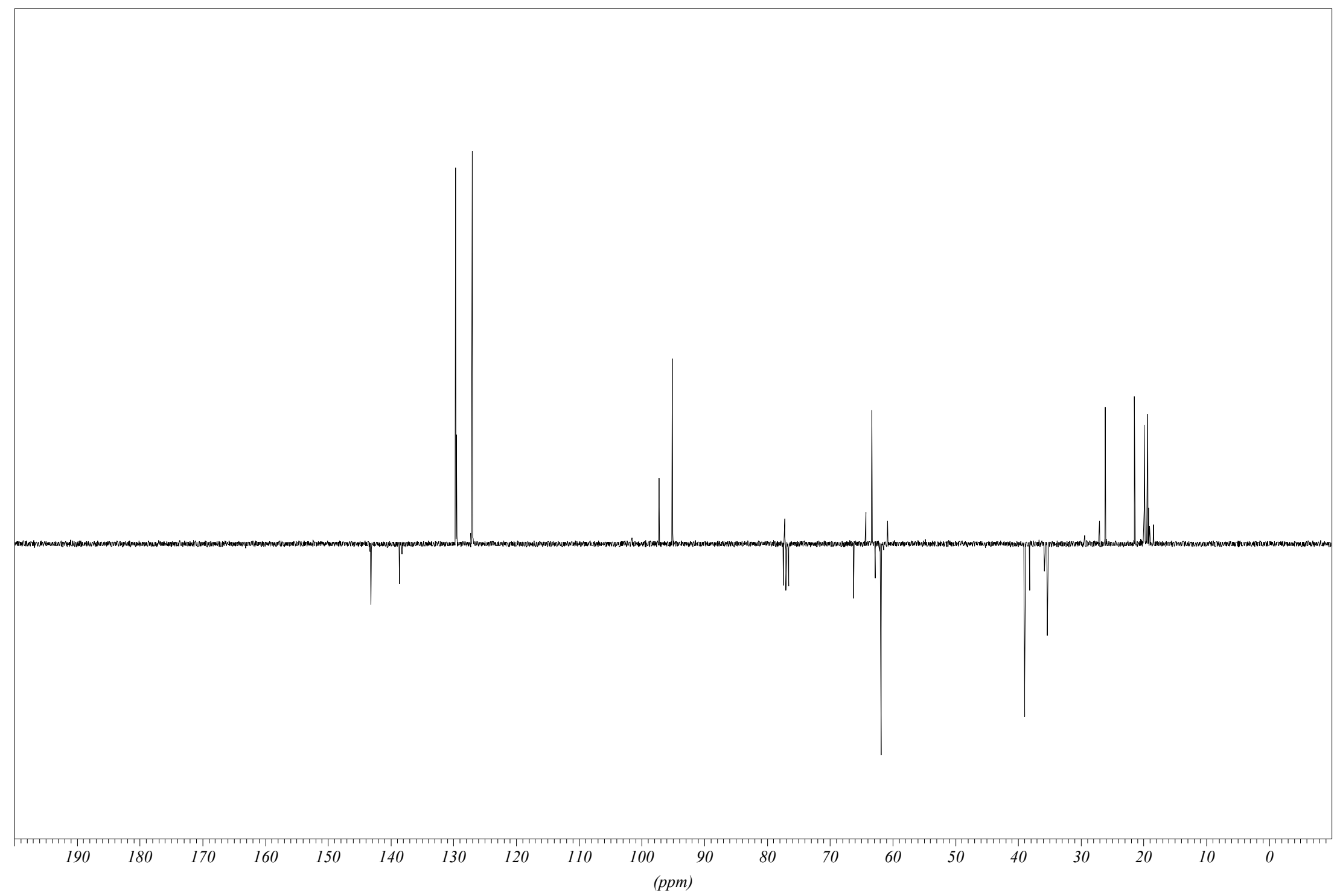

${ }^{13} \mathrm{C}$ NMR Spectrum $\left(75 \mathrm{MHz}\right.$ ) of $\mathbf{1 0 c}$ in $\mathrm{CDCl}_{3}$ 


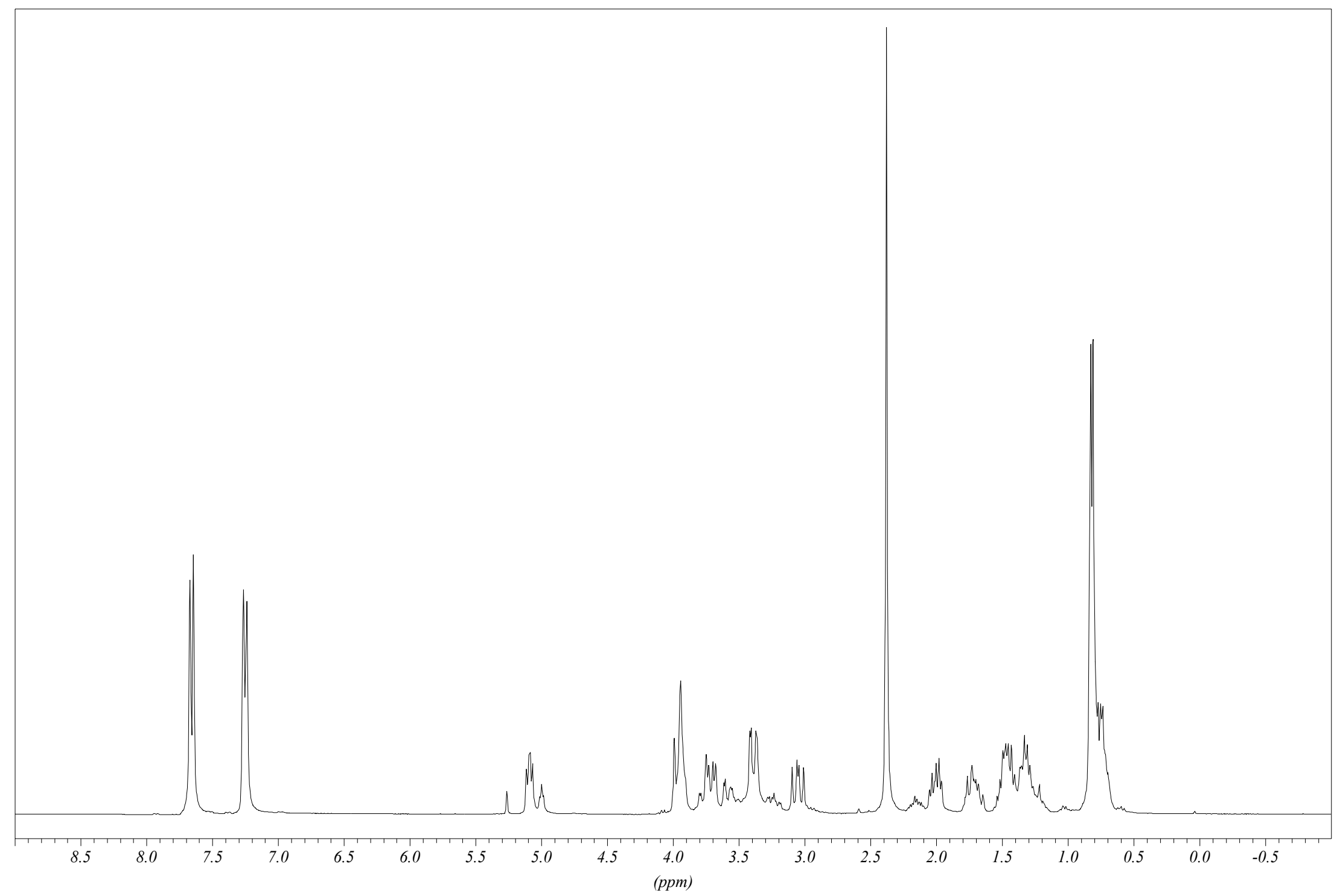

${ }^{1} \mathrm{H}$ NMR Spectrum (300 MHz) of $\mathbf{1 0 d}$ in $\mathrm{CDCl}_{3}$ 


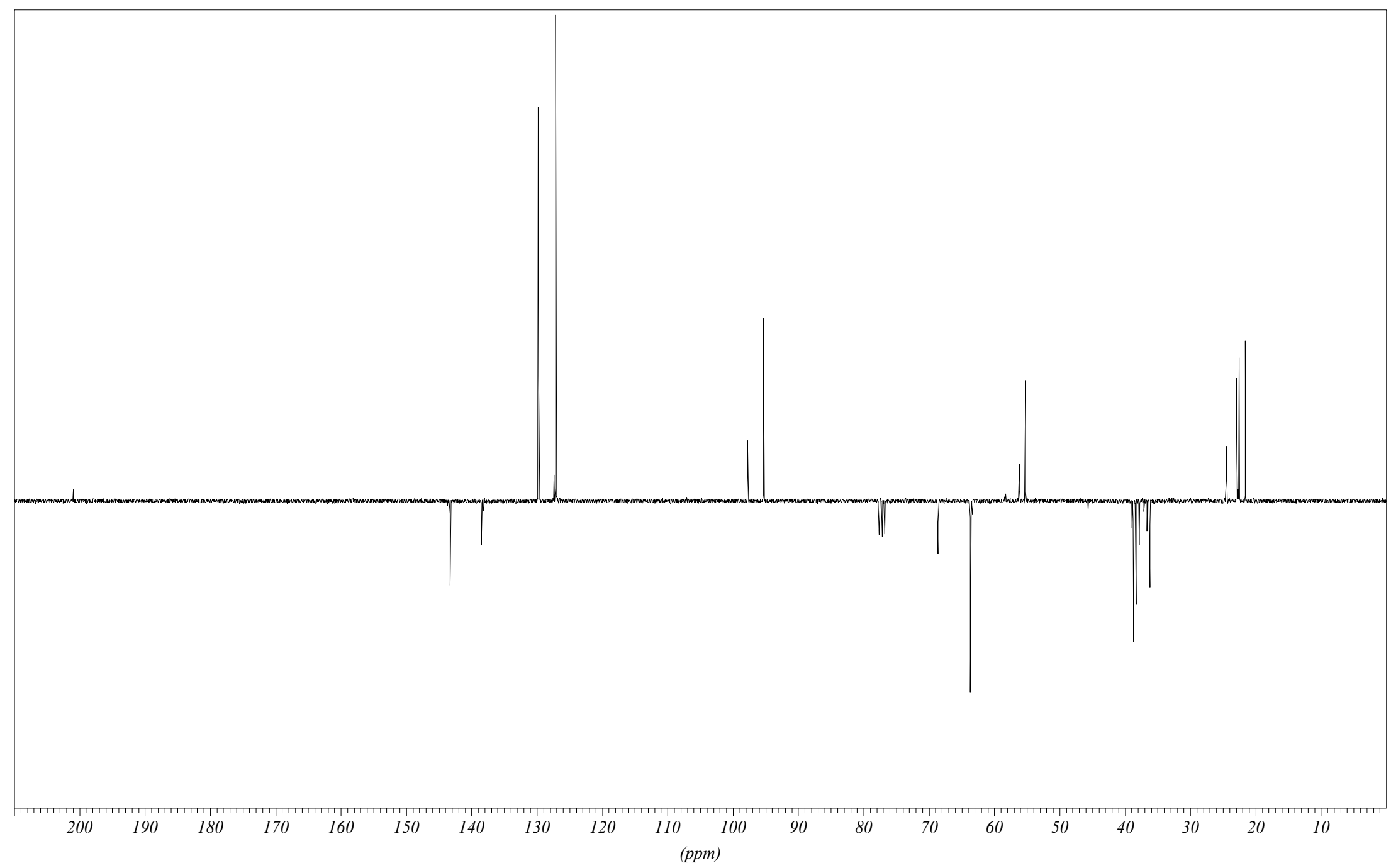

${ }^{13} \mathrm{C}$ NMR Spectrum $\left(75 \mathrm{MHz}\right.$ ) of $\mathbf{1 0 d}$ in $\mathrm{CDCl}_{3}$ 


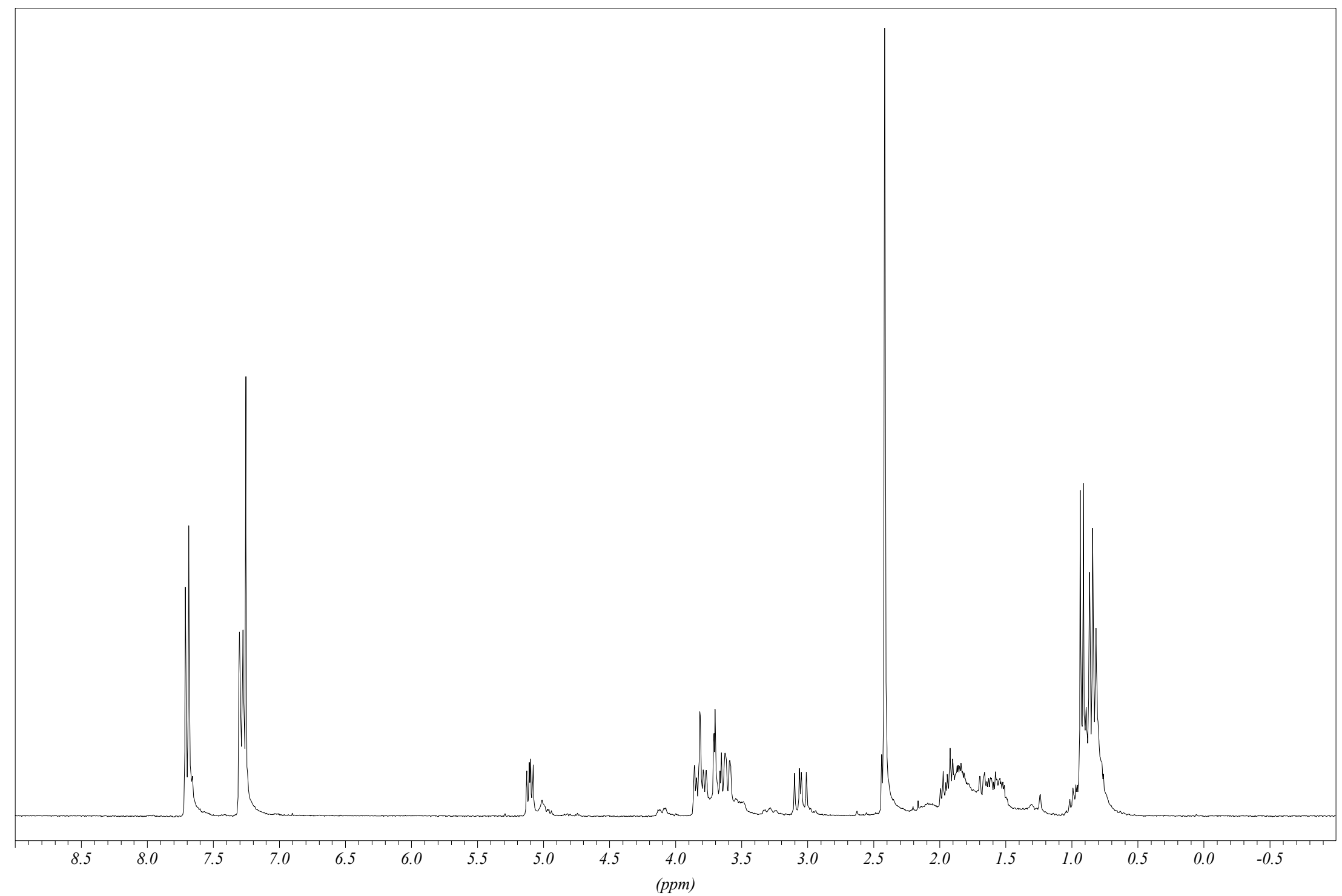

${ }^{1} \mathrm{H}$ NMR Spectrum $(300 \mathrm{MHz})$ of $\mathbf{1 0 e}$ in $\mathrm{CDCl}_{3}$ 


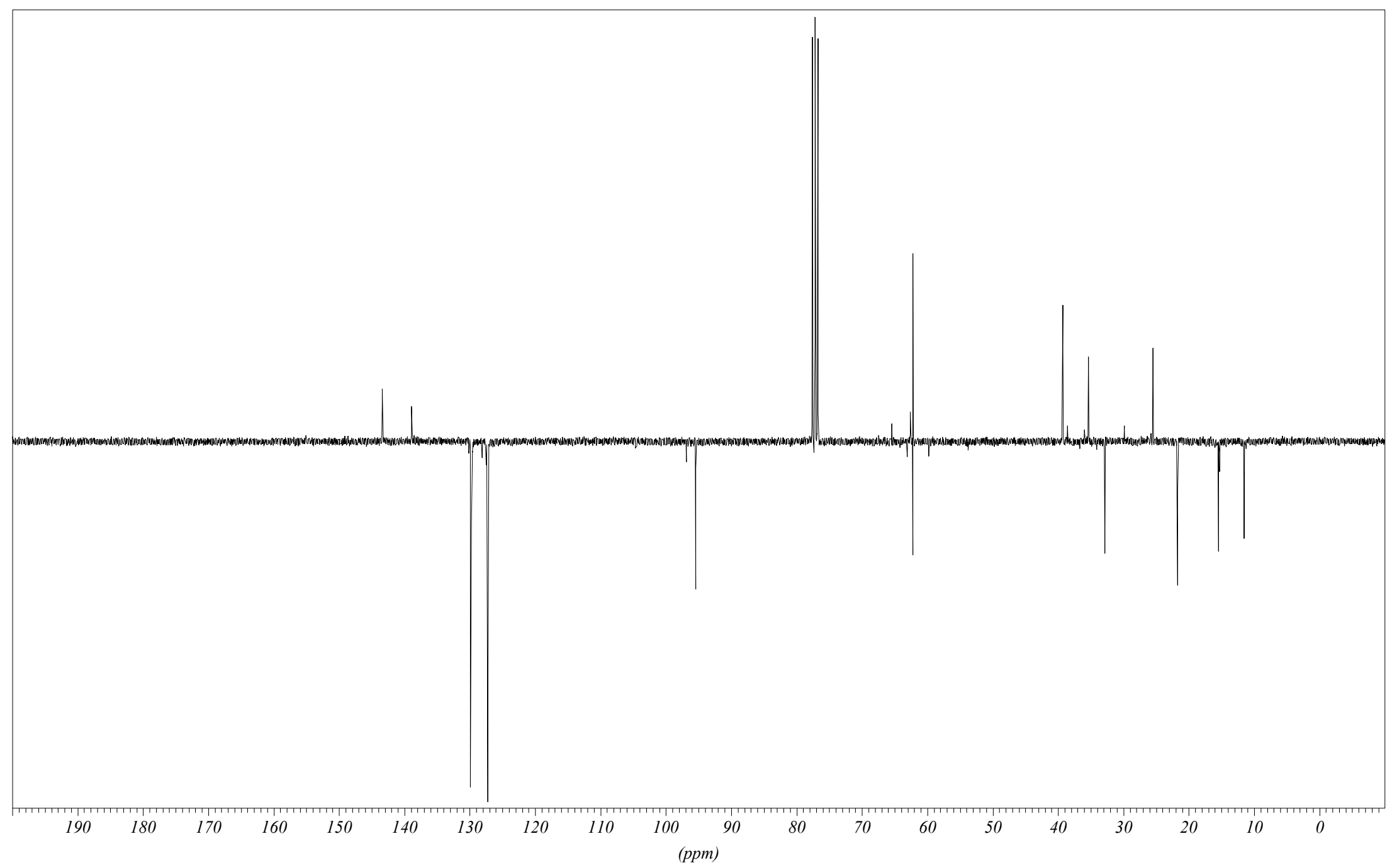

${ }^{13} \mathrm{C}$ NMR Spectrum $\left(75 \mathrm{MHz}\right.$ ) of $\mathbf{1 0 e}$ in $\mathrm{CDCl}_{3}$ 


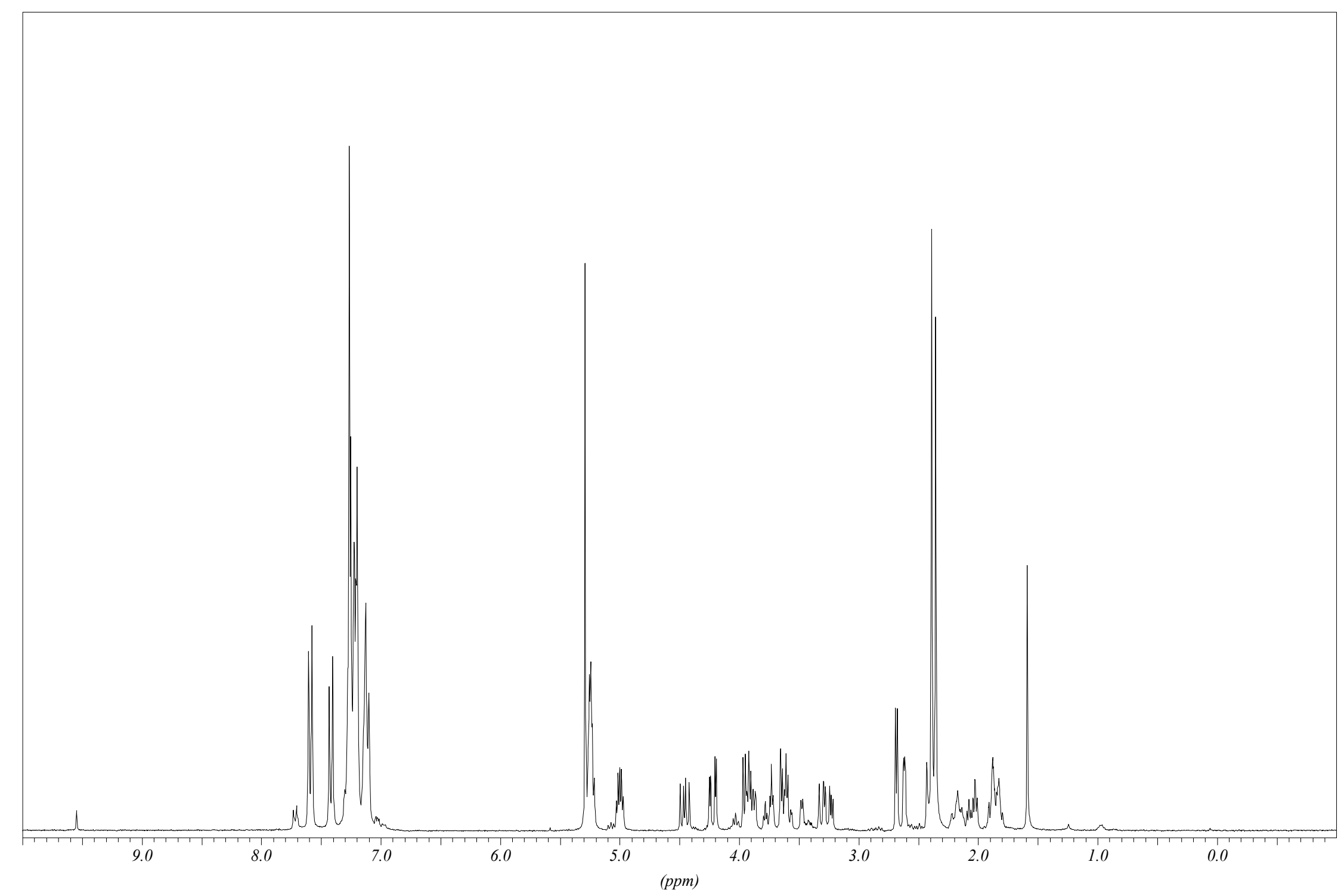

${ }^{1} \mathrm{H}$ NMR Spectrum (300 MHz) of $\mathbf{1 0 f}$ in $\mathrm{CDCl}_{3}$ 


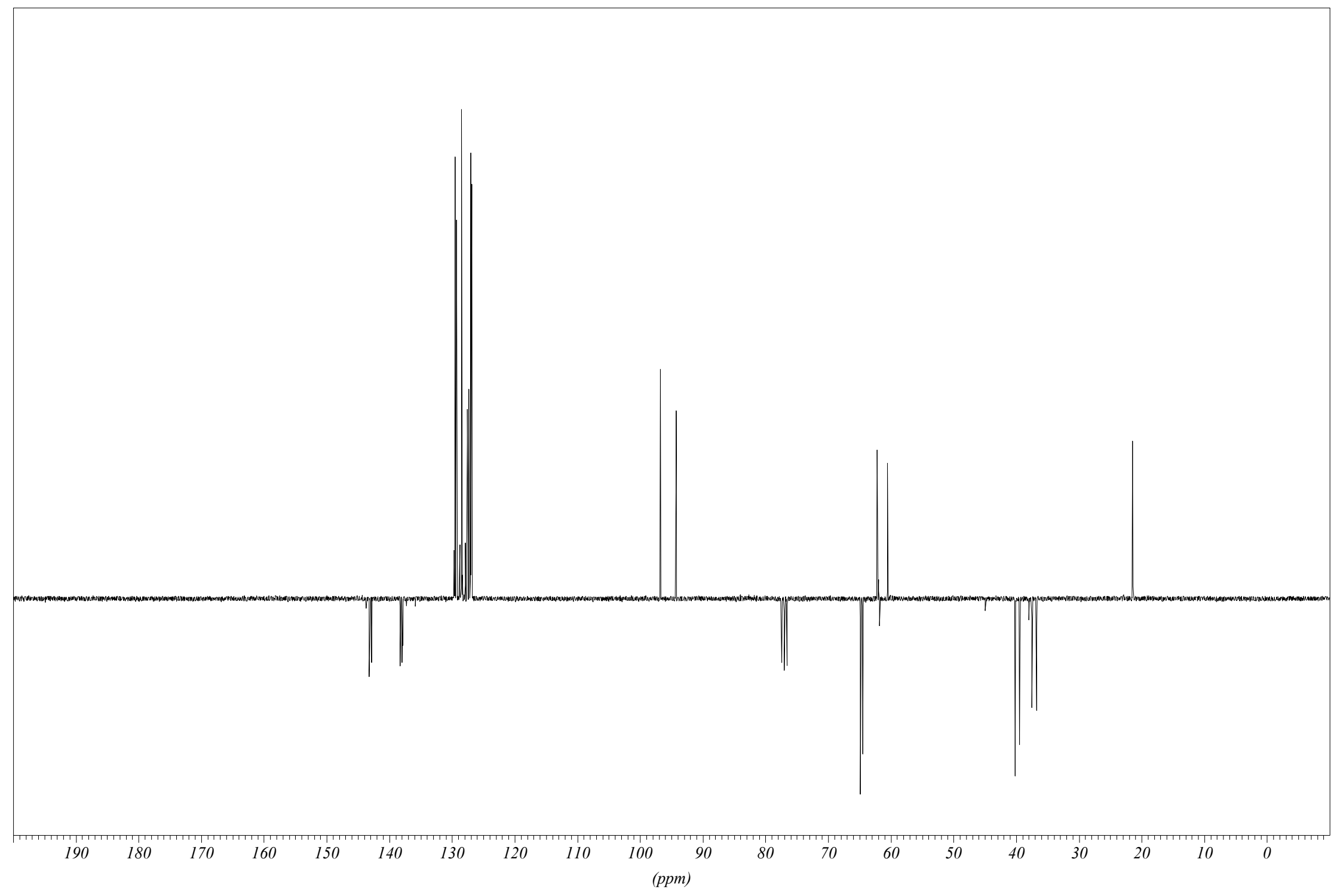

${ }^{13} \mathrm{C}$ NMR Spectrum (75 MHz) of $\mathbf{1 0 f}$ in $\mathrm{CDCl}_{3}$ 


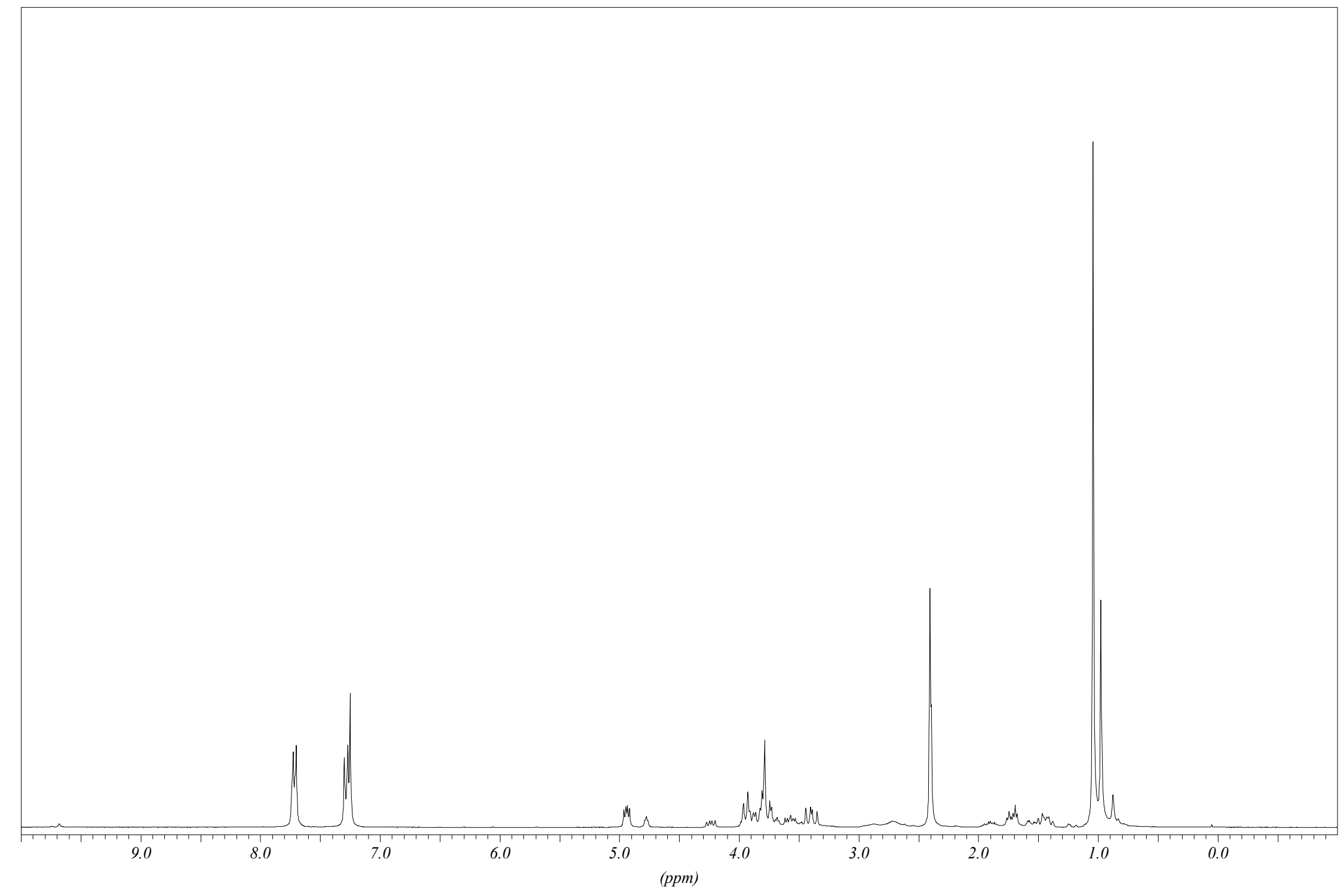

${ }^{1} \mathrm{H}$ NMR Spectrum (300 MHz) of $\mathbf{1 0 g}$ in $\mathrm{CDCl}_{3}$ 


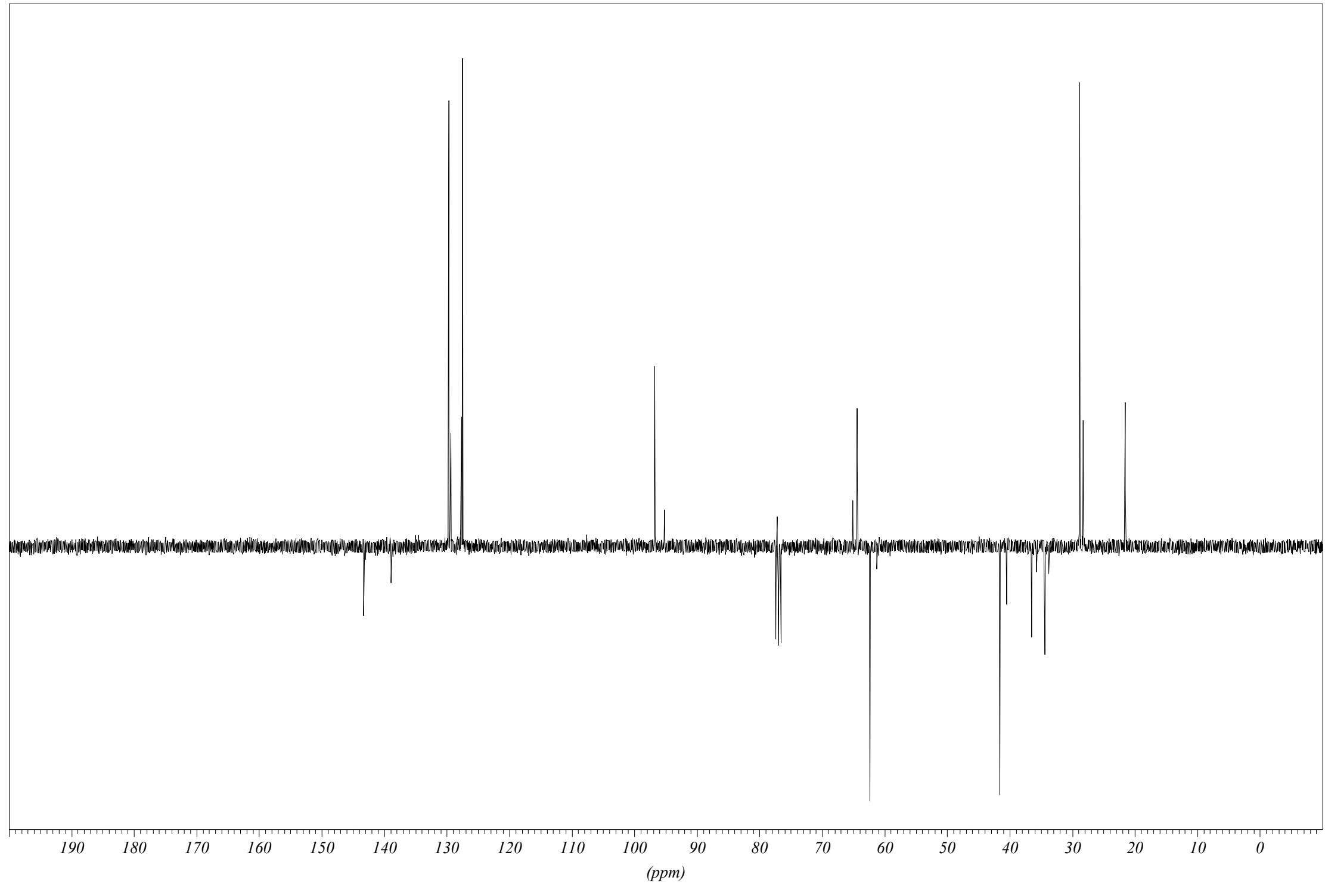

${ }^{13} \mathrm{C}$ NMR Spectrum $\left(75 \mathrm{MHz}\right.$ ) of $\mathbf{1 0 g}$ in $\mathrm{CDCl}_{3}$ 


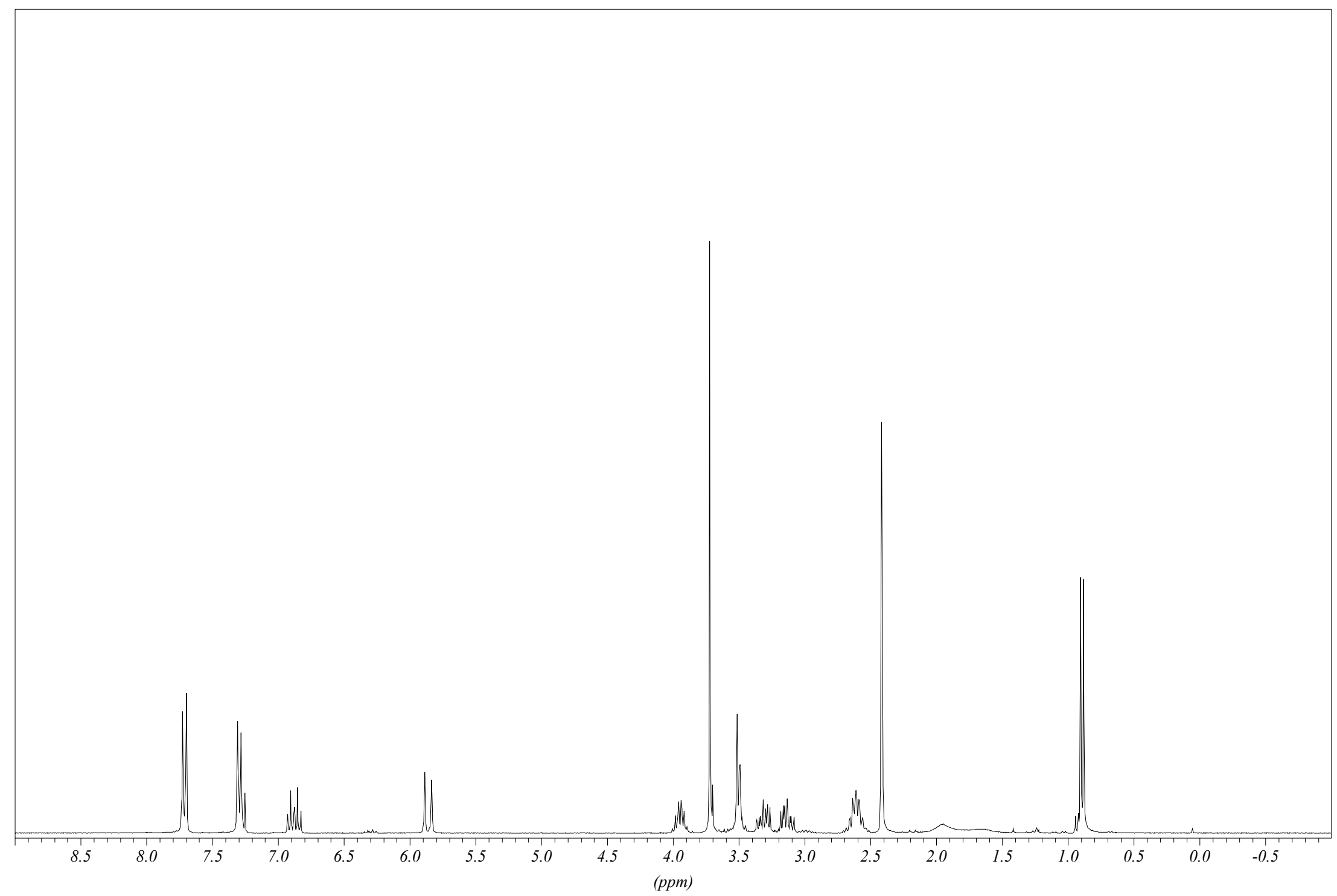

${ }^{1} \mathrm{H}$ NMR Spectrum (300 MHz) of 11a in $\mathrm{CDCl}_{3}$ 


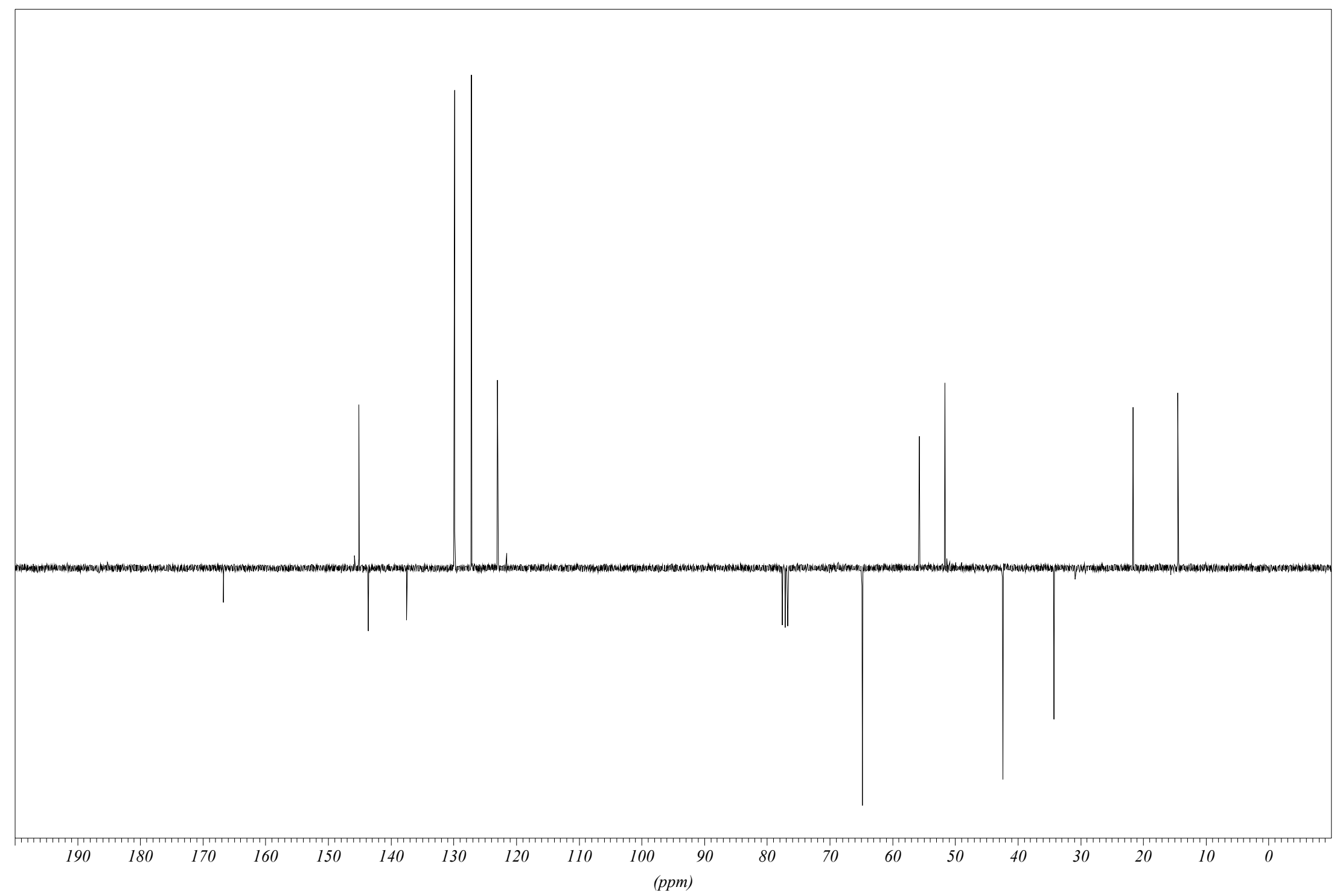

${ }^{13} \mathrm{C}$ NMR Spectrum (75 MHz) of 11a in $\mathrm{CDCl}_{3}$ 


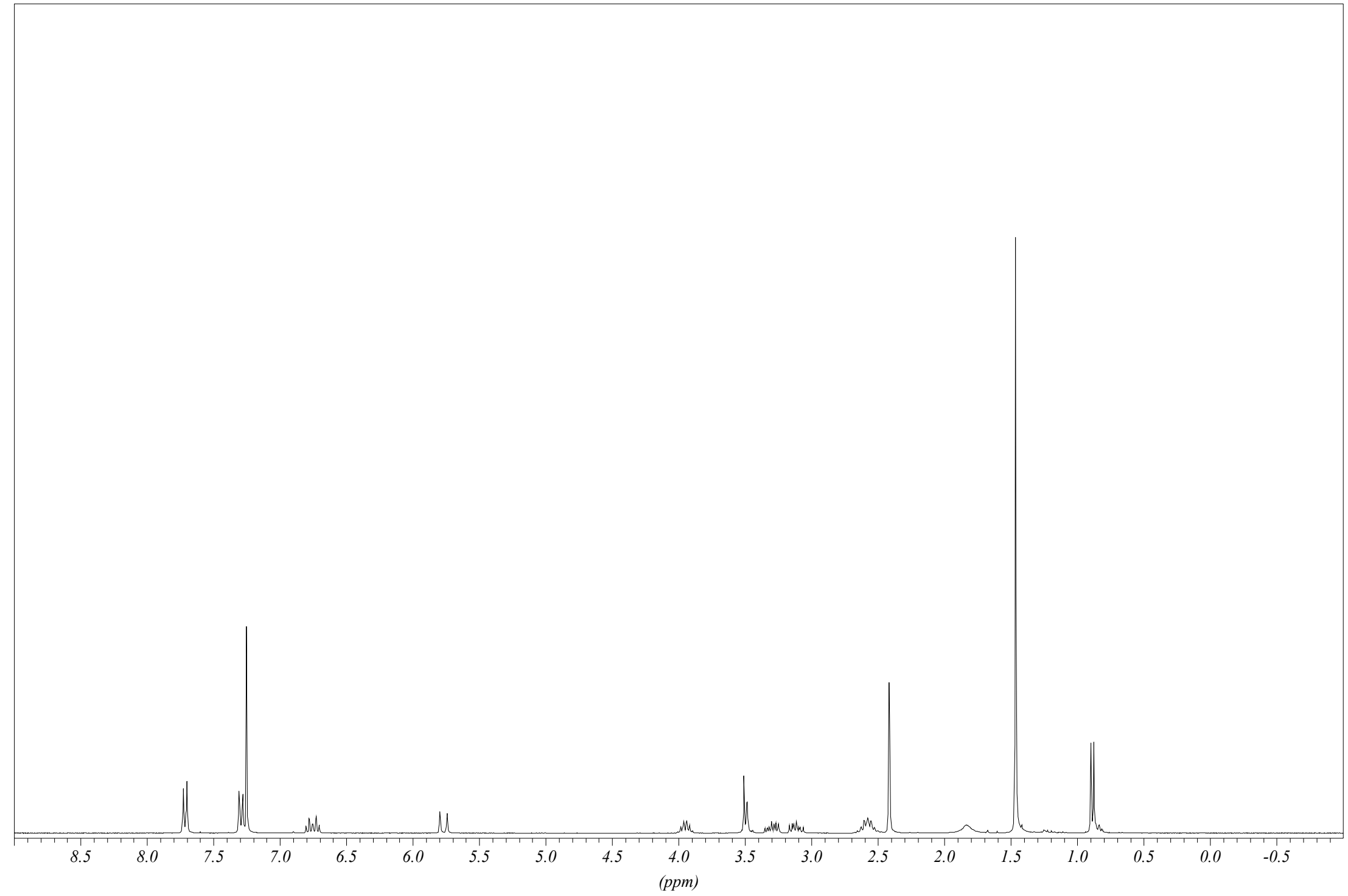

${ }^{1} \mathrm{H}$ NMR Spectrum (300 MHz) of $\mathbf{1 1 b}$ in $\mathrm{CDCl}_{3}$ 


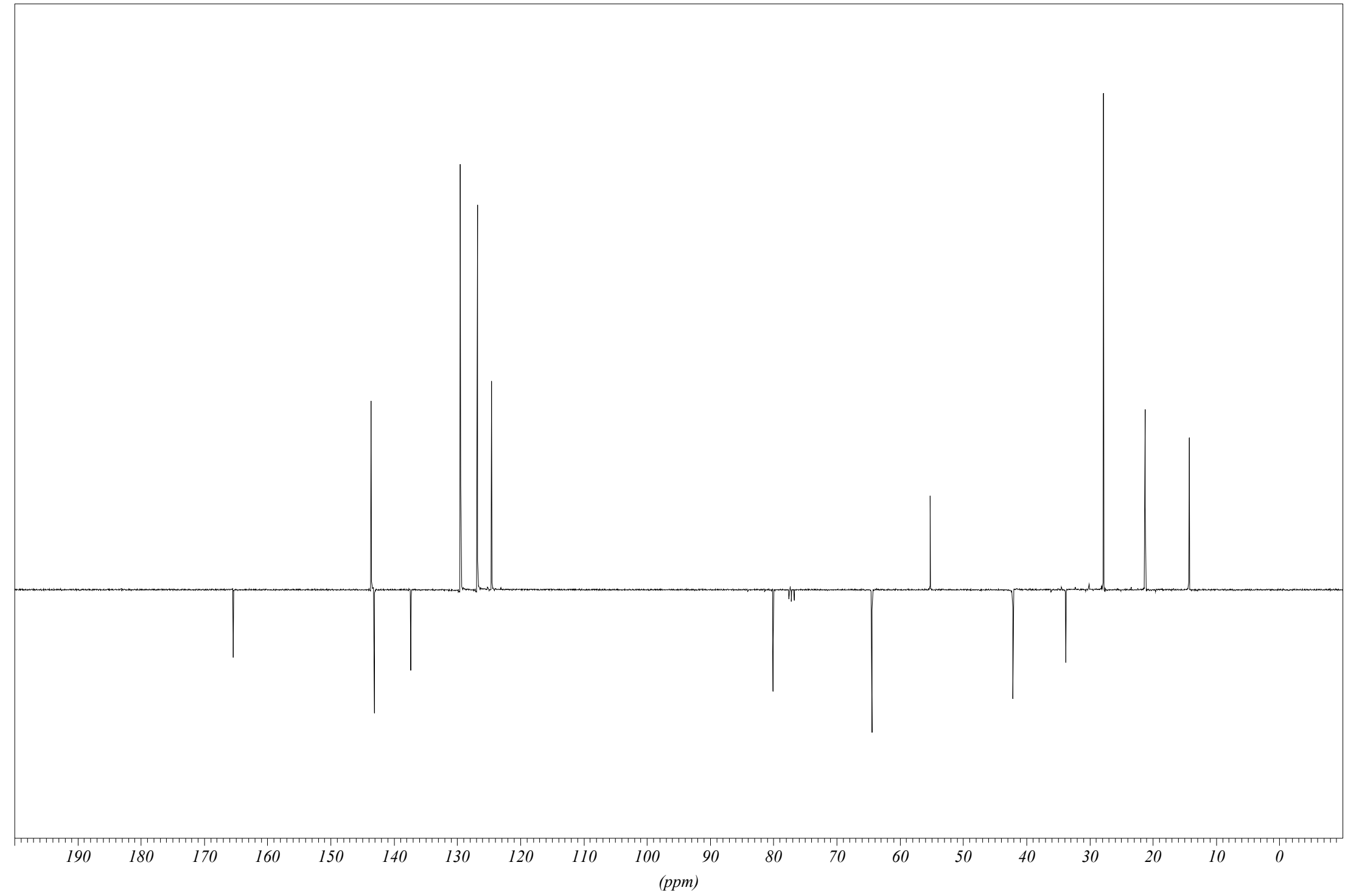

${ }^{13} \mathrm{C}$ NMR Spectrum $(75 \mathrm{MHz})$ of $\mathbf{1 1 b}$ in $\mathrm{CDCl}_{3}$ 


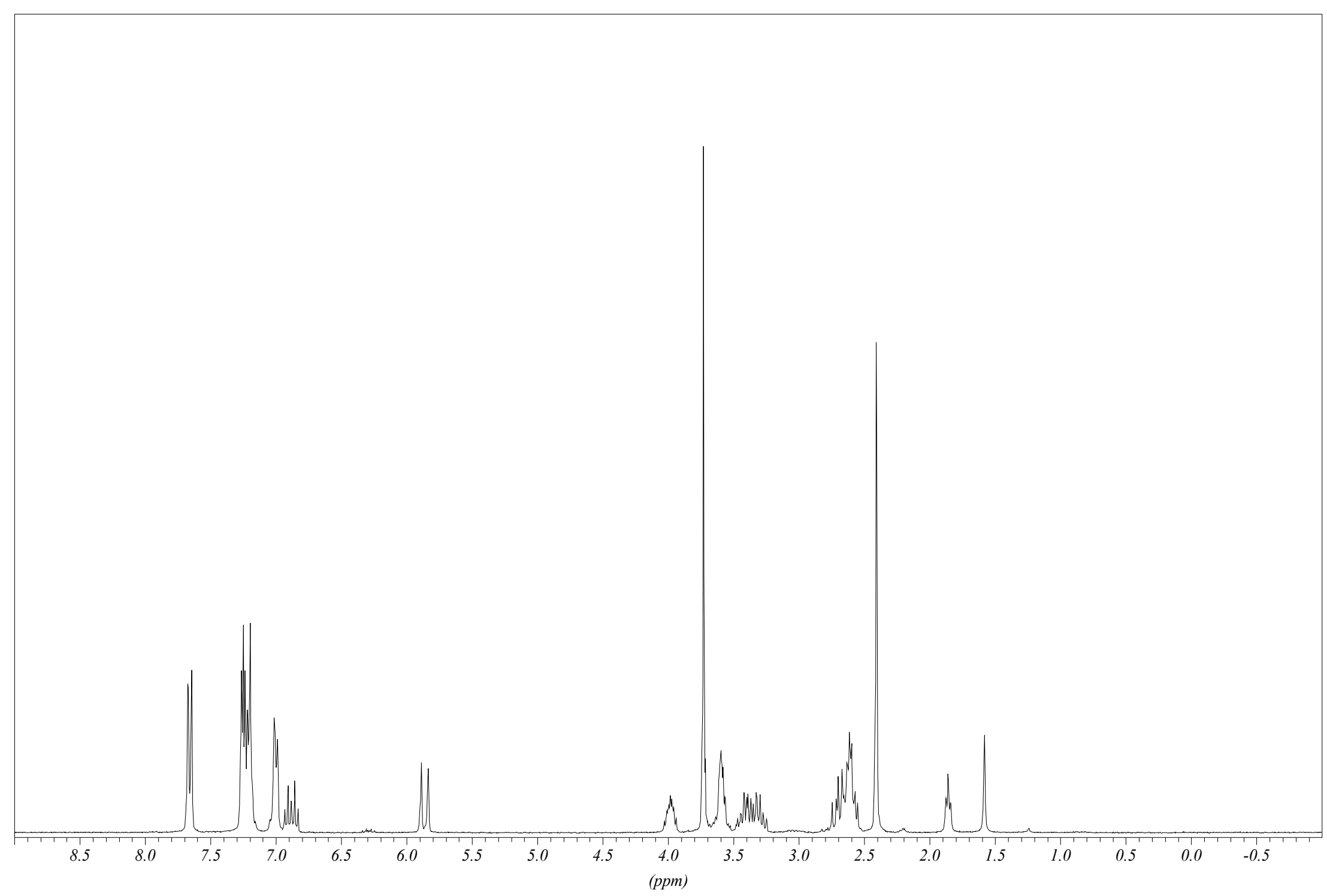

${ }^{1} \mathrm{H}$ NMR Spectrum (300 MHz) of $11 \mathbf{c}$ in $\mathrm{CDCl}_{3}$ 


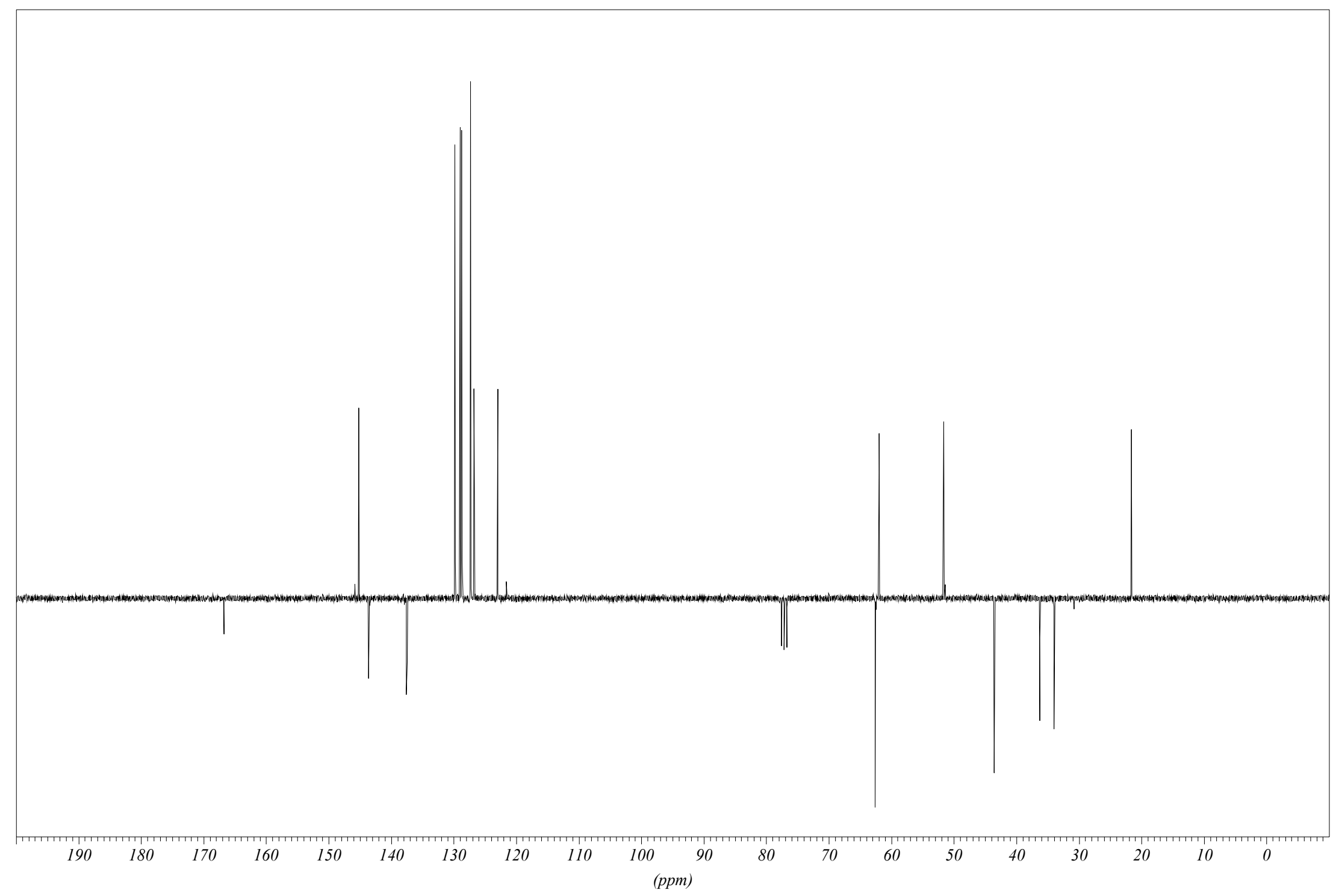

${ }^{13} \mathrm{C}$ NMR Spectrum (75 MHz) of 11c in $\mathrm{CDCl}_{3}$ 


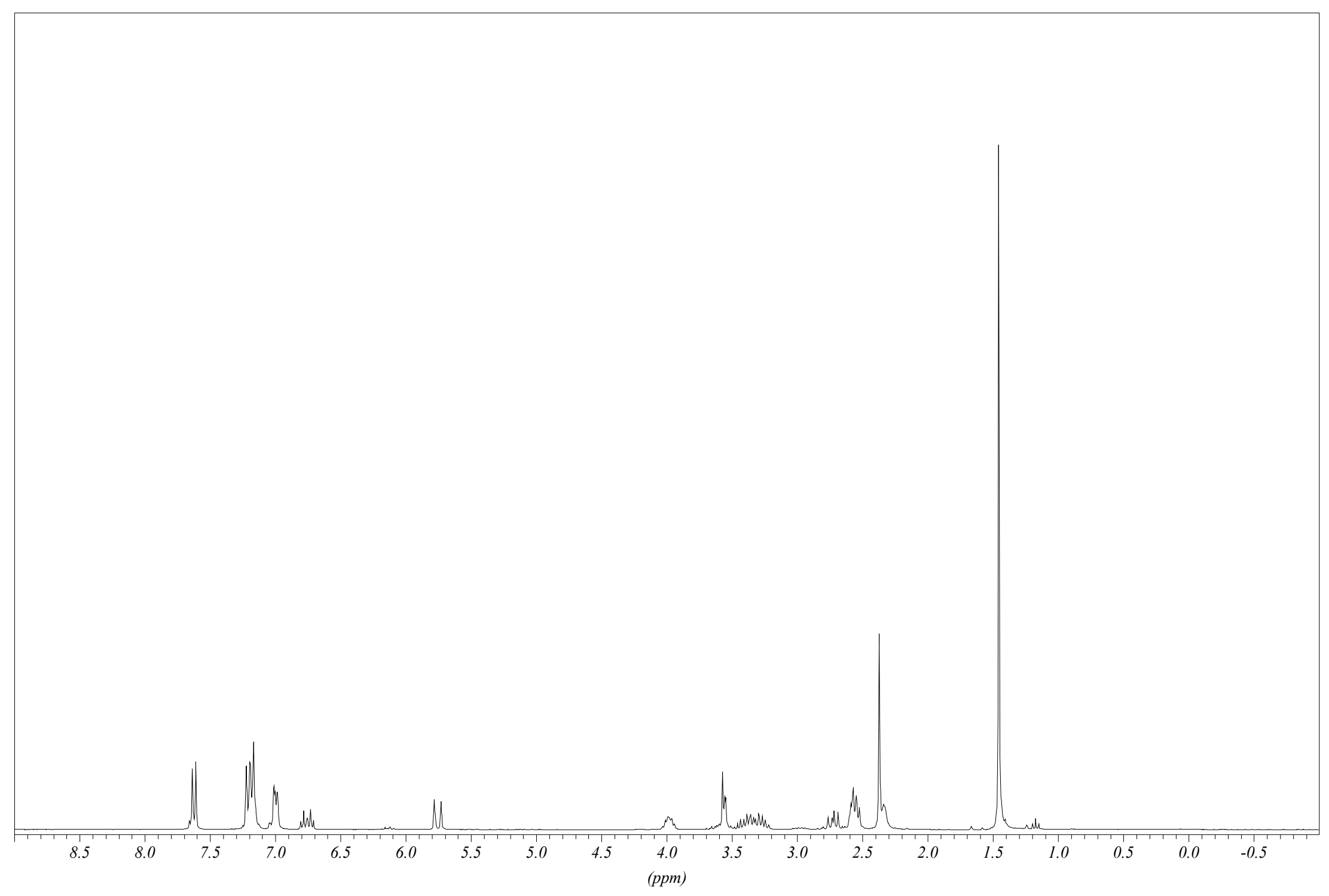

${ }^{1} \mathrm{H}$ NMR Spectrum (300 MHz) of $\mathbf{1 1 d}$ in $\mathrm{CDCl}_{3}$ 


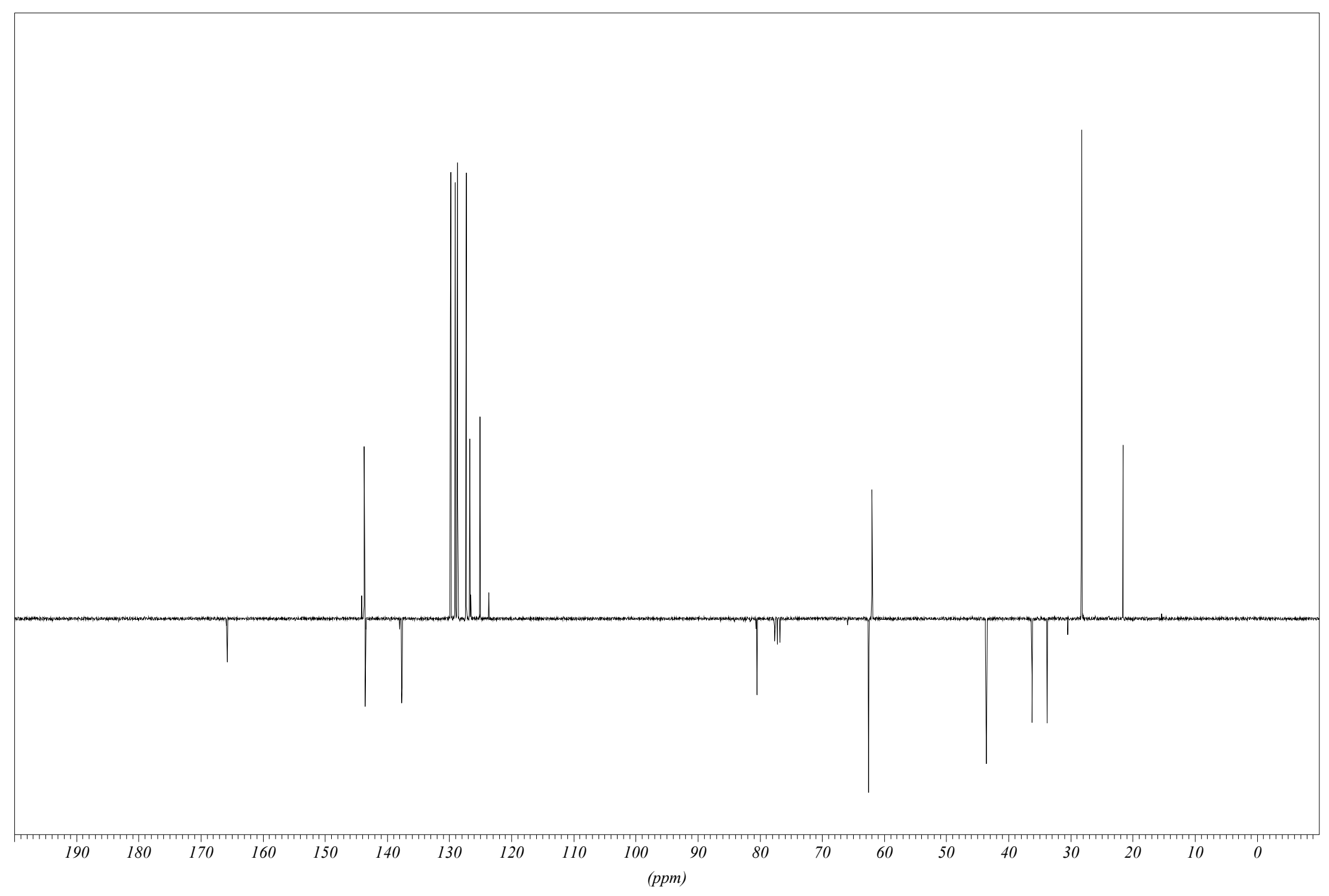

${ }^{13} \mathrm{C}$ NMR Spectrum $(75 \mathrm{MHz})$ of $\mathbf{1 1 d}$ in $\mathrm{CDCl}_{3}$ 


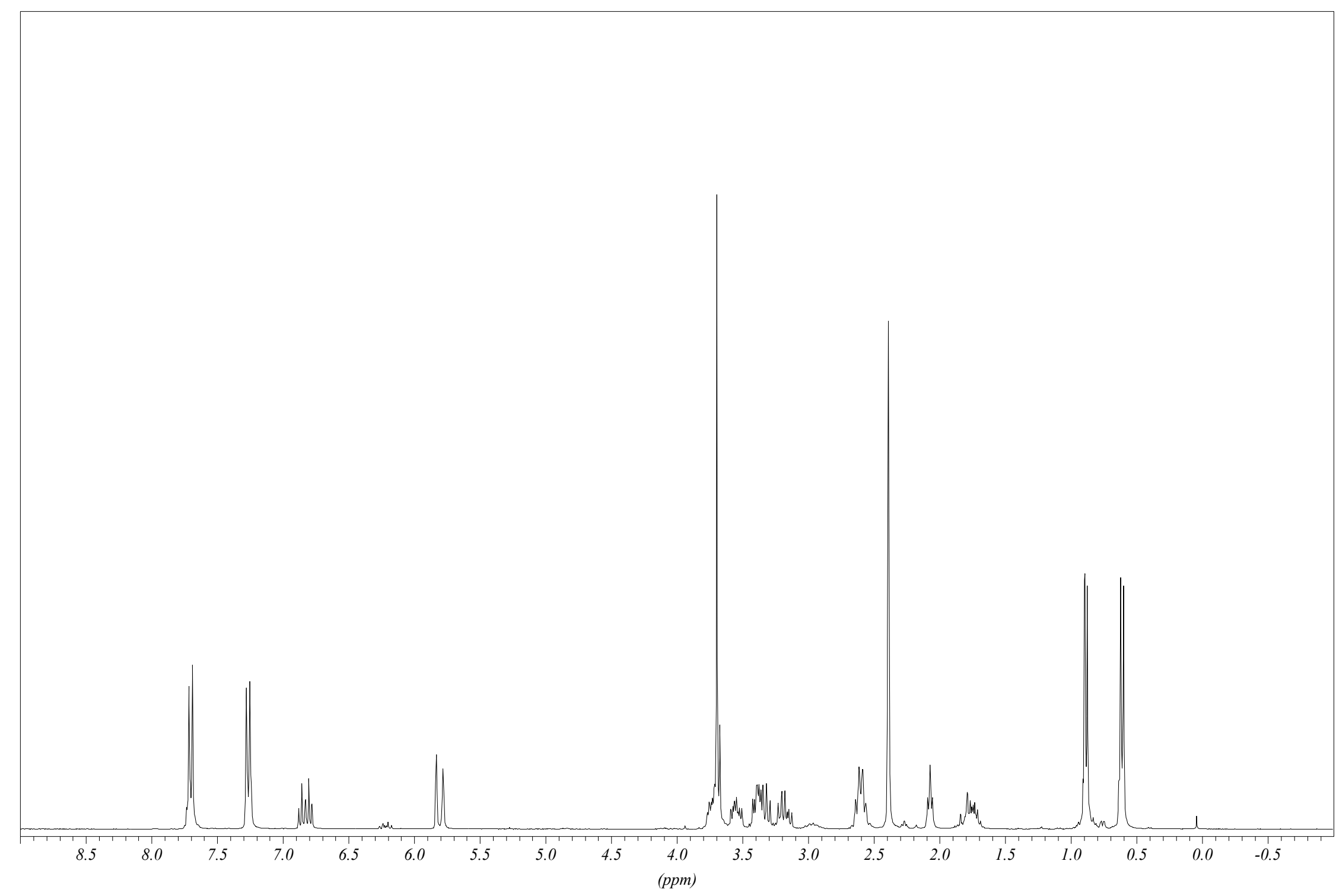

${ }^{1} \mathrm{H}$ NMR Spectrum (300 MHz) of $\mathbf{1 1 e}$ in $\mathrm{CDCl}_{3}$ 


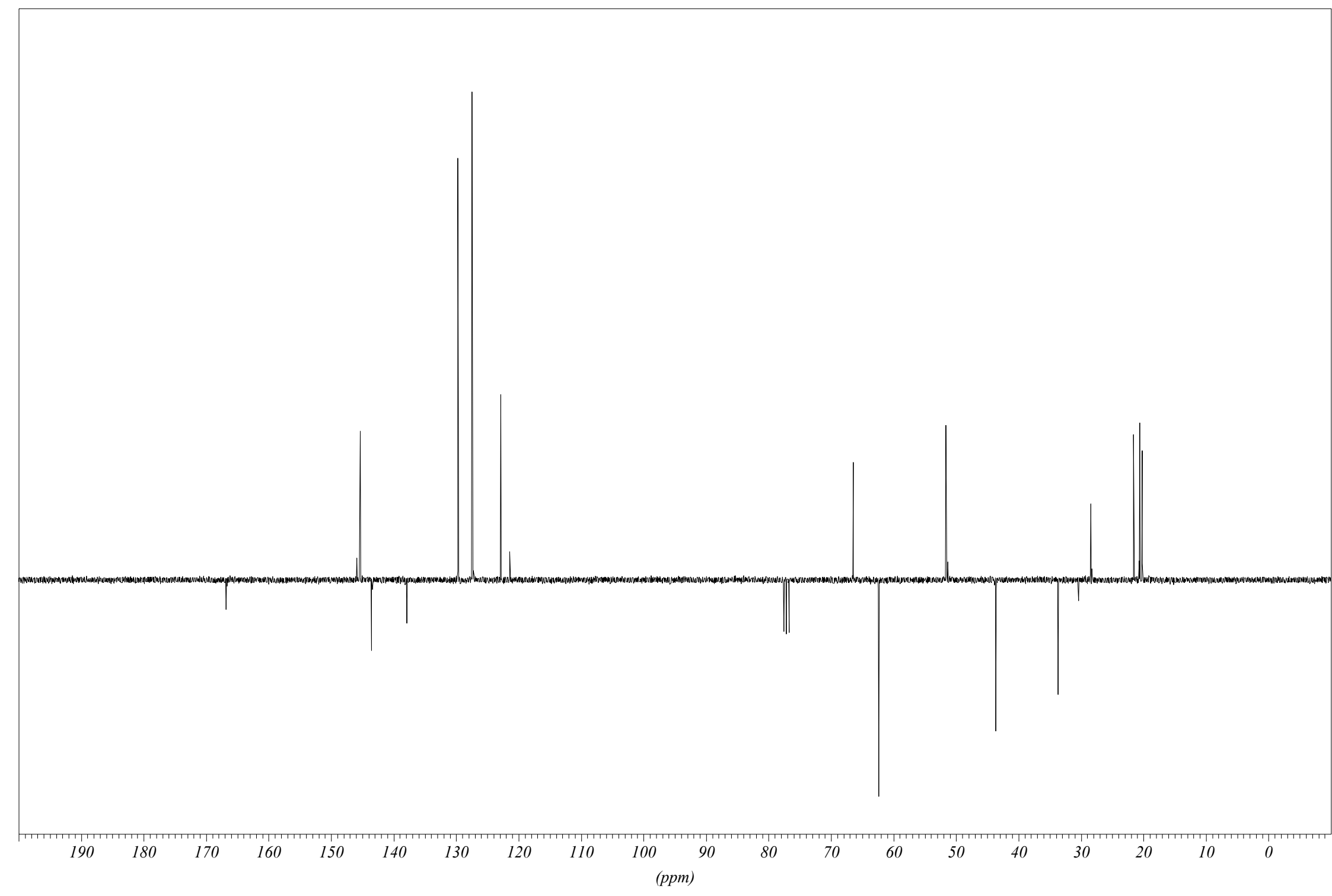

${ }^{13} \mathrm{C}$ NMR Spectrum (75 MHz) of 11e in $\mathrm{CDCl}_{3}$ 


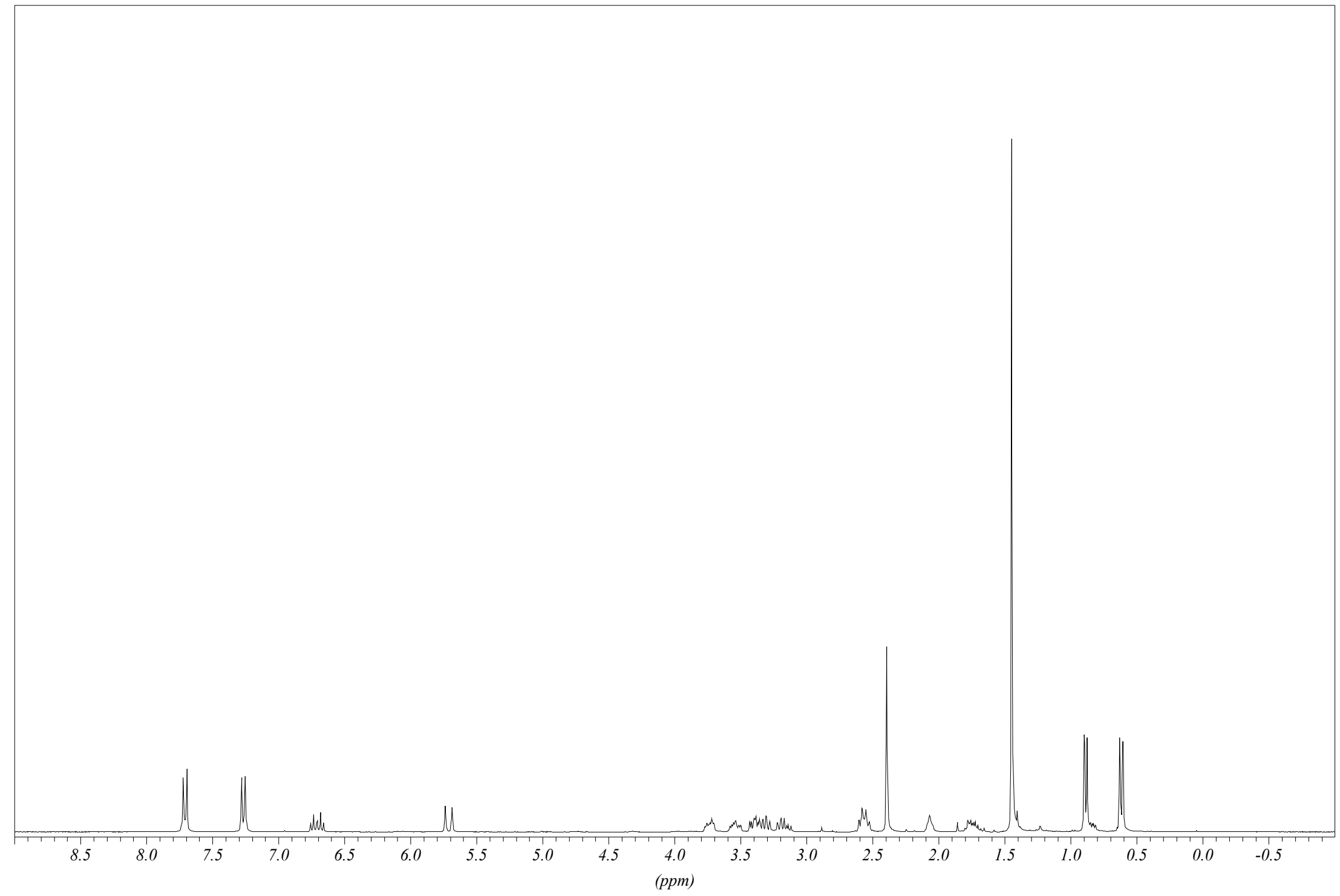

${ }^{1} \mathrm{H}$ NMR Spectrum (300 MHz) of $11 \mathrm{f}$ in $\mathrm{CDCl}_{3}$ 


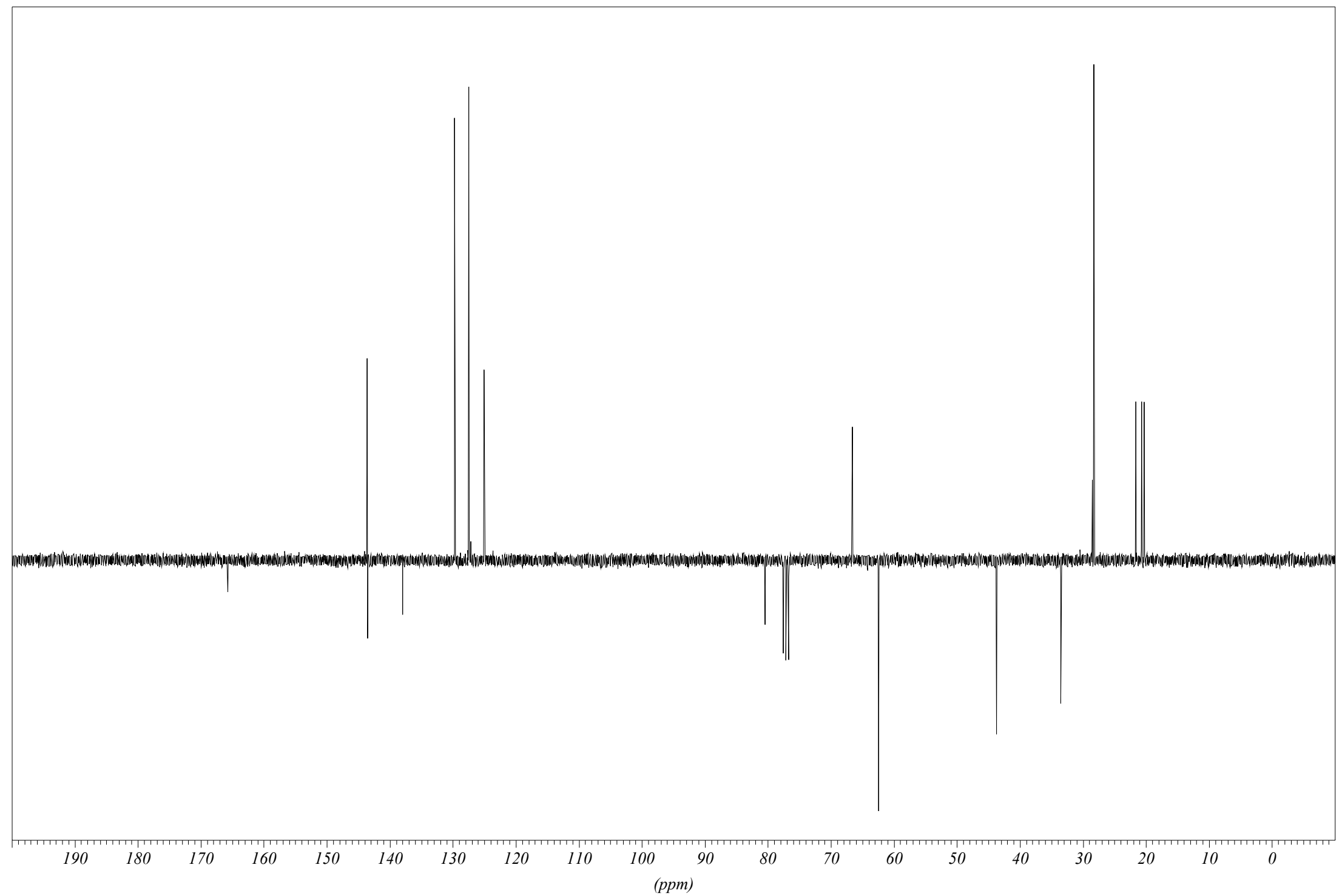

${ }^{13} \mathrm{C}$ NMR Spectrum (75 MHz) of $11 \mathrm{f}$ in $\mathrm{CDCl}_{3}$ 


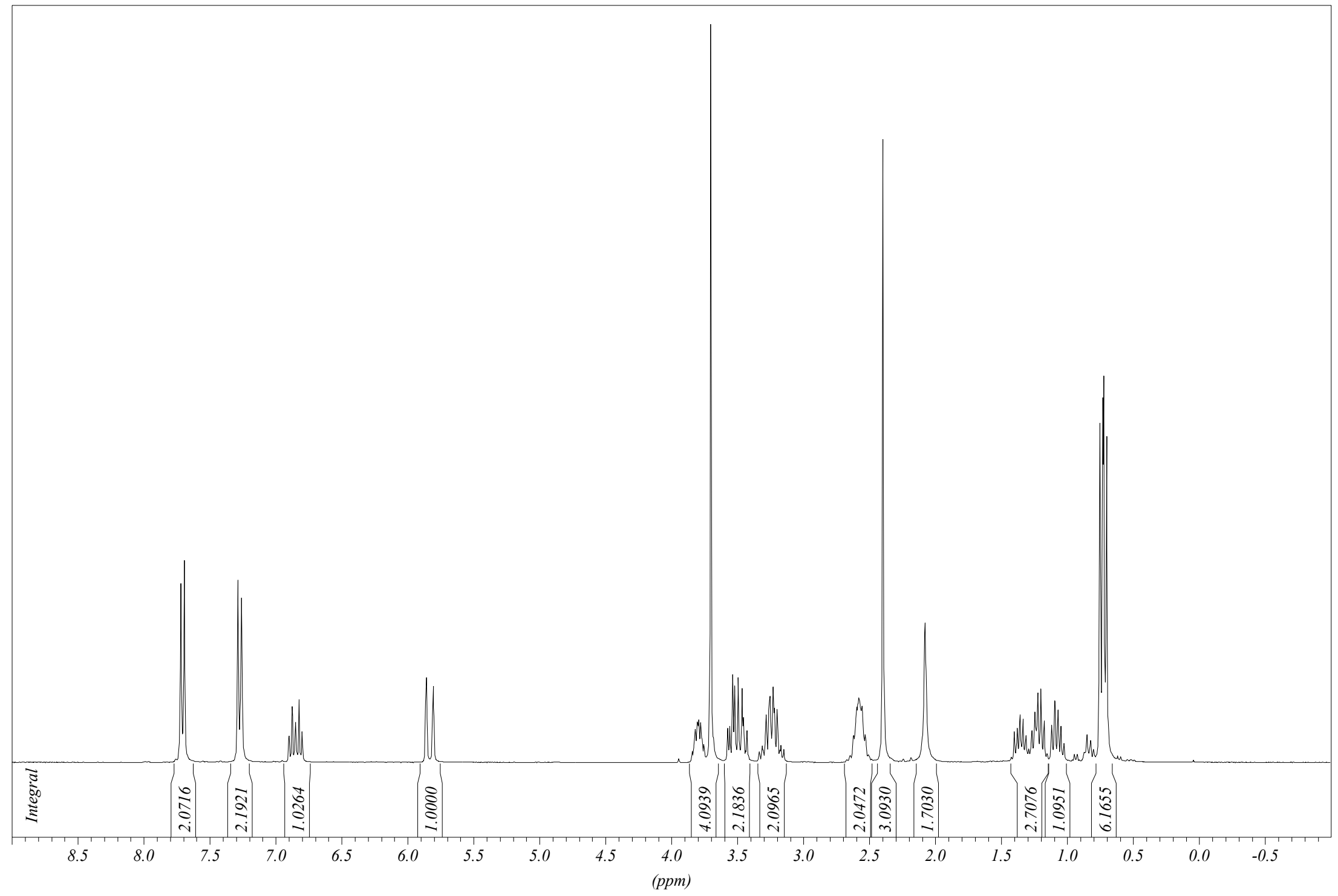

${ }^{1} \mathrm{H}$ NMR Spectrum (300 MHz) of $\mathbf{1 1 g}$ in $\mathrm{CDCl}_{3}$ 


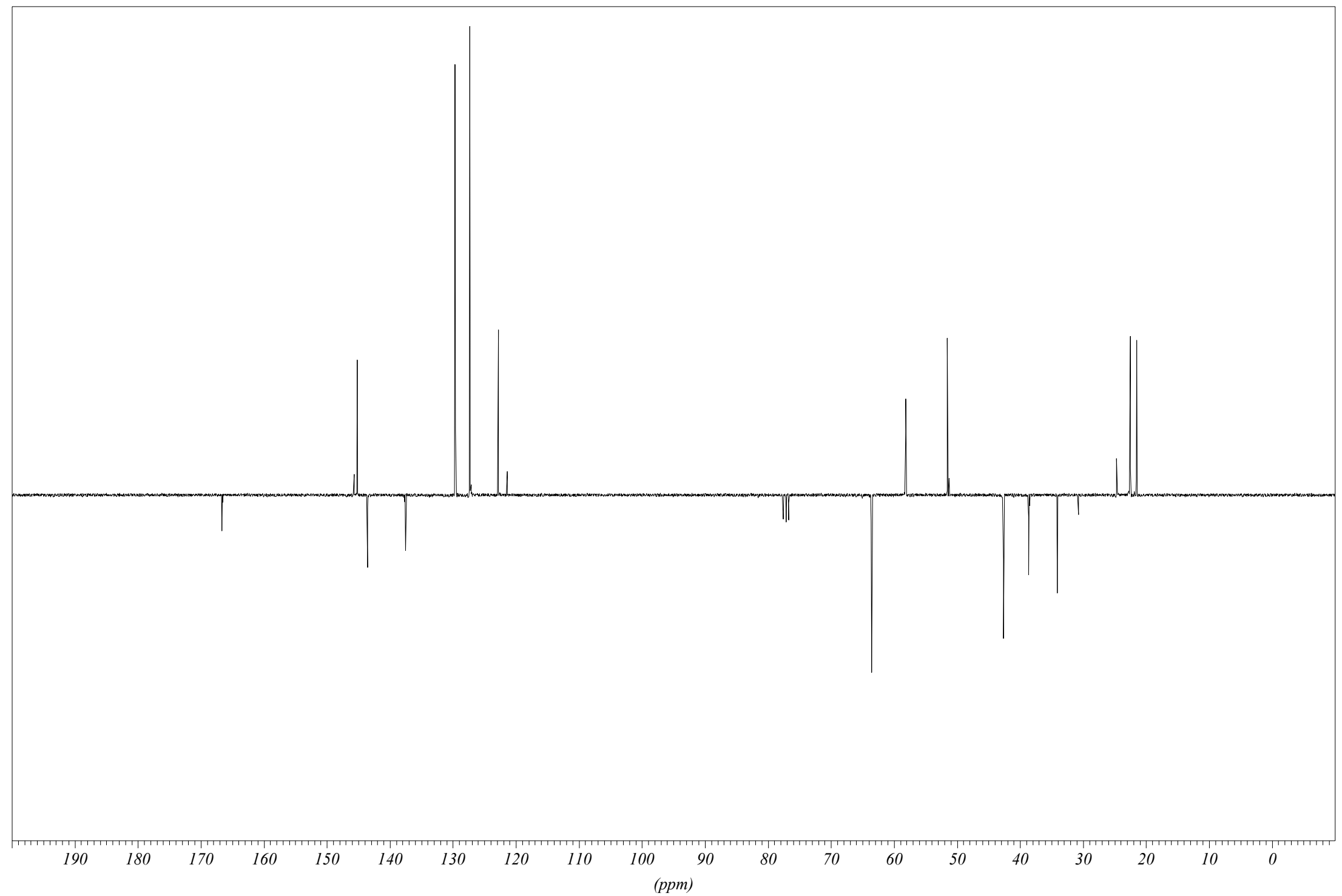

${ }^{13} \mathrm{C}$ NMR Spectrum (75 MHz) of $11 \mathrm{~g}$ in $\mathrm{CDCl}_{3}$ 


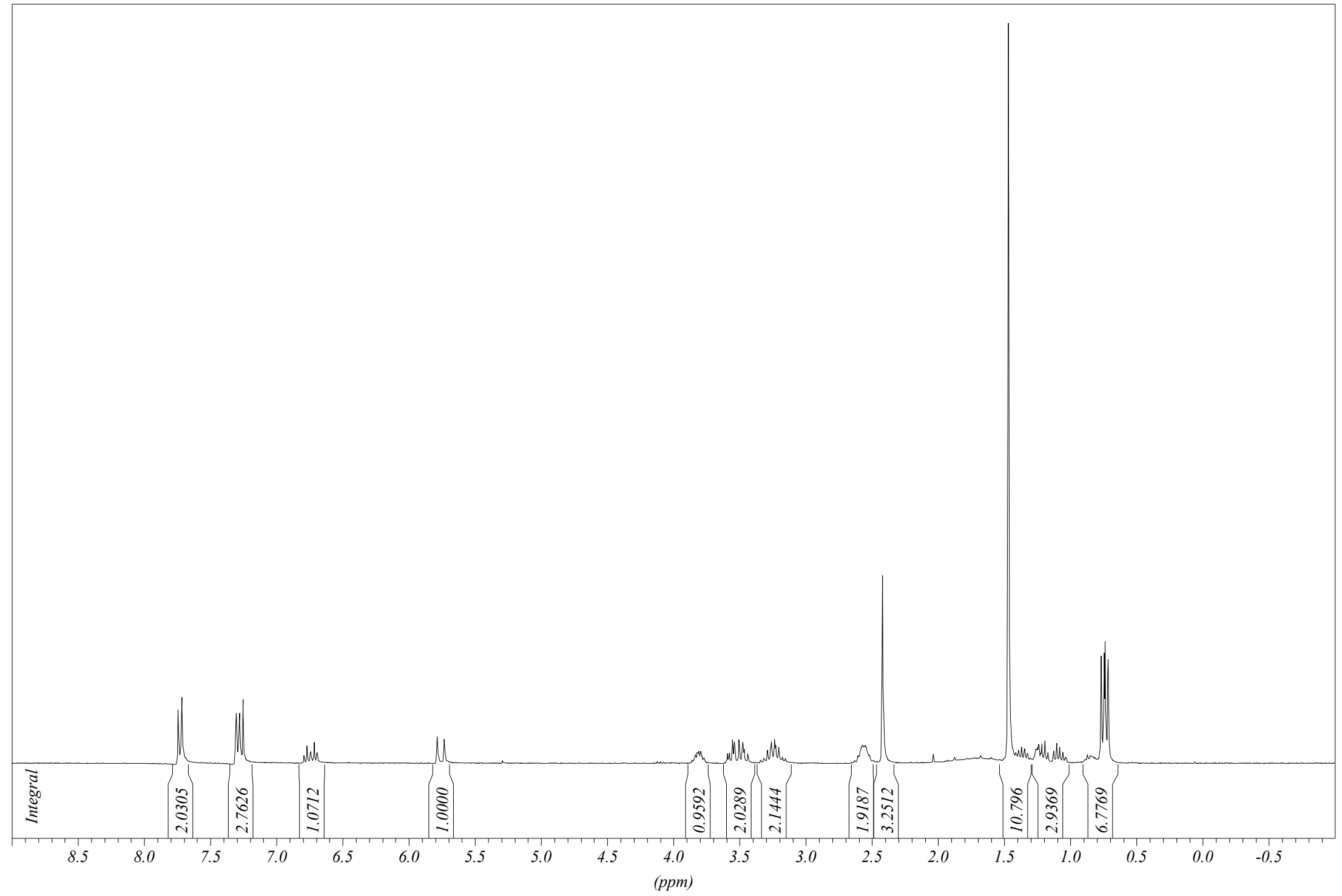

${ }^{1} \mathrm{H}$ NMR Spectrum (300 MHz) of $\mathbf{1 1} \mathbf{h}$ in $\mathrm{CDCl}_{3}$ 


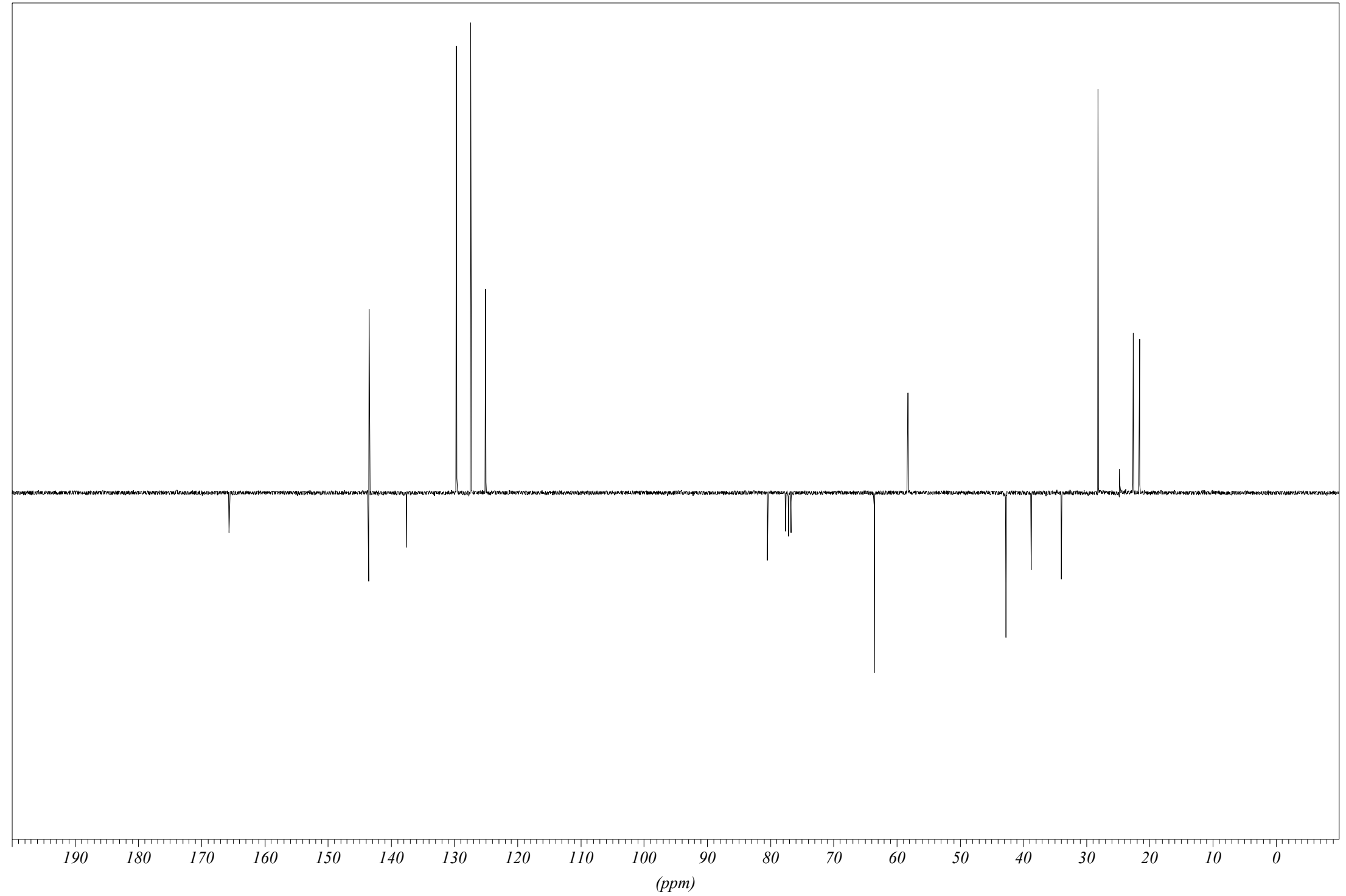

${ }^{13} \mathrm{C}$ NMR Spectrum (75 MHz) of $\mathbf{1 1 h}$ in $\mathrm{CDCl}_{3}$ 


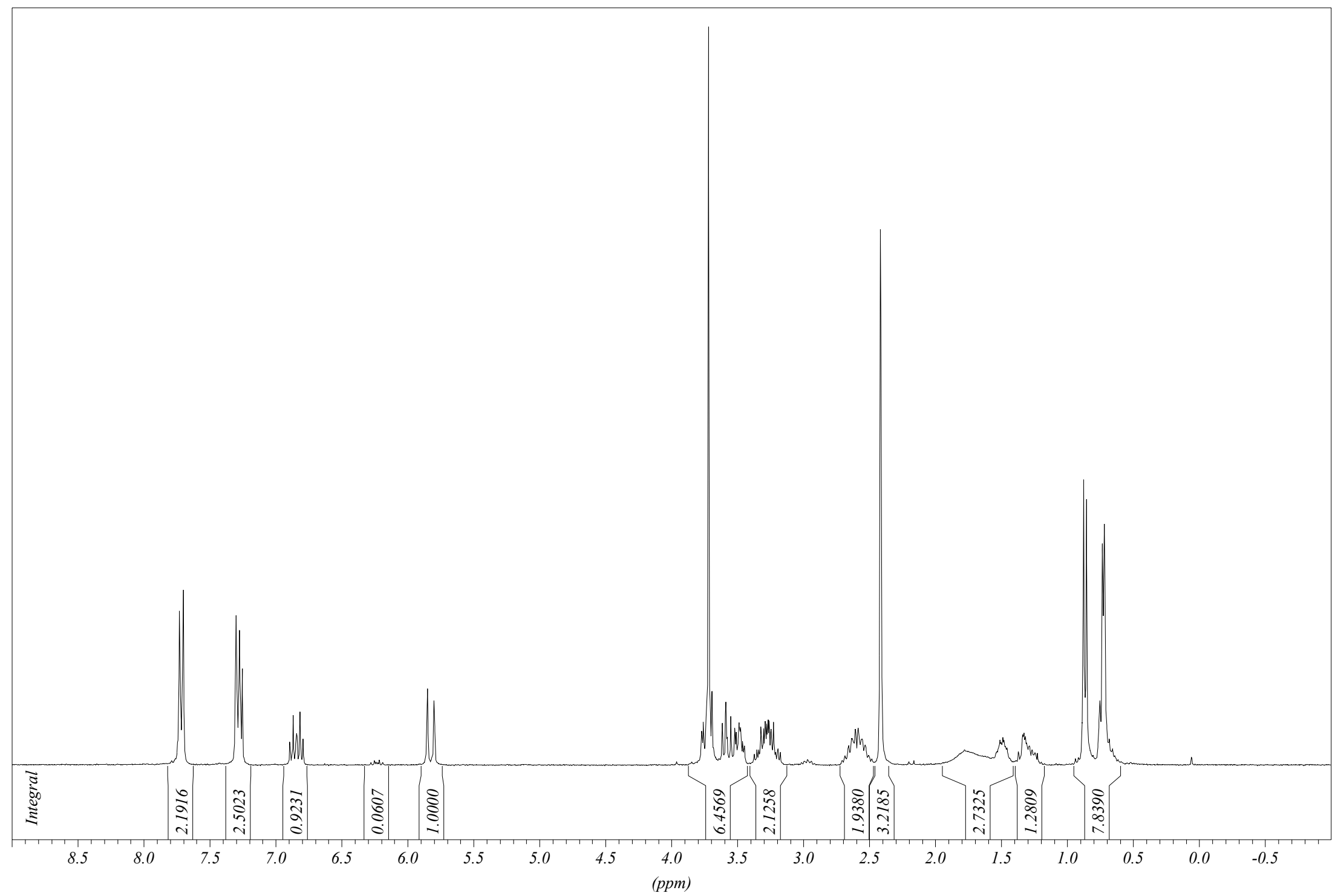

${ }^{1} \mathrm{H}$ NMR Spectrum (300 MHz) of $\mathbf{1 1 i}$ in $\mathrm{CDCl}_{3}$ 


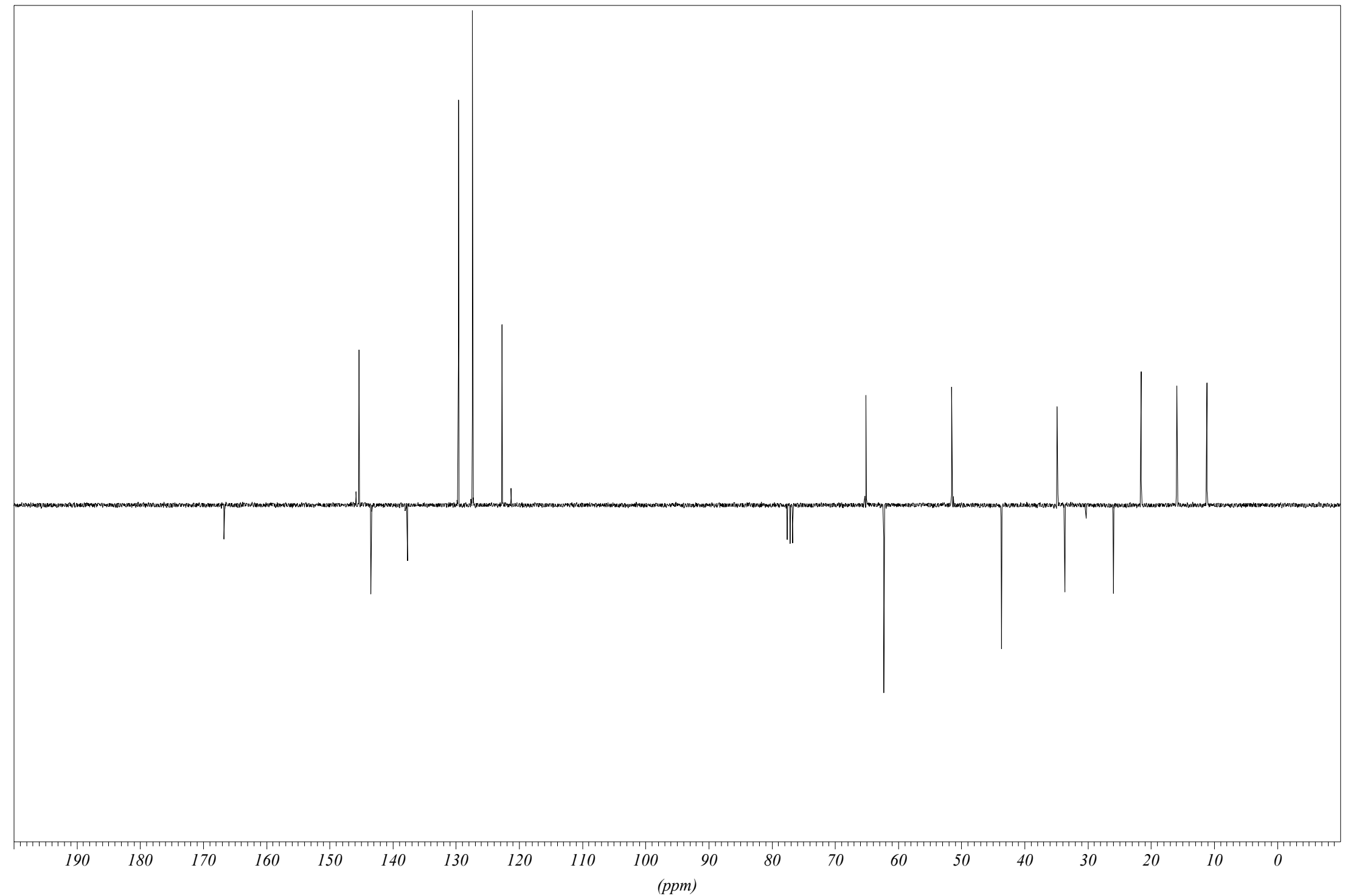

${ }^{13} \mathrm{C}$ NMR Spectrum (75 MHz) of $\mathbf{1 1 i}$ in $\mathrm{CDCl}_{3}$ 


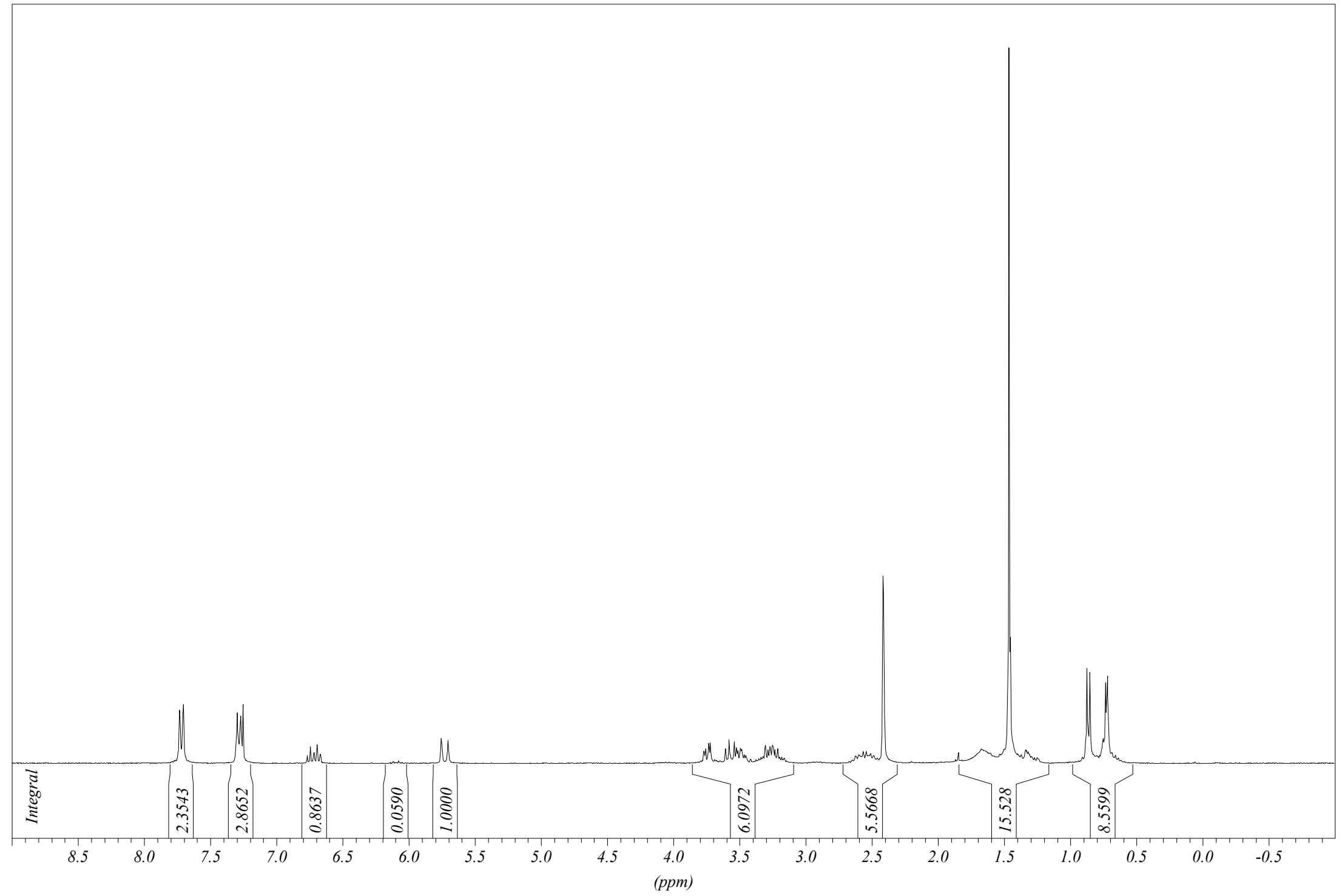

${ }^{1} \mathrm{H}$ NMR Spectrum $(300 \mathrm{MHz})$ of $\mathbf{1 1} \mathbf{j}$ in $\mathrm{CDCl}_{3}$ 


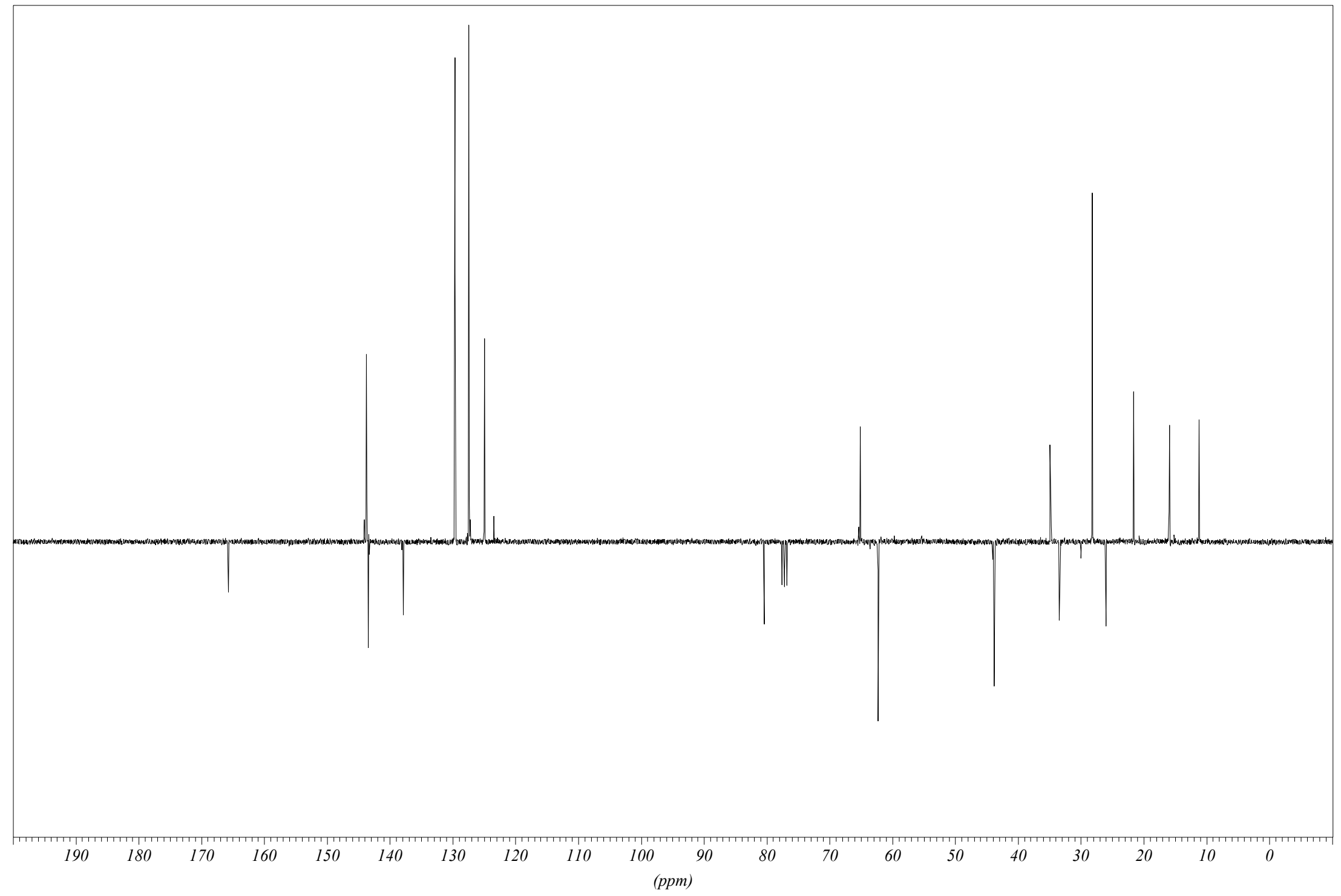

${ }^{13} \mathrm{C}$ NMR Spectrum (75 MHz) of $\mathbf{1 1} \mathbf{j}$ in $\mathrm{CDCl}_{3}$ 


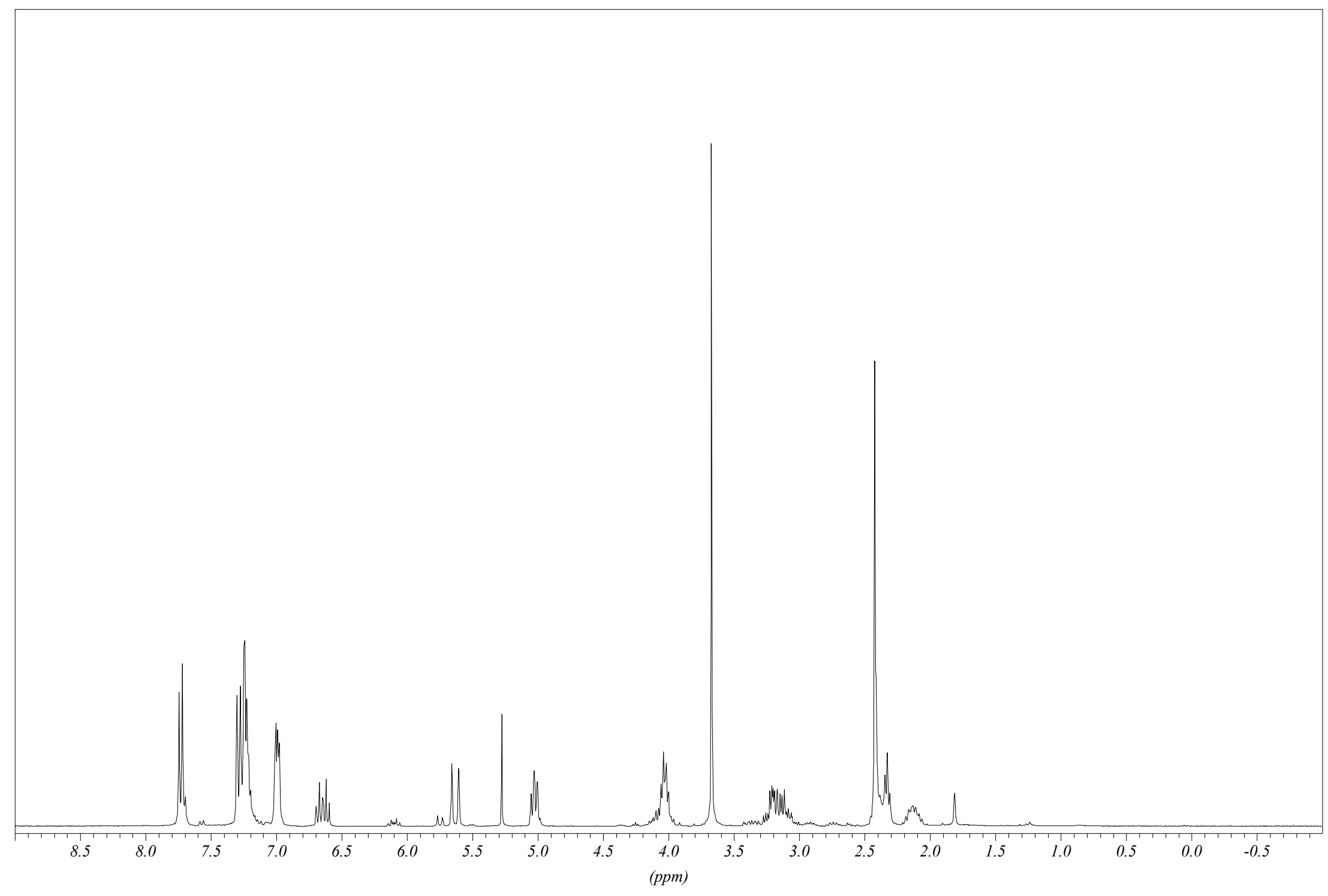

${ }^{1} \mathrm{H}$ NMR Spectrum $(300 \mathrm{MHz})$ of $\mathbf{1 1 k}$ in $\mathrm{CDCl}_{3}-$ cis trans mix 


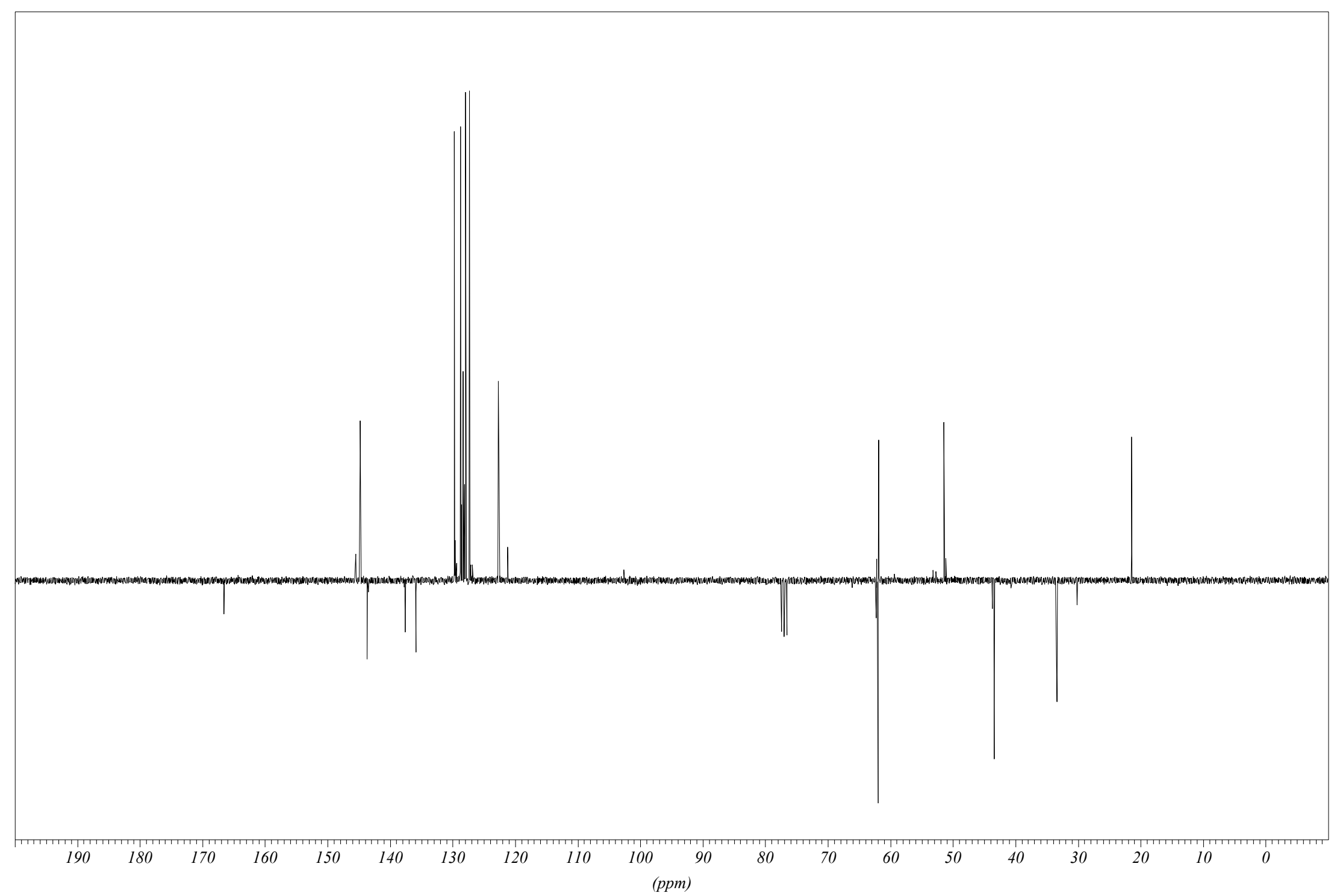

${ }^{13} \mathrm{C}$ NMR Spectrum $(75 \mathrm{MHz})$ of $\mathbf{1 1} \mathbf{k}$ in $\mathrm{CDCl}_{3}-$ cis trans mix 


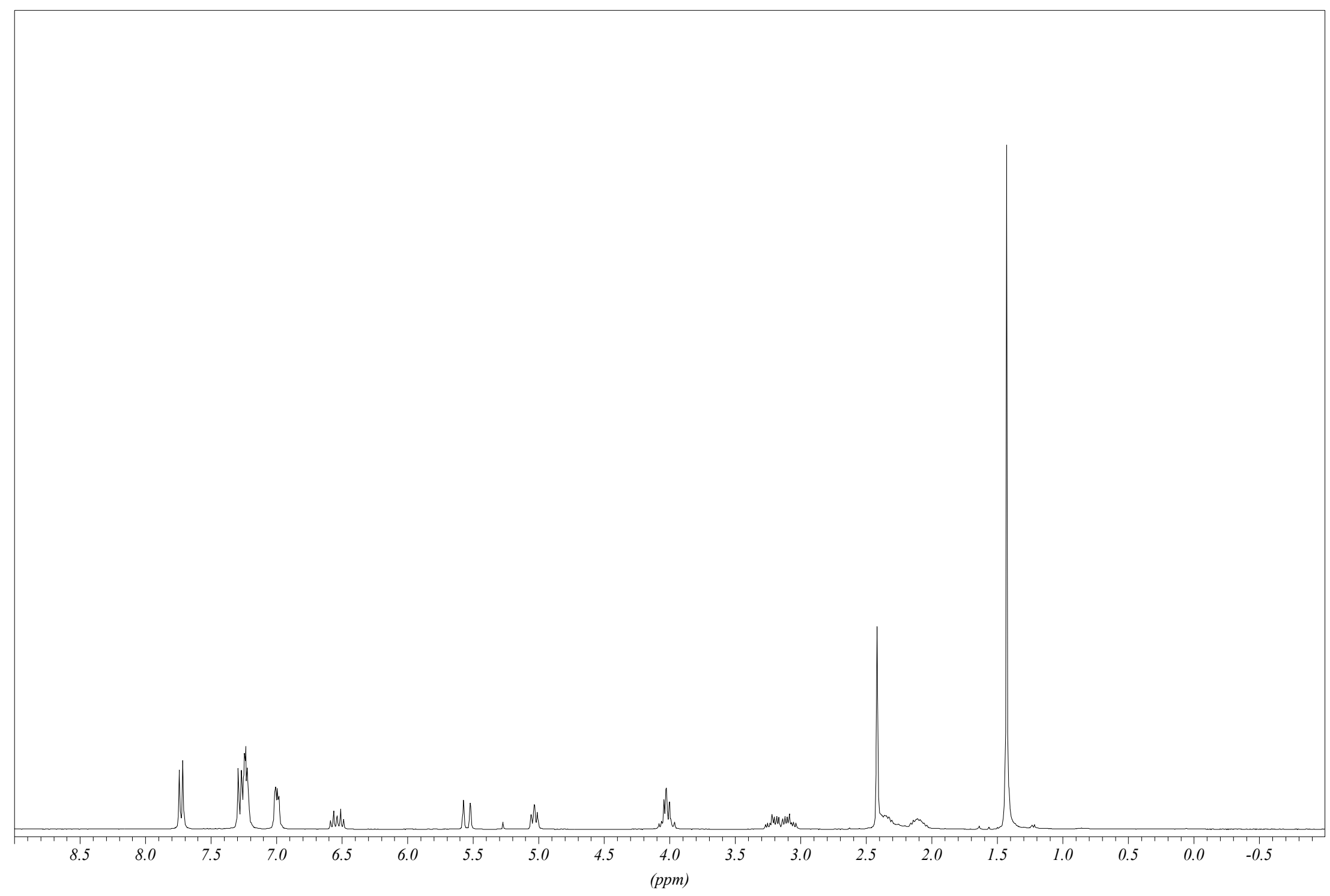

${ }^{1} \mathrm{H}$ NMR Spectrum (300 MHz) of $\mathbf{1 1 l}$ in $\mathrm{CDCl}_{3}$ 


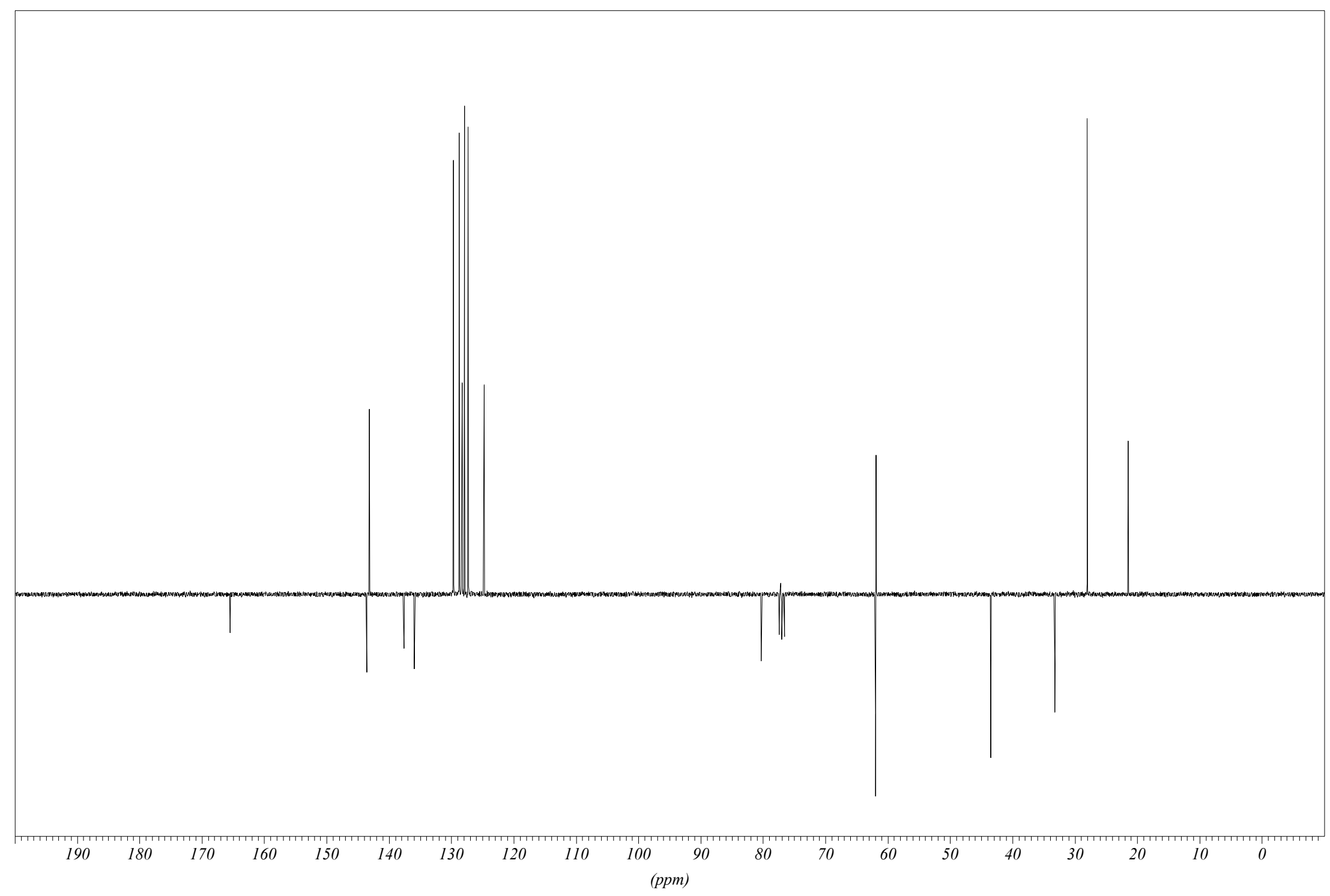

${ }^{13} \mathrm{C}$ NMR Spectrum $\left(75 \mathrm{MHz}\right.$ ) of $\mathbf{1 1 1}$ in $\mathrm{CDCl}_{3}$ 


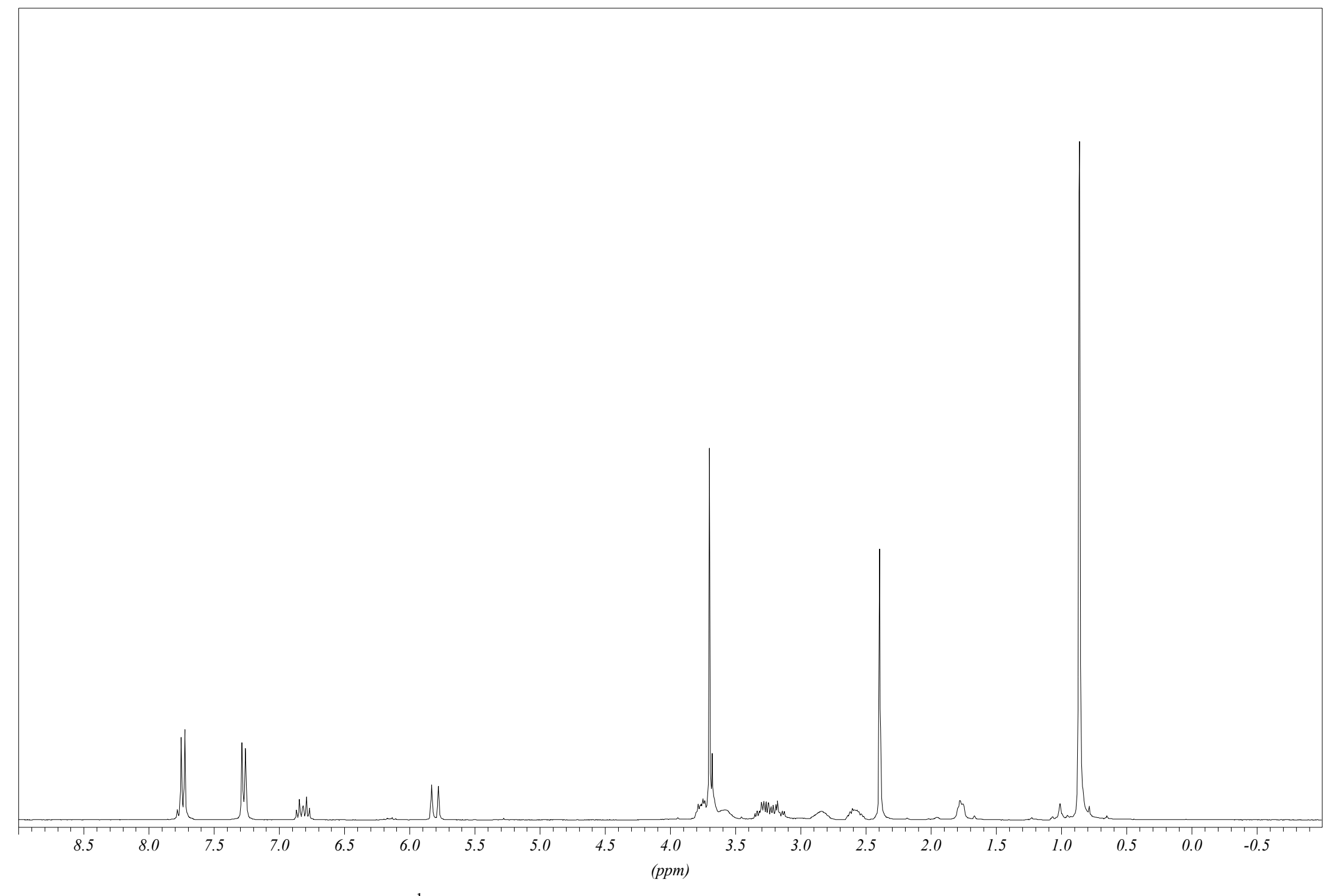

${ }^{1} \mathrm{H}$ NMR Spectrum (300 MHz) of $\mathbf{1 1} \mathbf{m}$ in $\mathrm{CDCl}_{3}$ 


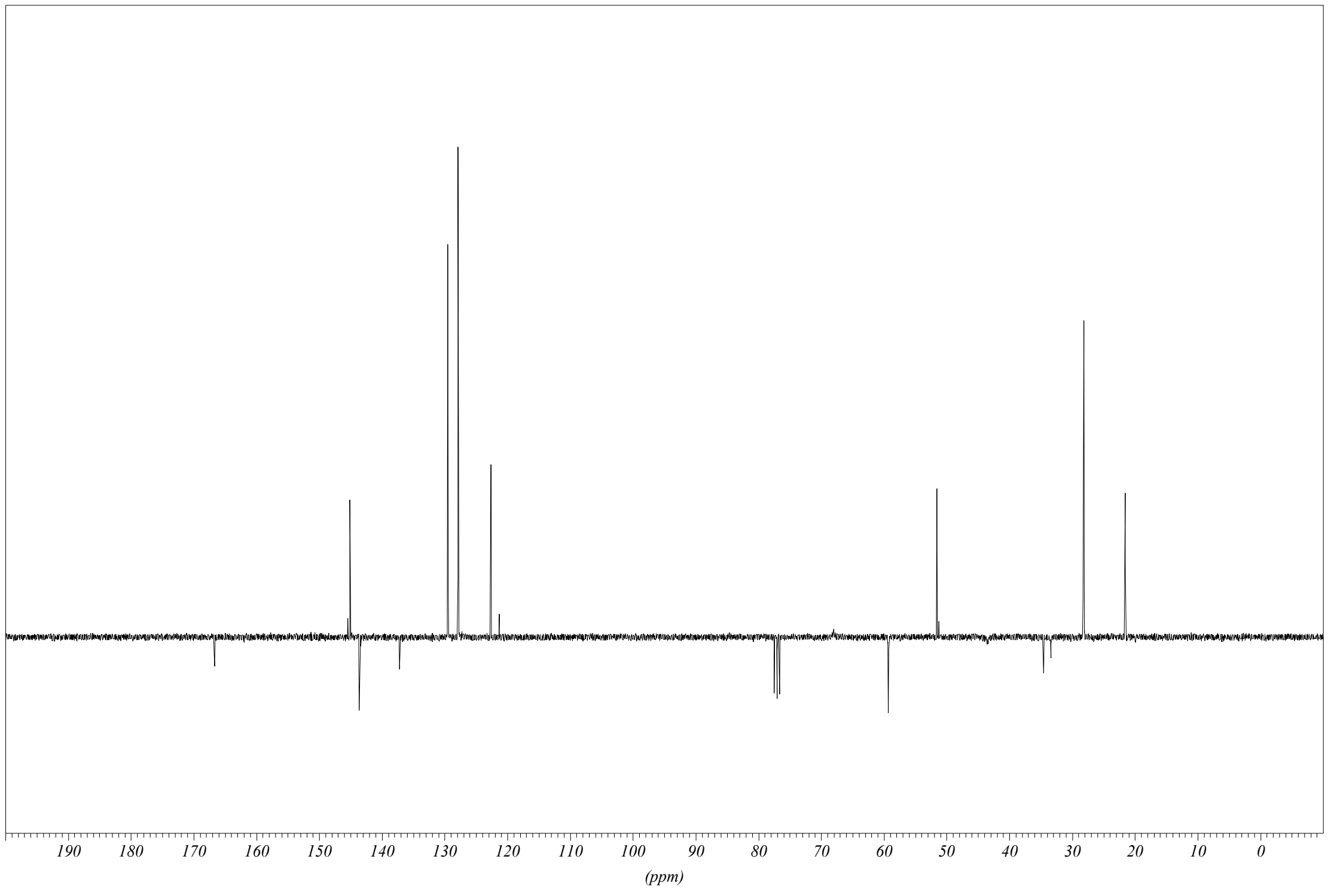

${ }^{13} \mathrm{C}$ NMR Spectrum (75 MHz) of $\mathbf{1 1} \mathbf{m}$ in $\mathrm{CDCl}_{3}$ 


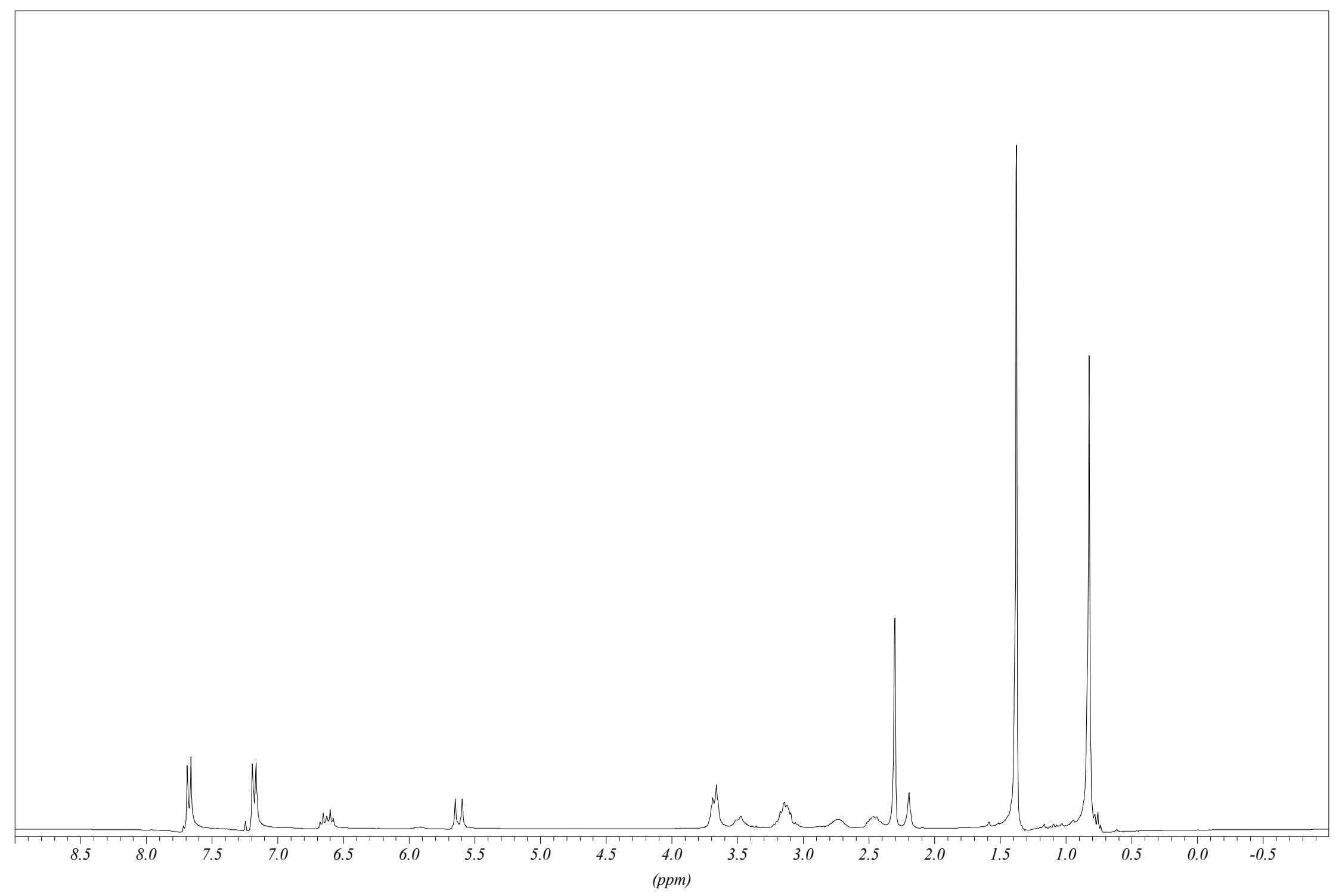

${ }^{1} \mathrm{H}$ NMR Spectrum (300 MHz) of $\mathbf{1 1} \mathbf{n}$ in $\mathrm{CDCl}_{3}$ 


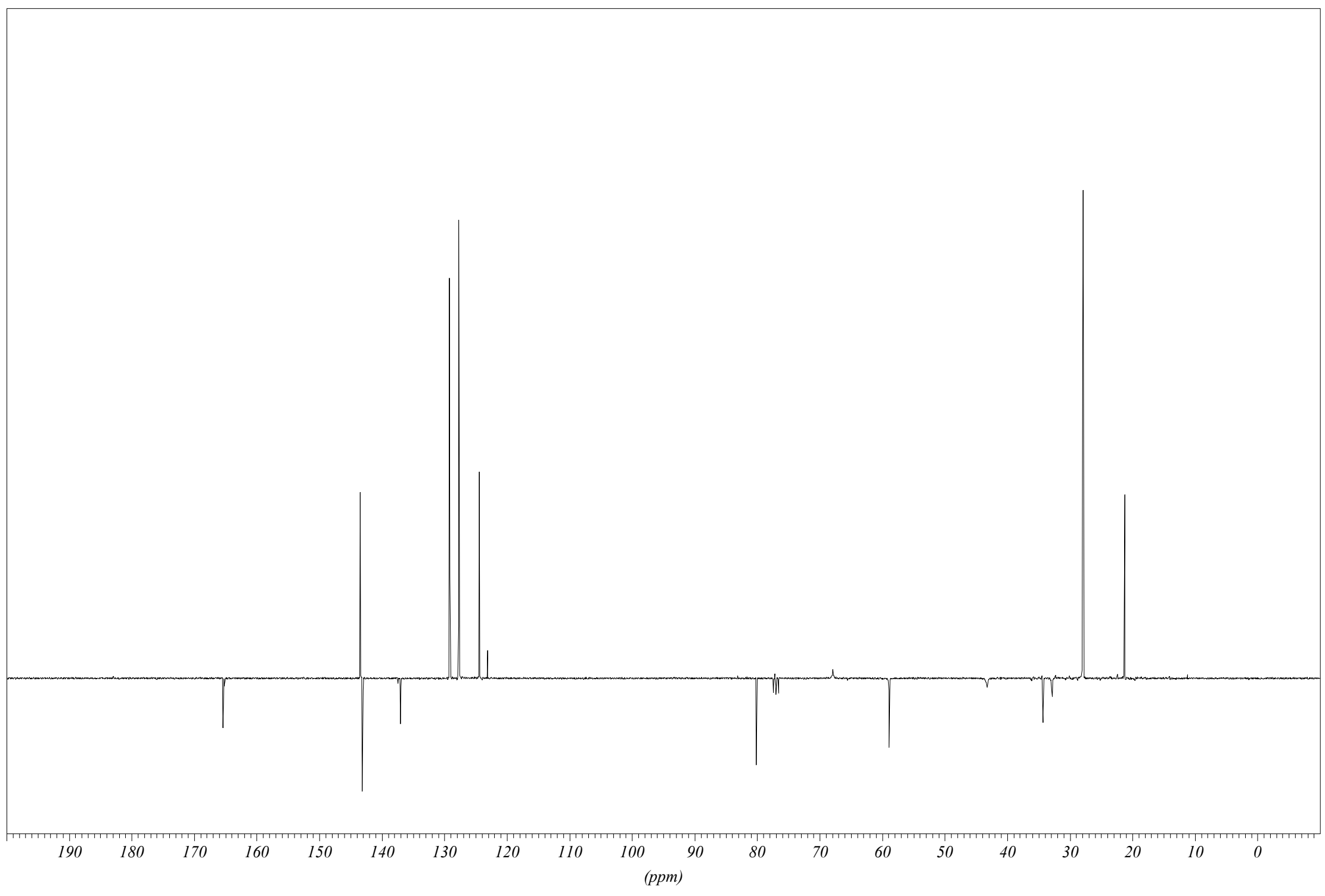

${ }^{13} \mathrm{C}$ NMR Spectrum $(75 \mathrm{MHz})$ of $\mathbf{1 1} \mathbf{n}$ in $\mathrm{CDCl}_{3}$ 


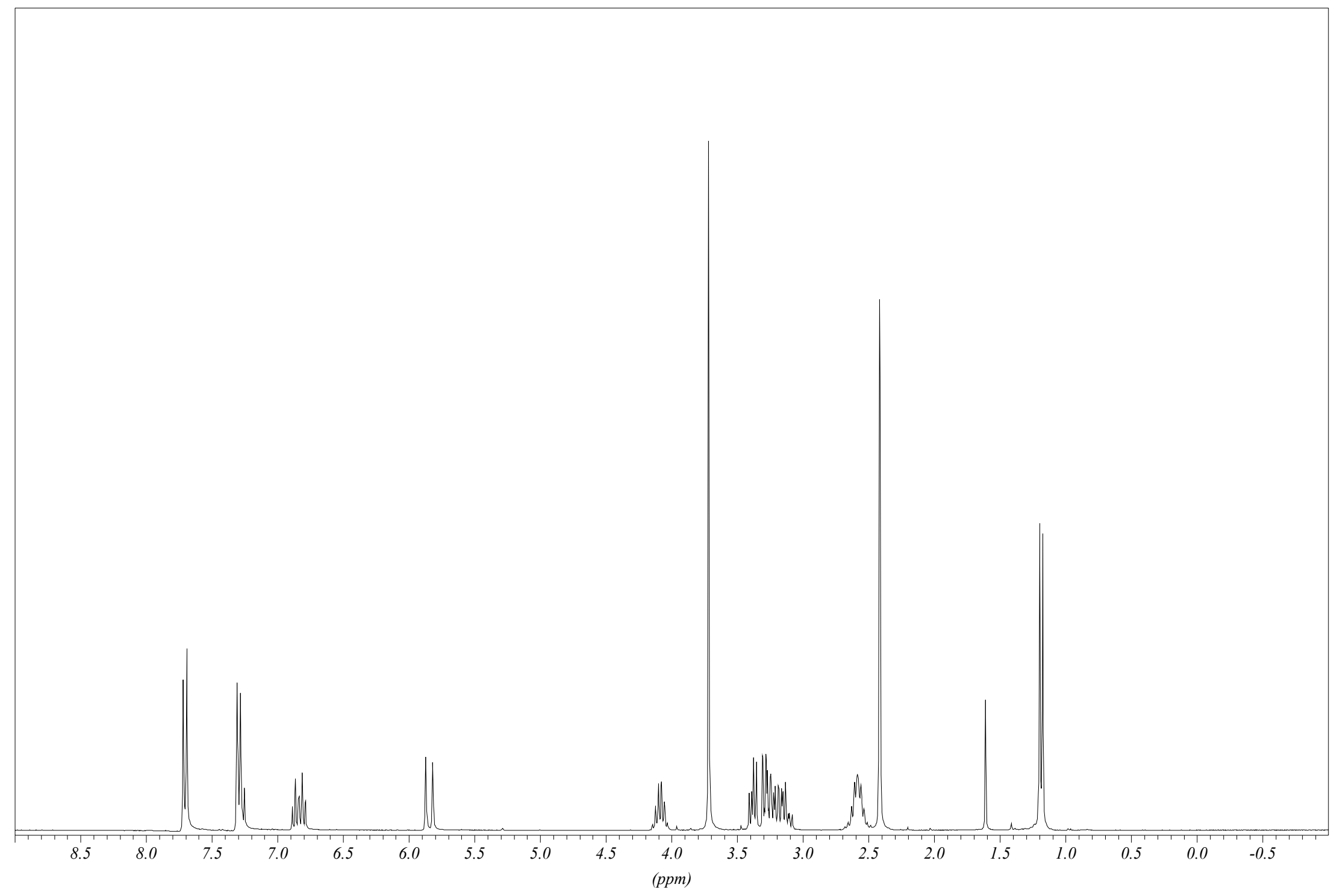

${ }^{1} \mathrm{H}$ NMR Spectrum (300 MHz) of $\mathbf{1 2 a}$ in $\mathrm{CDCl}_{3}$ 


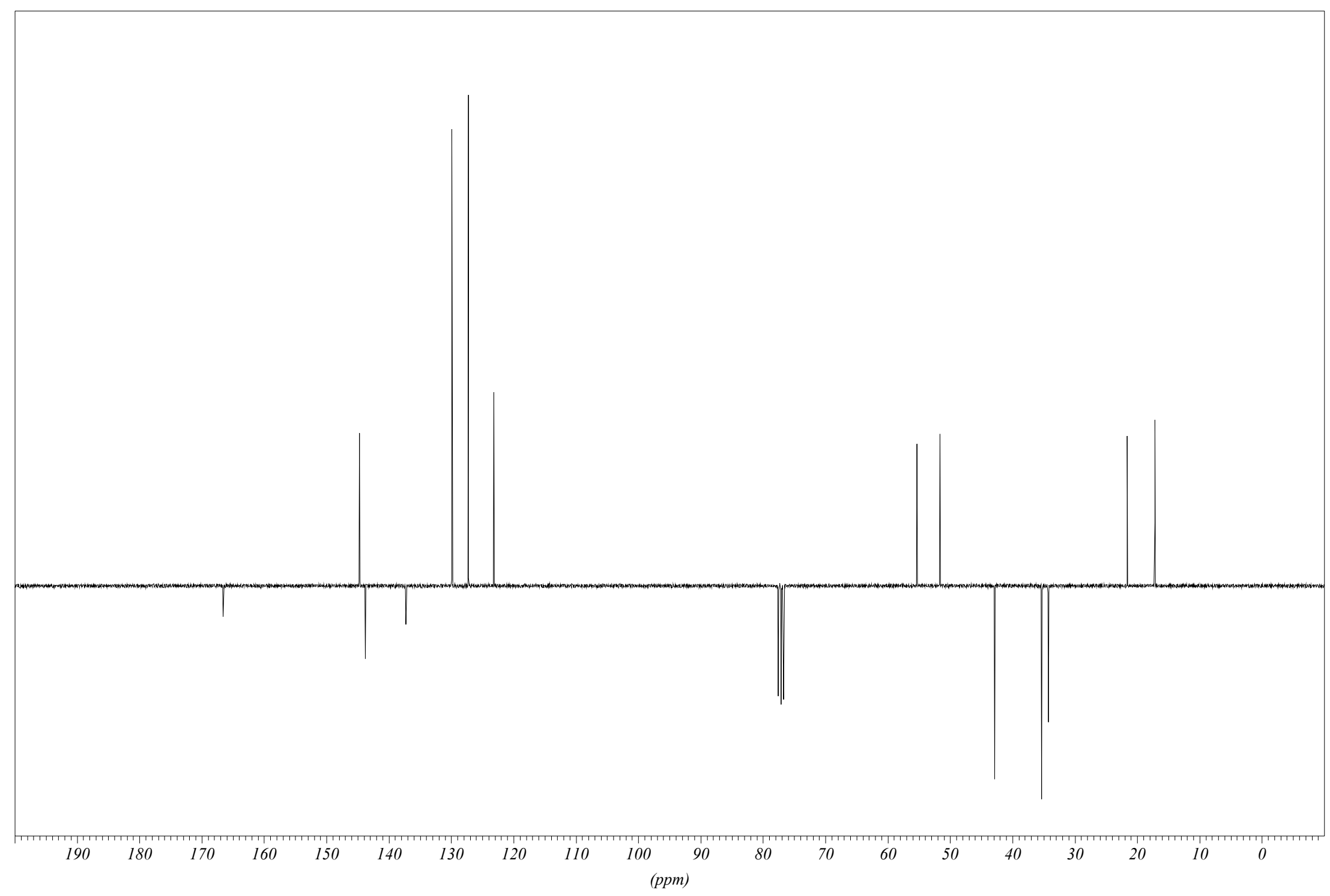

${ }^{13} \mathrm{C}$ NMR Spectrum (75 MHz) of 12a in $\mathrm{CDCl}_{3}$ 


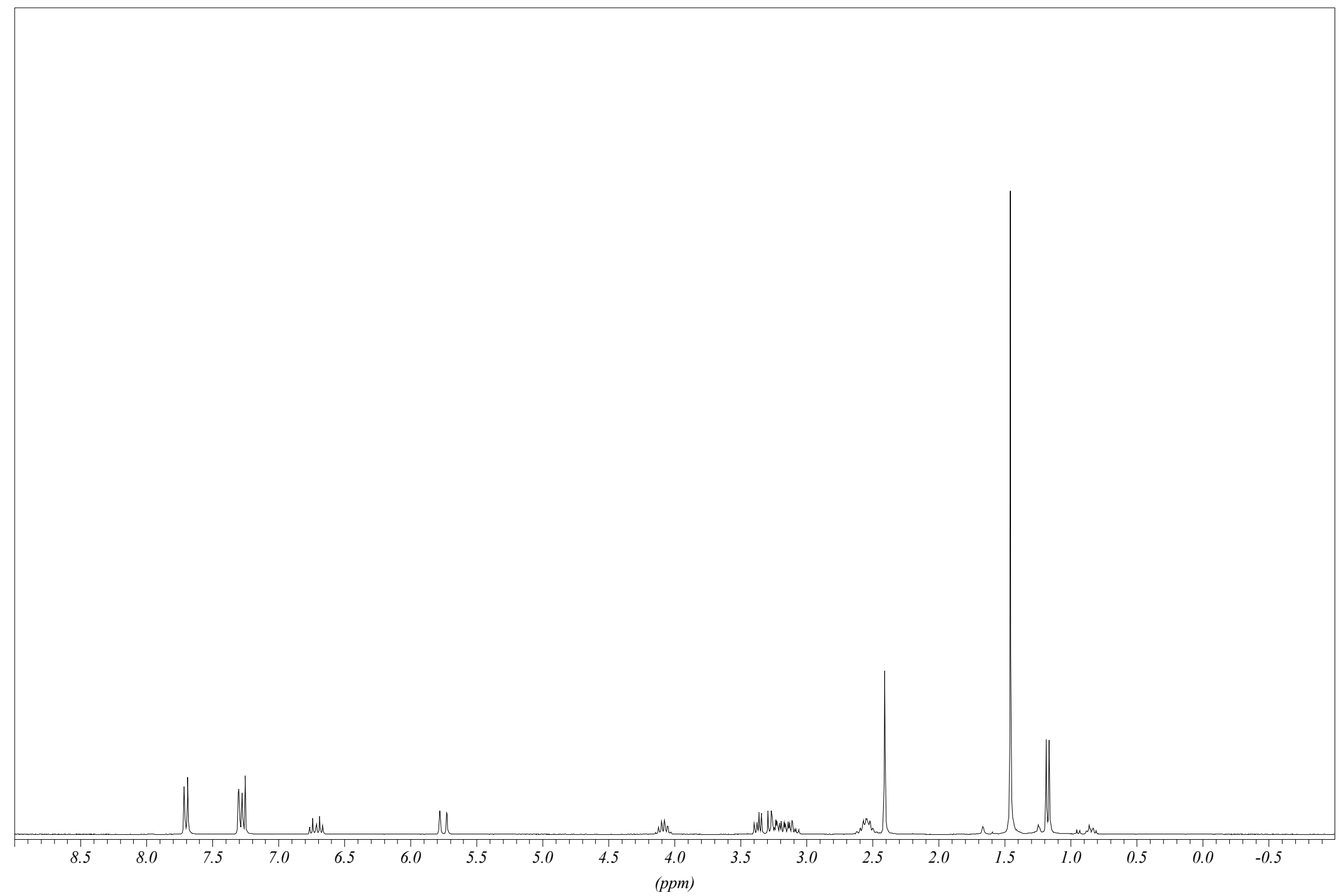

${ }^{1} \mathrm{H}$ NMR Spectrum (300 MHz) of $\mathbf{1 2 b}$ in $\mathrm{CDCl}_{3}$ 


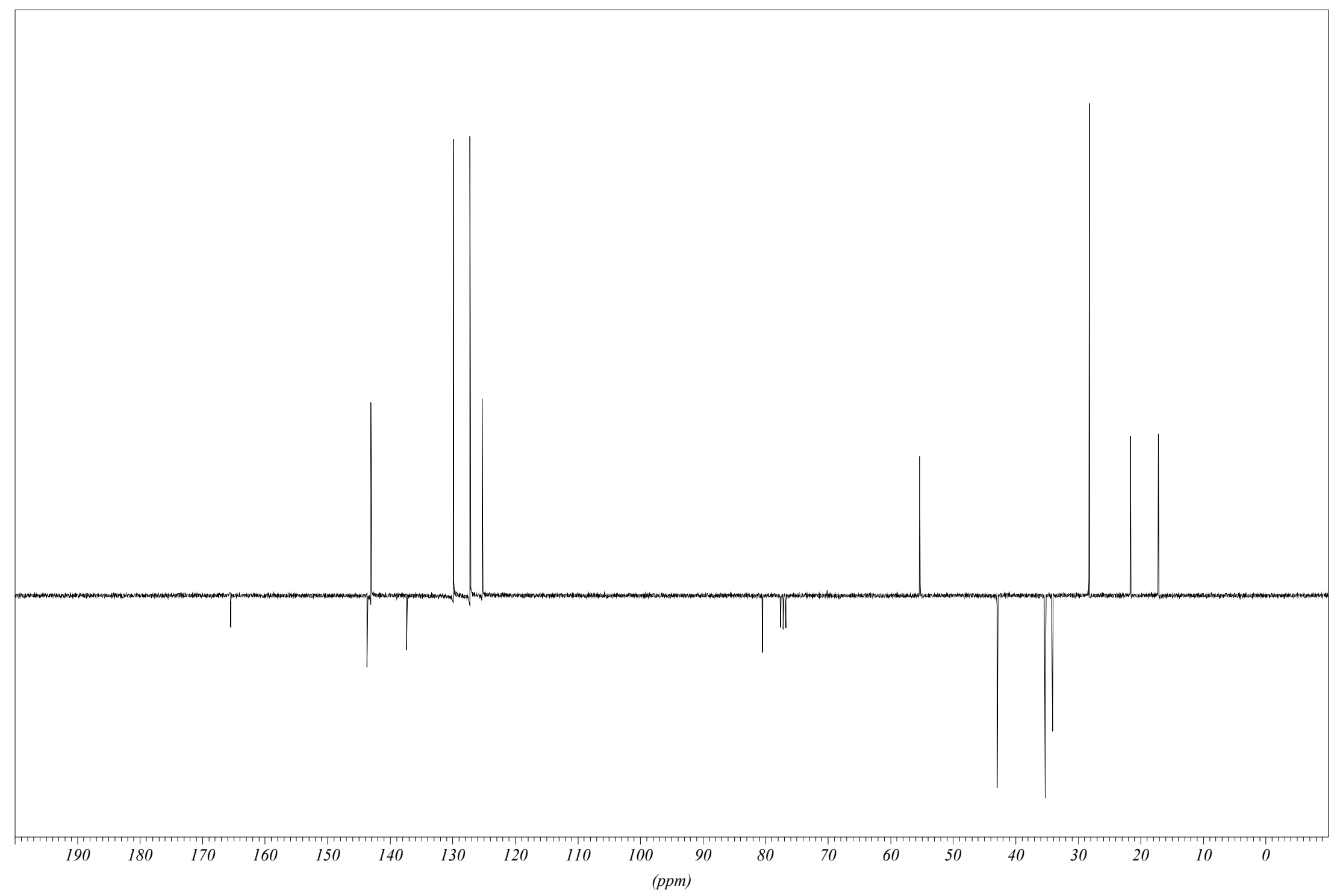

${ }^{13} \mathrm{C}$ NMR Spectrum $(75 \mathrm{MHz})$ of $\mathbf{1 2 b}$ in $\mathrm{CDCl}_{3}$ 


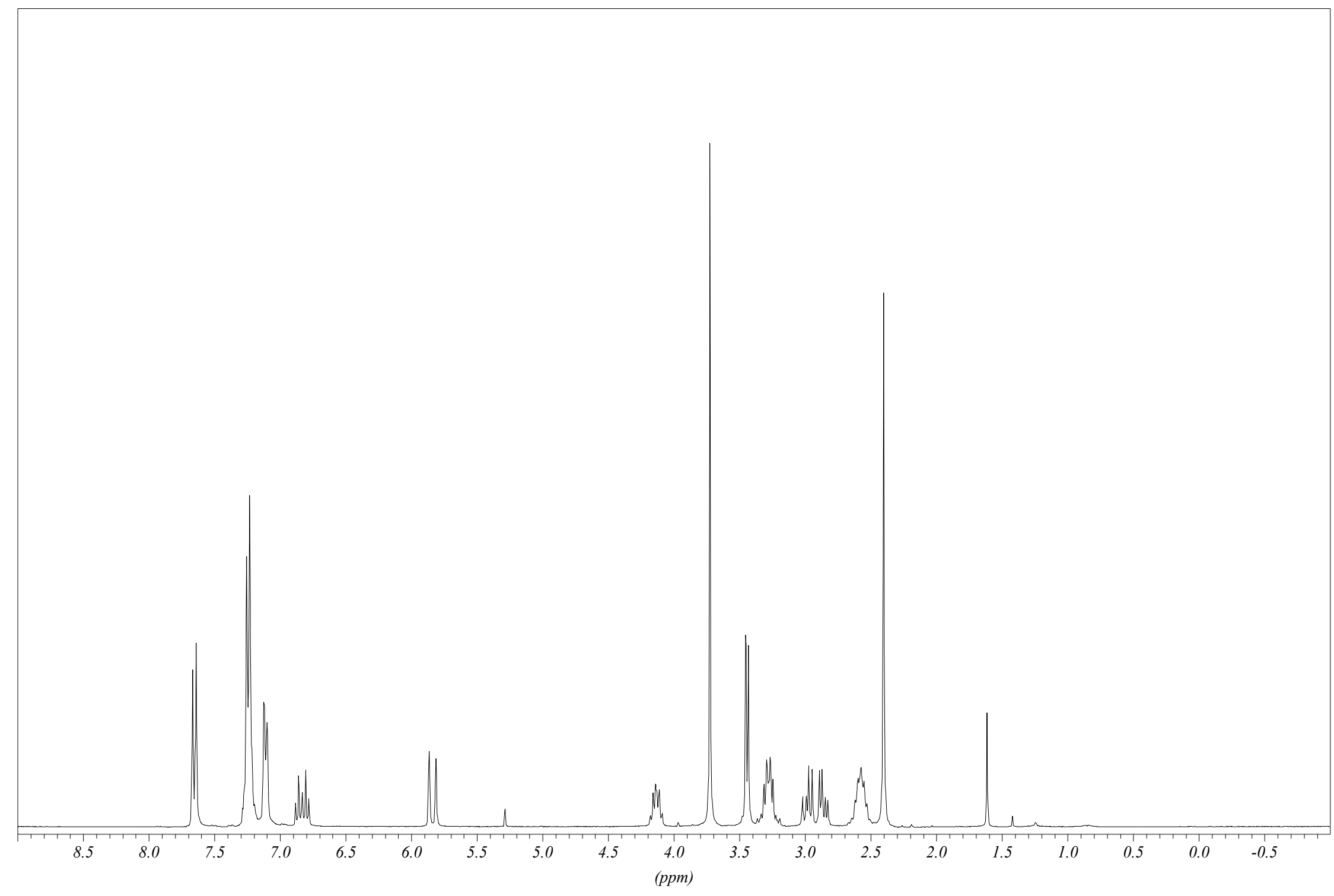

${ }^{1} \mathrm{H}$ NMR Spectrum (300 MHz) of $\mathbf{1 2 c}$ in $\mathrm{CDCl}_{3}$ 


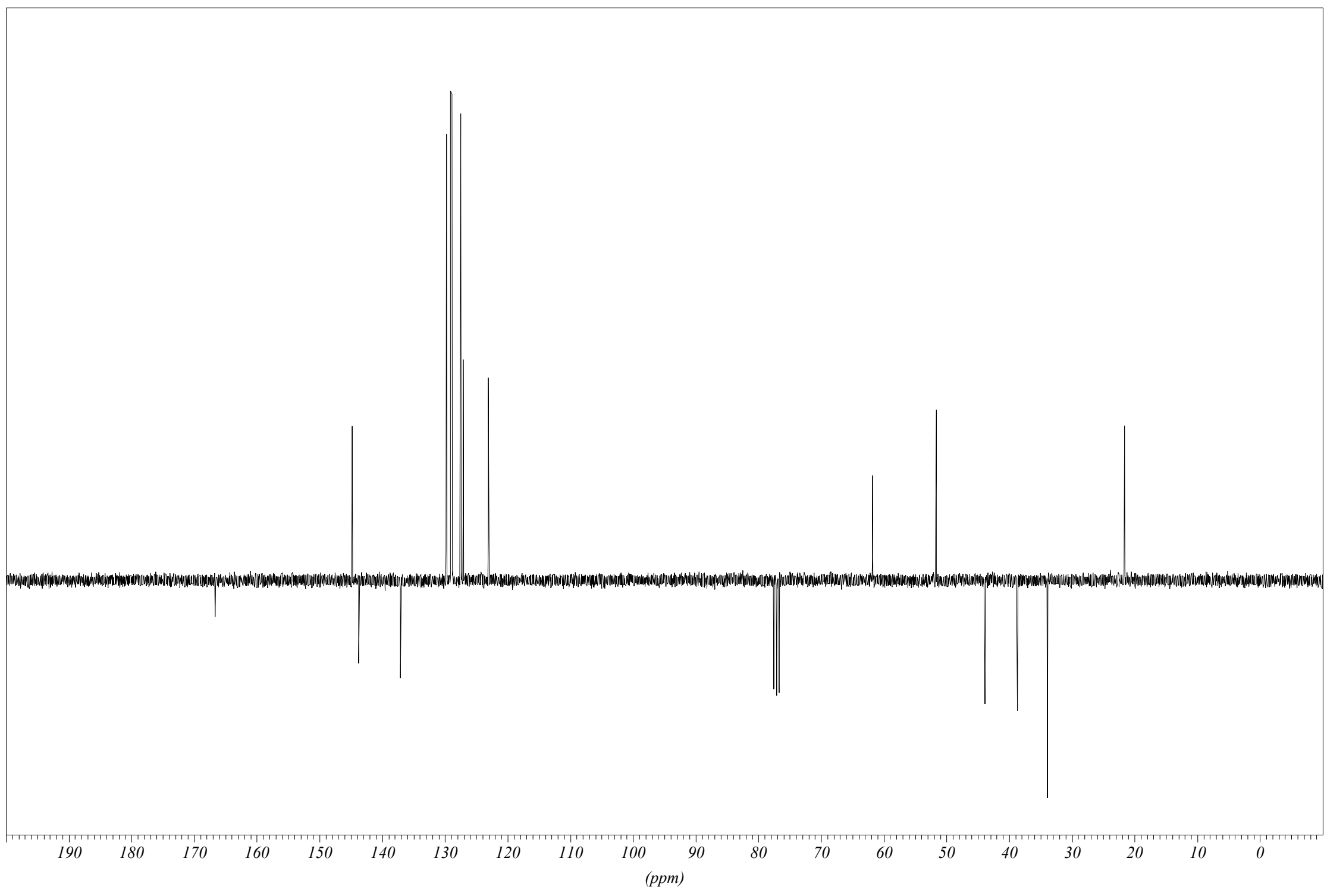

${ }^{13} \mathrm{C}$ NMR Spectrum (75 MHz) of $\mathbf{1 2 c}$ in $\mathrm{CDCl}_{3}$ 


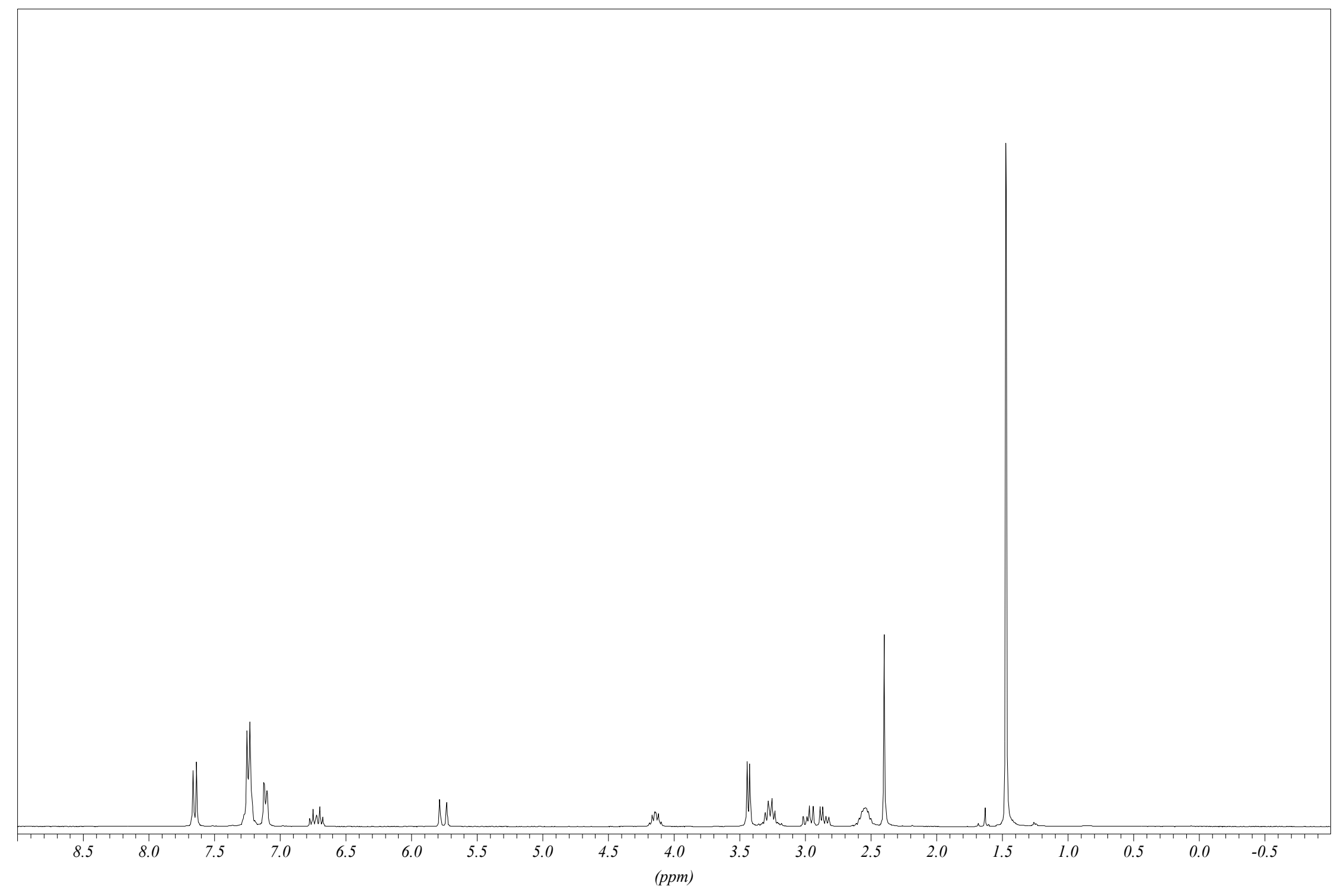

${ }^{1} \mathrm{H}$ NMR Spectrum (300 MHz) of $\mathbf{1 2 d}$ in $\mathrm{CDCl}_{3}$ 


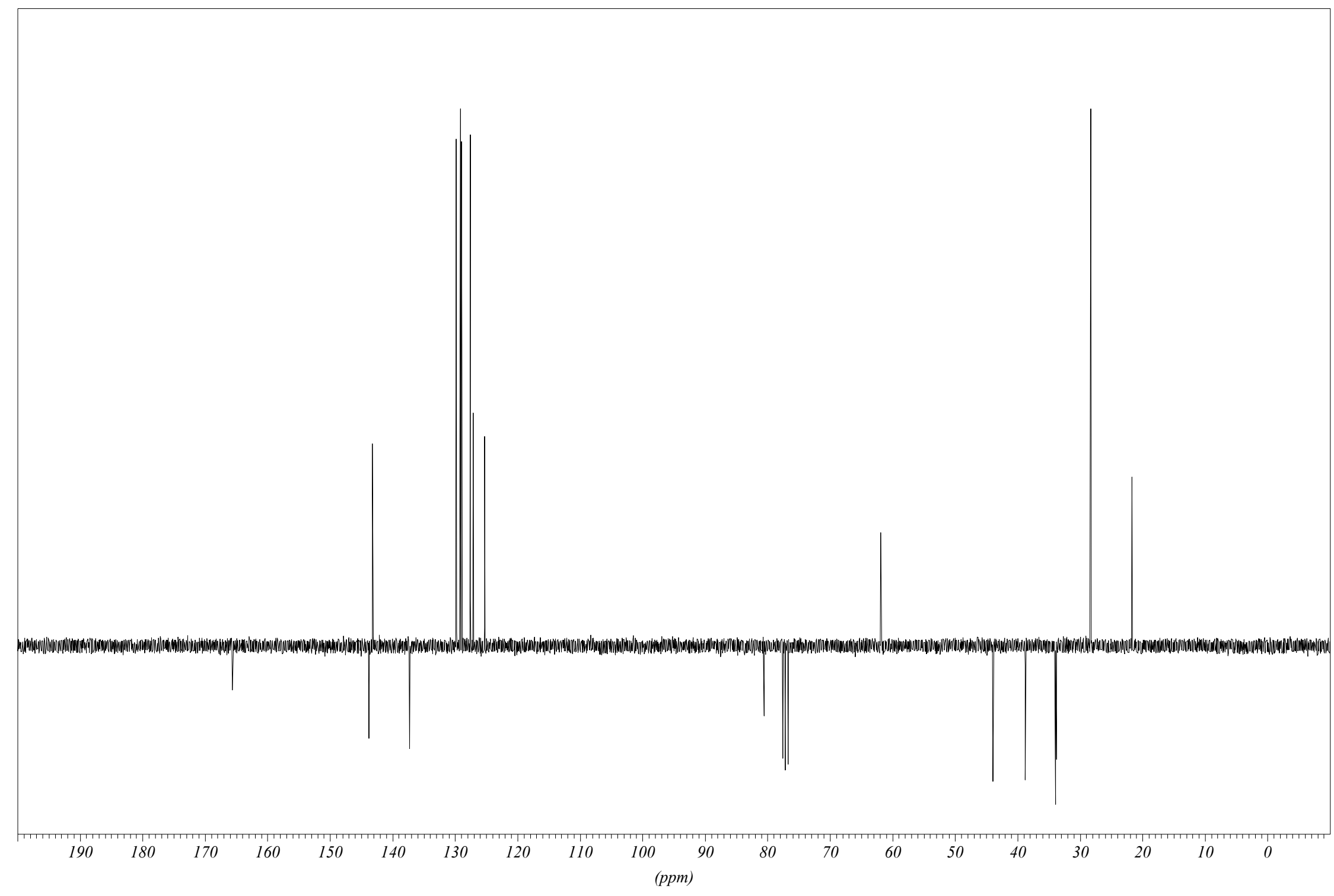

${ }^{13} \mathrm{C}$ NMR Spectrum (75 MHz) of $\mathbf{1 2 d}$ in $\mathrm{CDCl}_{3}$ 


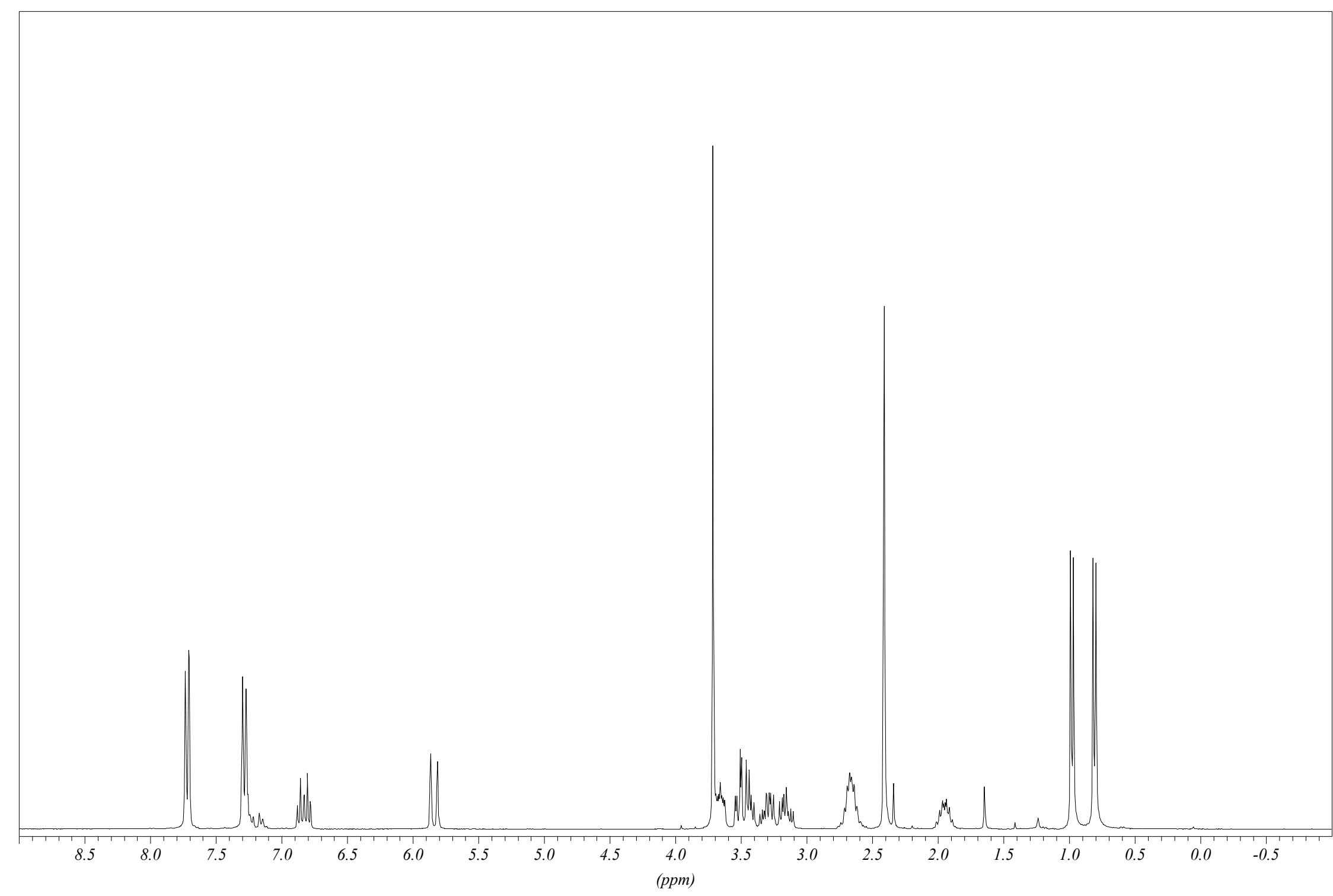

${ }^{1} \mathrm{H}$ NMR Spectrum (300 MHz) of $\mathbf{1 2 e}$ in $\mathrm{CDCl}_{3}$ 


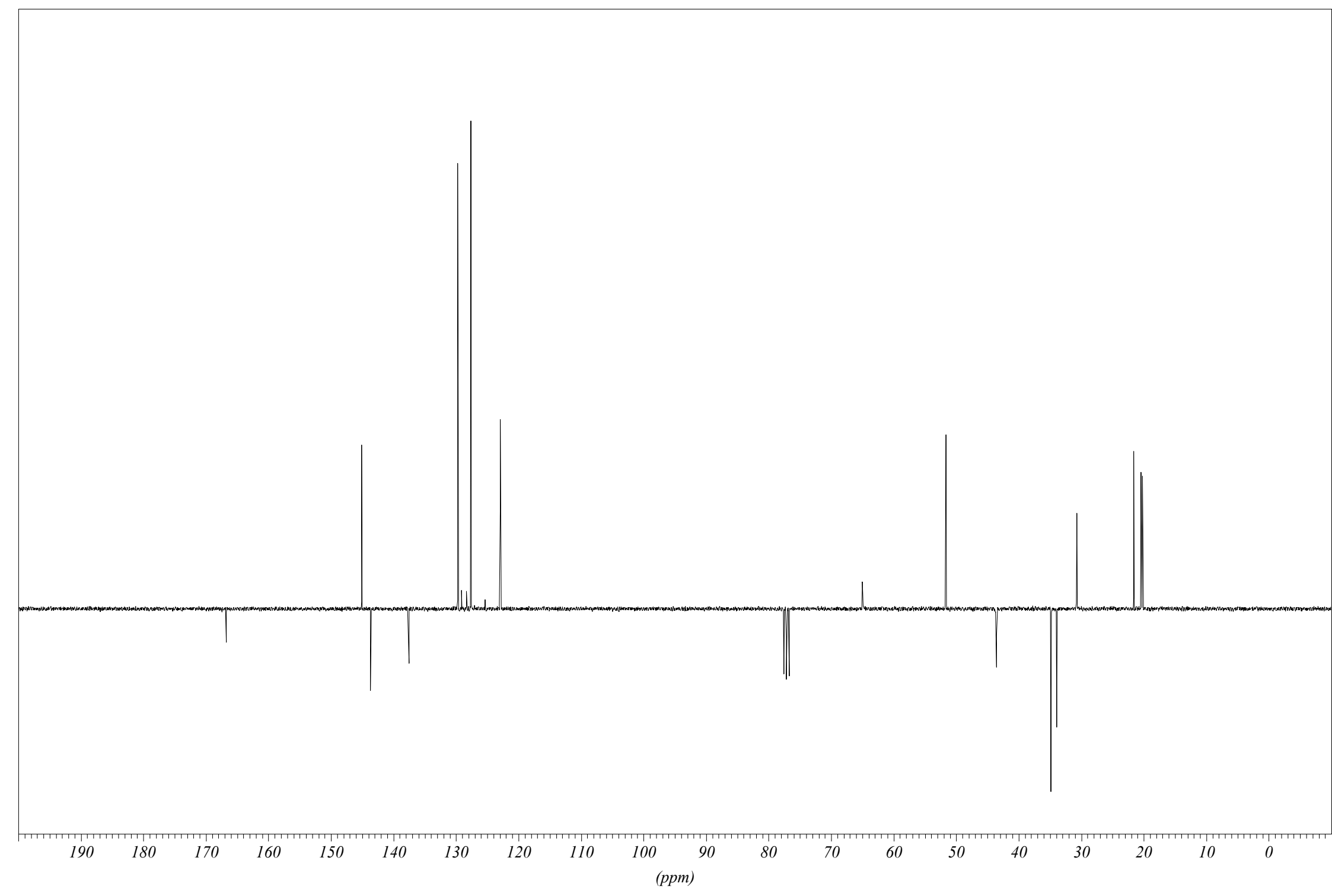

${ }^{13} \mathrm{C}$ NMR Spectrum (75 MHz) of $\mathbf{1 2 e}$ in $\mathrm{CDCl}_{3}$ 


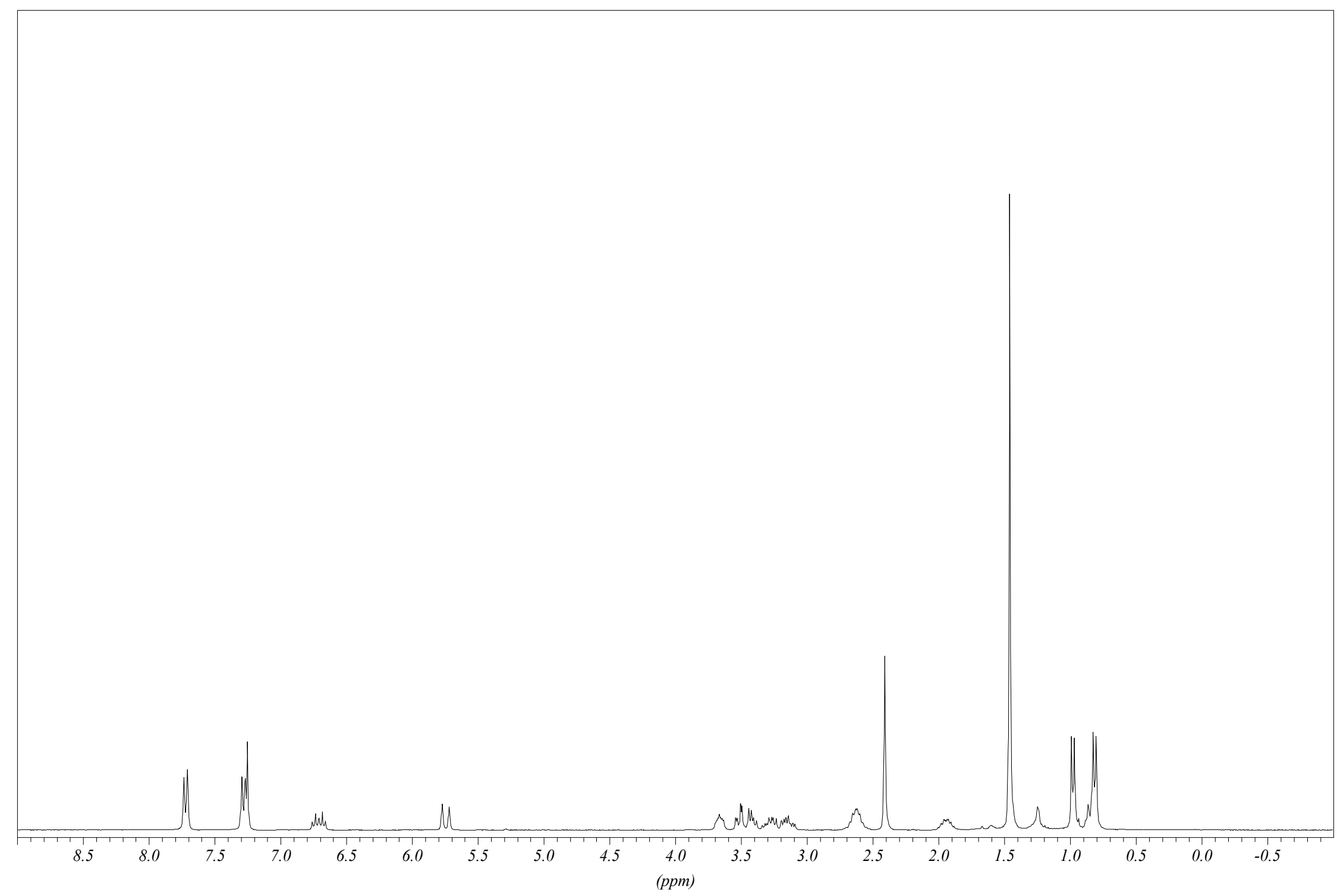

${ }^{1} \mathrm{H}$ NMR Spectrum (300 MHz) of $\mathbf{1 2 f}$ in $\mathrm{CDCl}_{3}$ 


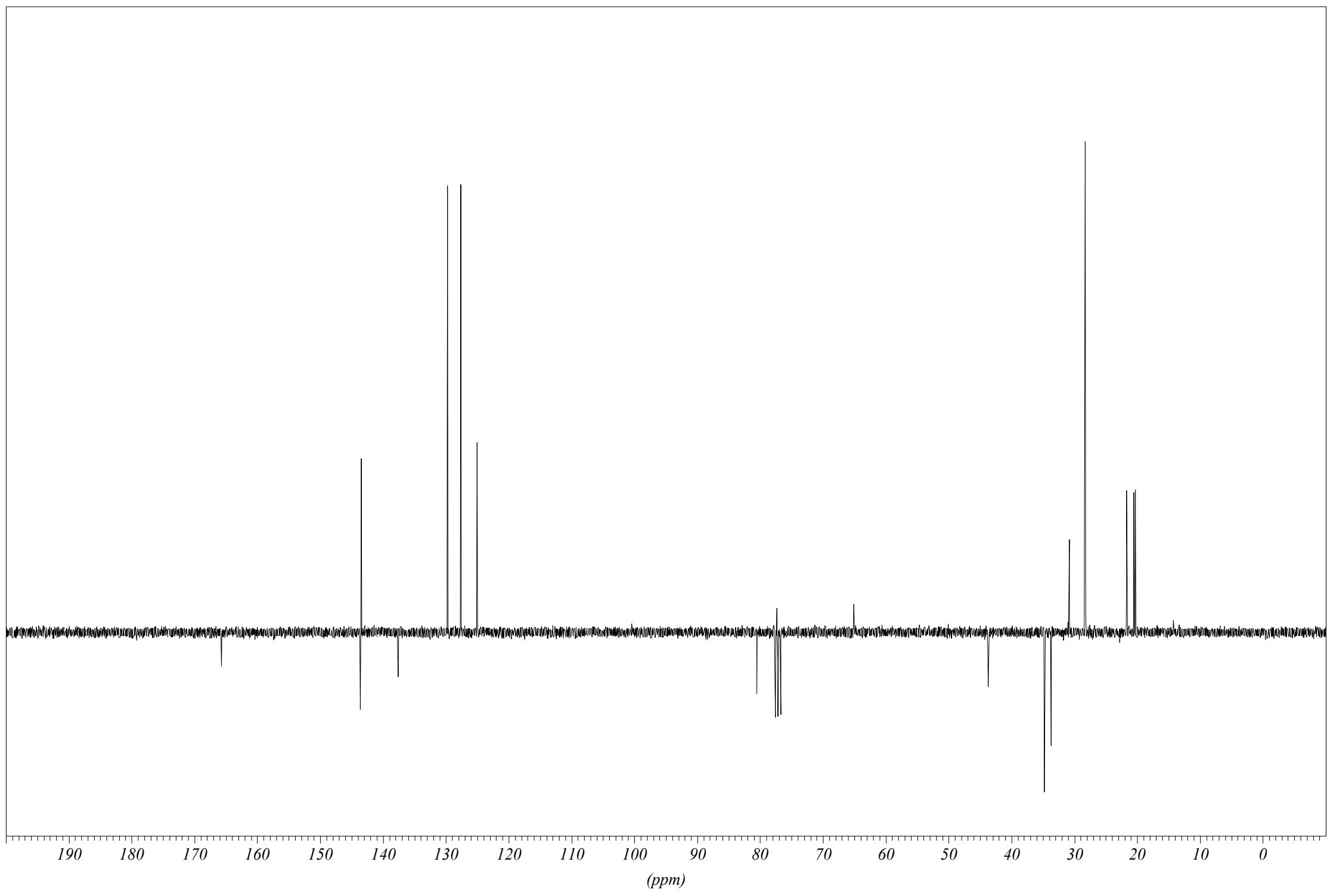

${ }^{13} \mathrm{C}$ NMR Spectrum $\left(75 \mathrm{MHz}\right.$ ) of $\mathbf{1 2 f}$ in $\mathrm{CDCl}_{3}$ 


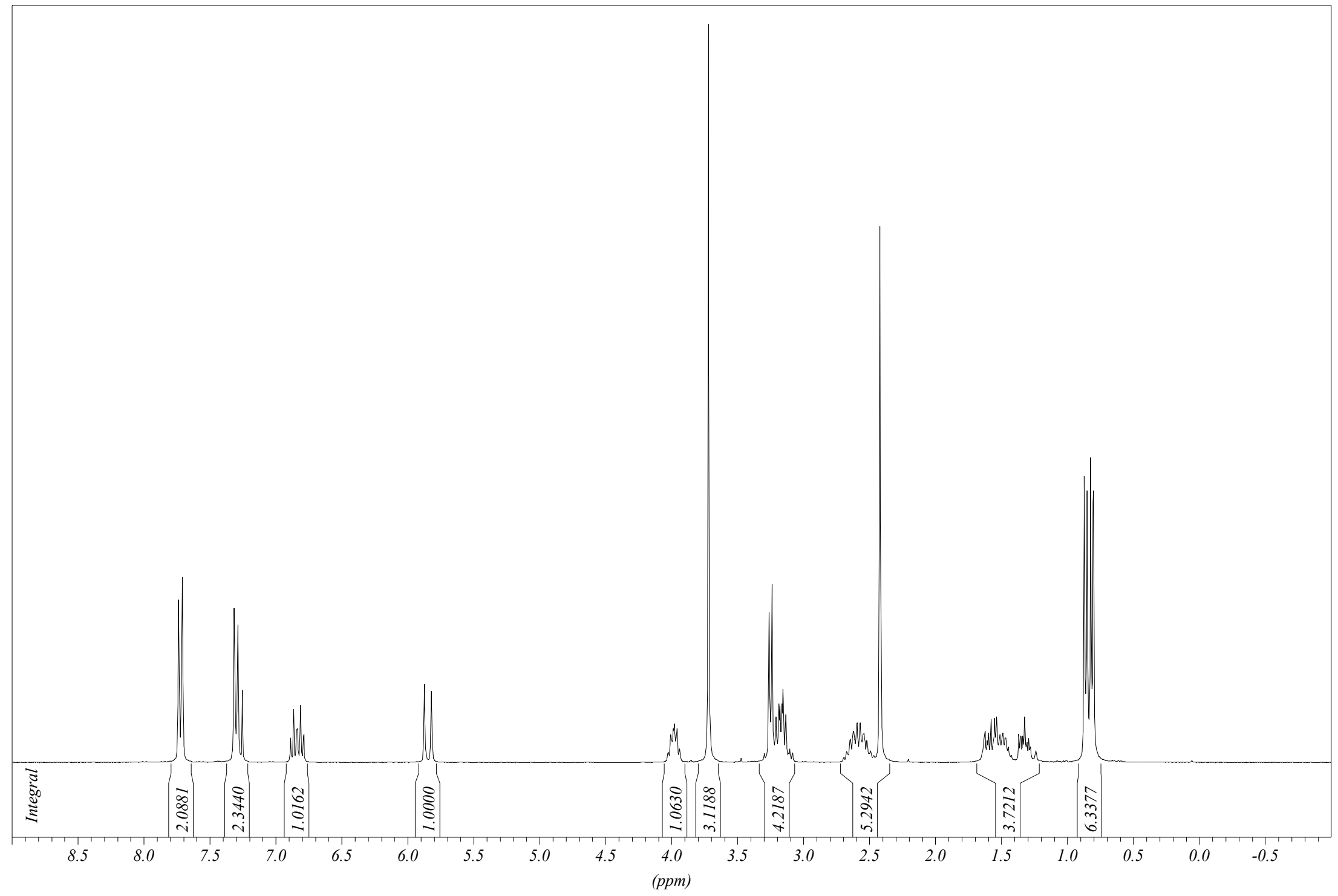

${ }^{1} \mathrm{H}$ NMR Spectrum (300 MHz) of $\mathbf{1 2 g}$ in $\mathrm{CDCl}_{3}$ 


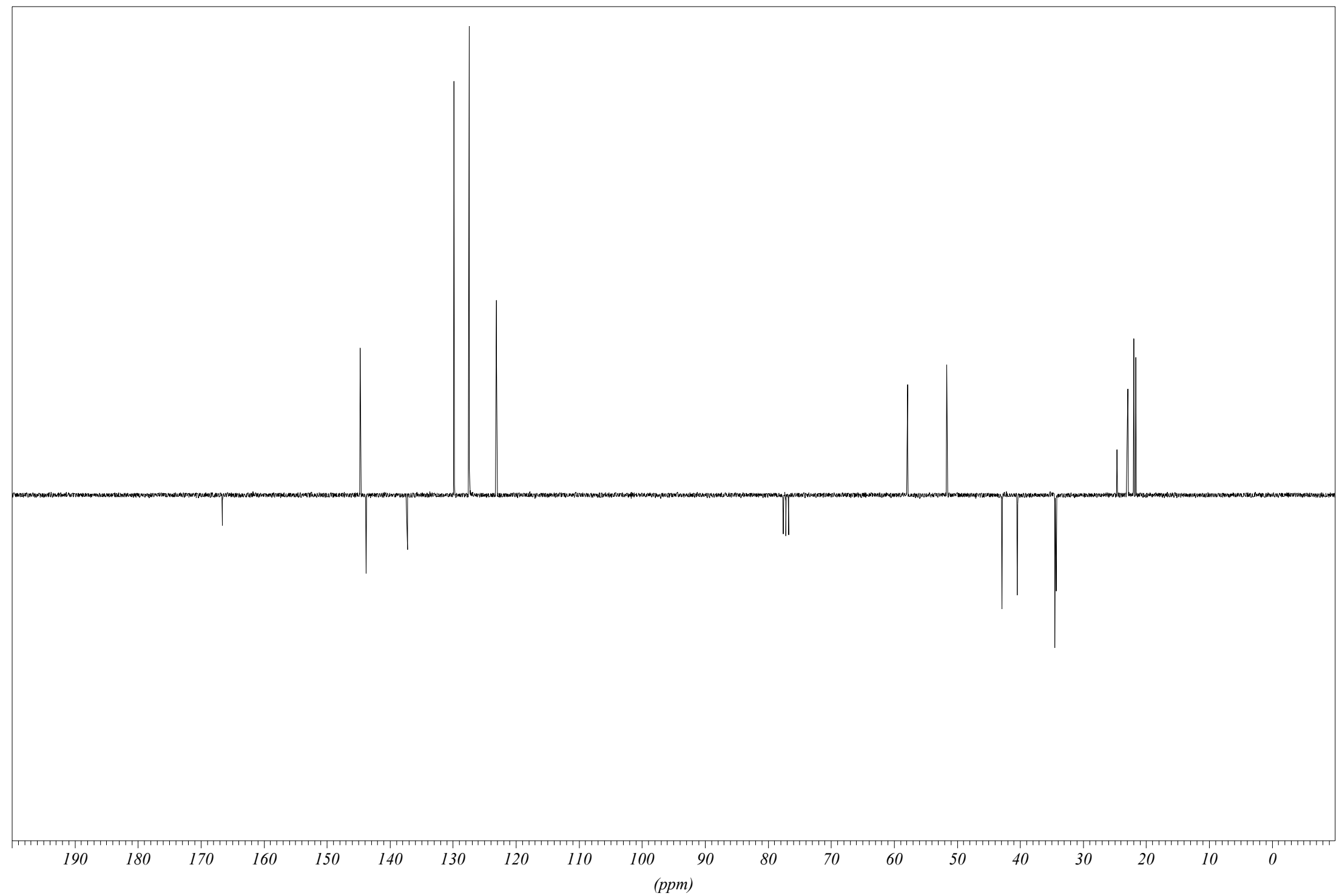

${ }^{13} \mathrm{C}$ NMR Spectrum (75 MHz) of $\mathbf{1 2 g}$ in $\mathrm{CDCl}_{3}$ 


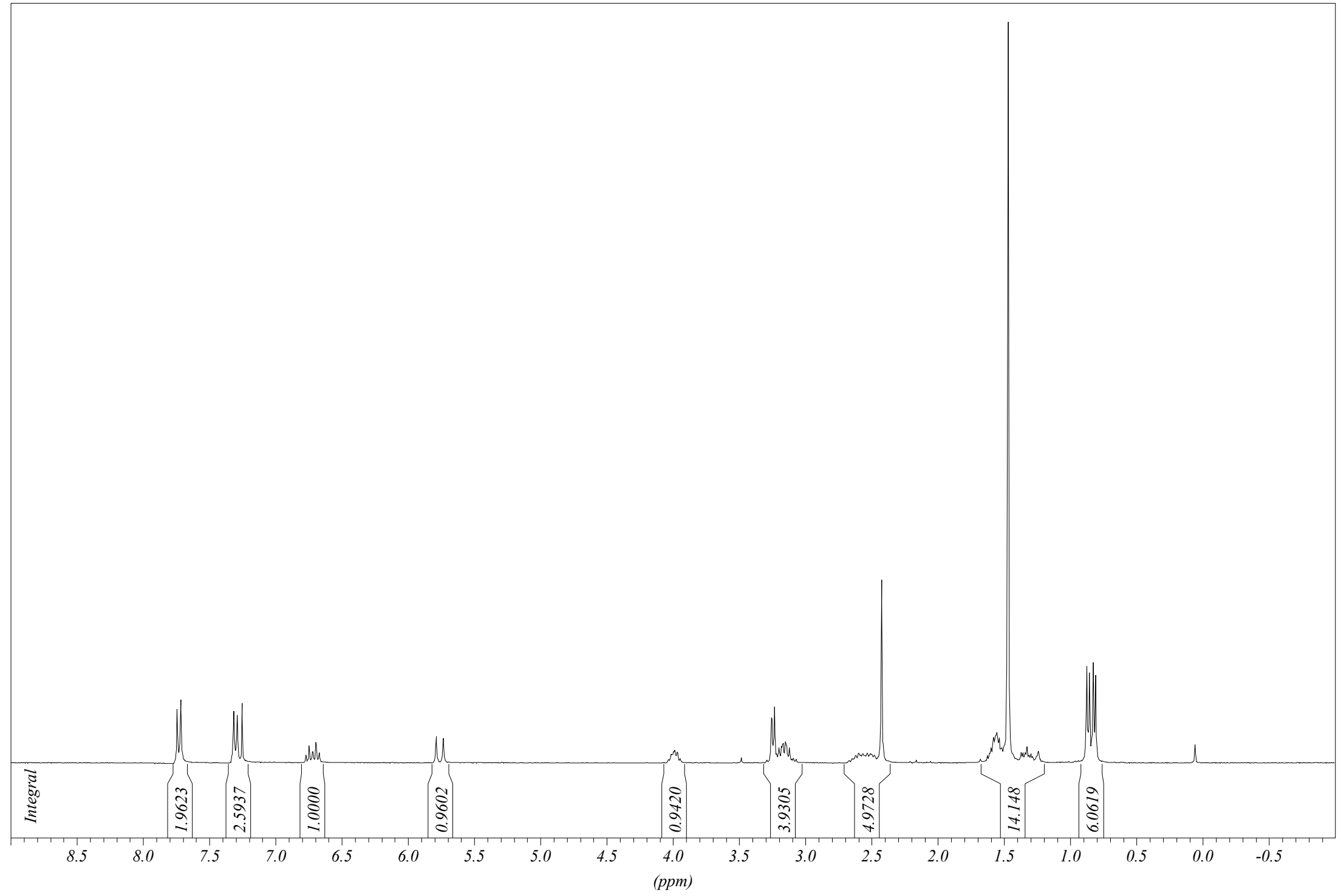

${ }^{1} \mathrm{H}$ NMR Spectrum (300 MHz) of $\mathbf{1 2 h}$ in $\mathrm{CDCl}_{3}$ 


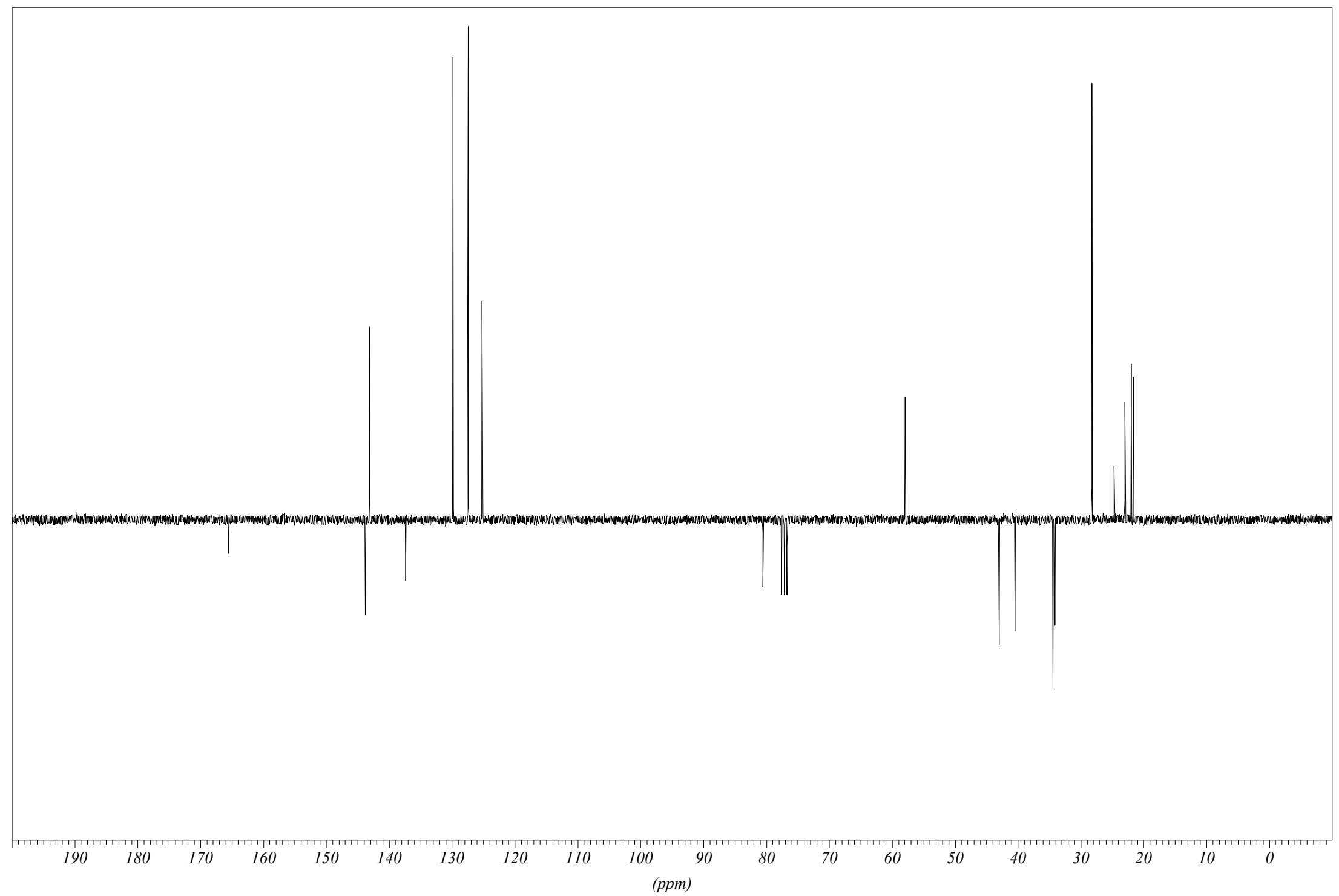

${ }^{13} \mathrm{C}$ NMR Spectrum (75 MHz) of $\mathbf{1 2 h}$ in $\mathrm{CDCl}_{3}$ 


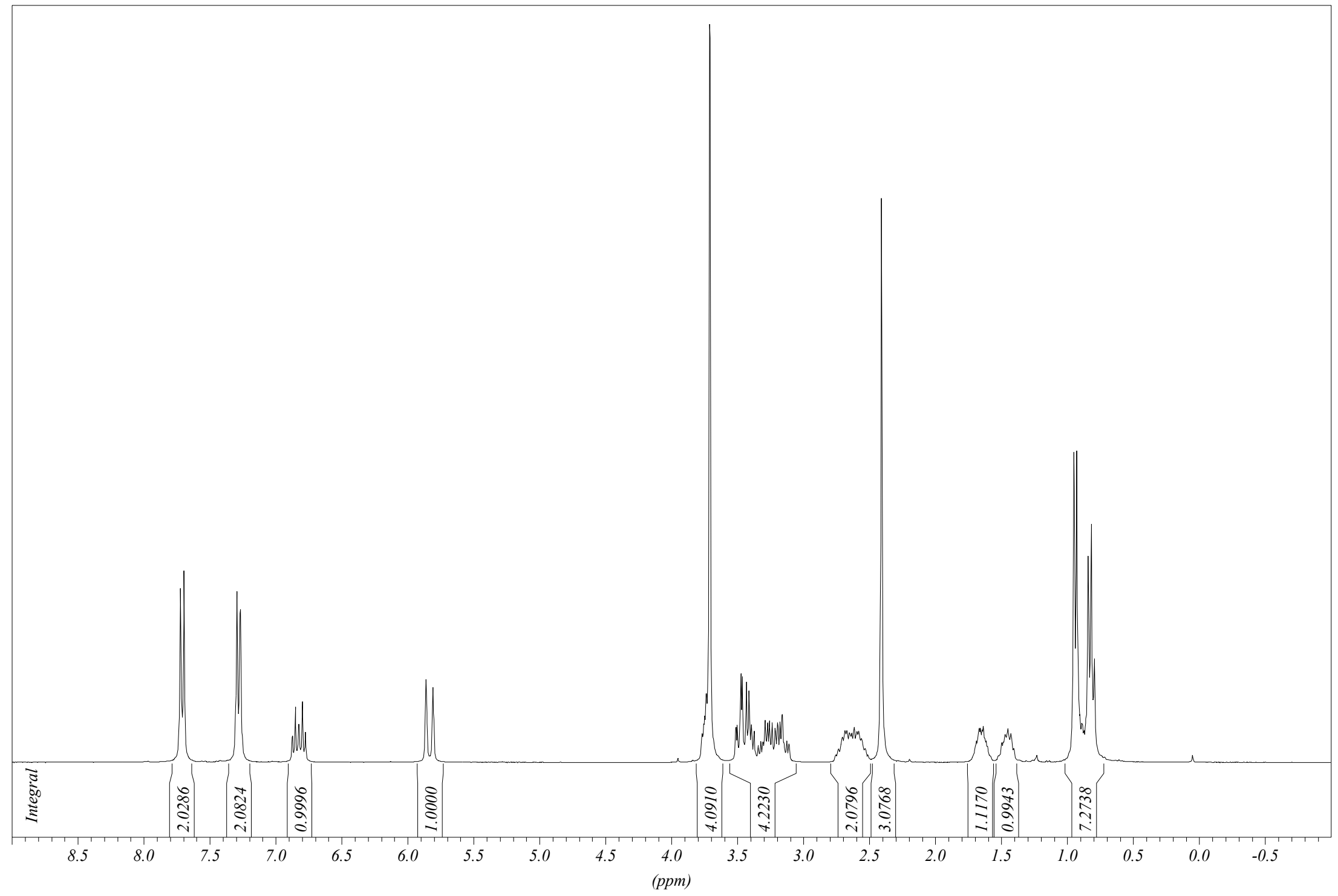

${ }^{1} \mathrm{H}$ NMR Spectrum (300 MHz) of $\mathbf{1 2 i}$ in $\mathrm{CDCl}_{3}$ 


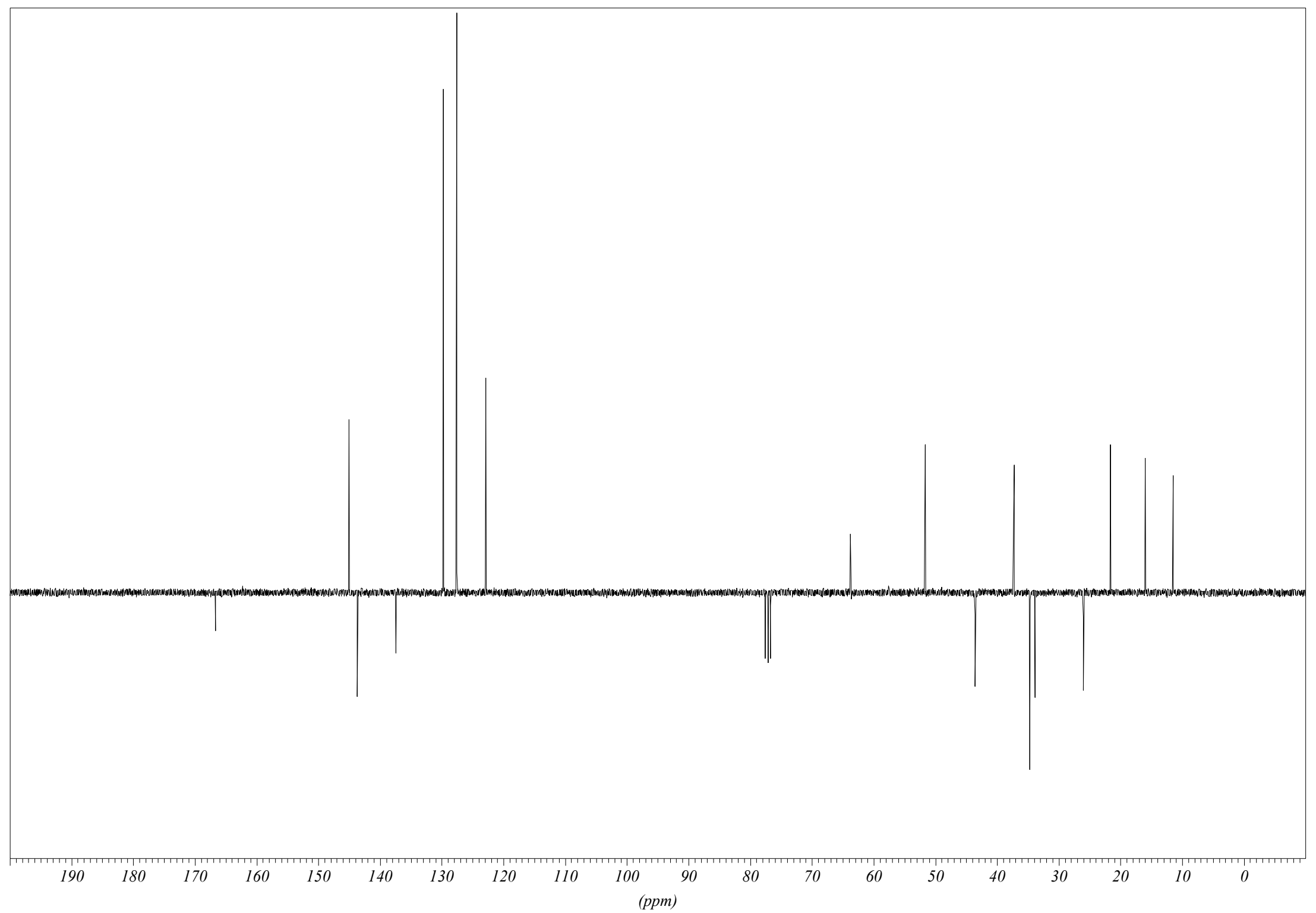

${ }^{13} \mathrm{C}$ NMR Spectrum (75 MHz) of $\mathbf{1 2 i}$ in $\mathrm{CDCl}_{3}$ 


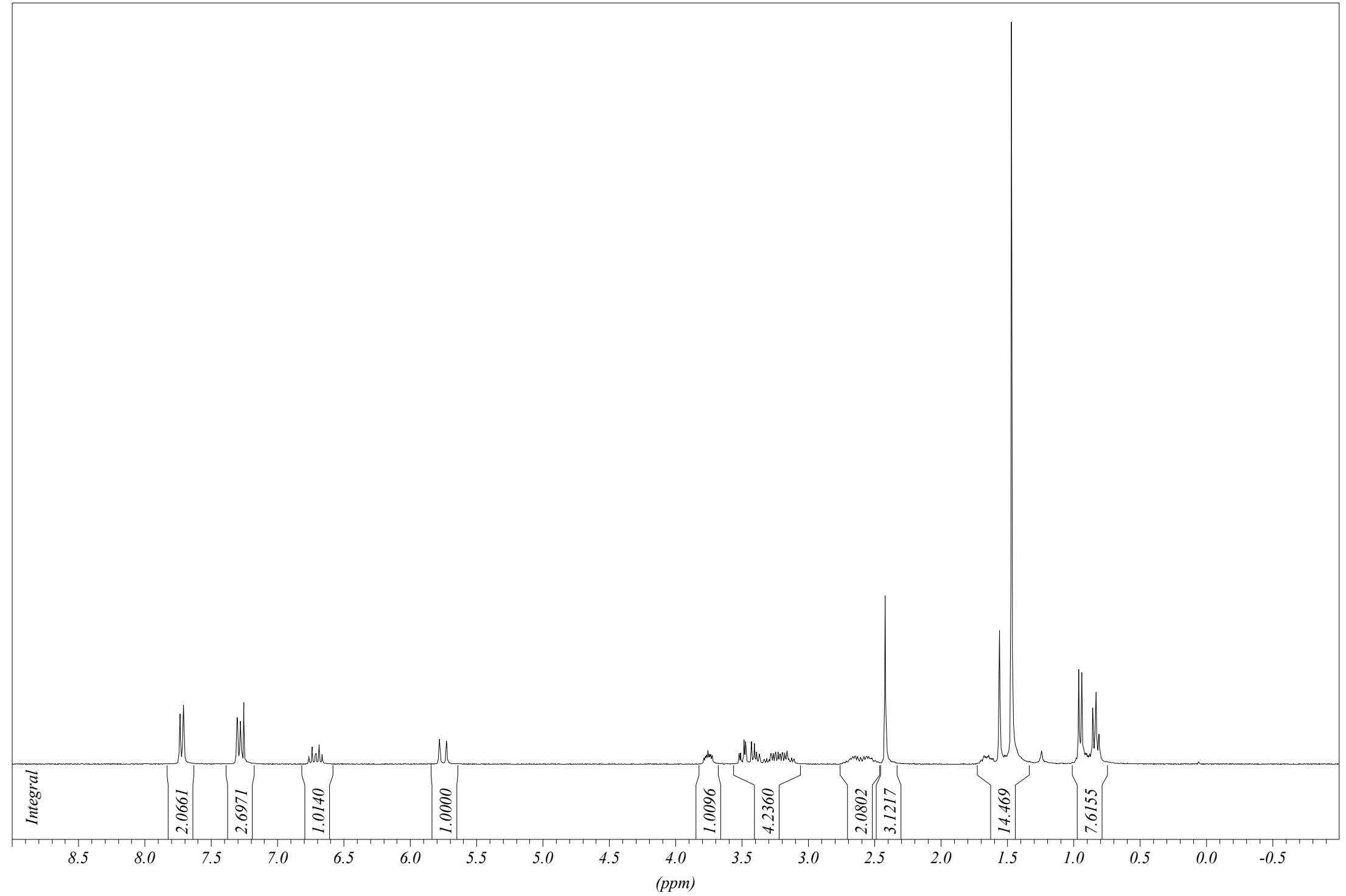

${ }^{1} \mathrm{H}$ NMR Spectrum $(300 \mathrm{MHz})$ of $\mathbf{1 2} \mathbf{j}$ in $\mathrm{CDCl}_{3}$ 


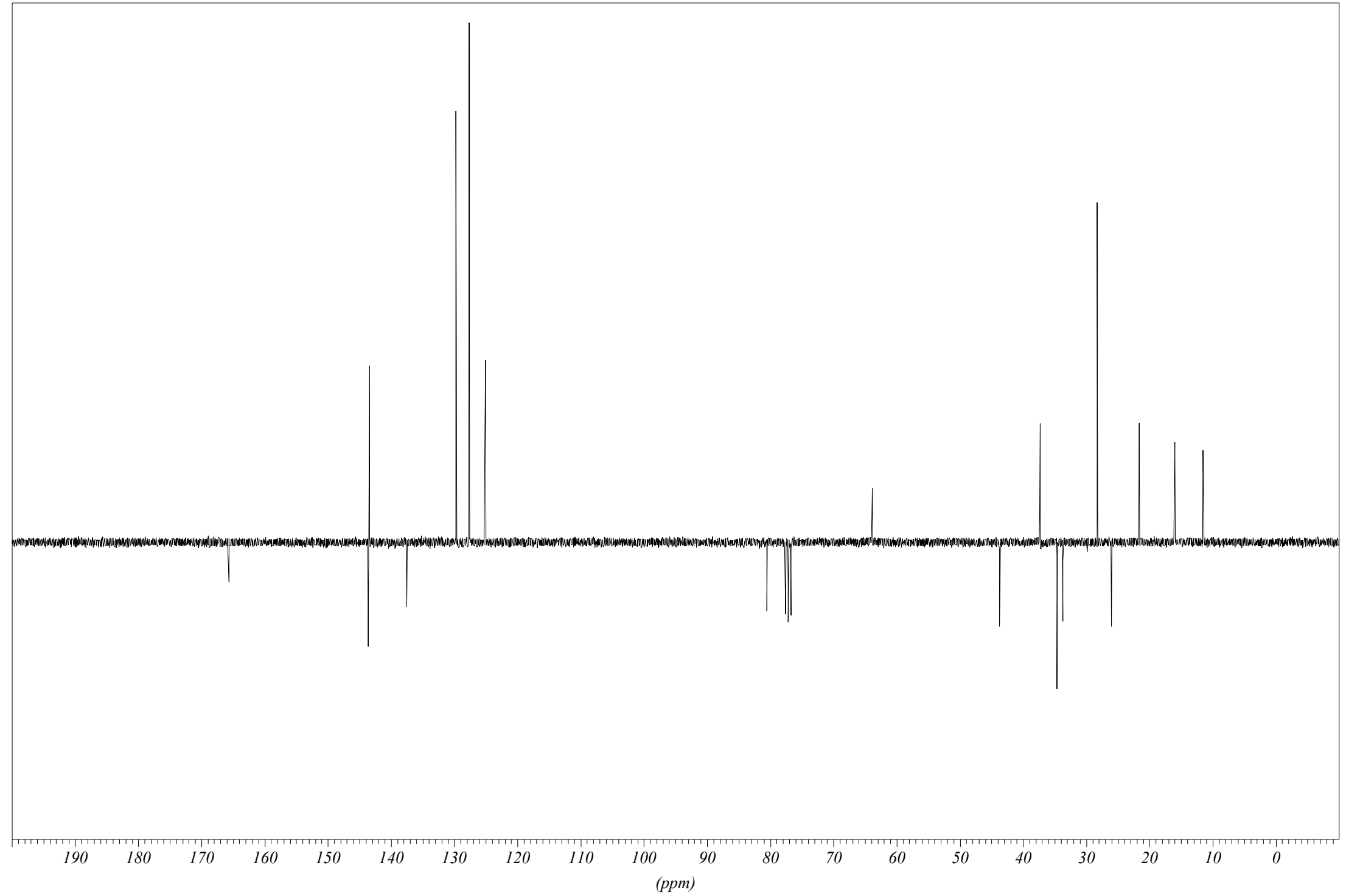

${ }^{13} \mathrm{C}$ NMR Spectrum (75 MHz) of $\mathbf{1 2} \mathbf{j}$ in $\mathrm{CDCl}_{3}$ 


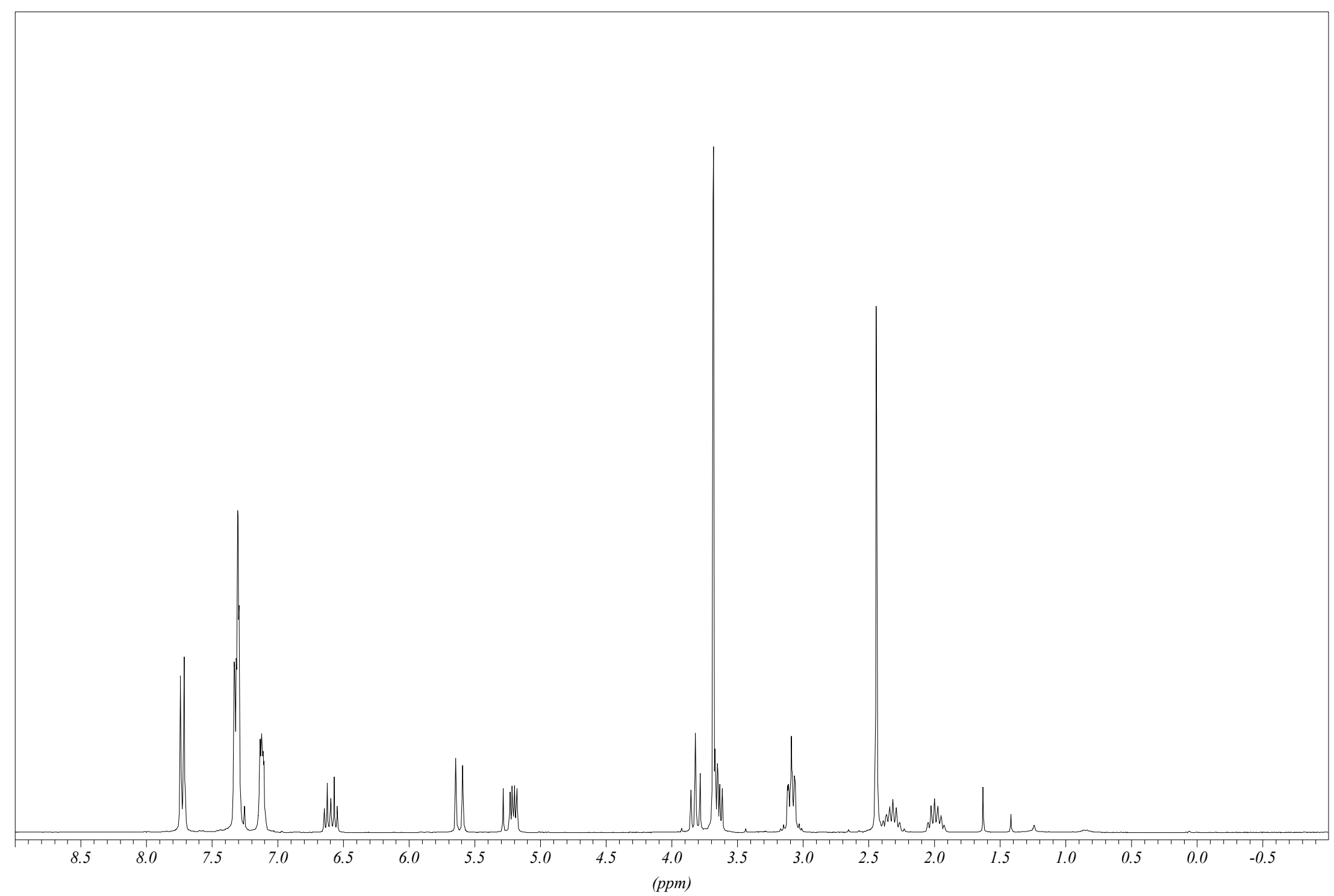

${ }^{1} \mathrm{H}$ NMR Spectrum (300 MHz) of $\mathbf{1 2} \mathbf{k}$ in $\mathrm{CDCl}_{3}$ 


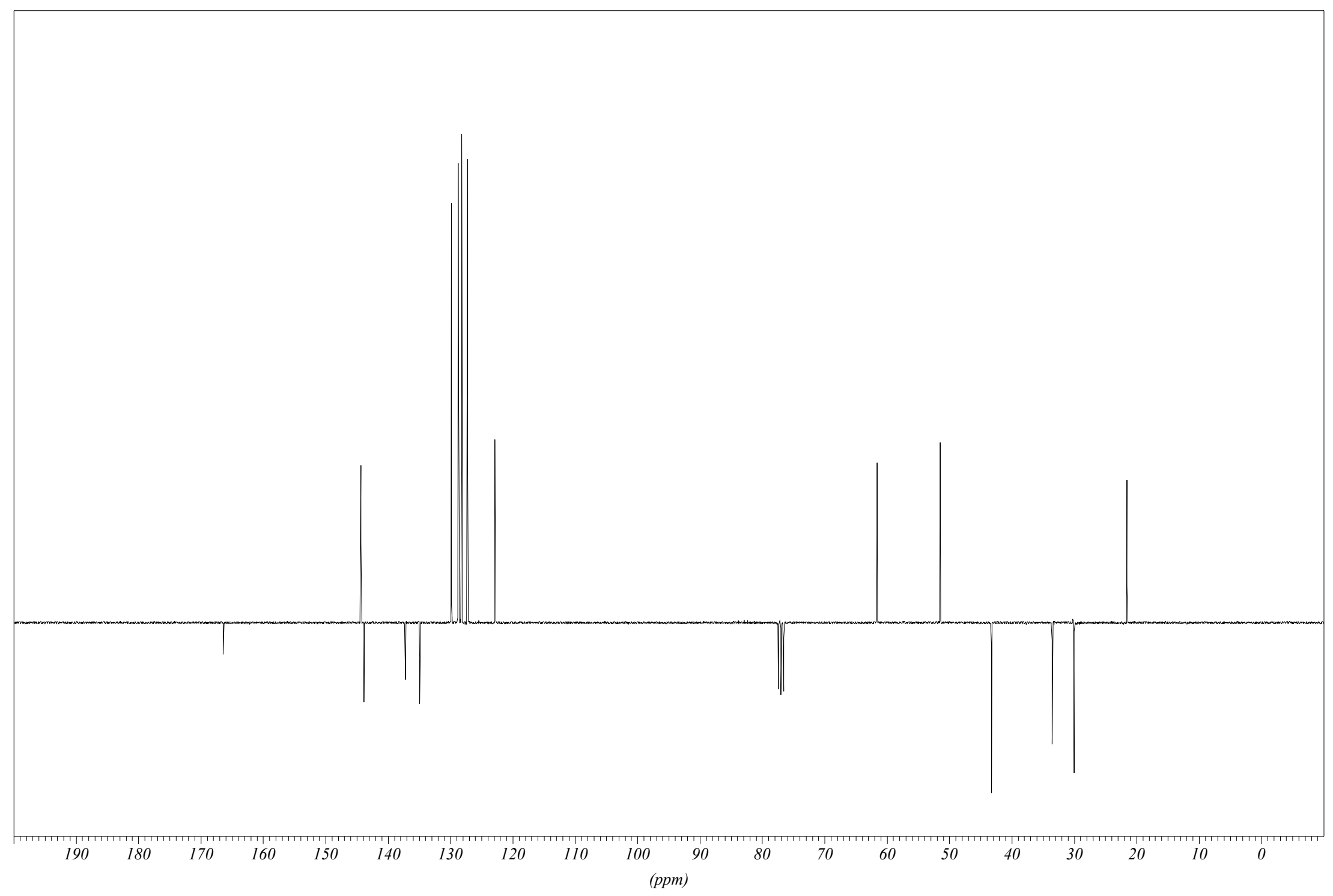

${ }^{13} \mathrm{C}$ NMR Spectrum (75 MHz) of $\mathbf{1 2} \mathbf{k}$ in $\mathrm{CDCl}_{3}$ 


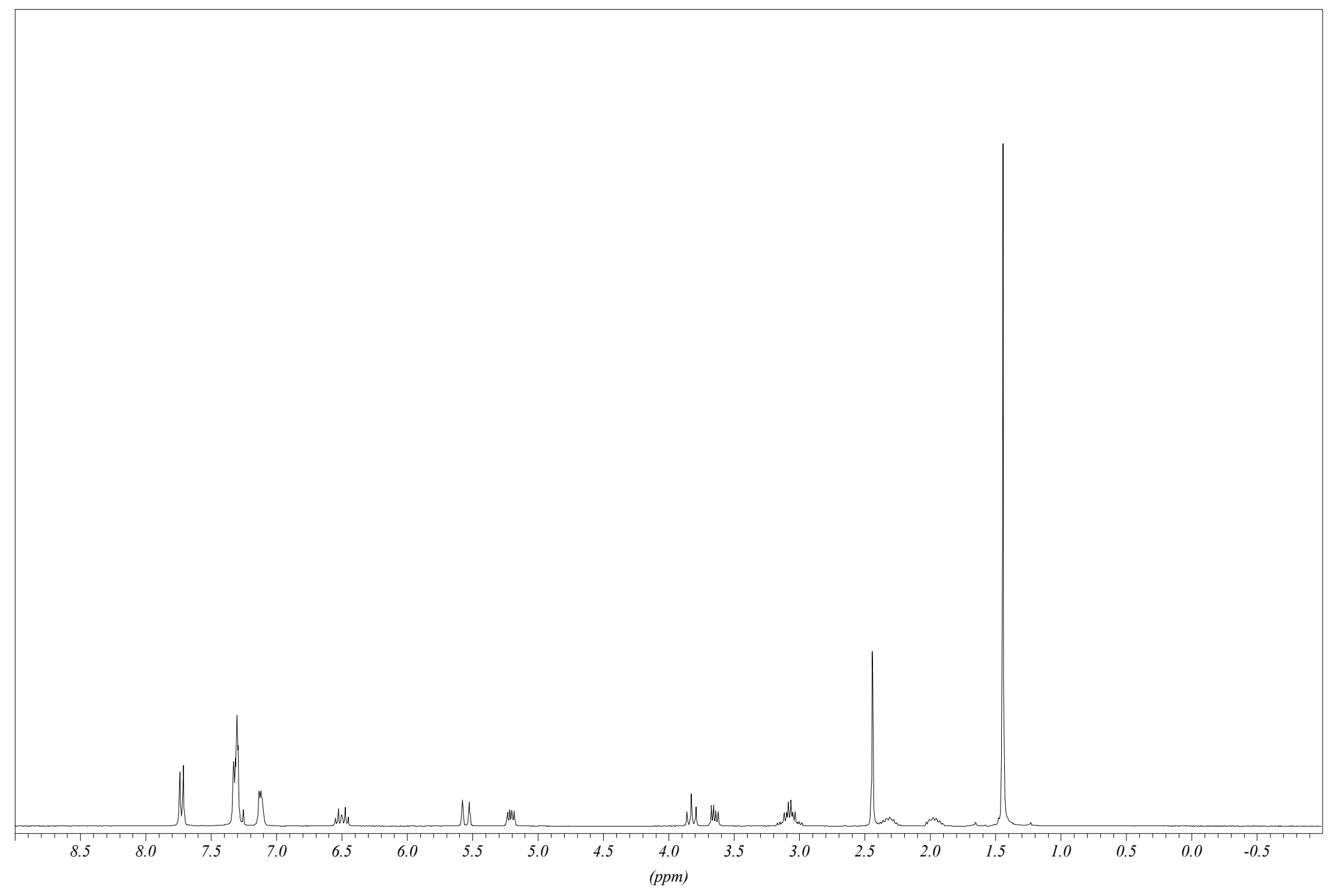

${ }^{1} \mathrm{H}$ NMR Spectrum (300 MHz) of $\mathbf{1 2 l}$ in $\mathrm{CDCl}_{3}$ 


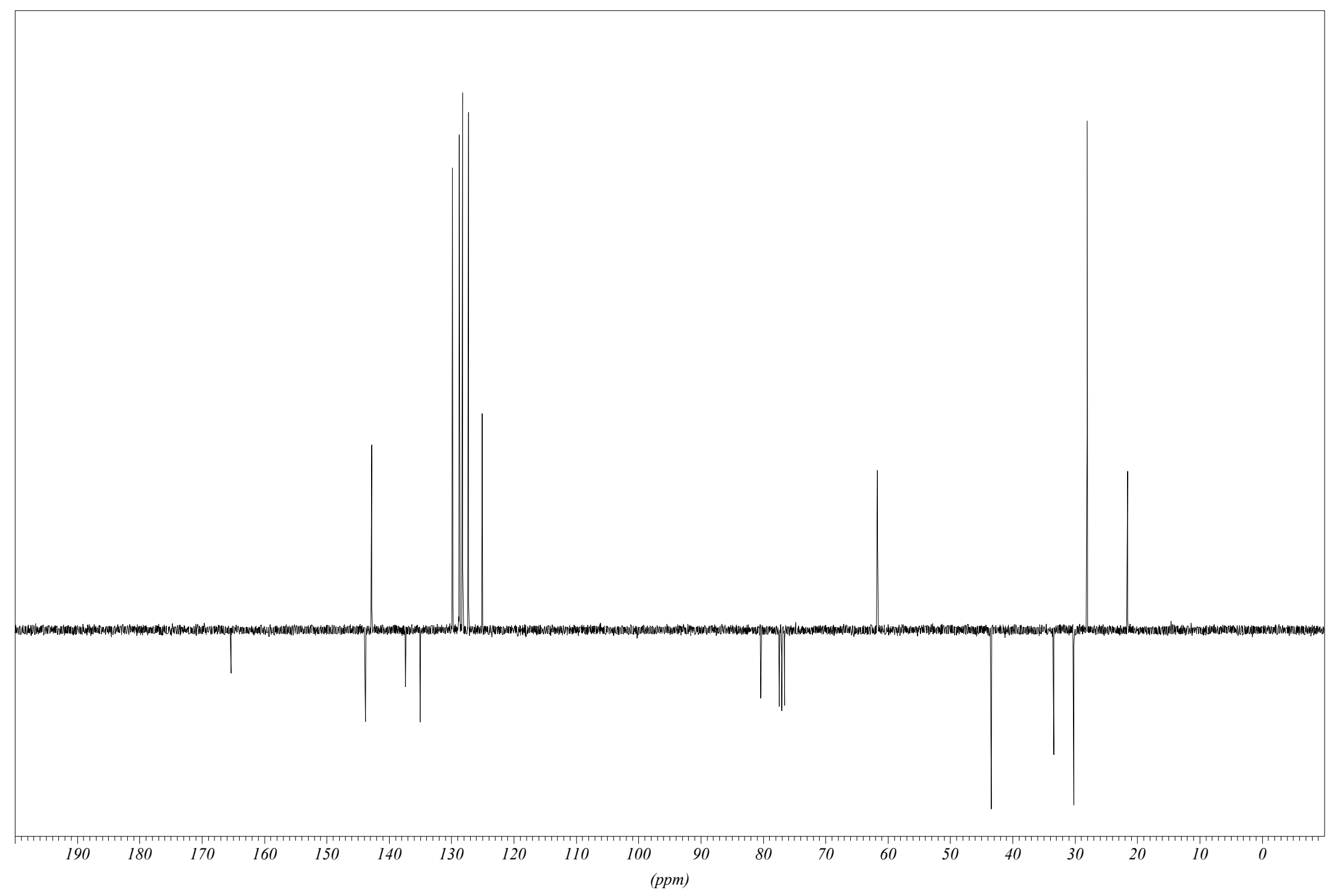

${ }^{13} \mathrm{C}$ NMR Spectrum (75 MHz) of $\mathbf{1 2 l}$ in $\mathrm{CDCl}_{3}$ 


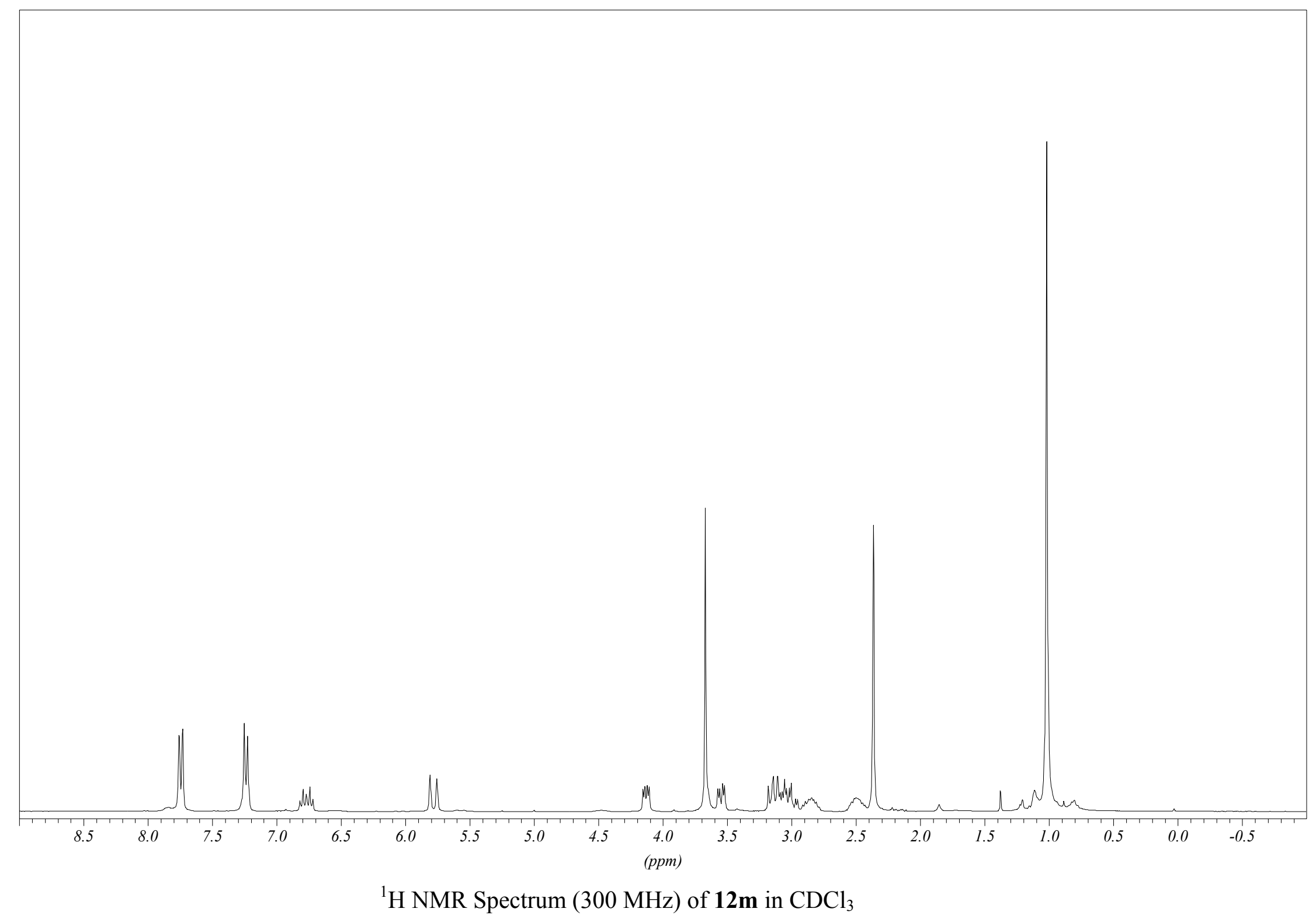




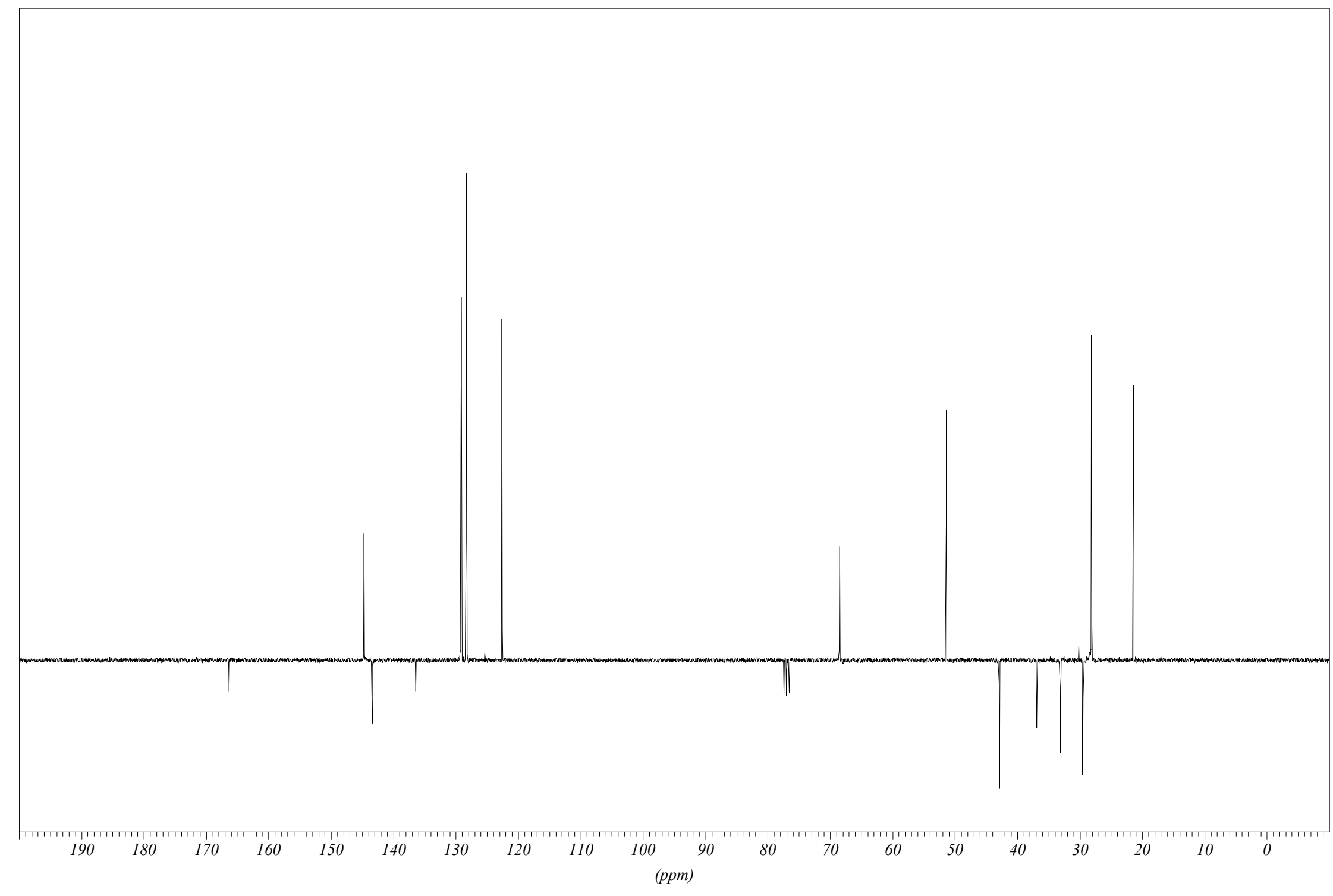

${ }^{13} \mathrm{C}$ NMR Spectrum (75 MHz) of $\mathbf{1 2} \mathbf{m}$ in $\mathrm{CDCl}_{3}$ 


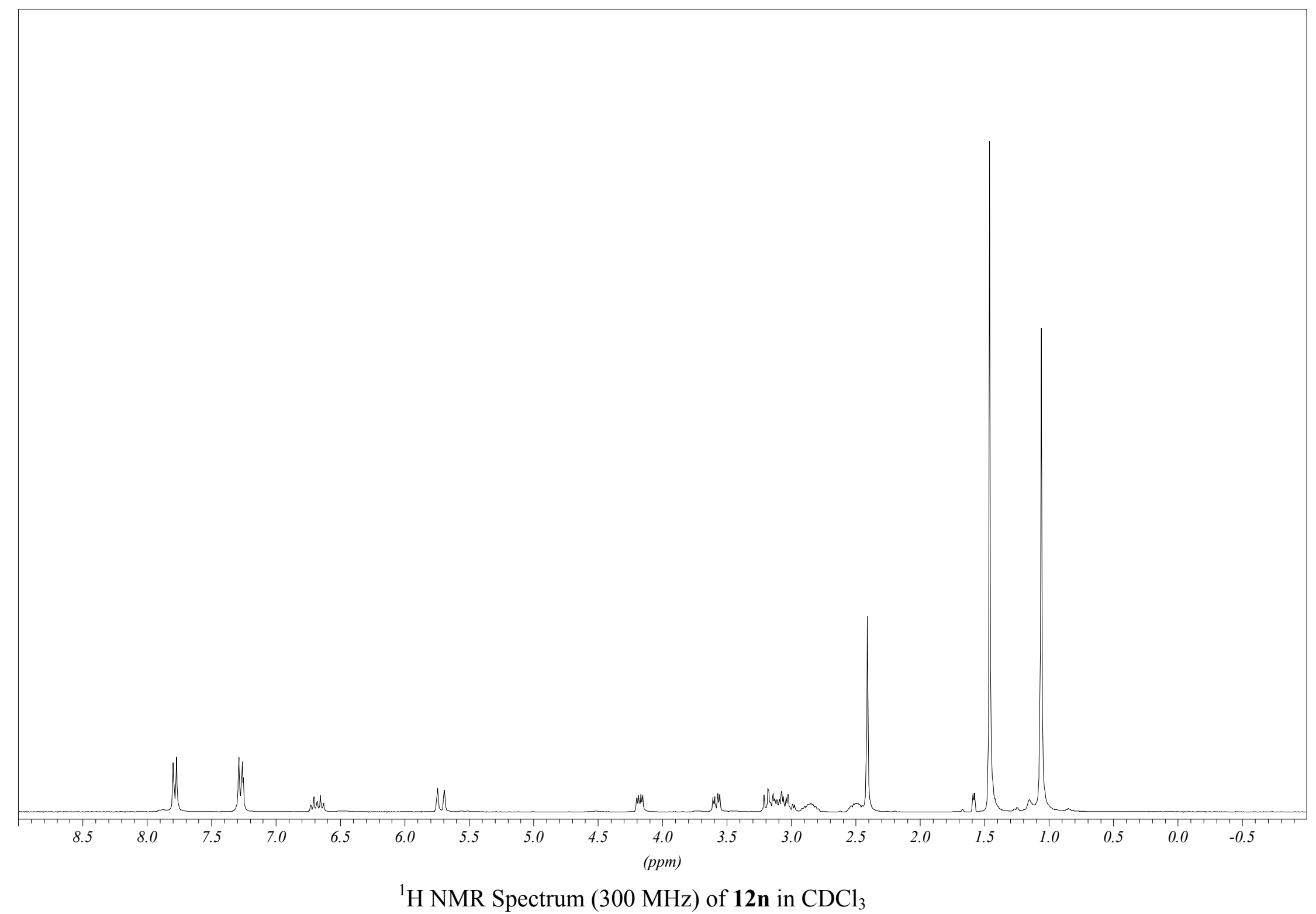




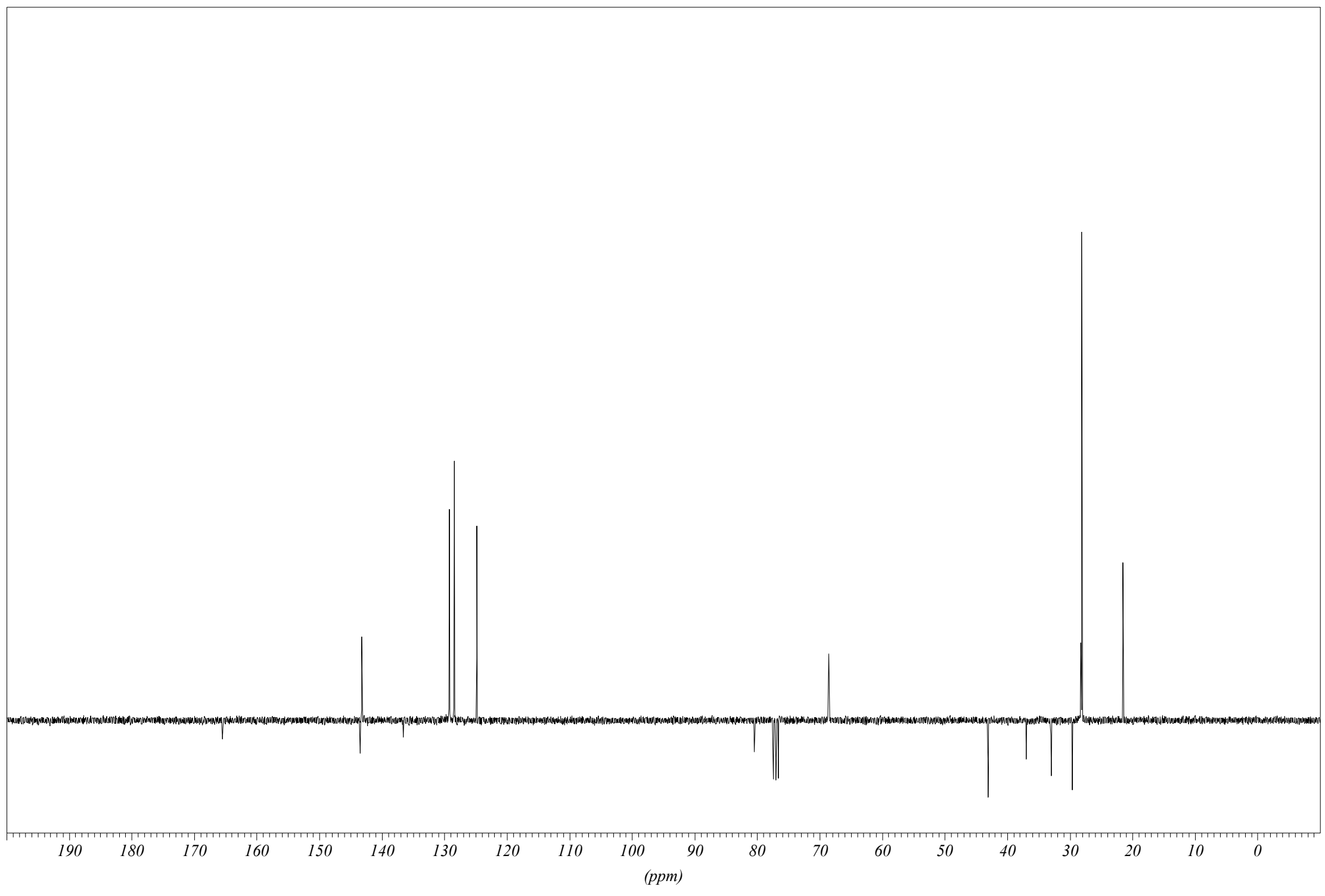

${ }^{13} \mathrm{C}$ NMR Spectrum $(75 \mathrm{MHz})$ of $\mathbf{1 2 n}$ in $\mathrm{CDCl}_{3}$ 


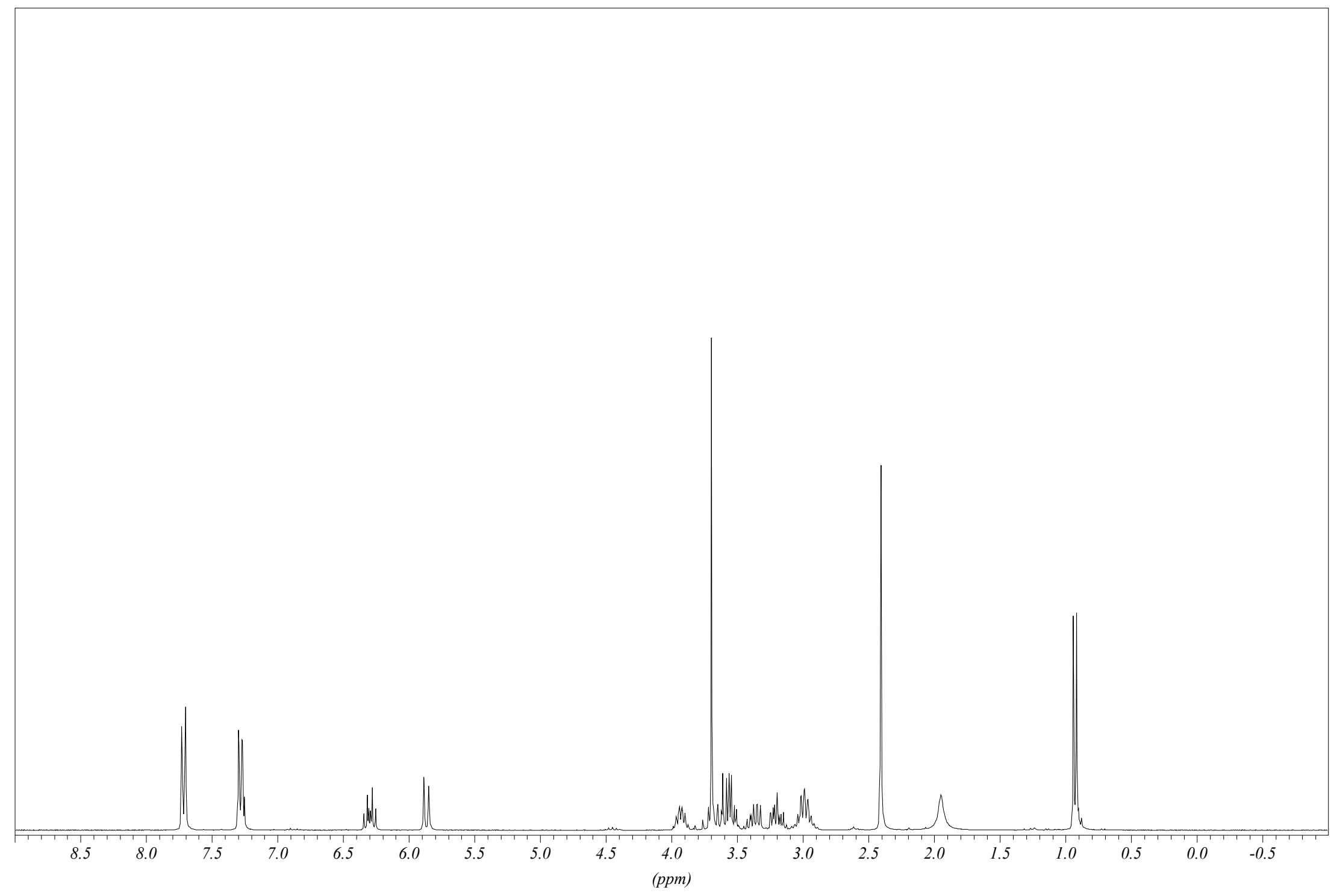

${ }^{1} \mathrm{H}$ NMR Spectrum (300 MHz) of $\mathbf{1 4 a}$ in $\mathrm{CDCl}_{3}$ 


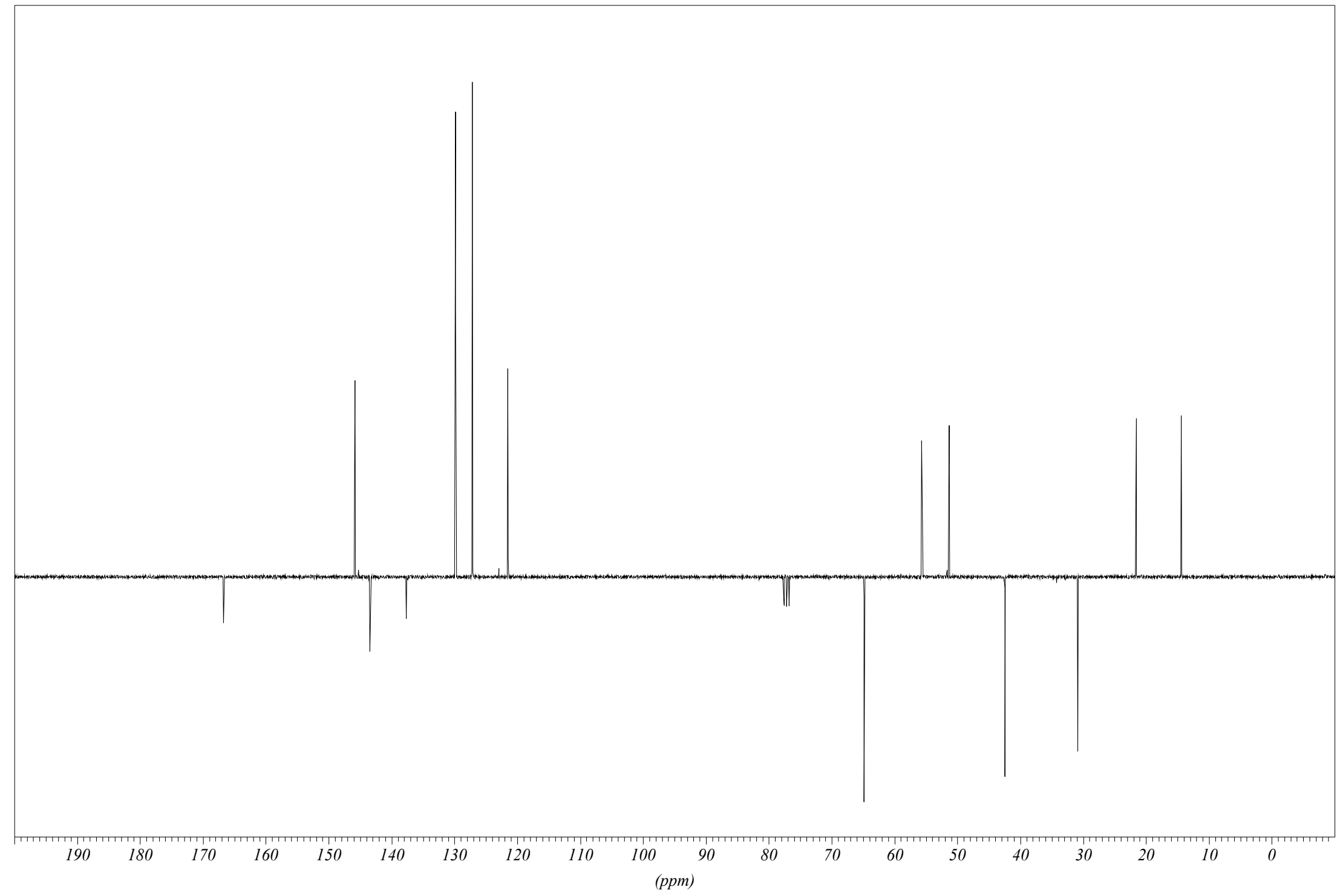

${ }^{13} \mathrm{C}$ NMR Spectrum (75 MHz) of $\mathbf{1 4 a}$ in $\mathrm{CDCl}_{3}$ 


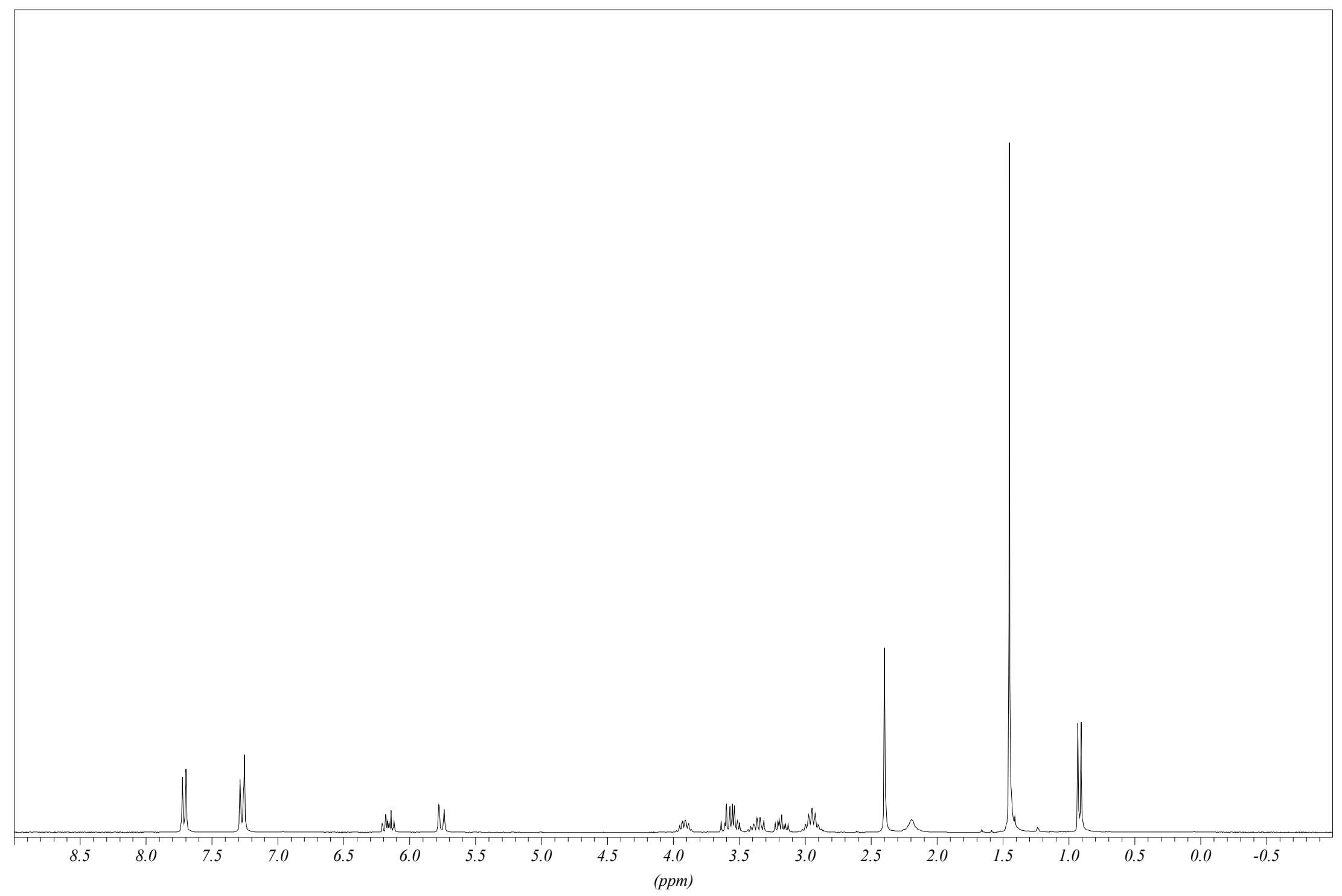

${ }^{1} \mathrm{H}$ NMR Spectrum (300 MHz) of $\mathbf{1 4 b}$ in $\mathrm{CDCl}_{3}$ 


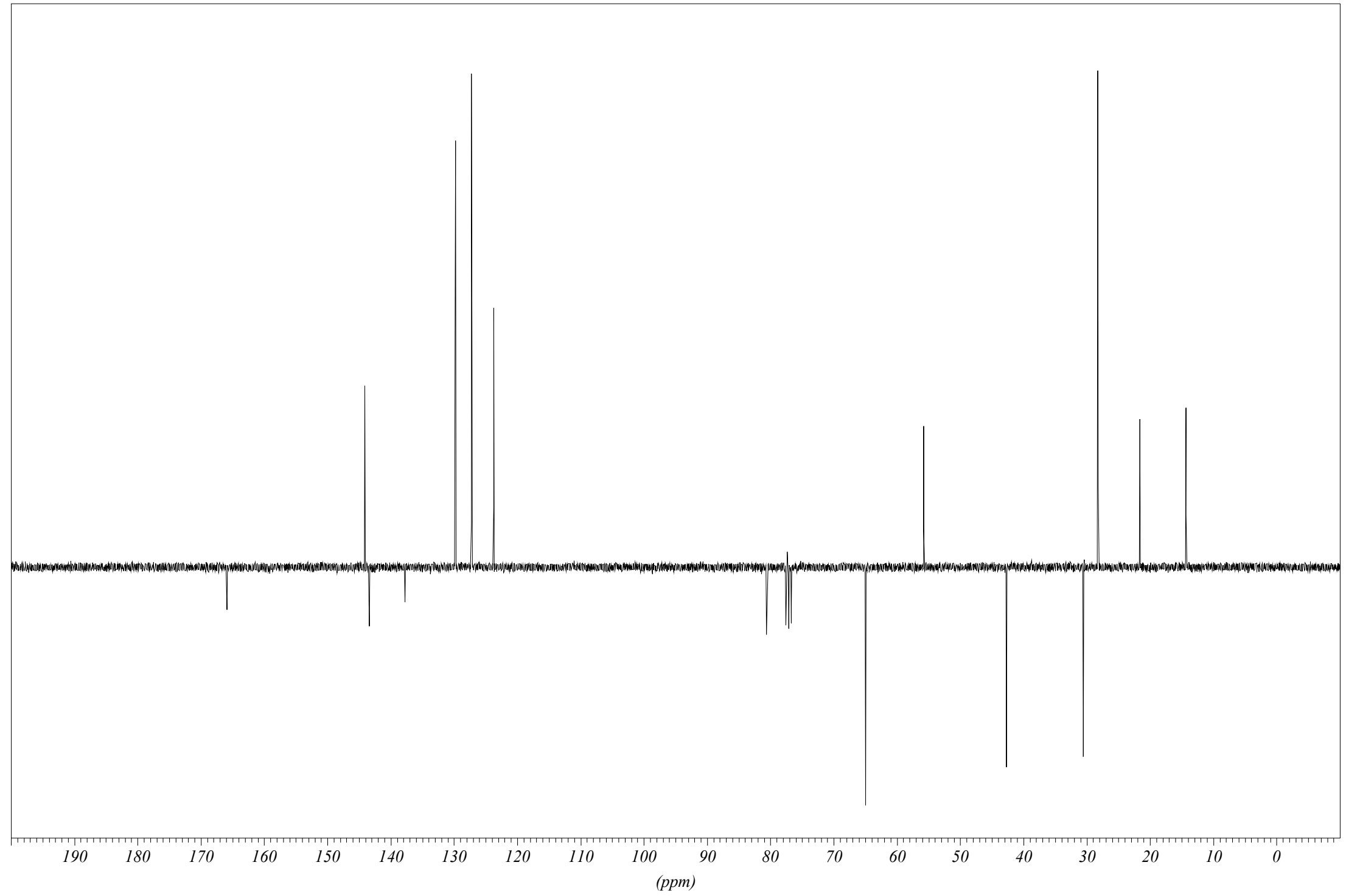

${ }^{13} \mathrm{C}$ NMR Spectrum $(75 \mathrm{MHz})$ of $\mathbf{1 4 b}$ in $\mathrm{CDCl}_{3}$ 


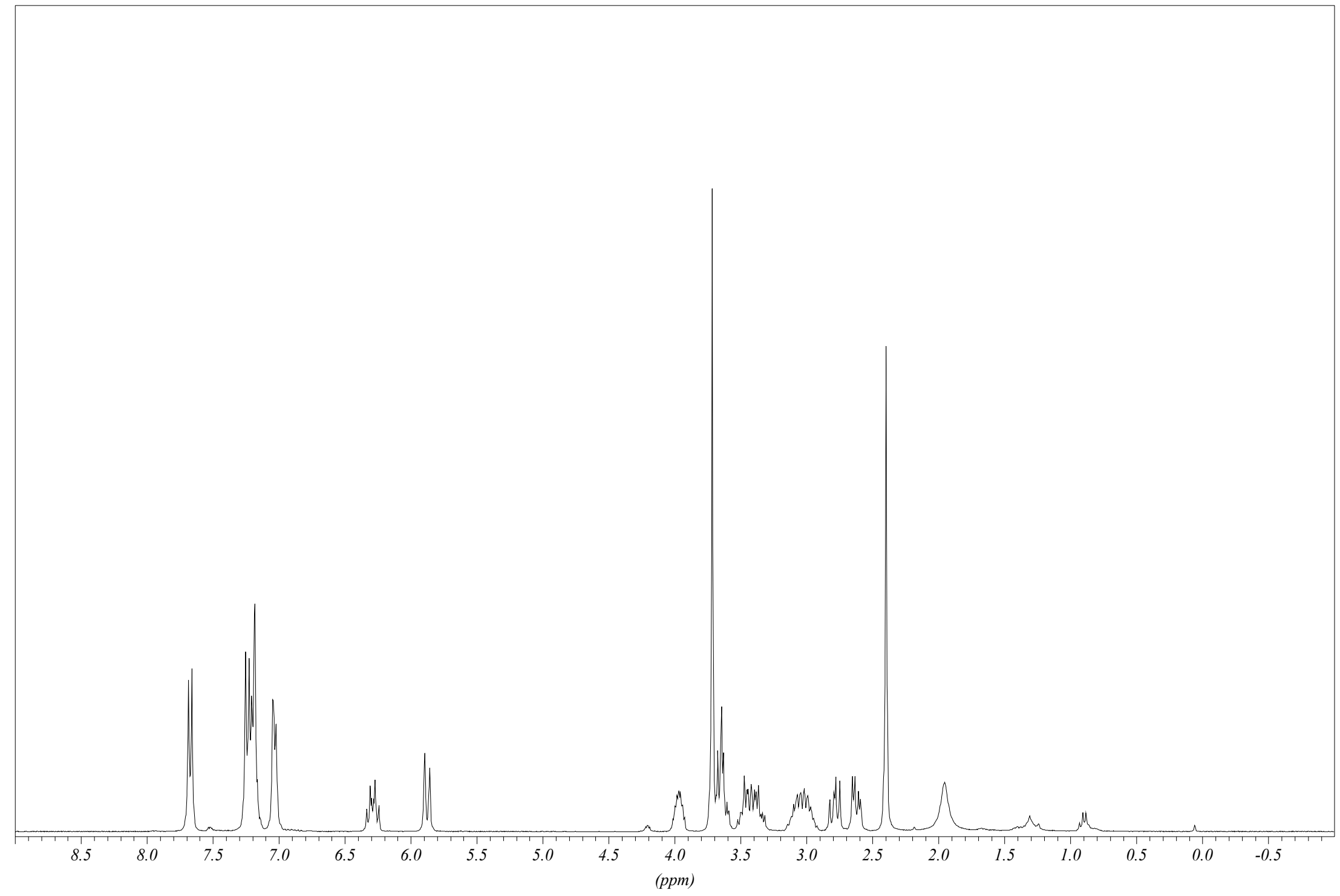

${ }^{1} \mathrm{H}$ NMR Spectrum (300 MHz) of $\mathbf{1 4 c}$ in $\mathrm{CDCl}_{3}$ 


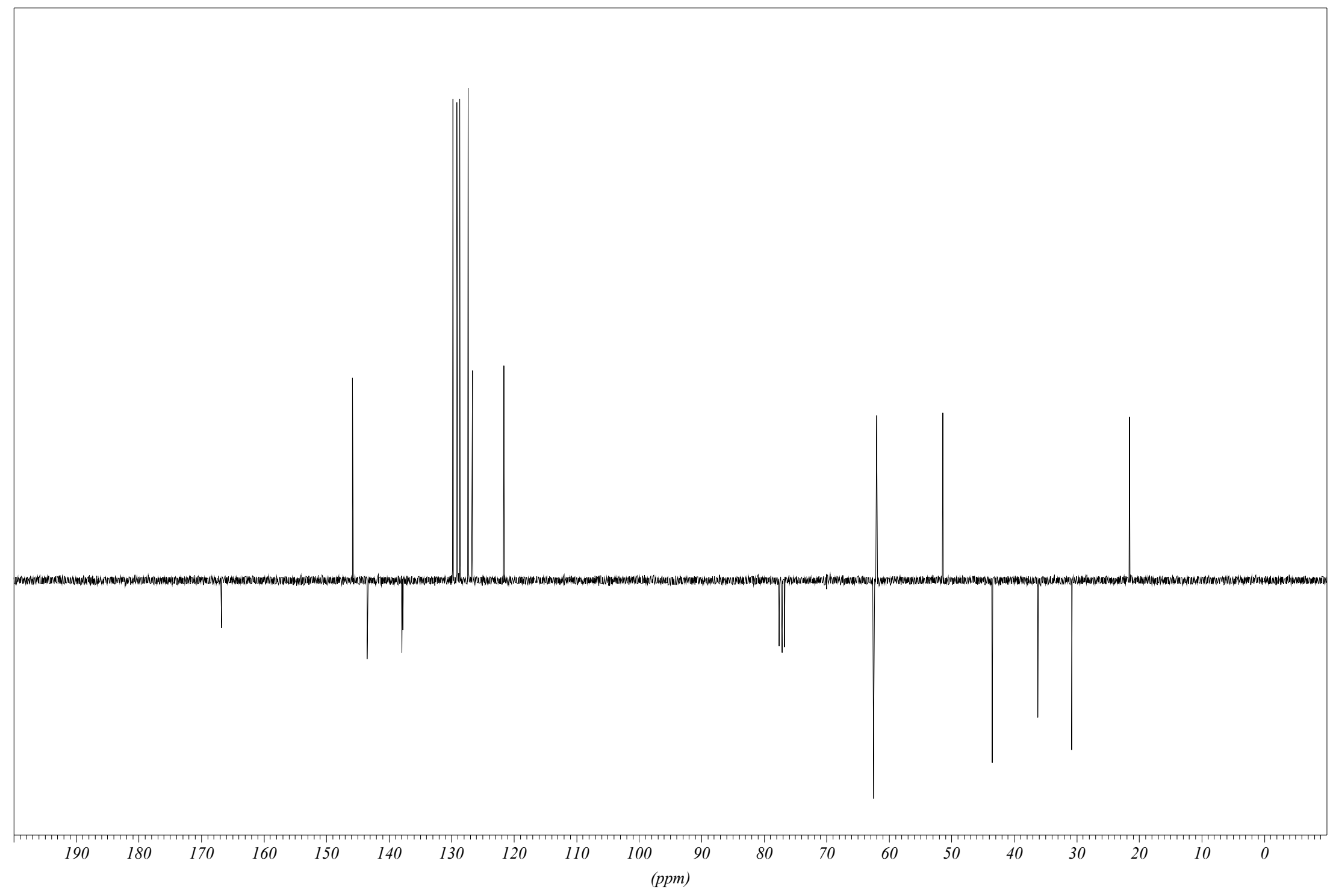

${ }^{13} \mathrm{C}$ NMR Spectrum (75 MHz) of $\mathbf{1 4 c}$ in $\mathrm{CDCl}_{3}$ 


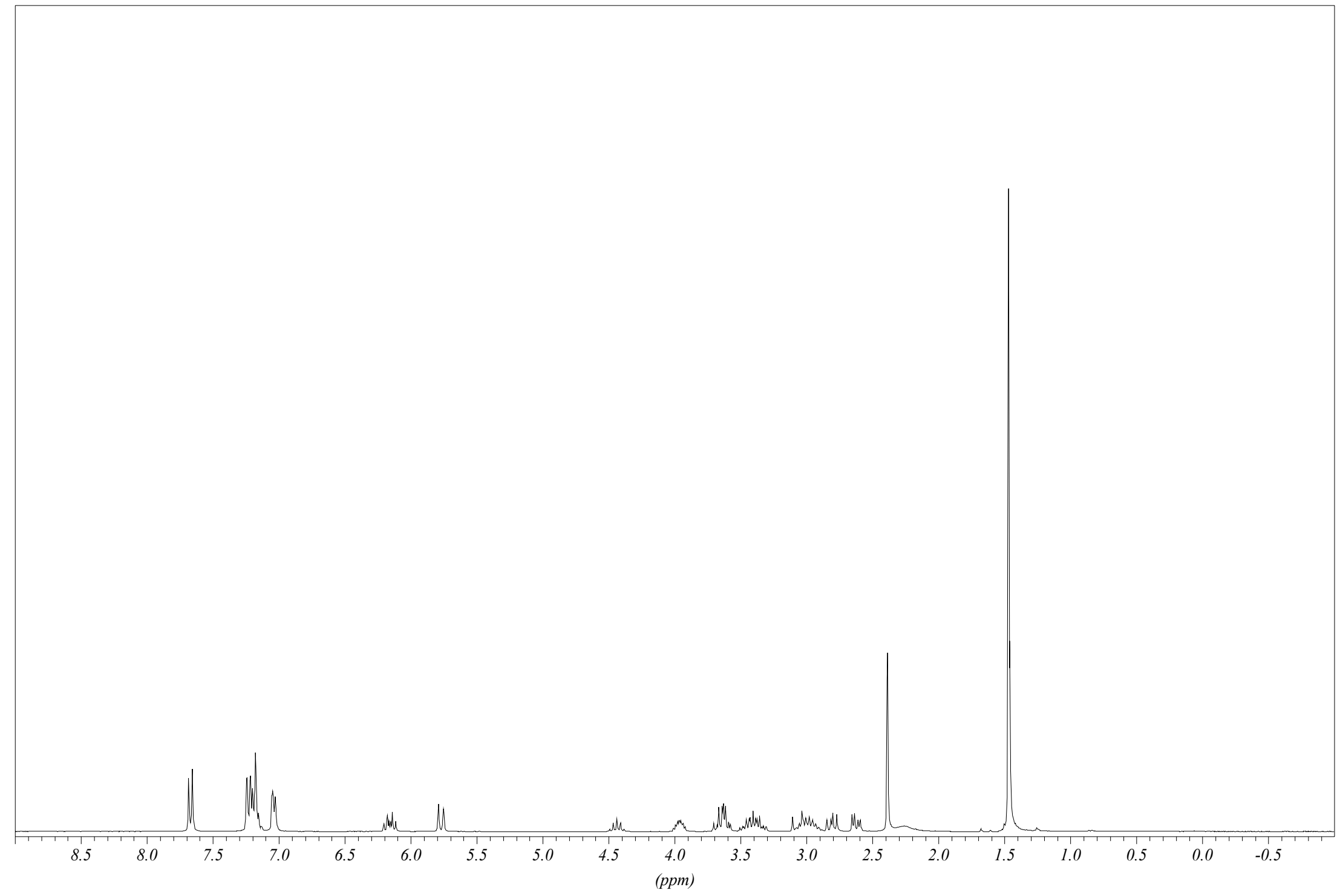

${ }^{1} \mathrm{H}$ NMR Spectrum (300 MHz) of $\mathbf{1 4 d}$ in $\mathrm{CDCl}_{3}$ 


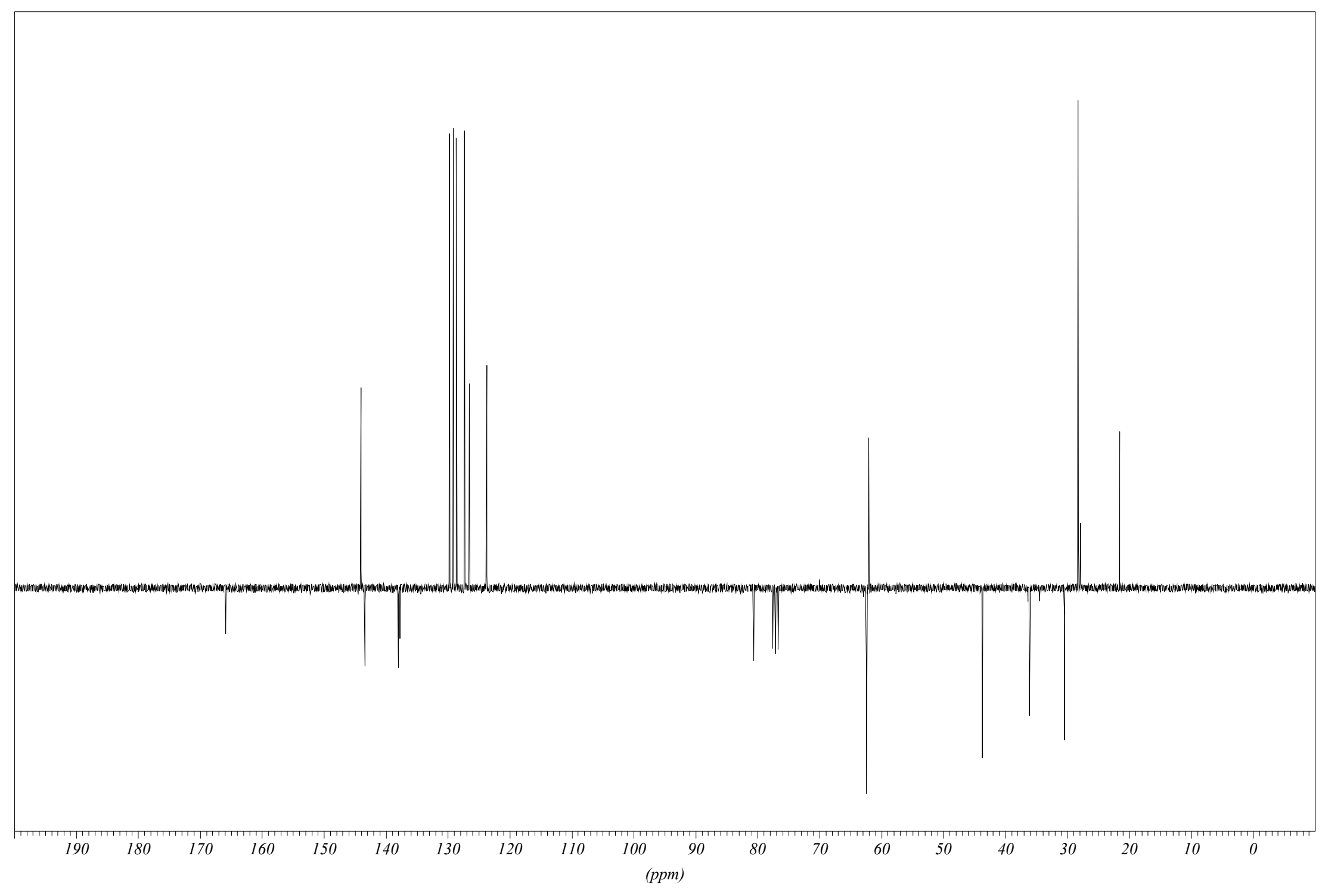

${ }^{13} \mathrm{C}$ NMR Spectrum $(75 \mathrm{MHz})$ of $\mathbf{1 4 d}$ in $\mathrm{CDCl}_{3}$ 


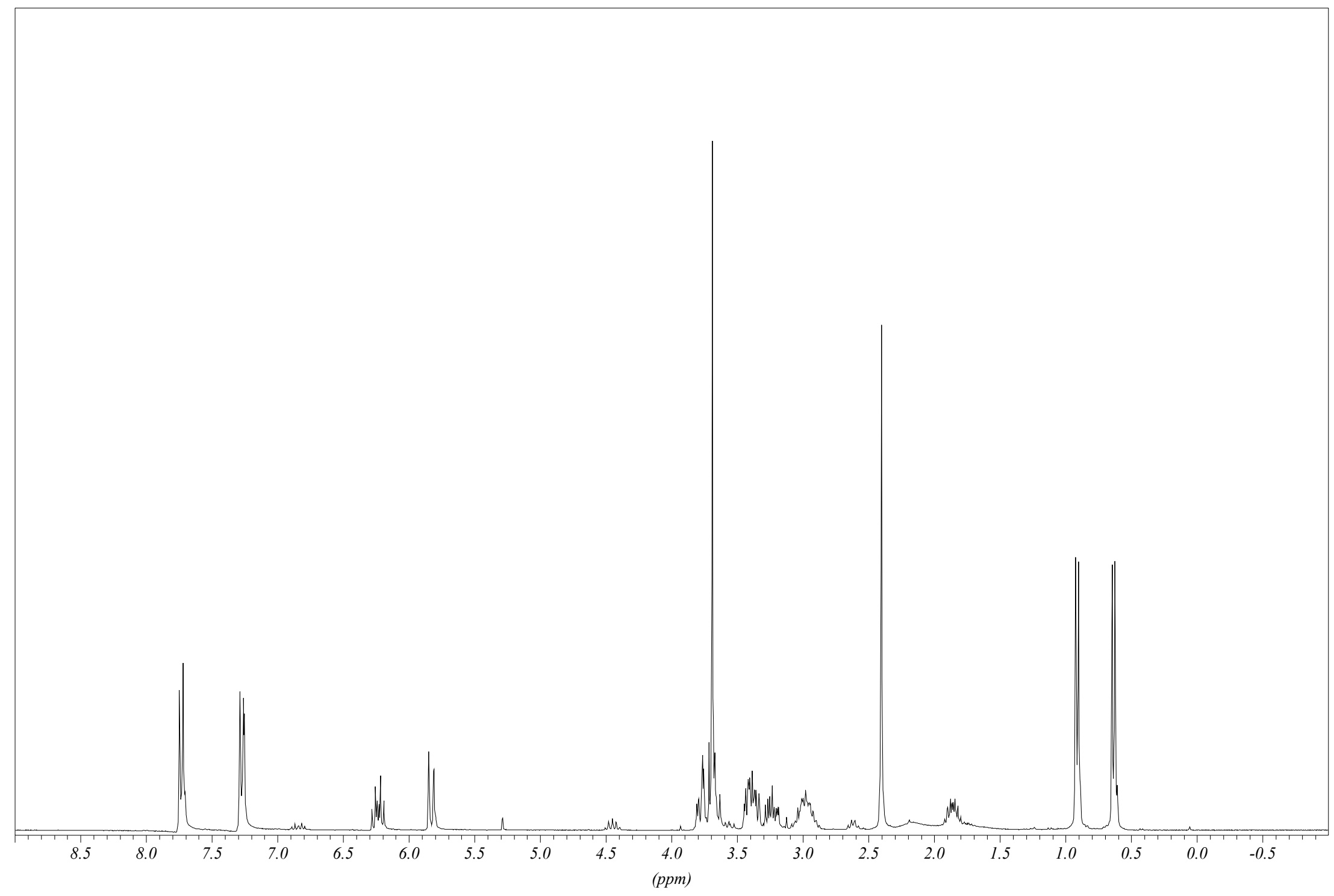

${ }^{1} \mathrm{H}$ NMR Spectrum (300 MHz) of $\mathbf{1 4 e}$ in $\mathrm{CDCl}_{3}$ 


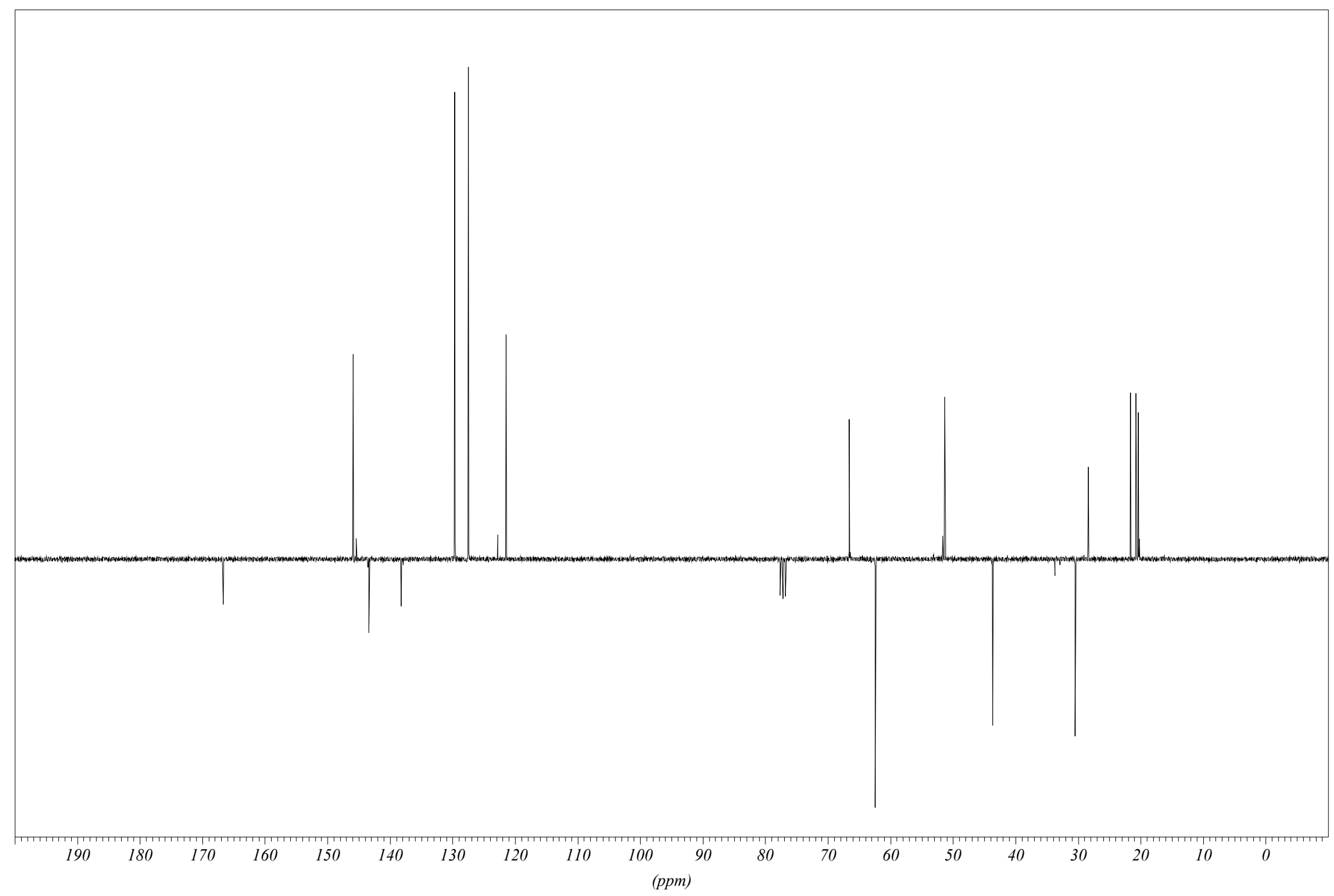

${ }^{13} \mathrm{C}$ NMR Spectrum (75 MHz) of $\mathbf{1 4 e}$ in $\mathrm{CDCl}_{3}$ 


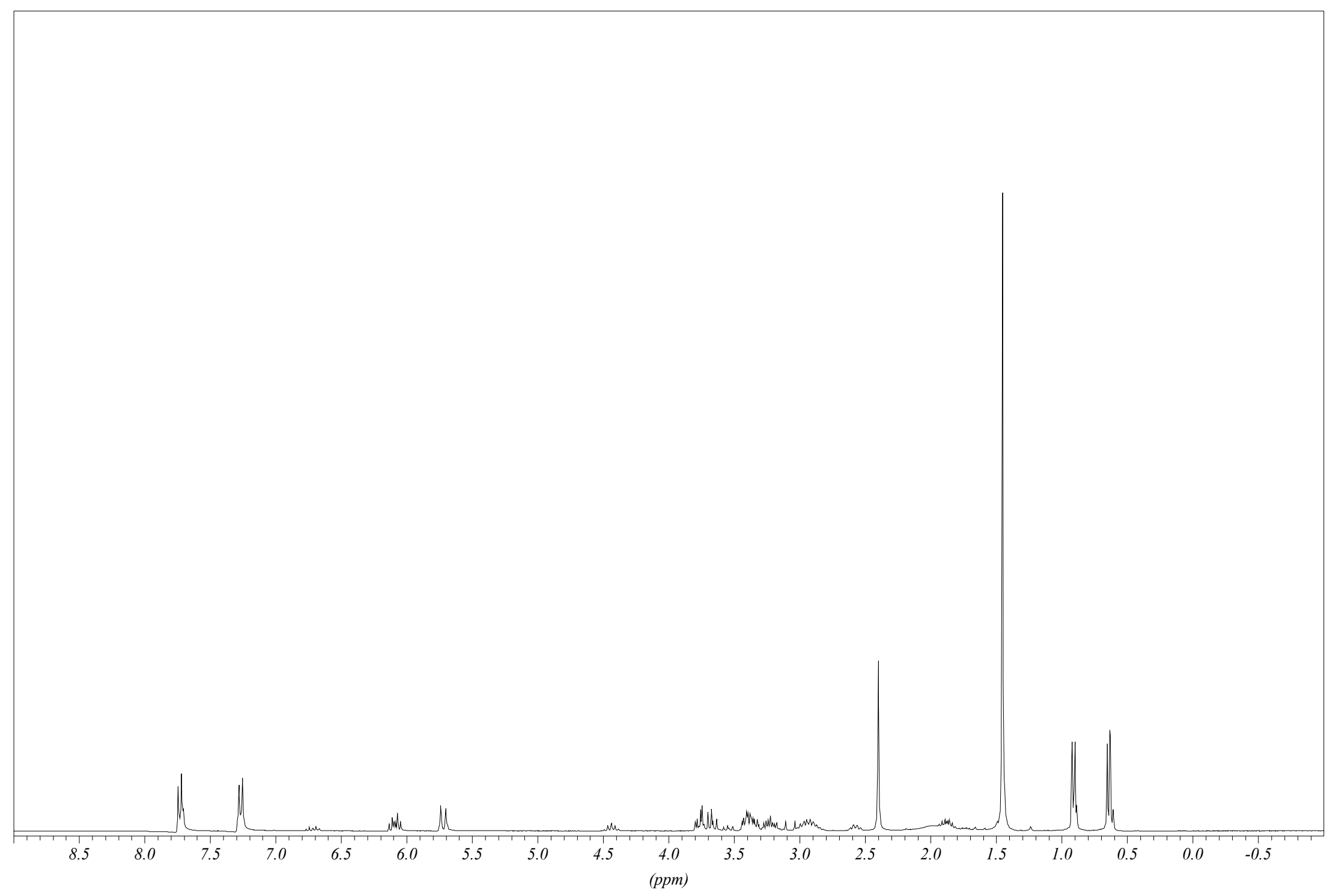

${ }^{1} \mathrm{H}$ NMR Spectrum (300 MHz) of $\mathbf{1 4 f}$ in $\mathrm{CDCl}_{3}$ 


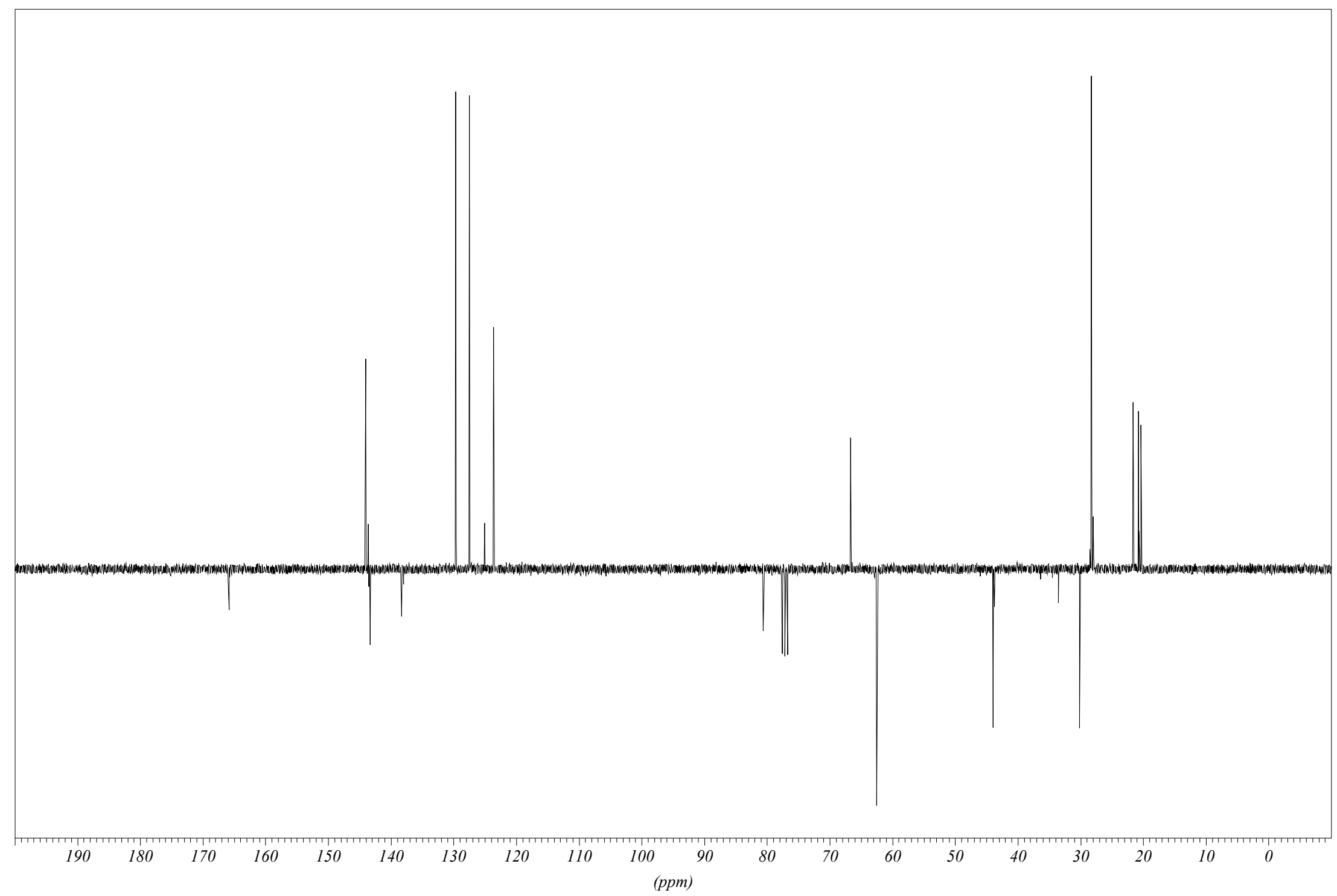

${ }^{13} \mathrm{C}$ NMR Spectrum $\left(75 \mathrm{MHz}\right.$ ) of $\mathbf{1 4 f}$ in $\mathrm{CDCl}_{3}$ 


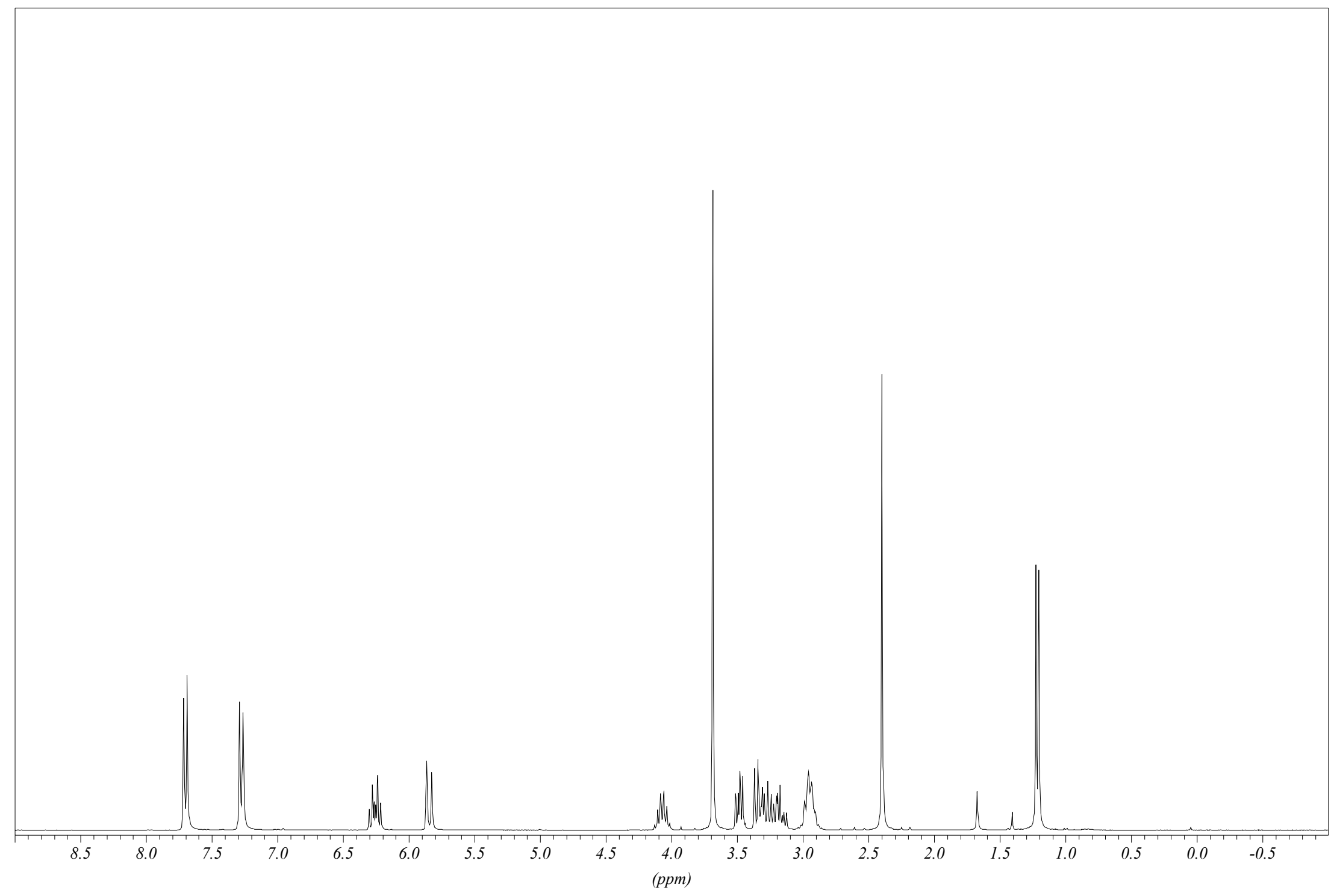

${ }^{1} \mathrm{H}$ NMR Spectrum (300 MHz) of $\mathbf{1 5 a}$ in $\mathrm{CDCl}_{3}$ 


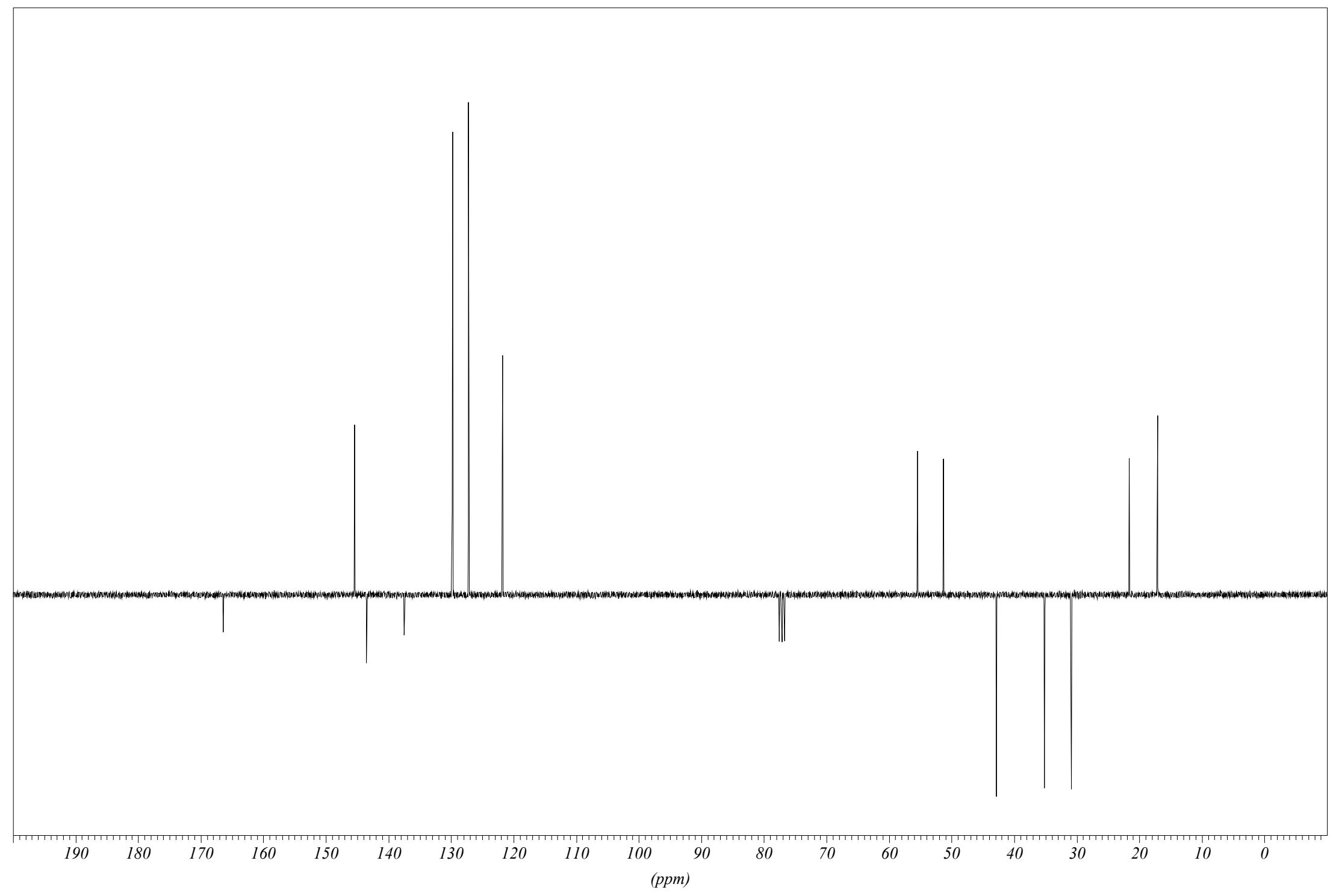

${ }^{13} \mathrm{C}$ NMR Spectrum (75 MHz) of $\mathbf{1 5 a}$ in $\mathrm{CDCl}_{3}$ 


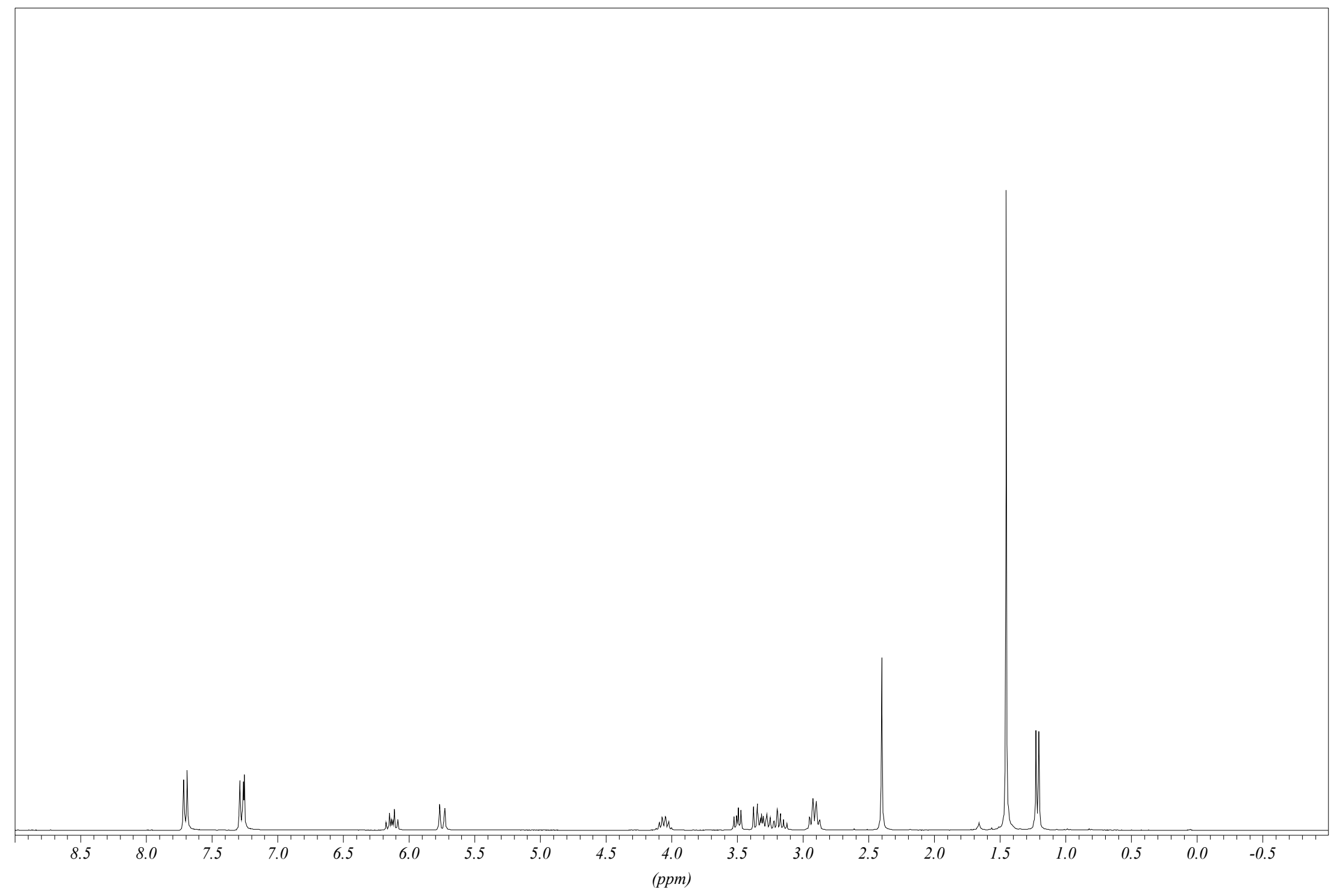

${ }^{1} \mathrm{H}$ NMR Spectrum (300 MHz) of $\mathbf{1 5 b}$ in $\mathrm{CDCl}_{3}$ 


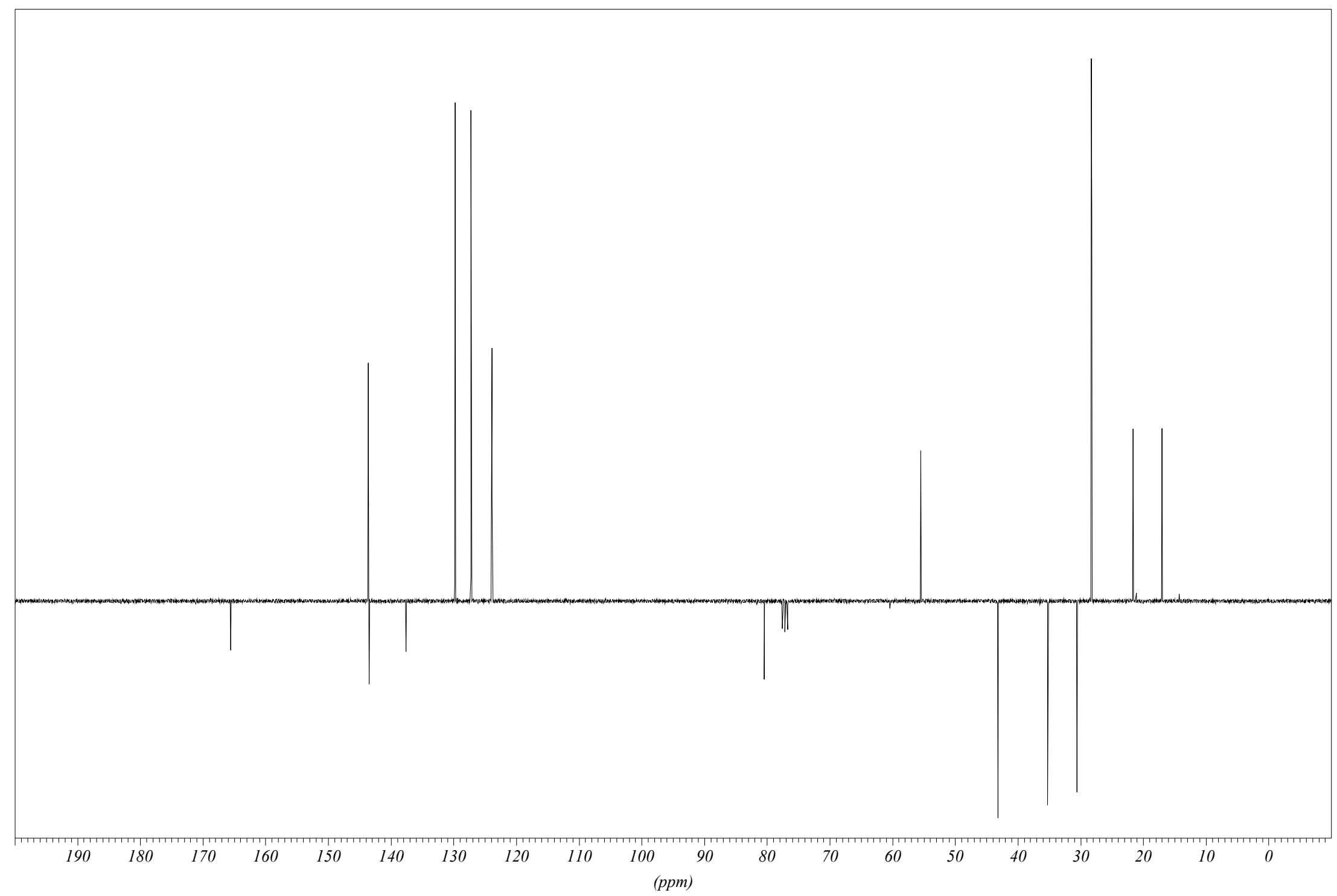

${ }^{13} \mathrm{C}$ NMR Spectrum $(75 \mathrm{MHz})$ of $\mathbf{1 5 b}$ in $\mathrm{CDCl}_{3}$ 


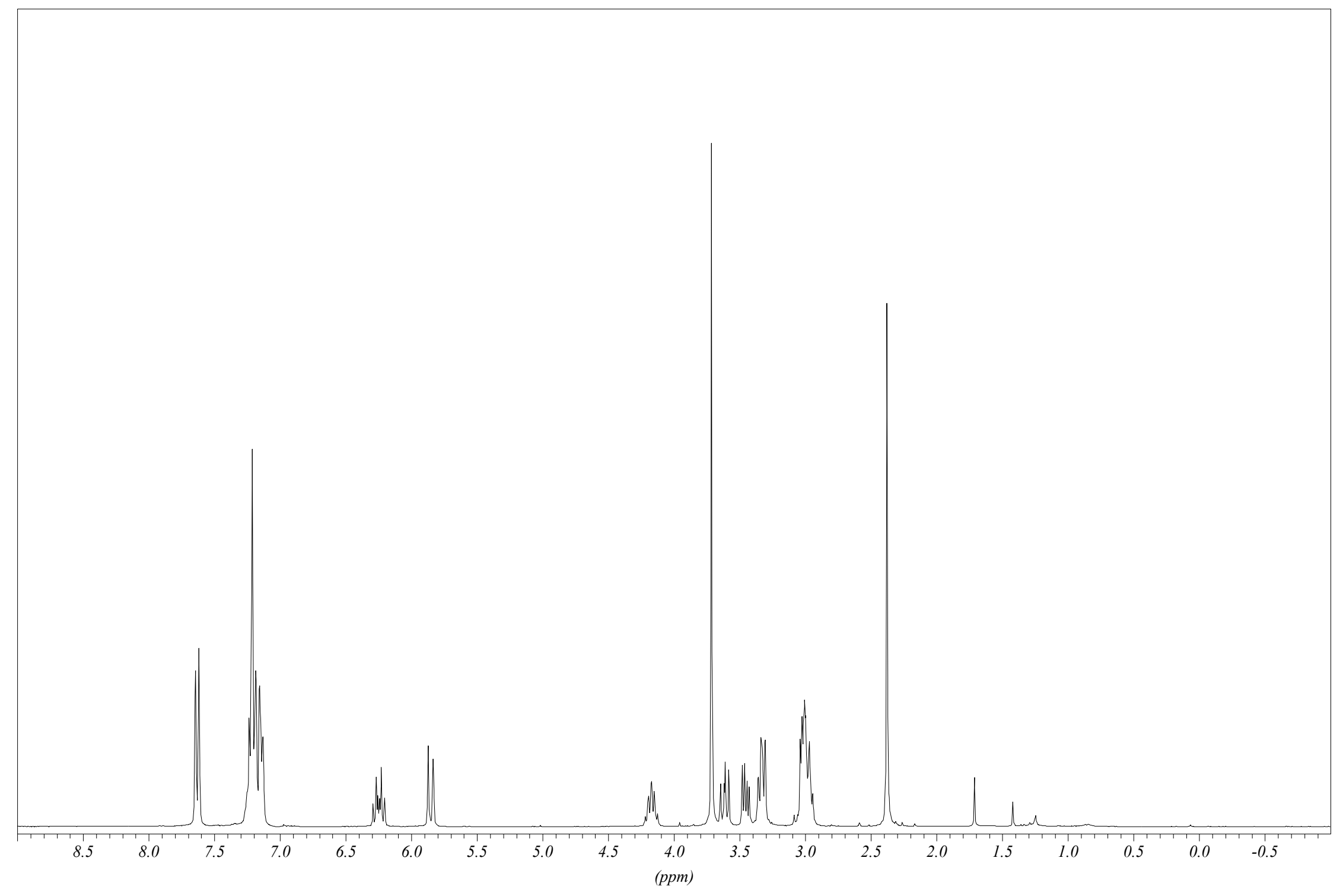

${ }^{1} \mathrm{H}$ NMR Spectrum (300 MHz) of $\mathbf{1 5 c}$ in $\mathrm{CDCl}_{3}$ 


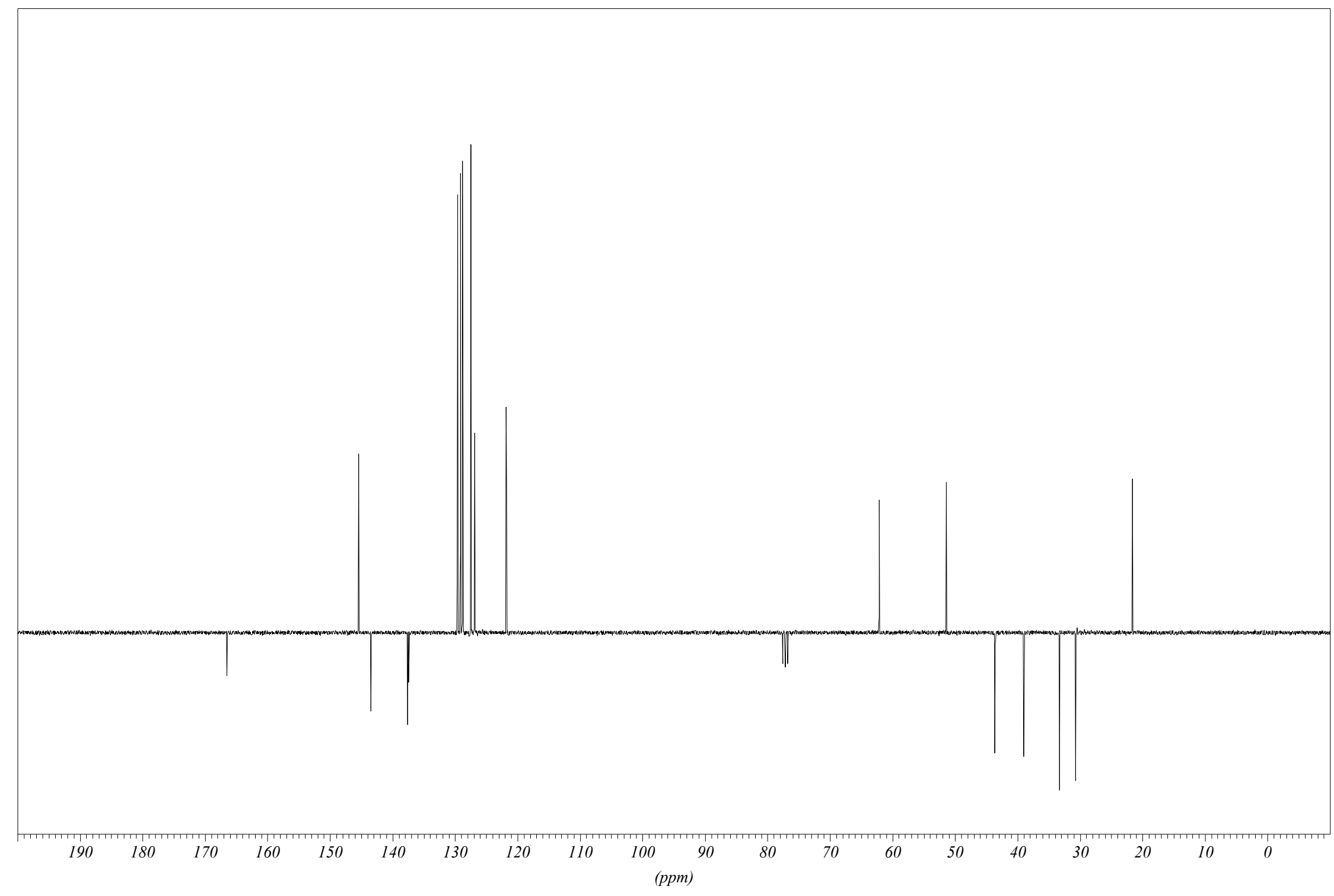

${ }^{13} \mathrm{C}$ NMR Spectrum (75 MHz) of $\mathbf{1 5 c}$ in $\mathrm{CDCl}_{3}$ 


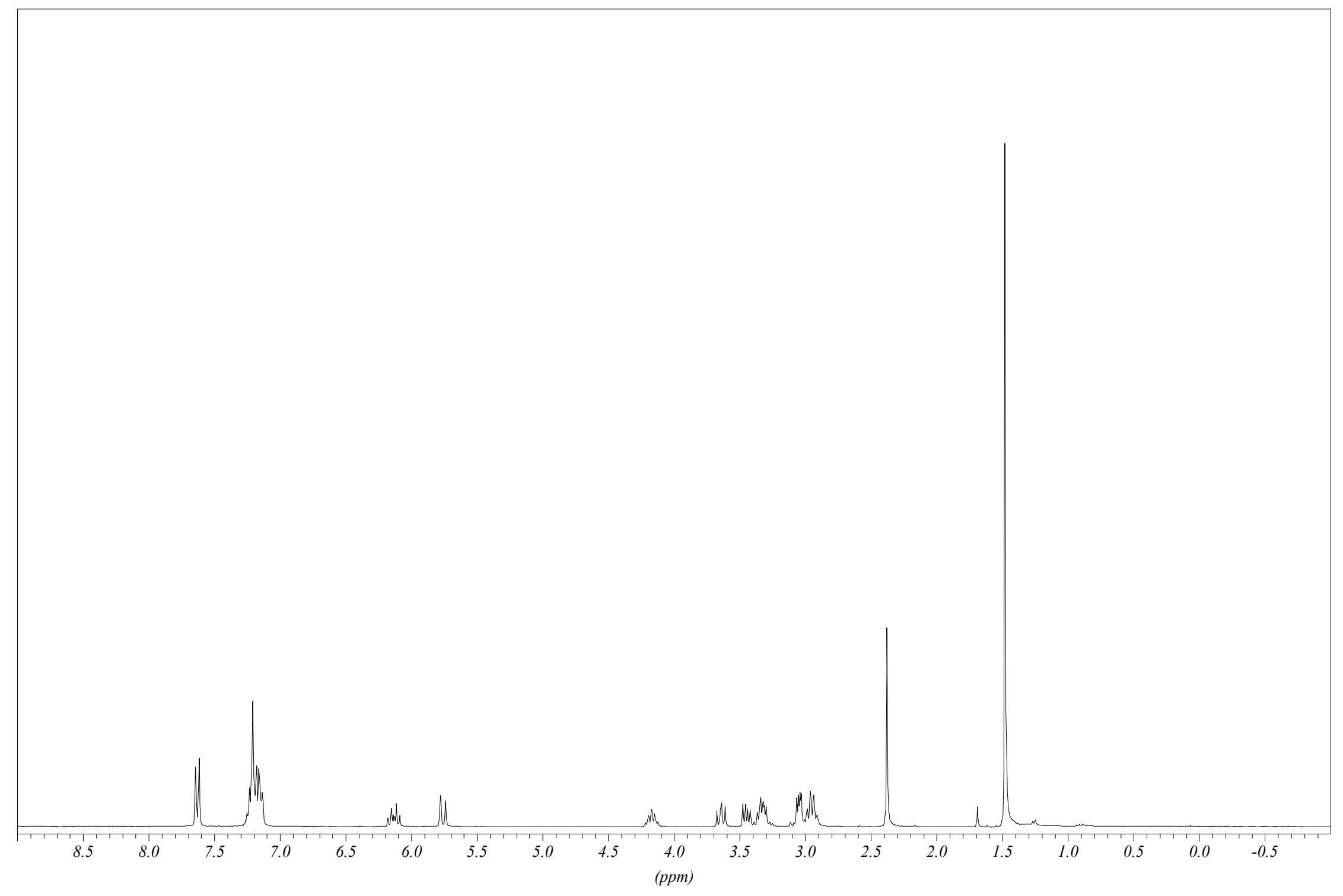

${ }^{1} \mathrm{H}$ NMR Spectrum (300 MHz) of $\mathbf{1 5 d}$ in $\mathrm{CDCl}_{3}$ 


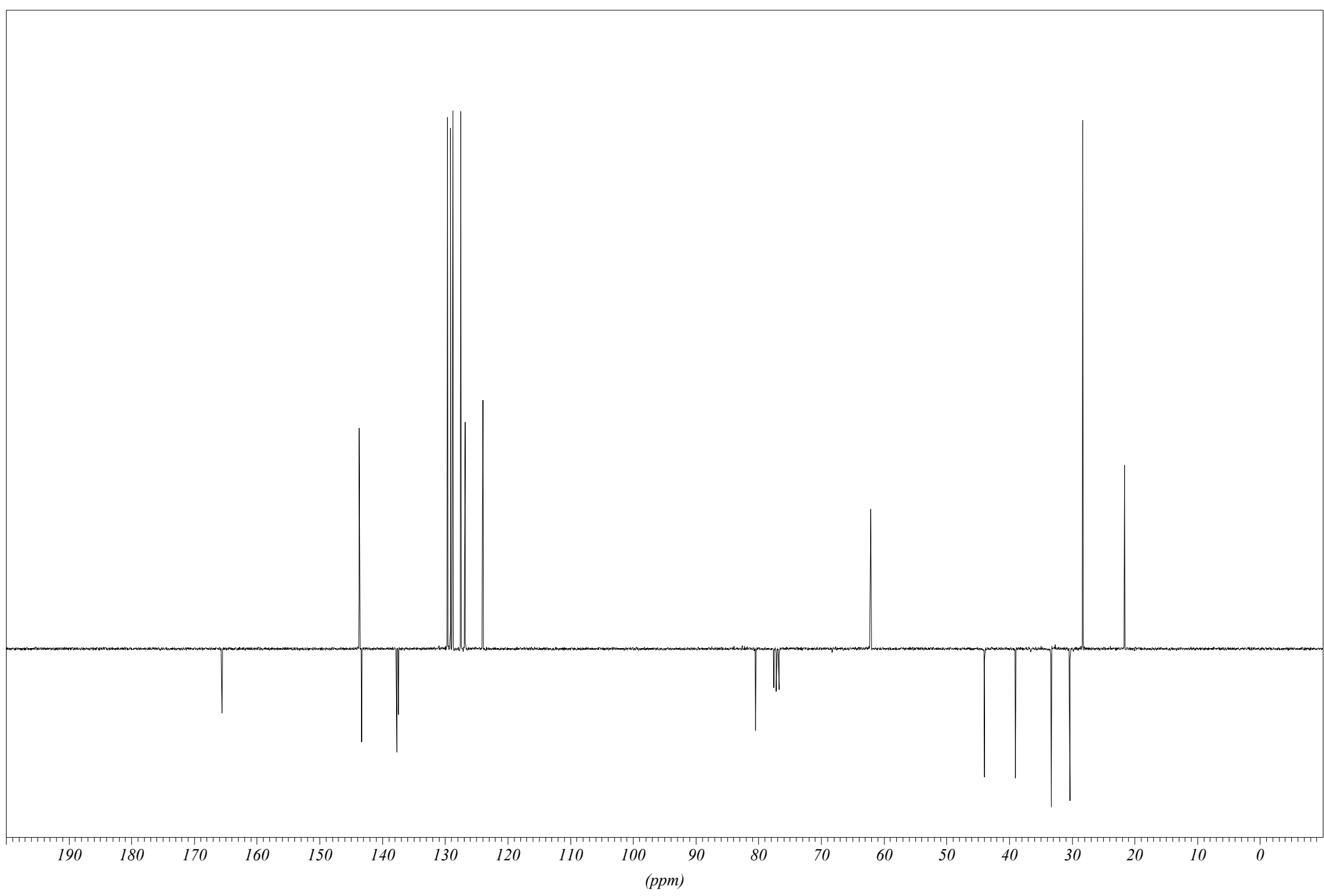

${ }^{13} \mathrm{C}$ NMR Spectrum $(75 \mathrm{MHz})$ of $\mathbf{1 5 d}$ in $\mathrm{CDCl}_{3}$ 


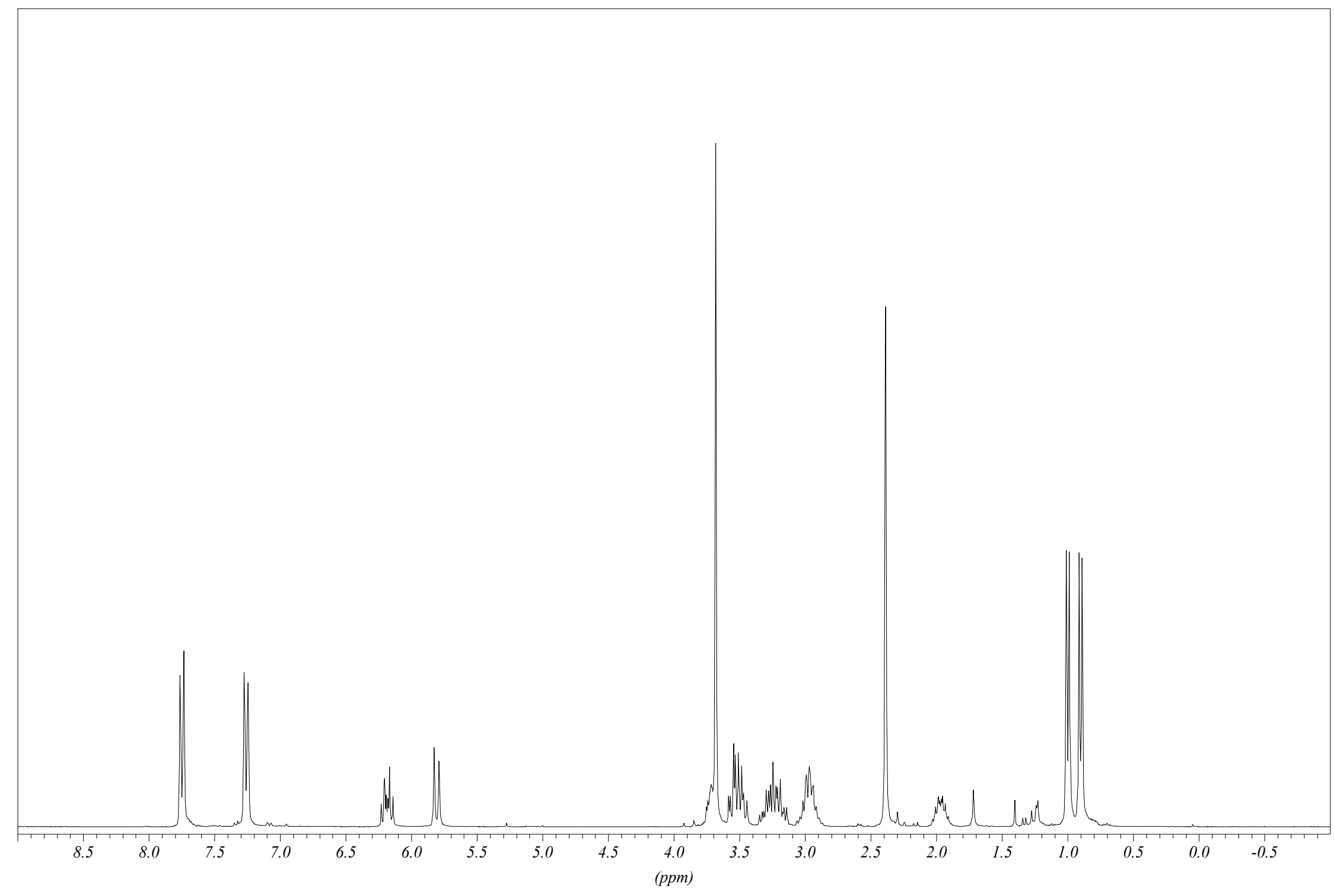

${ }^{1} \mathrm{H}$ NMR spectrum $\left(300 \mathrm{MHz}\right.$ ) of $\mathbf{1 5 e}$ in $\mathrm{CDCl}_{3}$ 


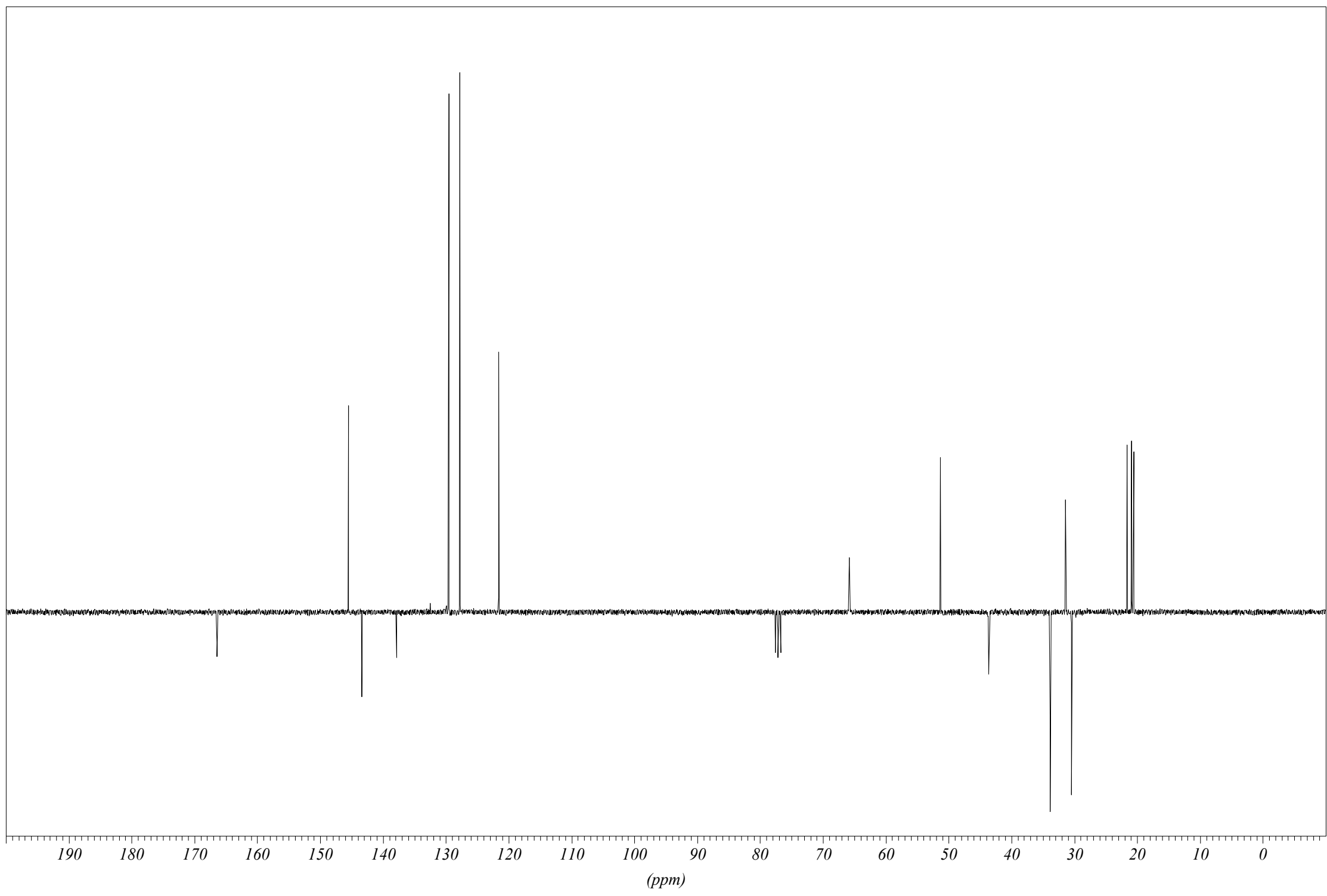

${ }^{13} \mathrm{C}$ NMR Spectrum (75 MHz) of $\mathbf{1 5 e}$ in $\mathrm{CDCl}_{3}$ 


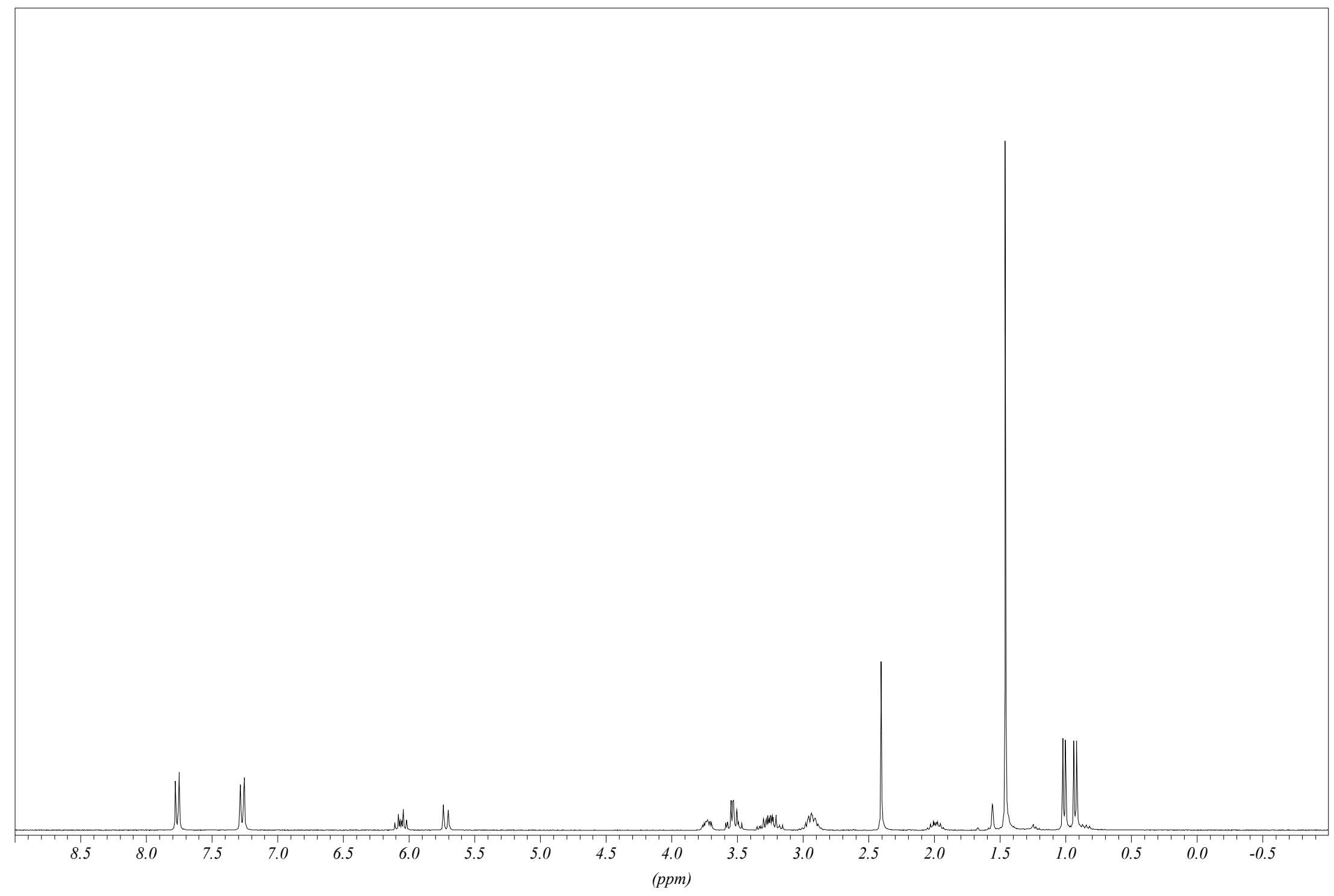

${ }^{1} \mathrm{H}$ NMR Spectrum (300 MHz) of $\mathbf{1 5 f}$ in $\mathrm{CDCl}_{3}$ 


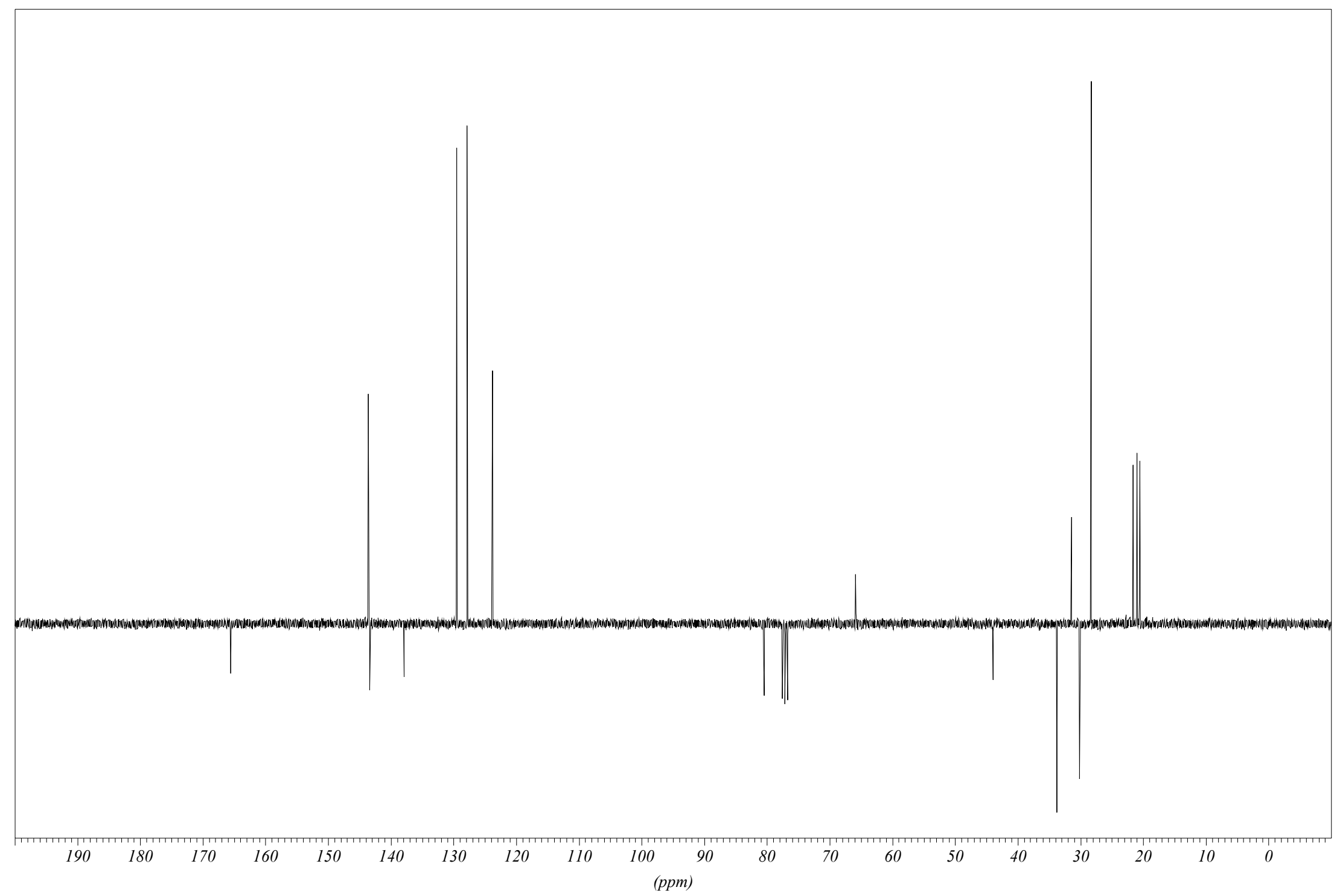

${ }^{13} \mathrm{C}$ NMR Spectrum (75 MHz) of $\mathbf{1 5 f}$ in $\mathrm{CDCl}_{3}$ 


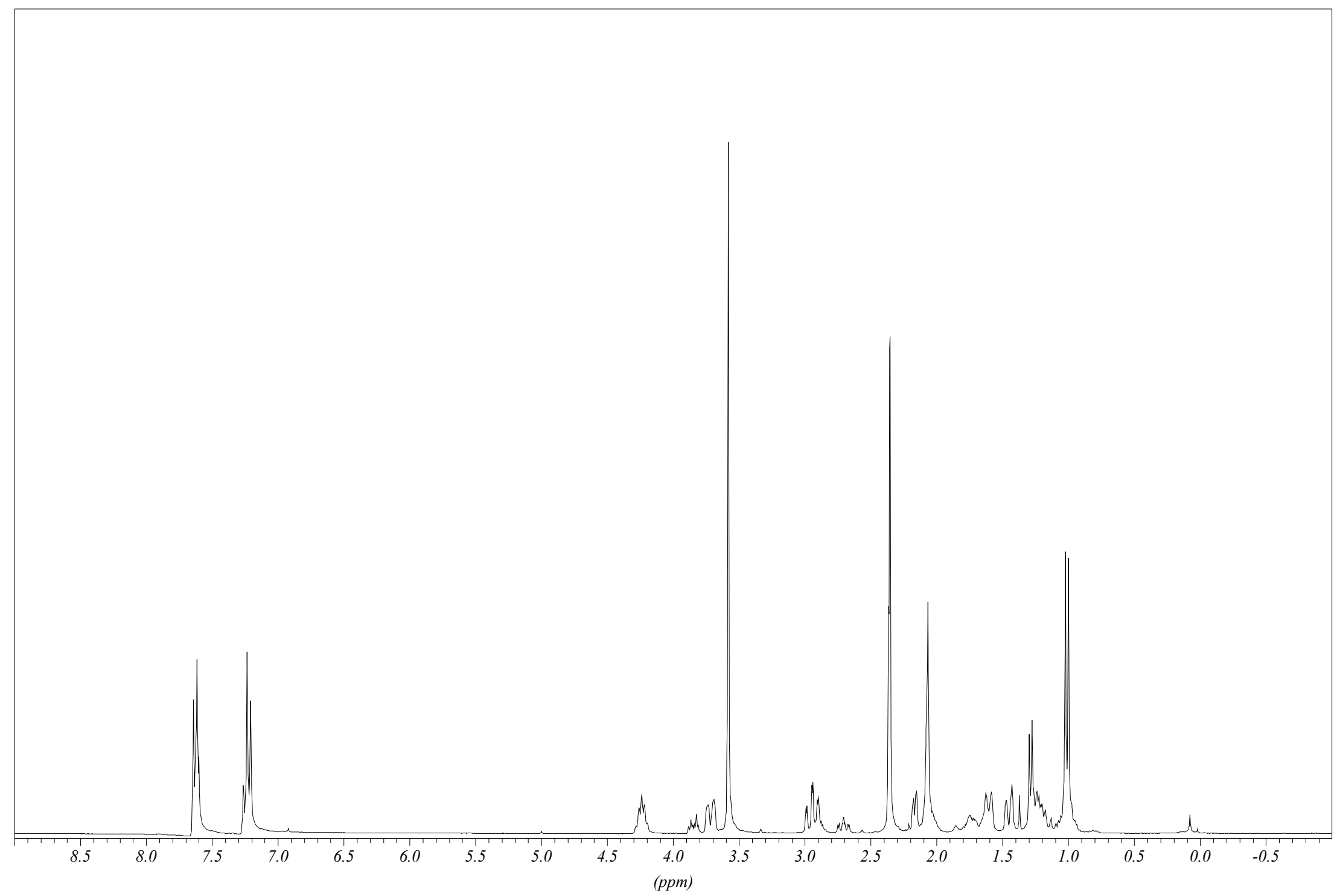

${ }^{1} \mathrm{H}$ NMR Spectrum $(300 \mathrm{MHz})$ of a mixture of 16a and 17a in $\mathrm{CDCl}_{3}$ 


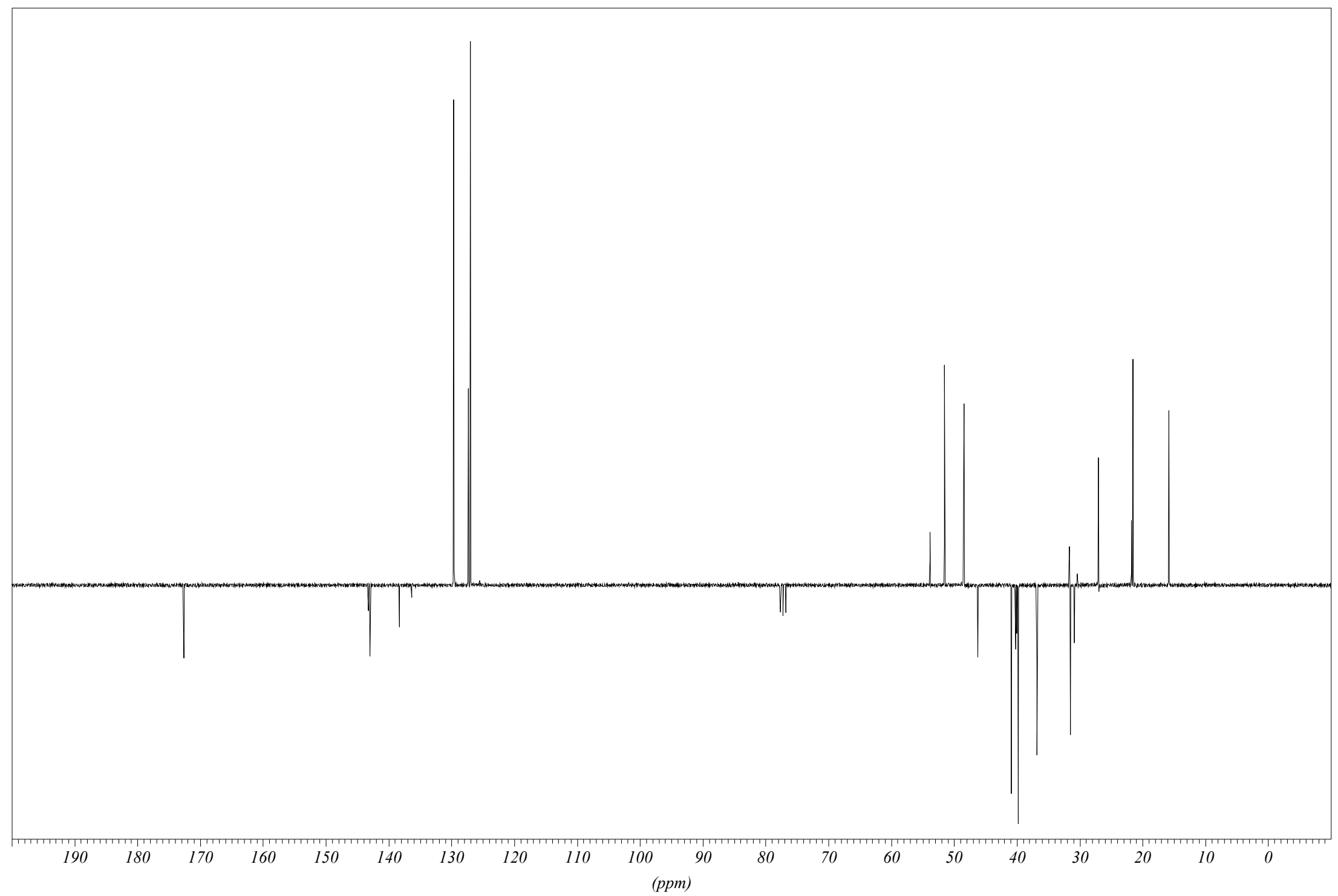

${ }^{13} \mathrm{C}$ NMR Spectrum $(75 \mathrm{MHz})$ of a mixture of $\mathbf{1 6 a}$ and $\mathbf{1 7} \mathbf{a}$ in $\mathrm{CDCl}_{3}$ 


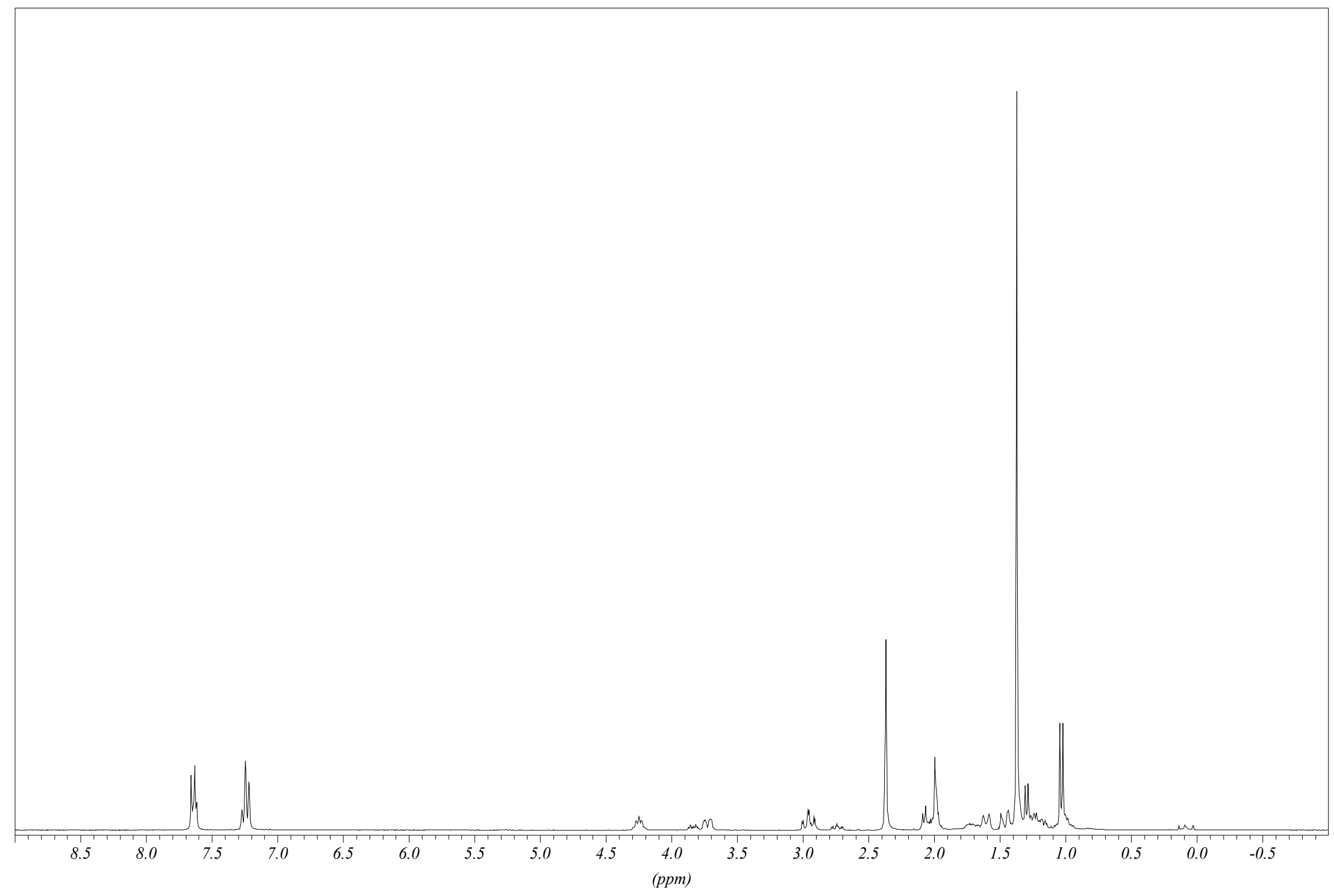

${ }^{1} \mathrm{H}$ NMR Spectrum $(300 \mathrm{MHz})$ of a mixture of $\mathbf{1 6} \mathbf{b}$ and $\mathbf{1 7} \mathbf{b}$ in $\mathrm{CDCl}_{3}$ 


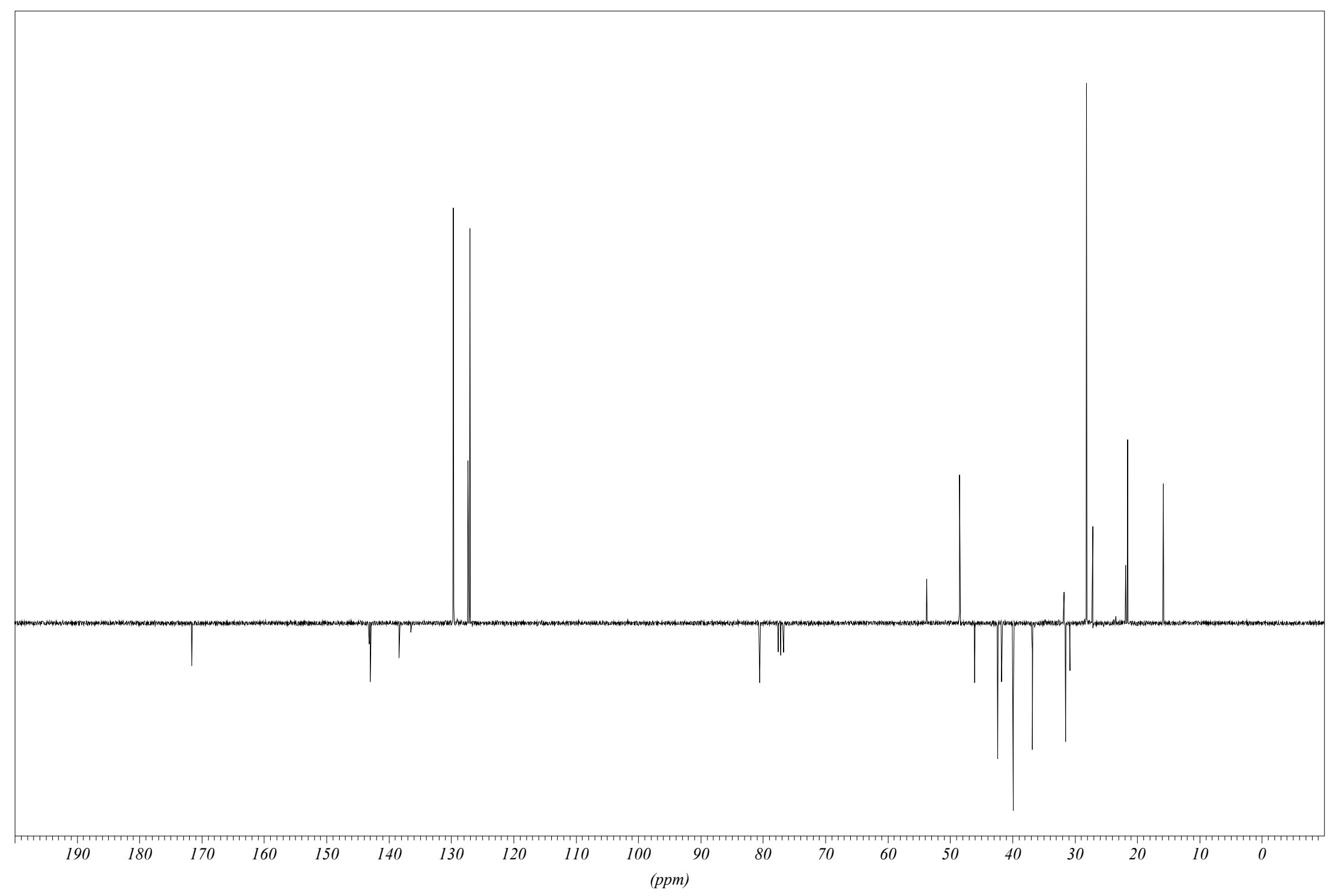

${ }^{13} \mathrm{C}$ NMR Spectrum $\left(75 \mathrm{MHz}\right.$ ) of a mixture of $\mathbf{1 6 b}$ and $\mathbf{1 7} \mathbf{b}$ in $\mathrm{CDCl}_{3}$ 


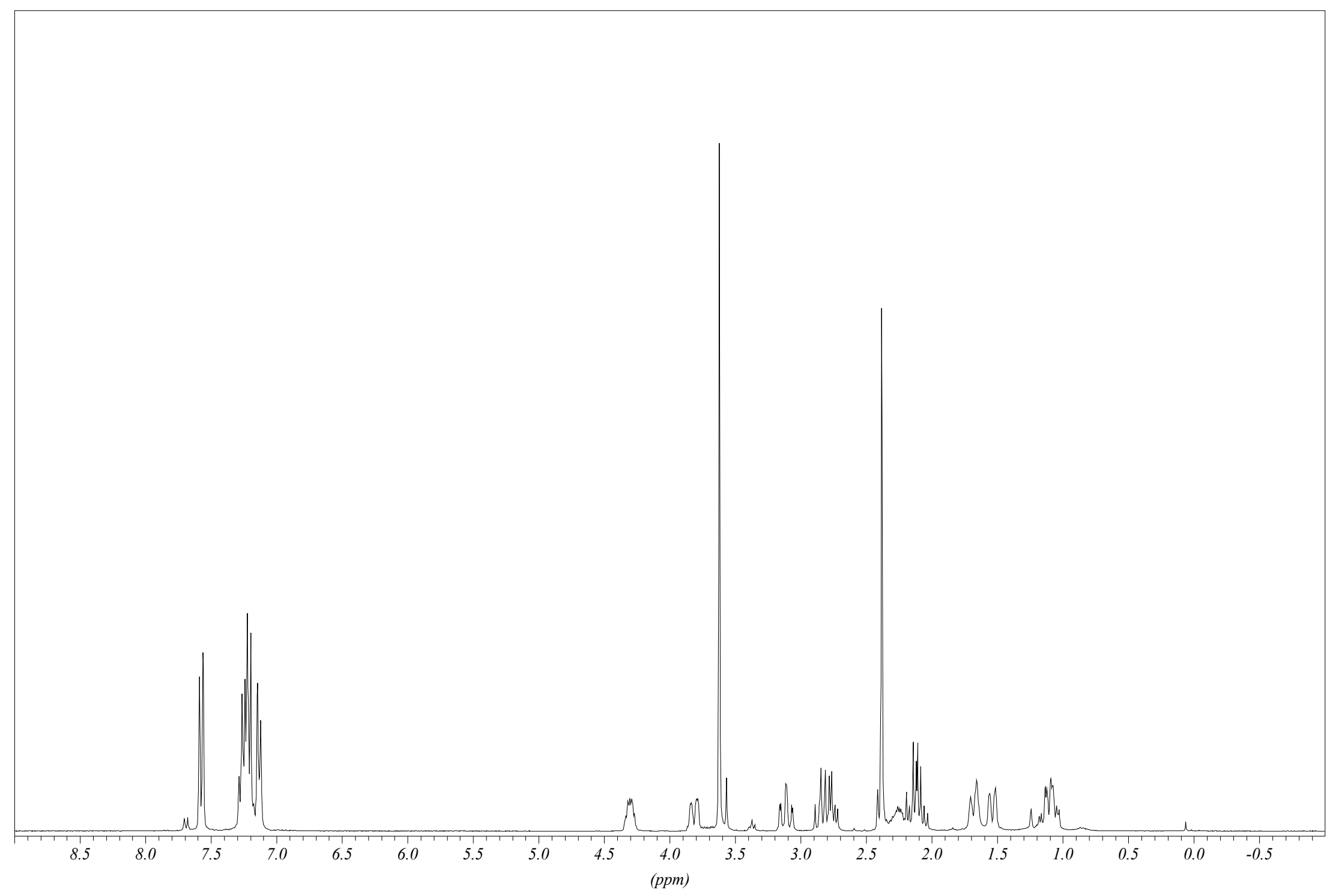

${ }^{1} \mathrm{H}$ NMR Spectrum $(300 \mathrm{MHz})$ of a mixture of $\mathbf{1 6} \mathbf{c}$ and $\mathbf{1 7} \mathbf{c}$ in $\mathrm{CDCl}_{3}$ 


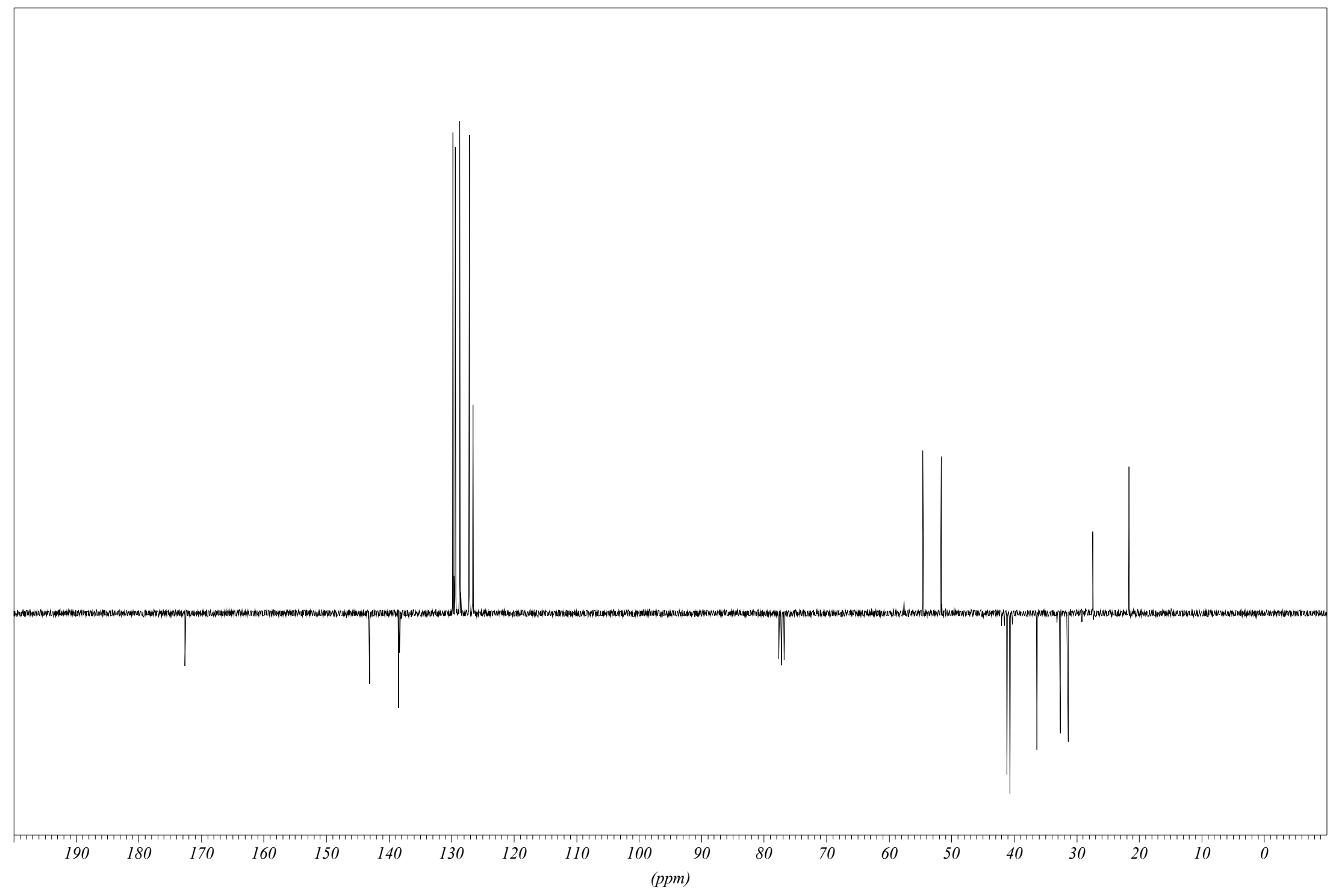

${ }^{13} \mathrm{C}$ NMR Spectrum $(75 \mathrm{MHz})$ of a mixture of $\mathbf{1 6 c}$ and $\mathbf{1 7 c}$ in $\mathrm{CDCl}_{3}$ 


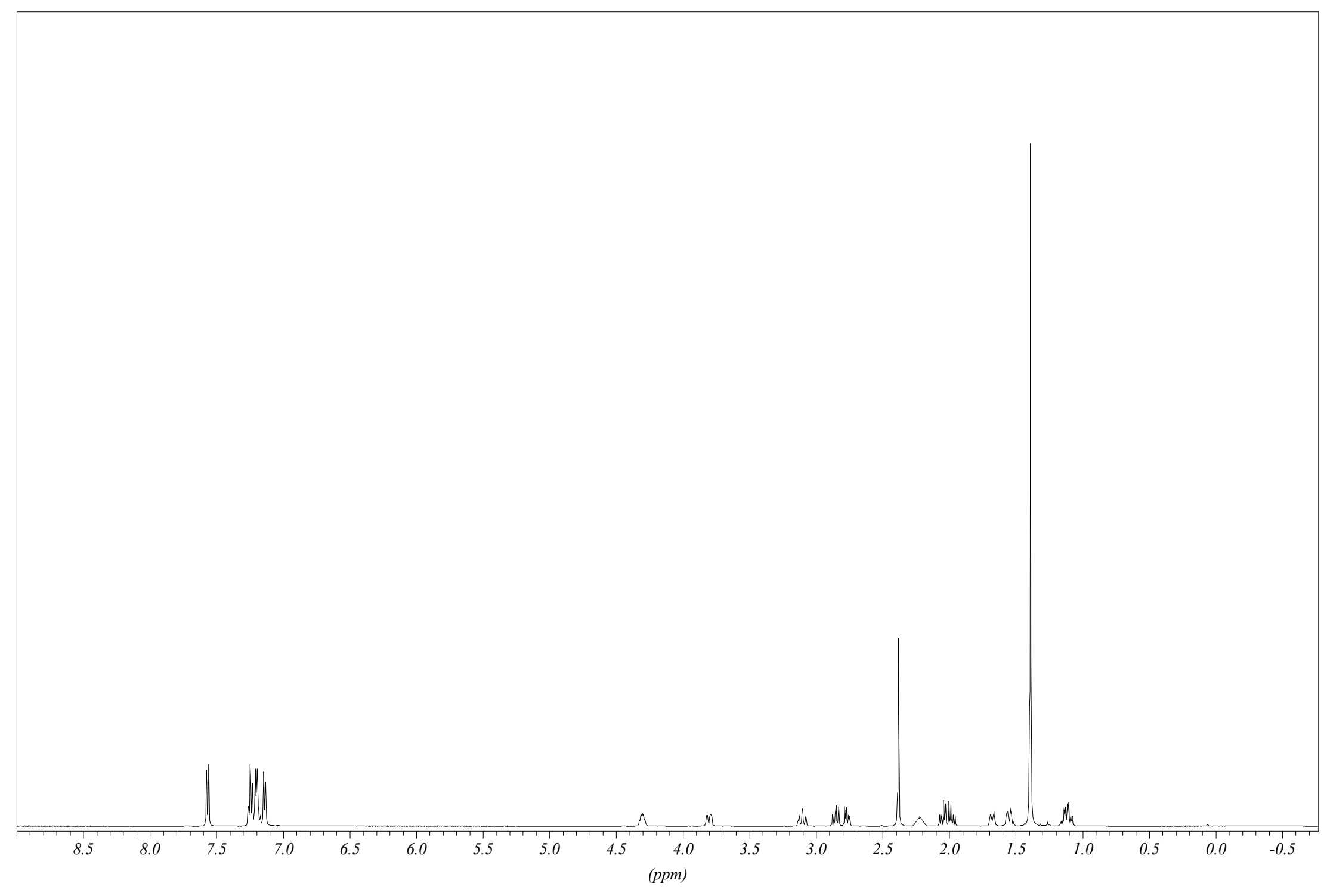

${ }^{1} \mathrm{H}$ NMR Spectrum (300 MHz) of $\mathbf{1 6 d}$ in $\mathrm{CDCl}_{3}$ 


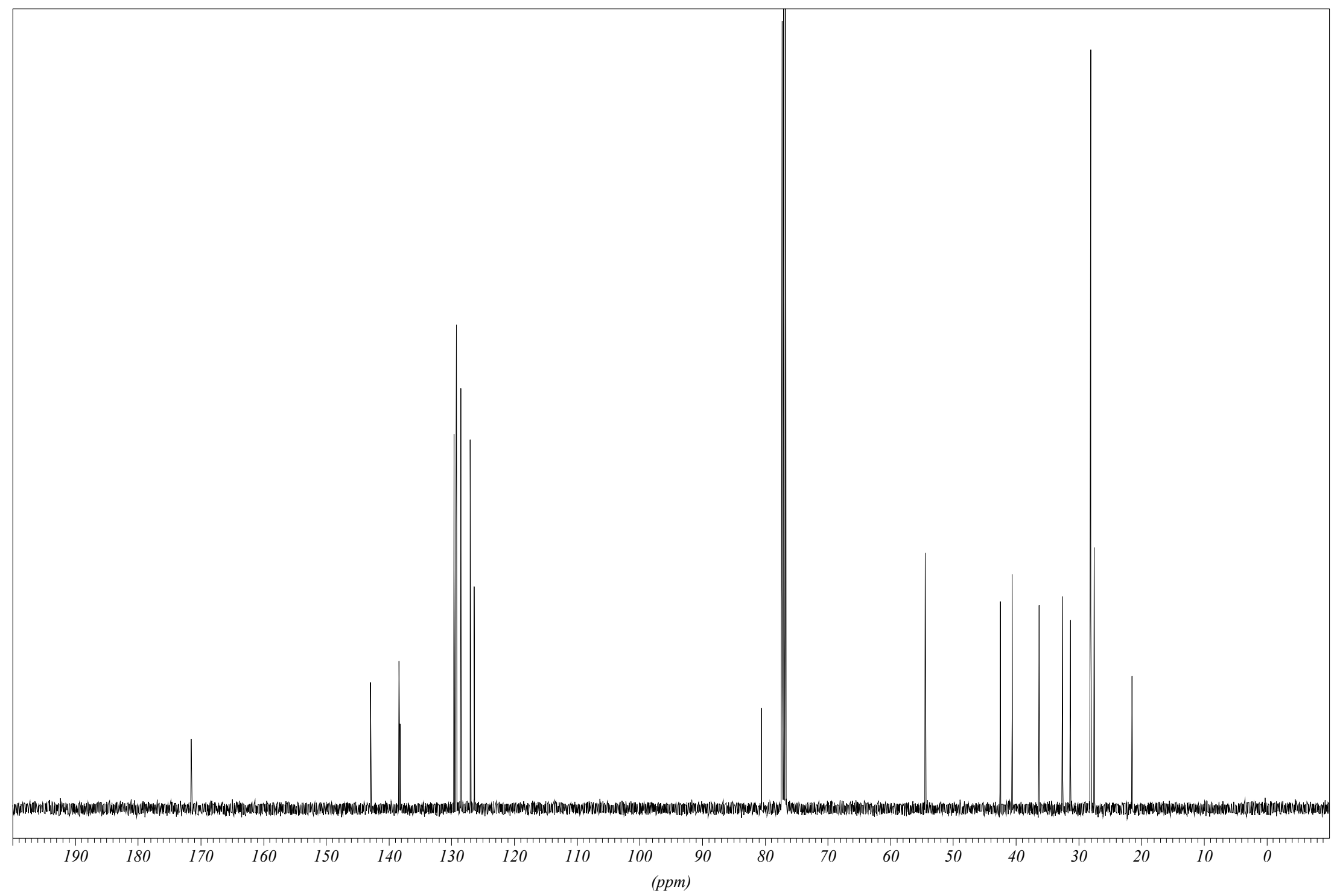

${ }^{13} \mathrm{C}$ NMR Spectrum $(125 \mathrm{MHz})$ of $\mathbf{1 6 d}$ in $\mathrm{CDCl}_{3}$ 


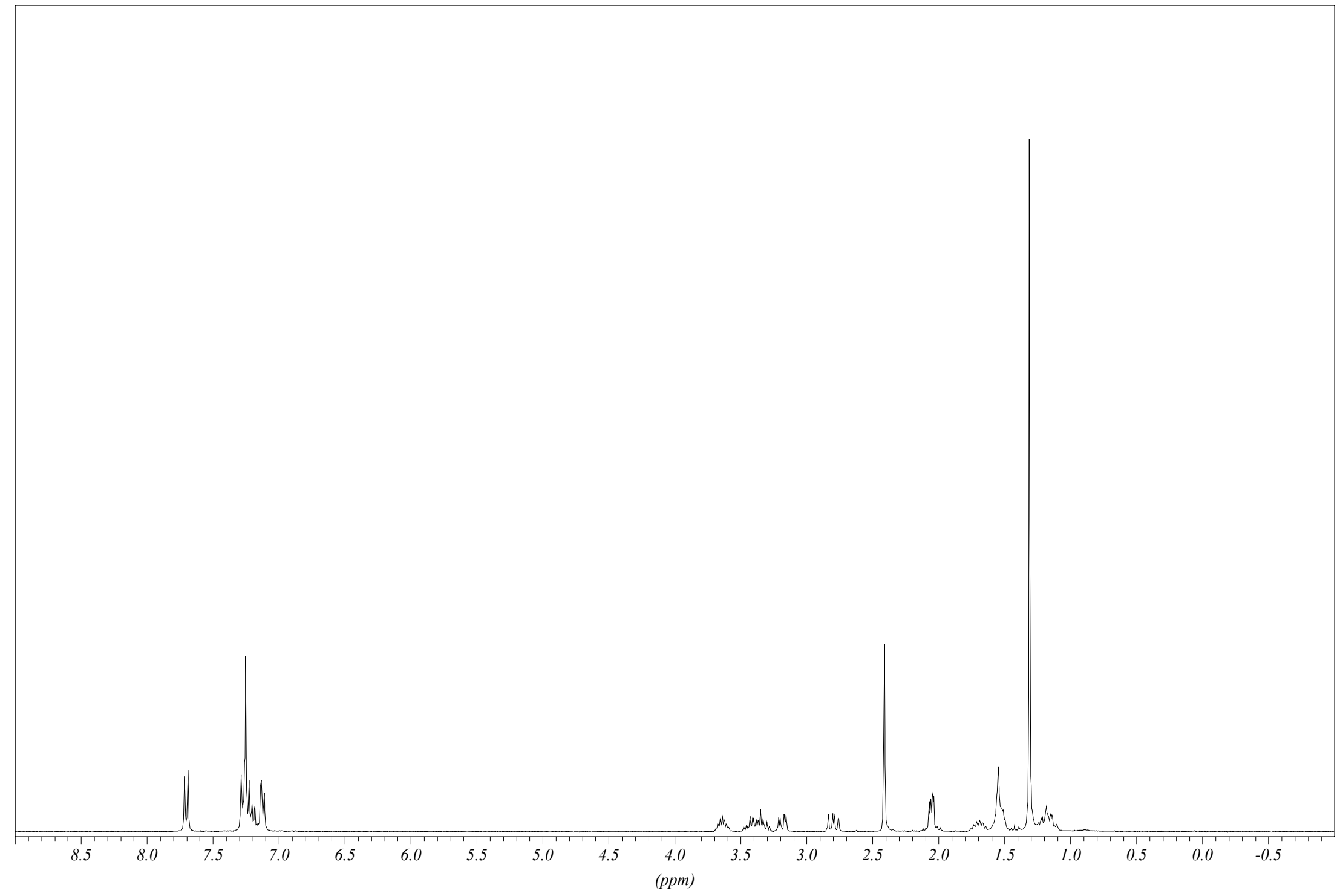

${ }^{1} \mathrm{H}$ NMR Spectrum (300 MHz) of $\mathbf{1 7} \mathbf{d}$ in $\mathrm{CDCl}_{3}$ 


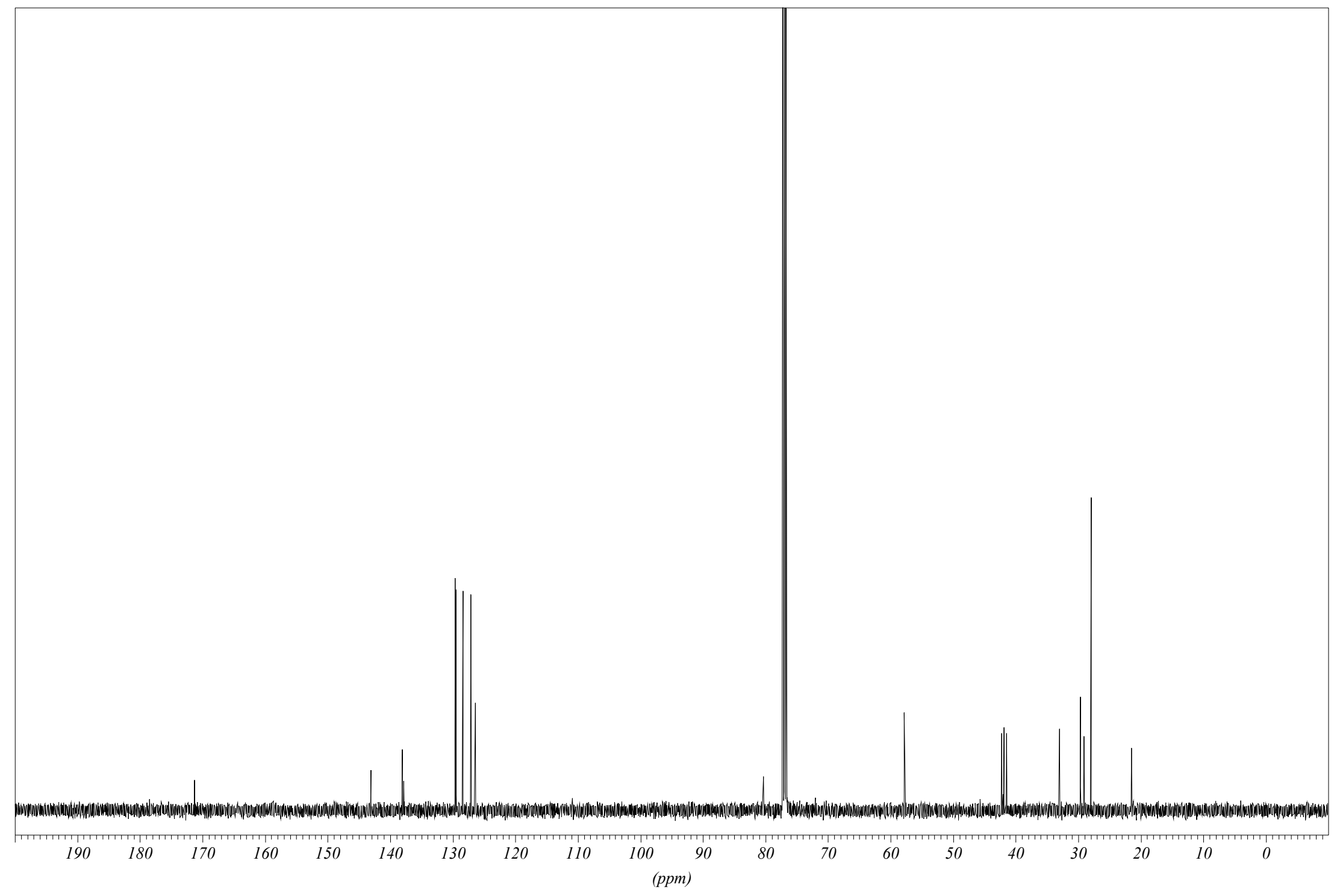

${ }^{13} \mathrm{C}$ NMR Spectrum $(125 \mathrm{MHz})$ of $\mathbf{1 7 d}$ in $\mathrm{CDCl}_{3}$ 


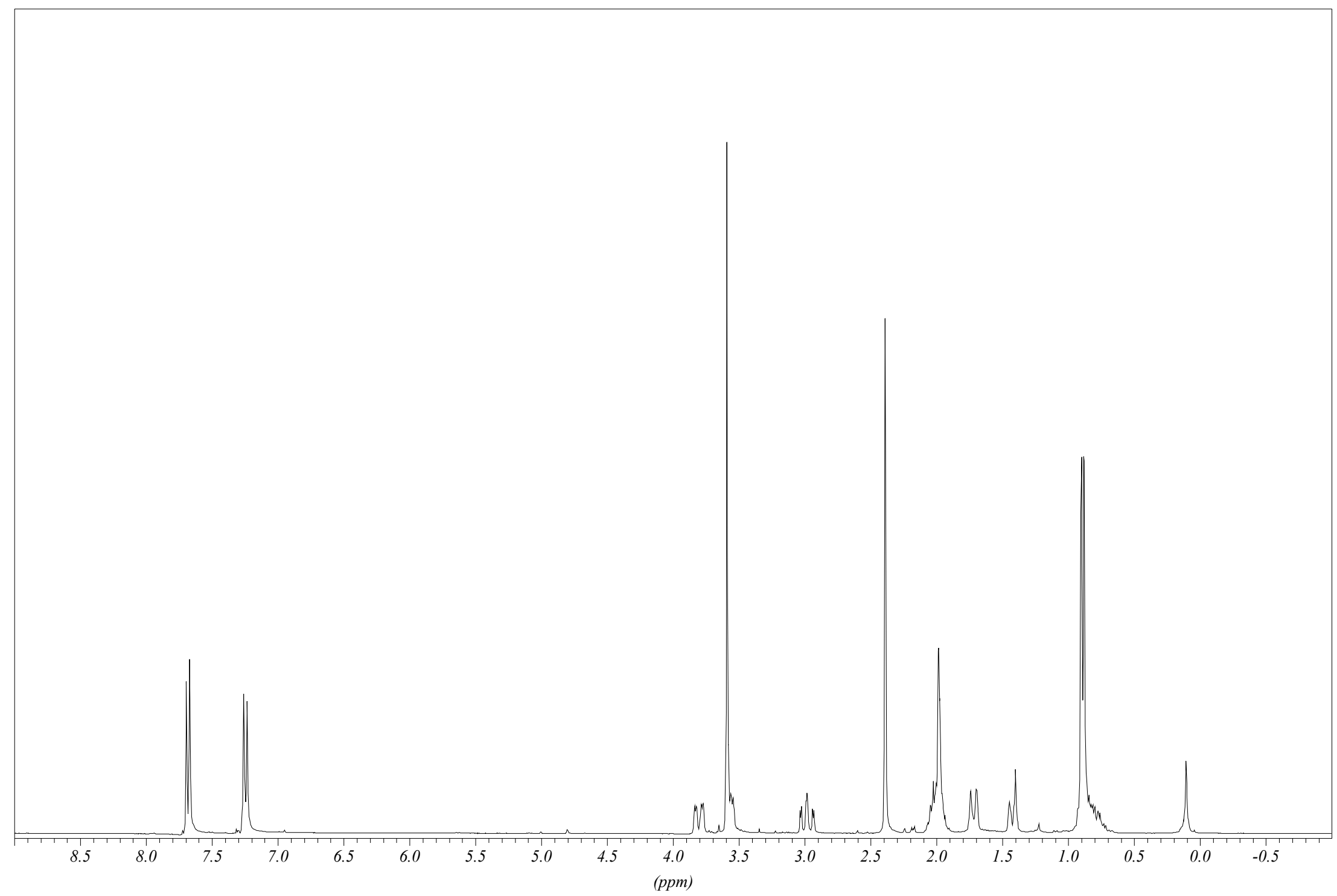

${ }^{1} \mathrm{H}$ NMR Spectrum (300 MHz) of $\mathbf{1 6 e}$ in $\mathrm{CDCl}_{3}$ 


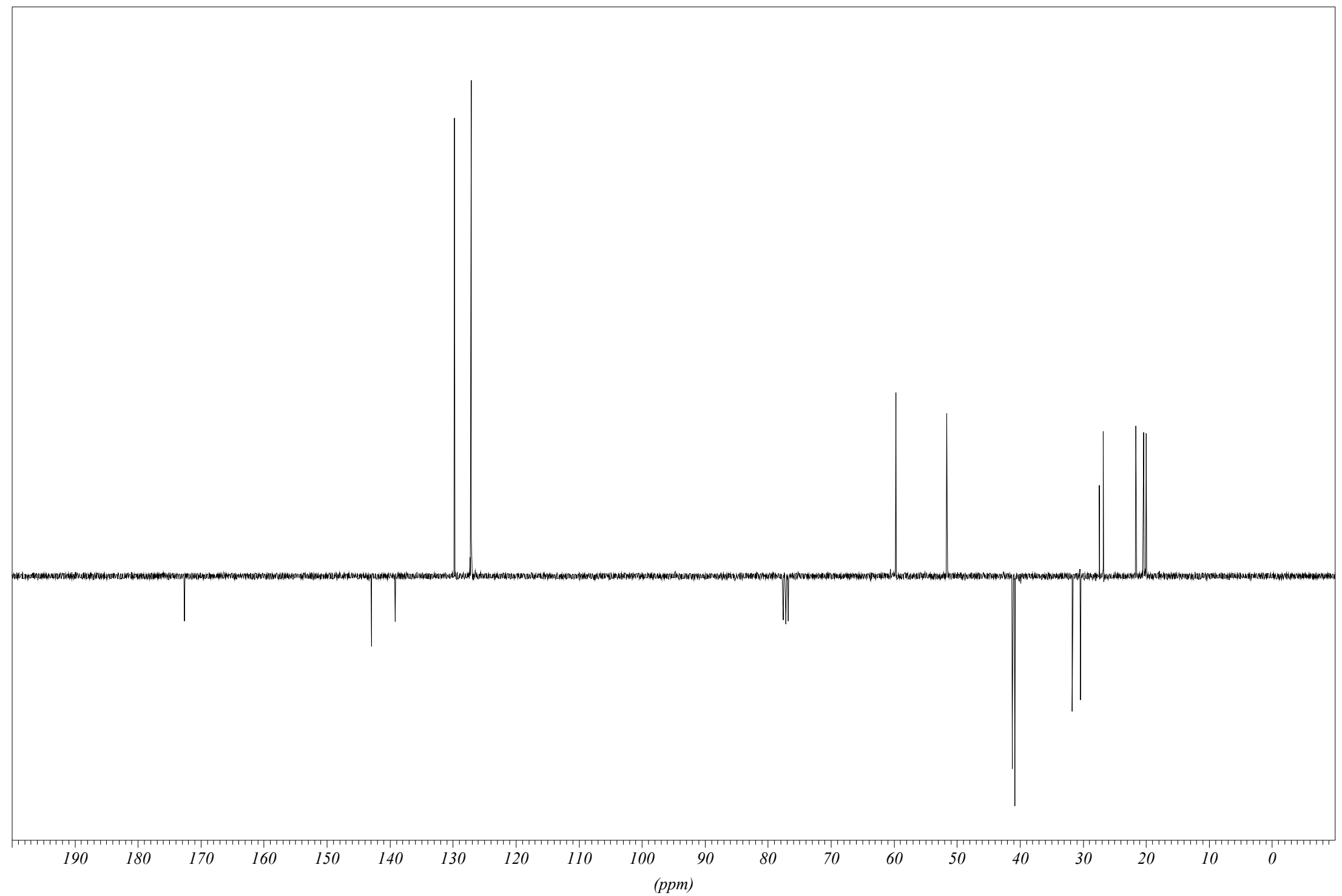

${ }^{13} \mathrm{C}$ NMR Spectrum (75 MHz) of $\mathbf{1 6 e}$ in $\mathrm{CDCl}_{3}$ 


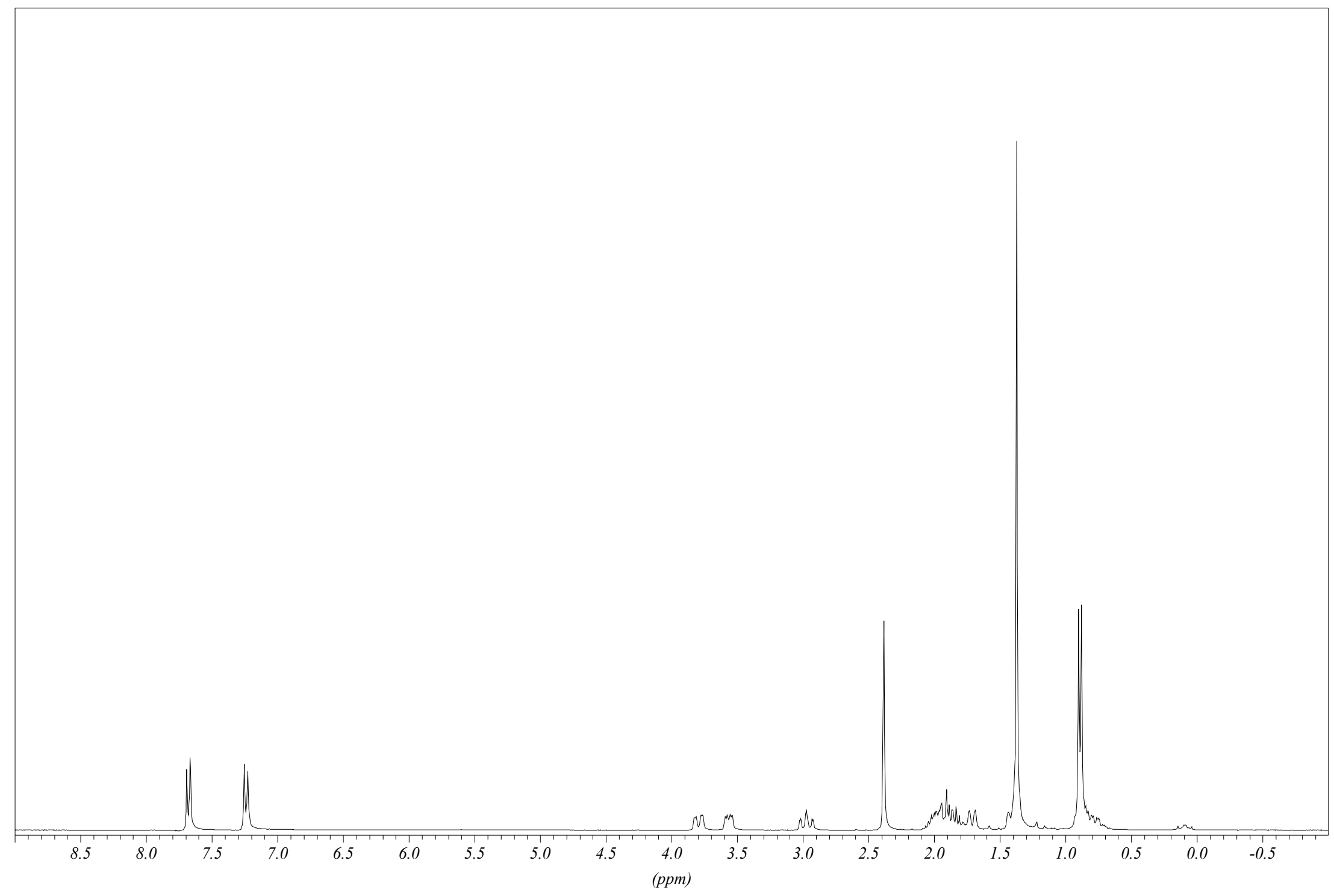

${ }^{1} \mathrm{H}$ NMR Spectrum (300 MHz) of $\mathbf{1 6} \mathbf{f}$ in $\mathrm{CDCl}_{3}$ 


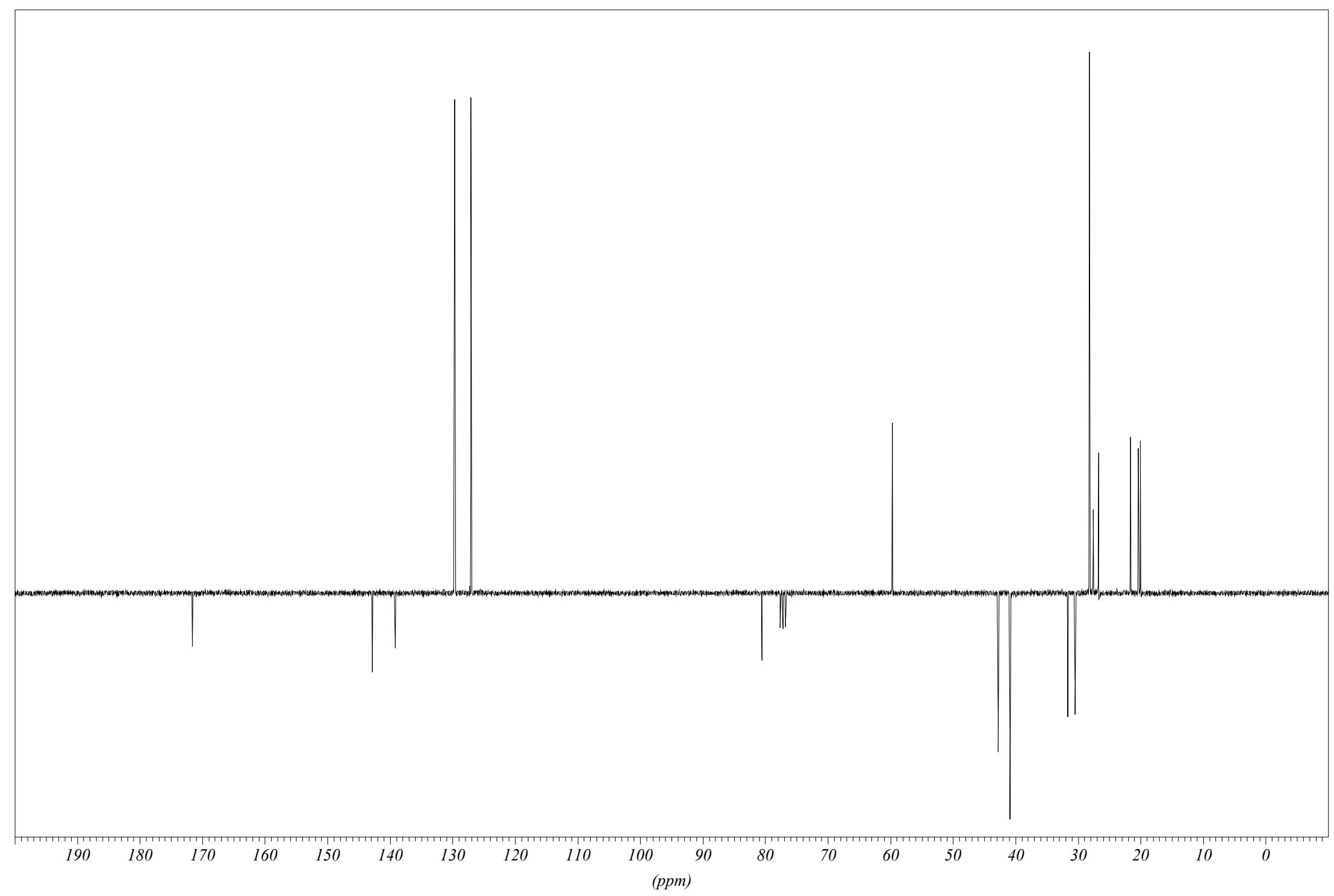

${ }^{13} \mathrm{C}$ NMR Spectrum (75 MHz) of $\mathbf{1 6 f}$ in $\mathrm{CDCl}_{3}$ 


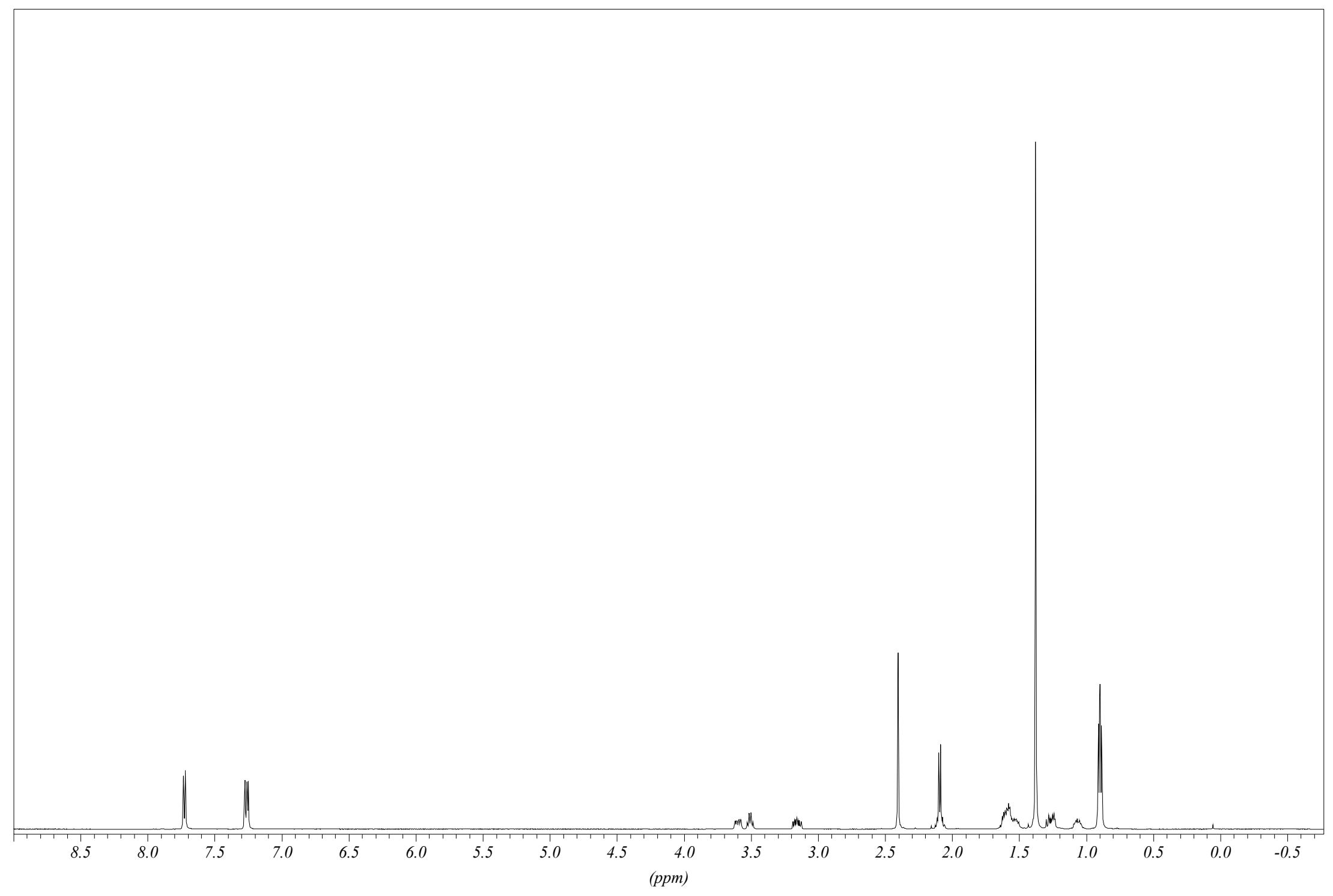

${ }^{1} \mathrm{H}$ NMR Spectrum $(500 \mathrm{MHz})$ of $\mathbf{1 7 f}$ in $\mathrm{CDCl}_{3}$ 


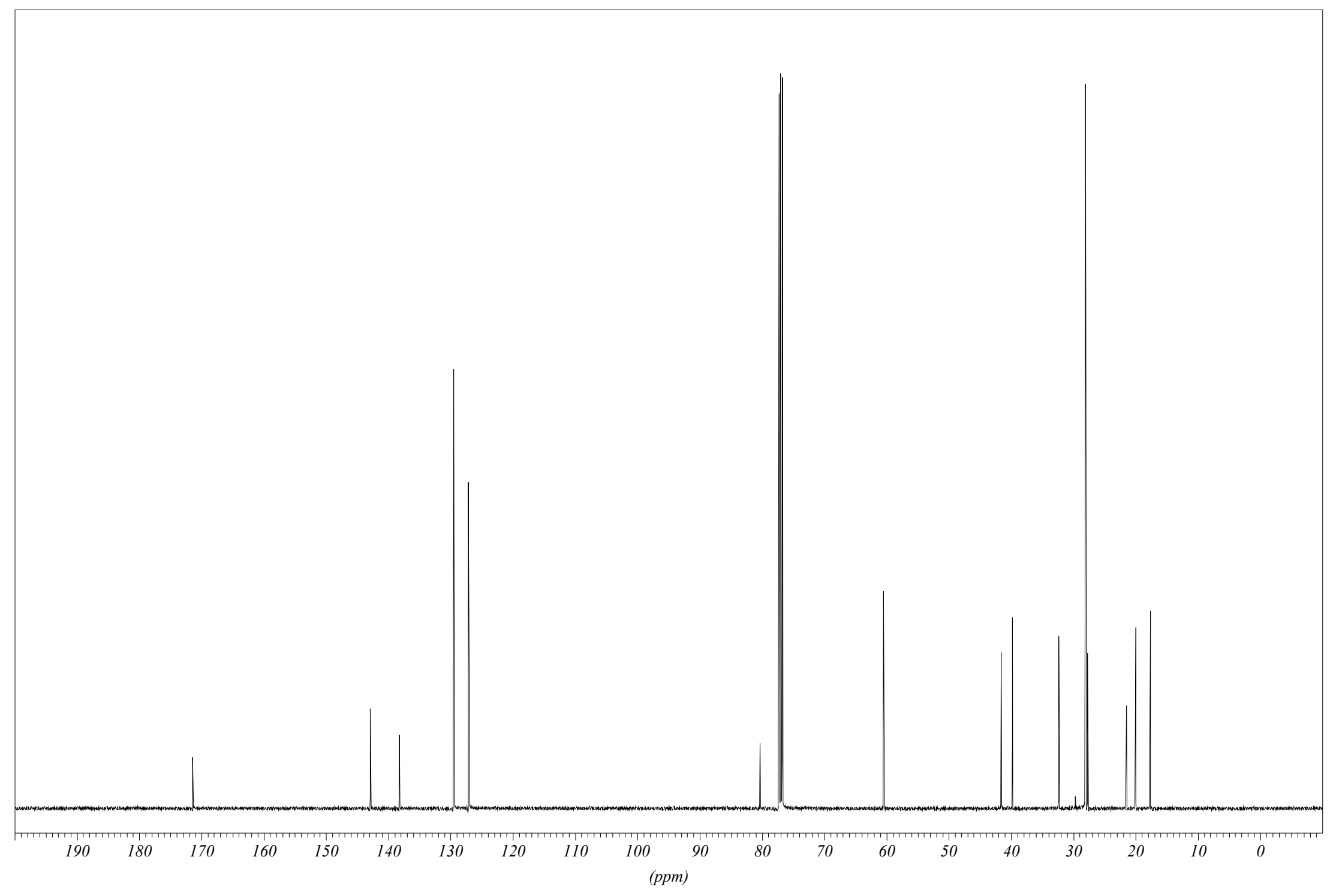

${ }^{13} \mathrm{C}$ NMR Spectrum (125 MHz) of $\mathbf{1 7 f}$ in $\mathrm{CDCl}_{3}$ 


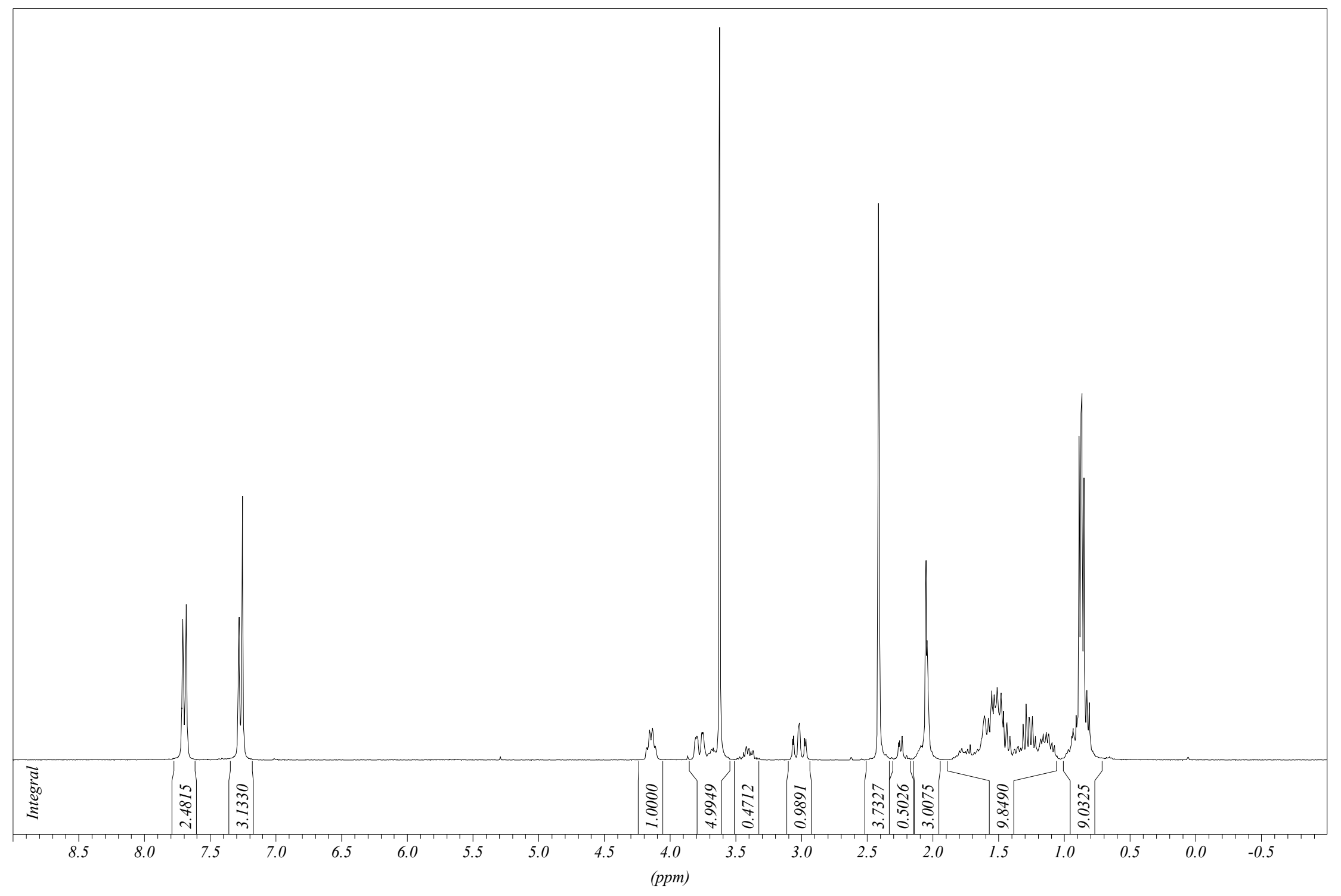

${ }^{1} \mathrm{H}$ NMR Spectrum $(300 \mathrm{MHz})$ of $\mathbf{1 6 g}$ and $\mathbf{1 7 g}(77: 23)$ in $\mathrm{CDCl}_{3}$ 


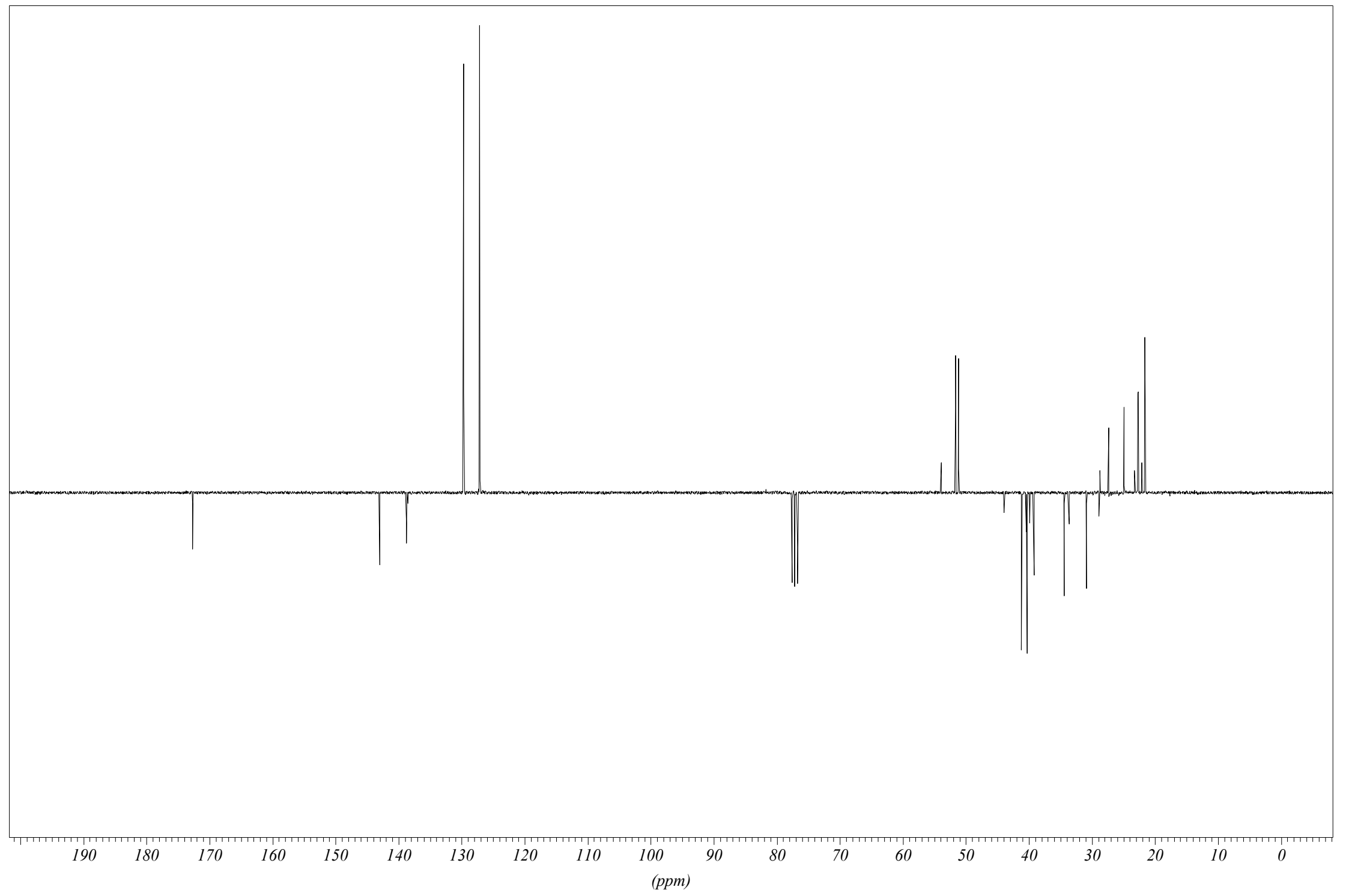

${ }^{13} \mathrm{C}$ NMR Spectrum $(75 \mathrm{MHz})$ of $\mathbf{1 6 g}$ and $\mathbf{1 7} \mathbf{g}(77: 23)$ in $\mathrm{CDCl}_{3}$ 


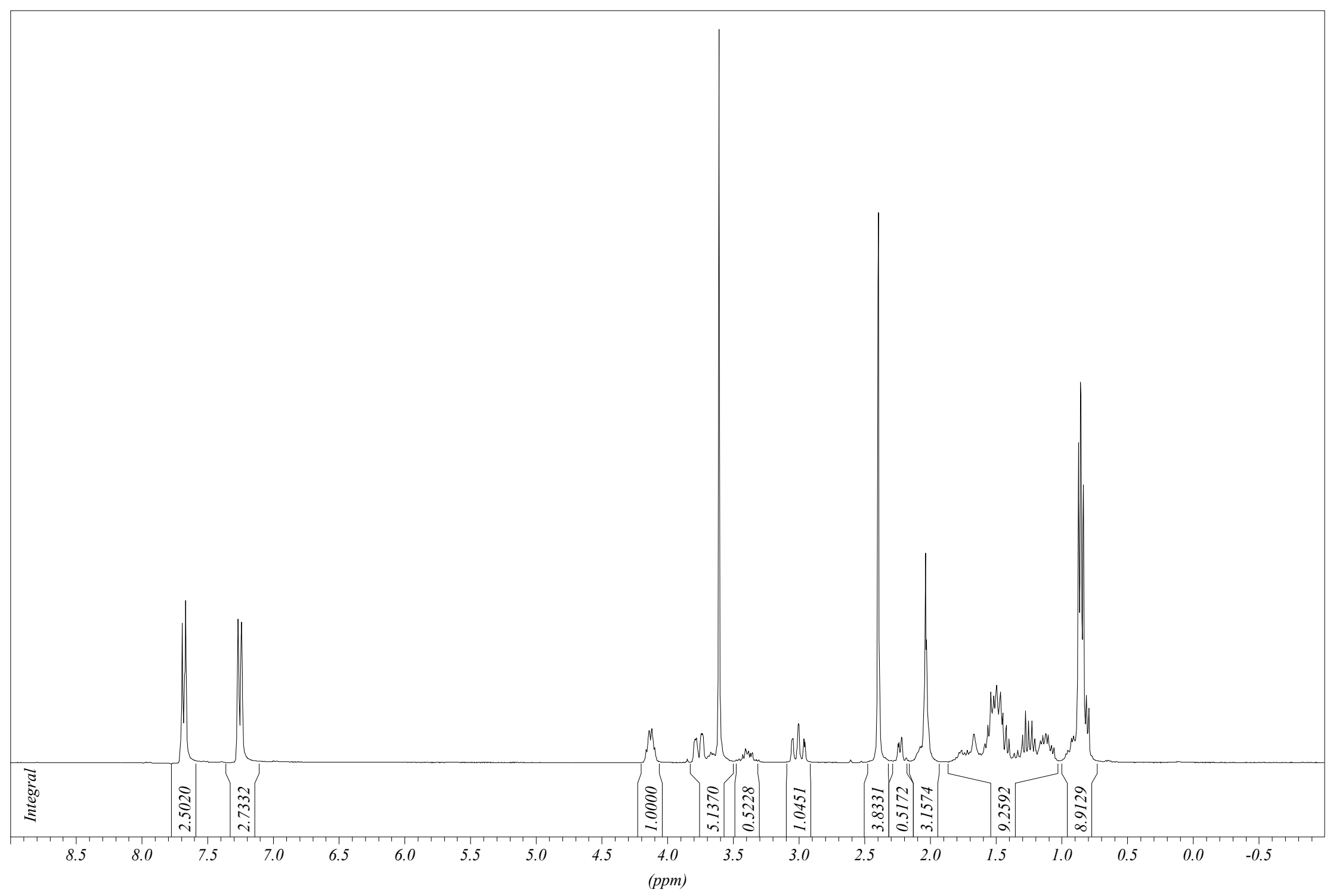

${ }^{1} \mathrm{H}$ NMR Spectrum (300 MHz) of $\mathbf{1 6 g}$ and $\mathbf{1 7 g}(85: 15)$ in $\mathrm{CDCl}_{3}$ 


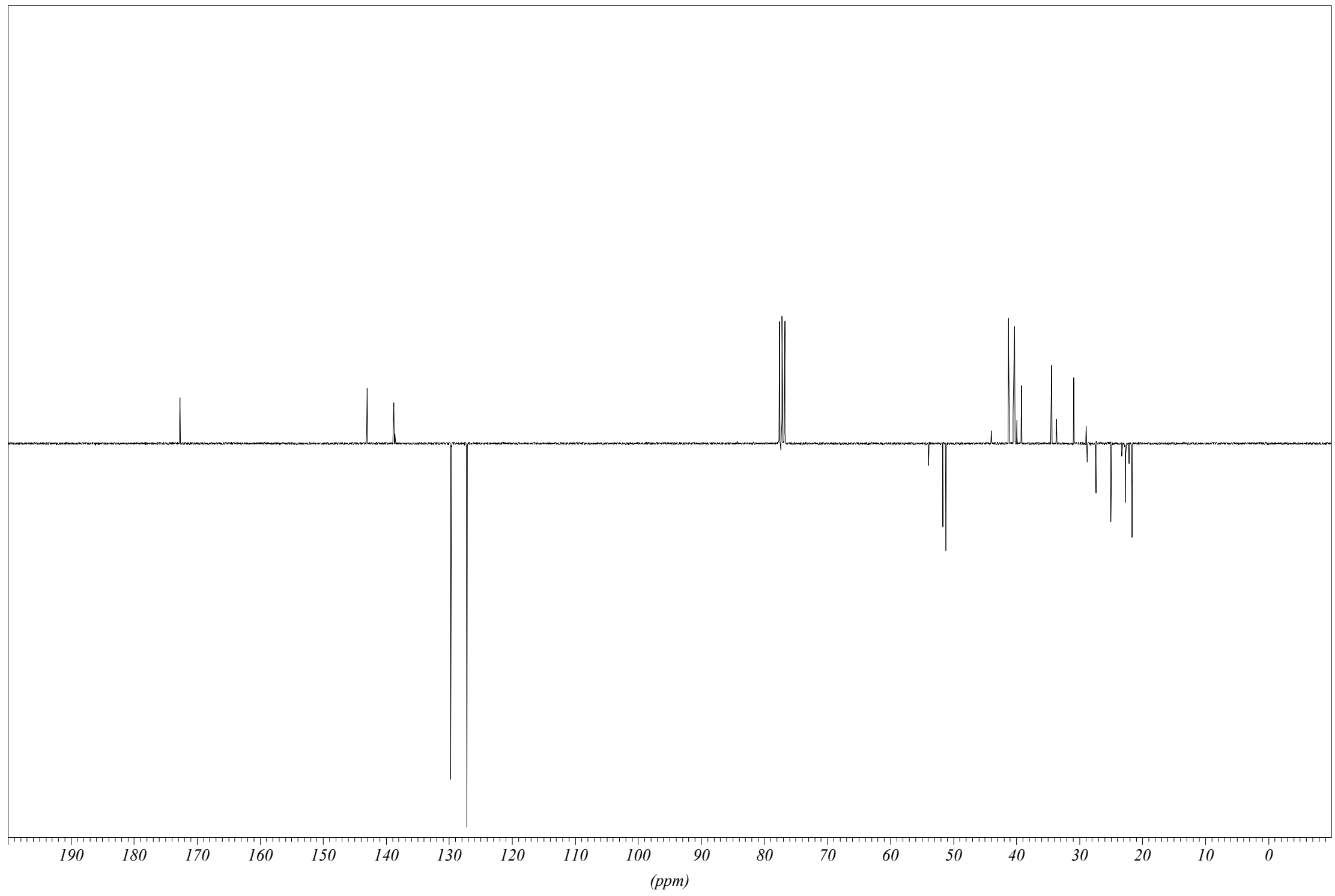

${ }^{13} \mathrm{C}$ NMR Spectrum $(75 \mathrm{MHz})$ of $\mathbf{1 6 g}$ and $\mathbf{1 7} \mathbf{g}(85: 15)$ in $\mathrm{CDCl}_{3}$ 


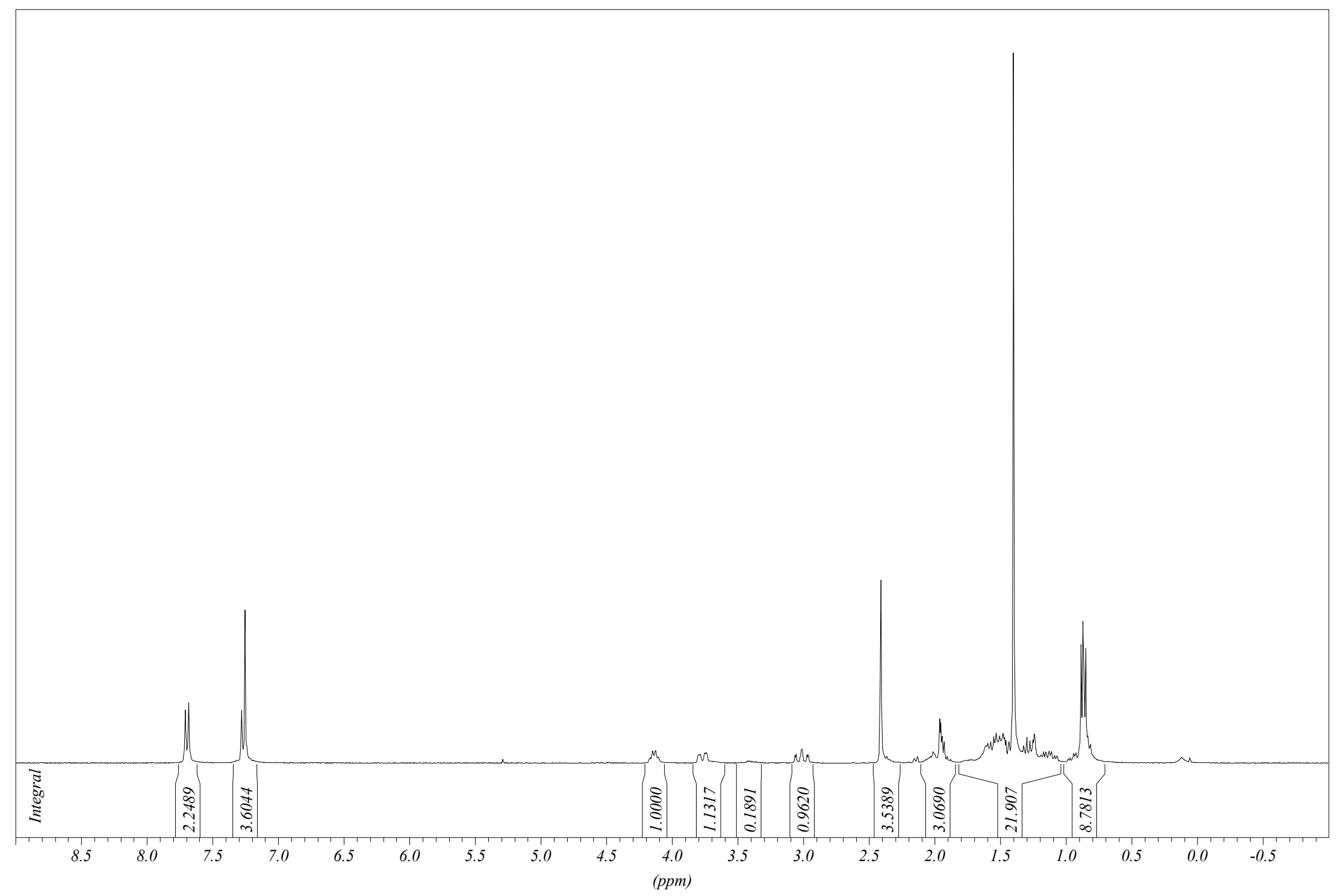

${ }^{1} \mathrm{H}$ NMR Spectrum (300 MHz) of $\mathbf{1 6 h}$ and $\mathbf{1 7} \mathbf{h}$ from TTMSS cyclization in $\mathrm{CDCl}_{3}$ 


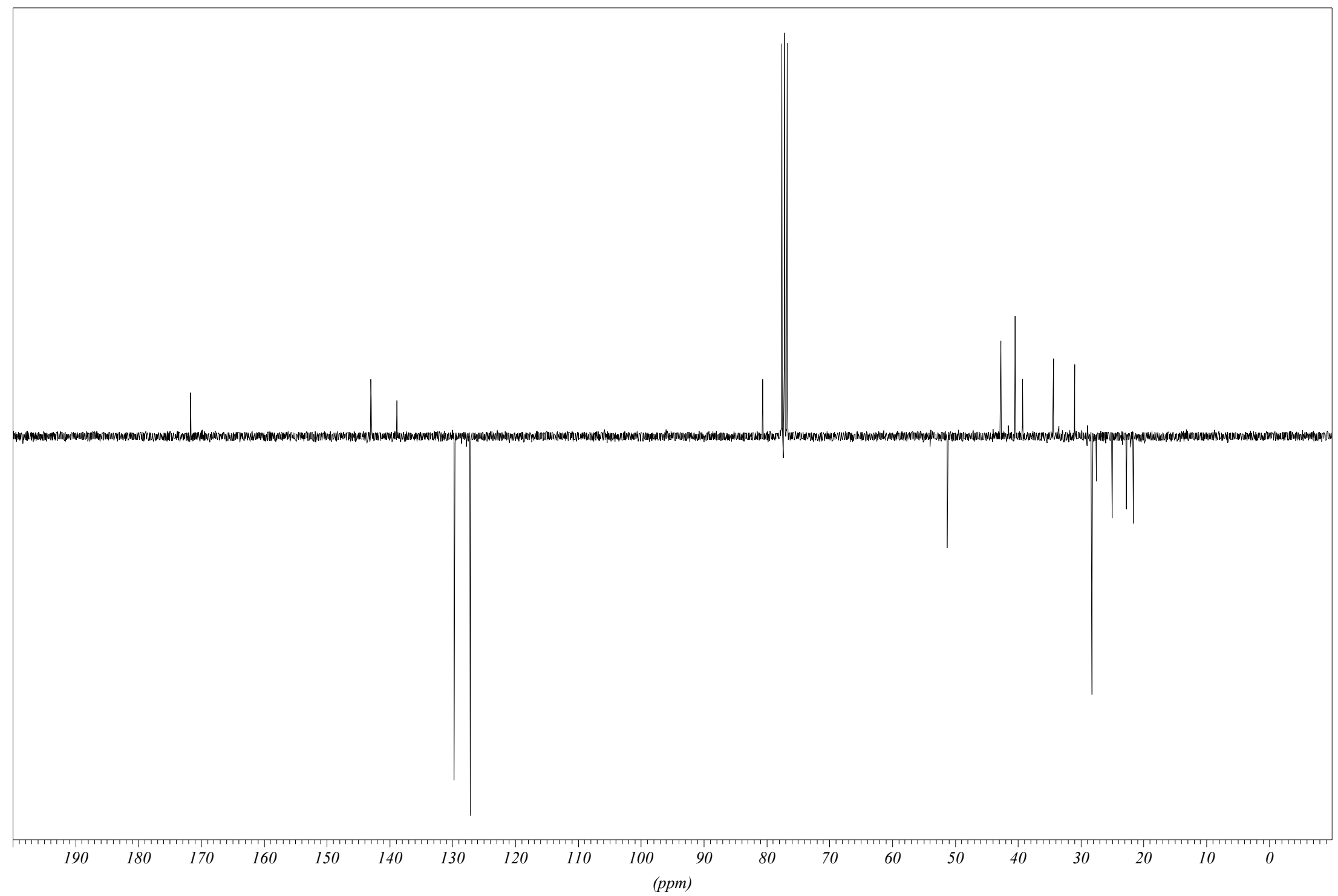

${ }^{13} \mathrm{C}$ NMR Spectrum (75 MHz) of $\mathbf{1 6} \mathbf{h}$ and $\mathbf{1 7} \mathbf{h}$ from TTMSS cyclization in $\mathrm{CDCl}_{3}$ 


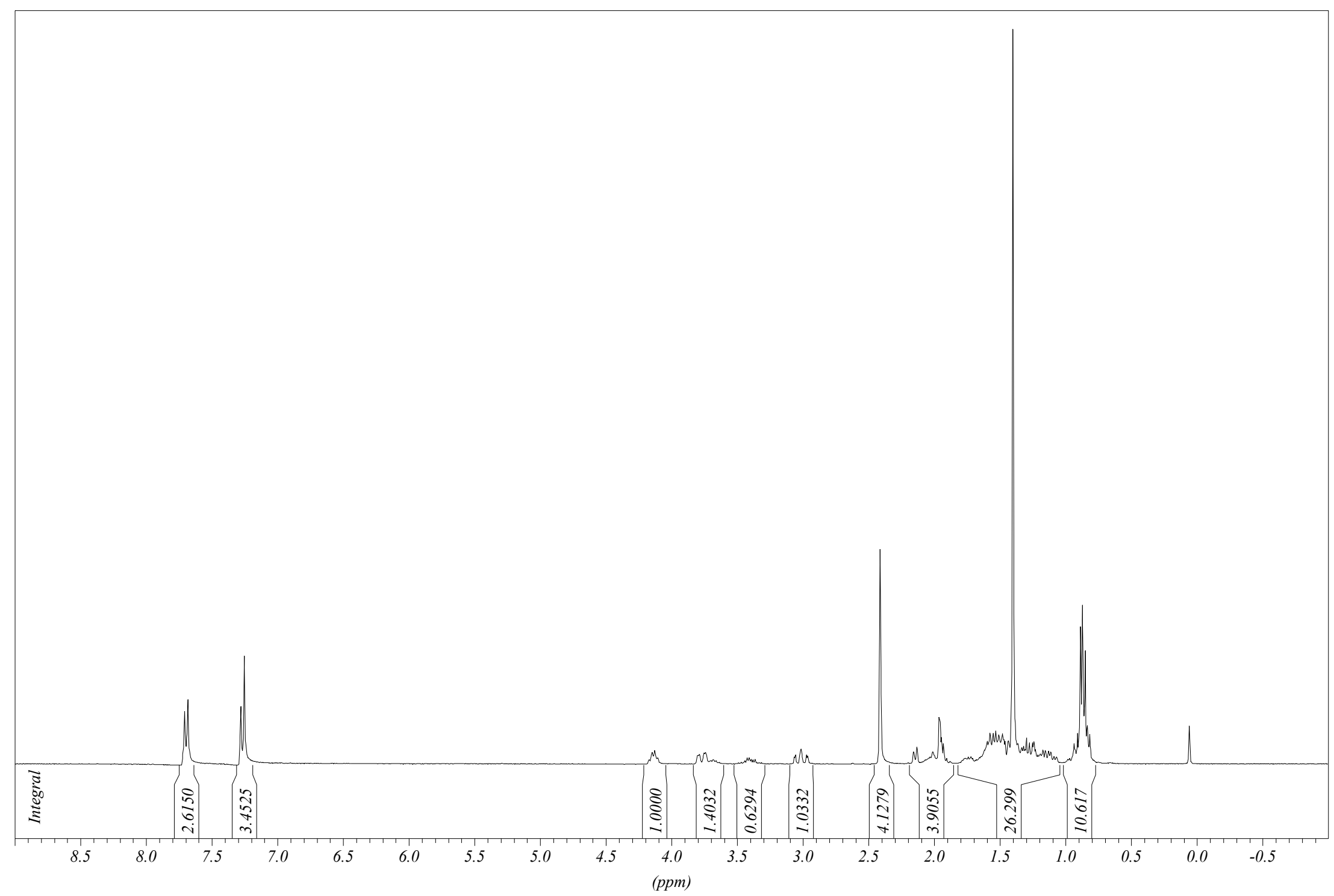

${ }^{1} \mathrm{H}$ NMR Spectrum (300 MHz) of $\mathbf{1 6} \mathbf{h}$ and $\mathbf{1 7} \mathbf{h}$ from TBTH cyclization in $\mathrm{CDCl}_{3}$ 


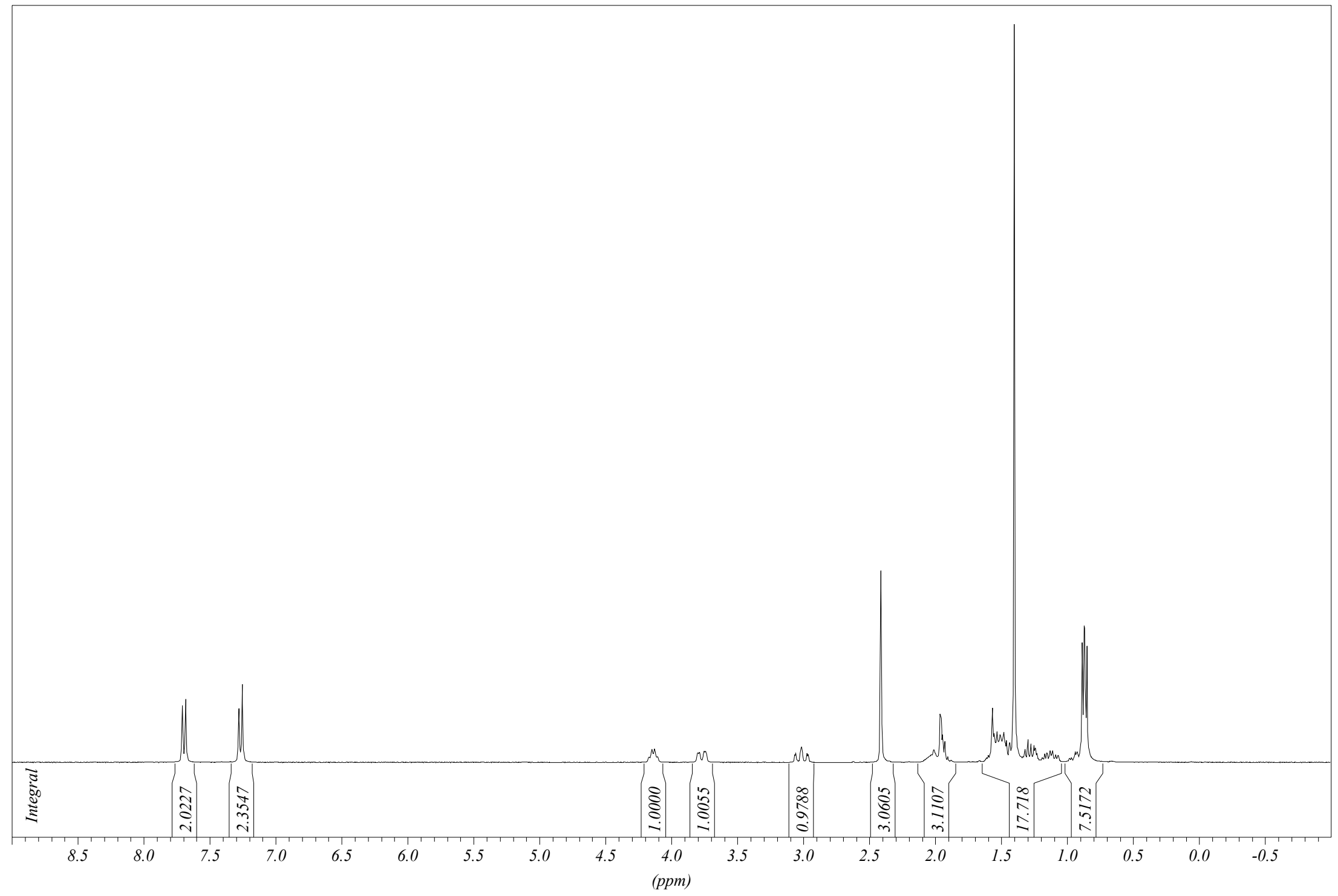

${ }^{1} \mathrm{H}$ NMR Spectrum (300 MHz) of $\mathbf{1 6} \mathbf{h}$ in $\mathrm{CDCl}_{3}$ 


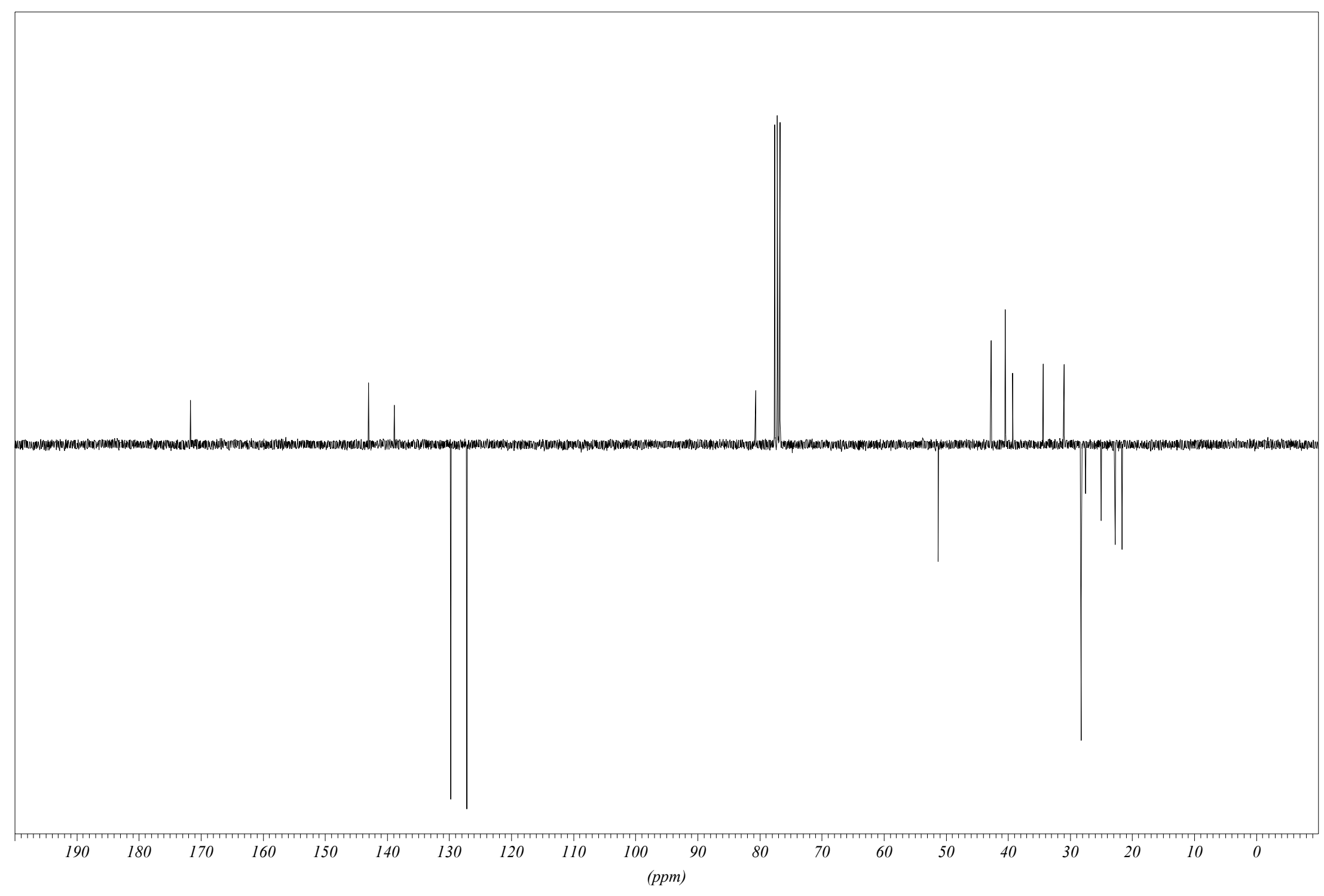

${ }^{13} \mathrm{C}$ NMR Spectrum (75 MHz) of $\mathbf{1 6} \mathbf{h}$ in $\mathrm{CDCl}_{3}$ 


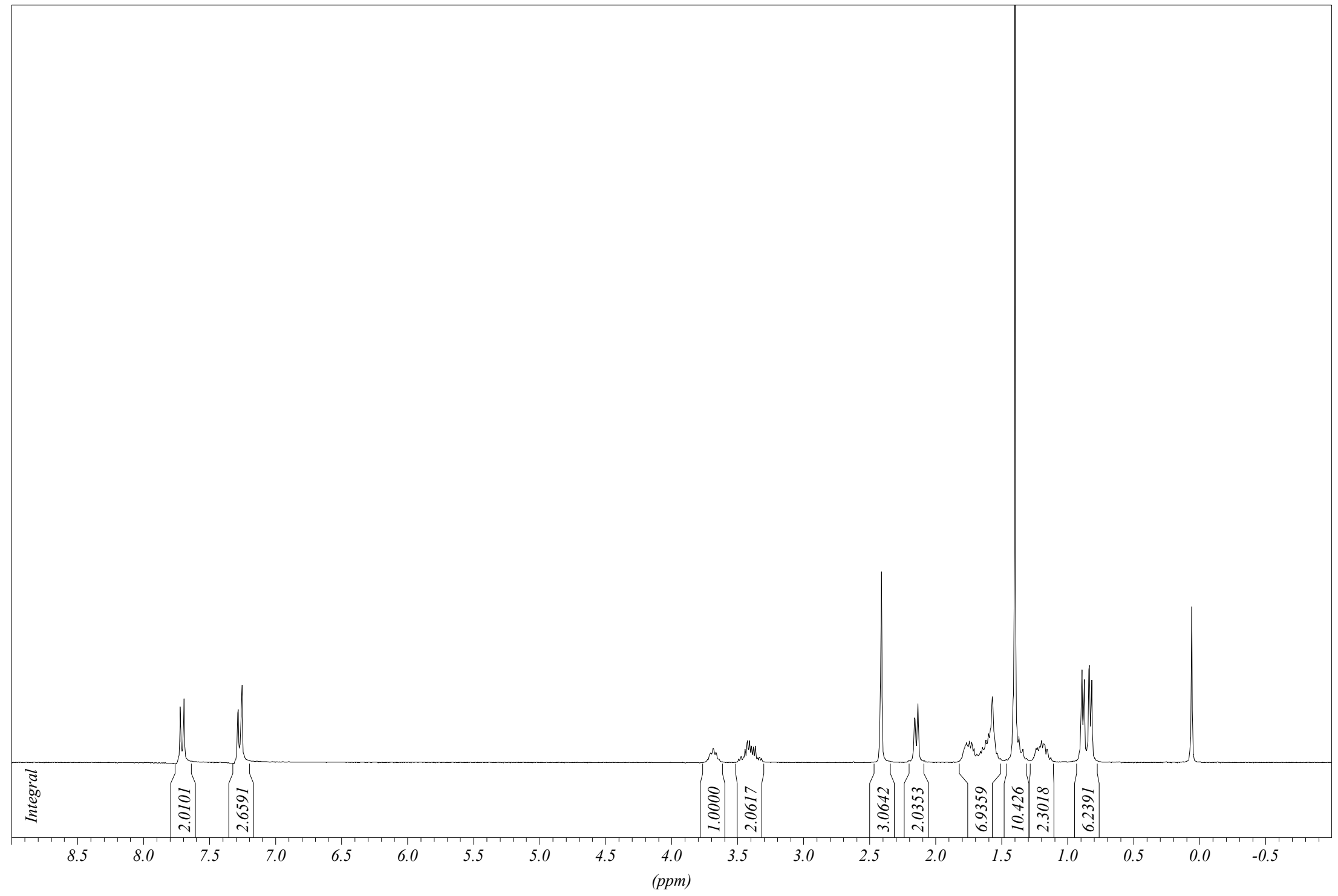

${ }^{1} \mathrm{H}$ NMR Spectrum (300 MHz) of $\mathbf{1 7 h}$ in $\mathrm{CDCl}_{3}$ 


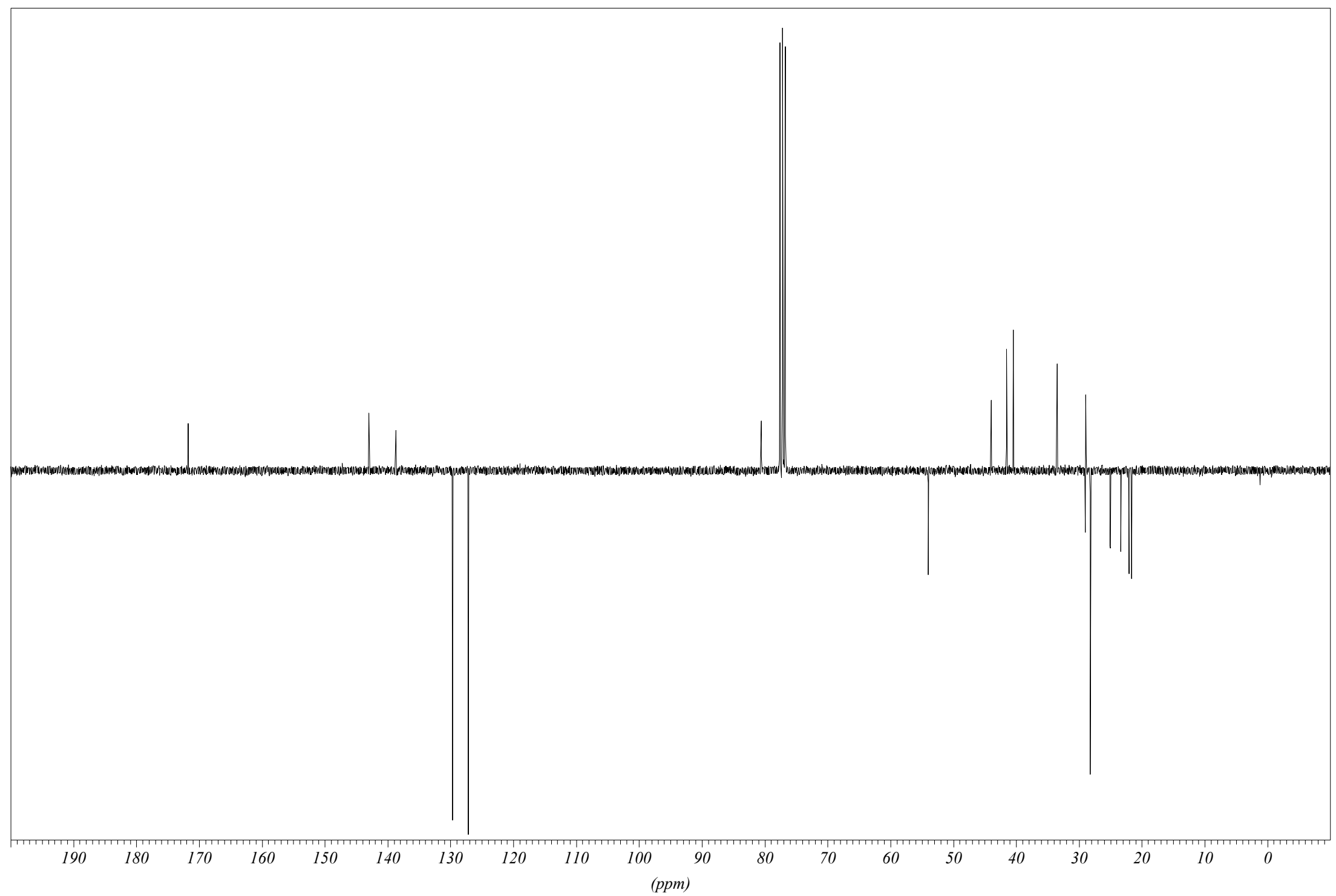

${ }^{13} \mathrm{C}$ NMR Spectrum (75 MHz) of $\mathbf{1 7} \mathbf{h}$ in $\mathrm{CDCl}_{3}$ 


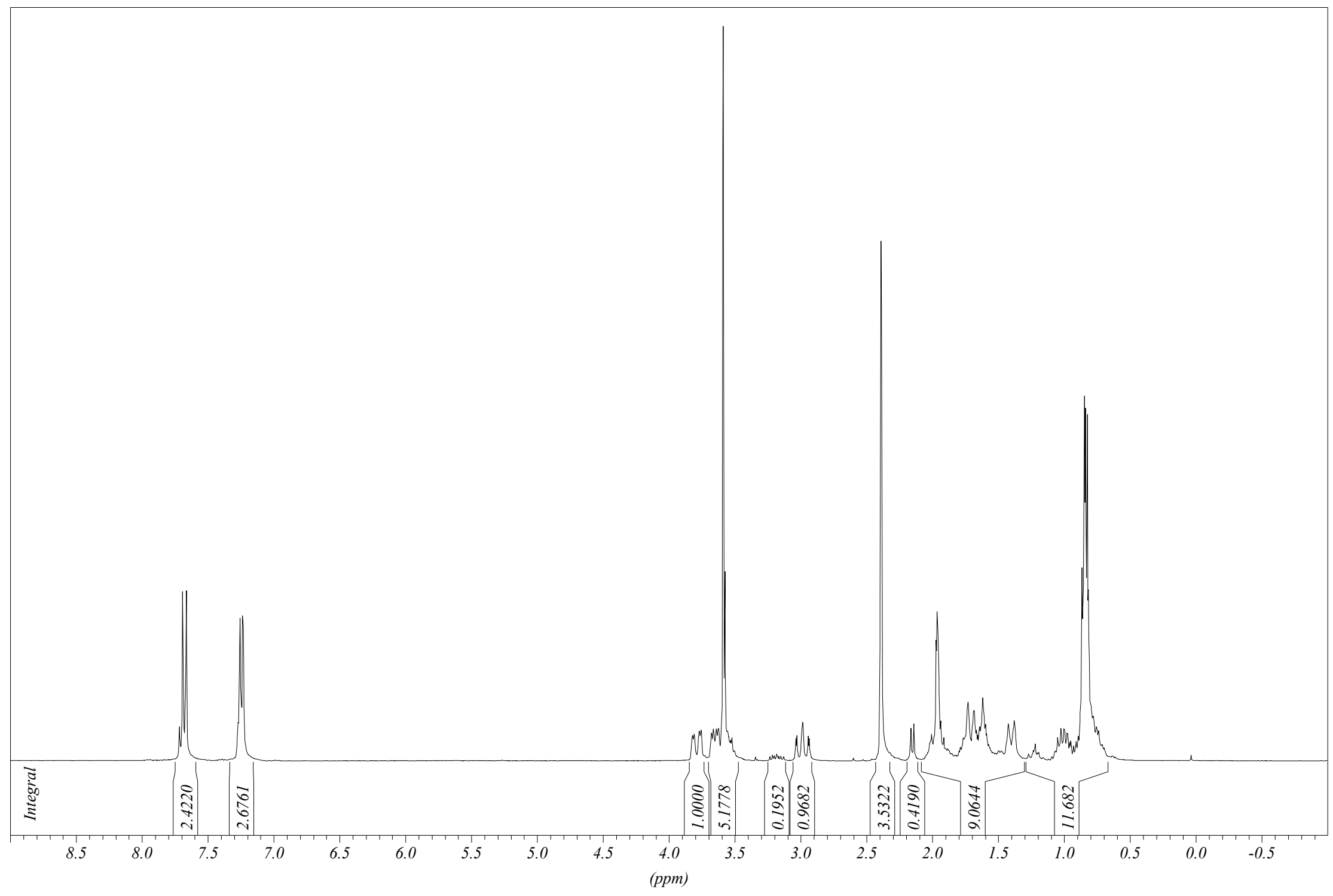

${ }^{1} \mathrm{H}$ NMR Spectrum $(300 \mathrm{MHz})$ of $\mathbf{1 6 i}$ and $\mathbf{1 7} \mathbf{i}(85: 15)$ in $\mathrm{CDCl}_{3}$ 


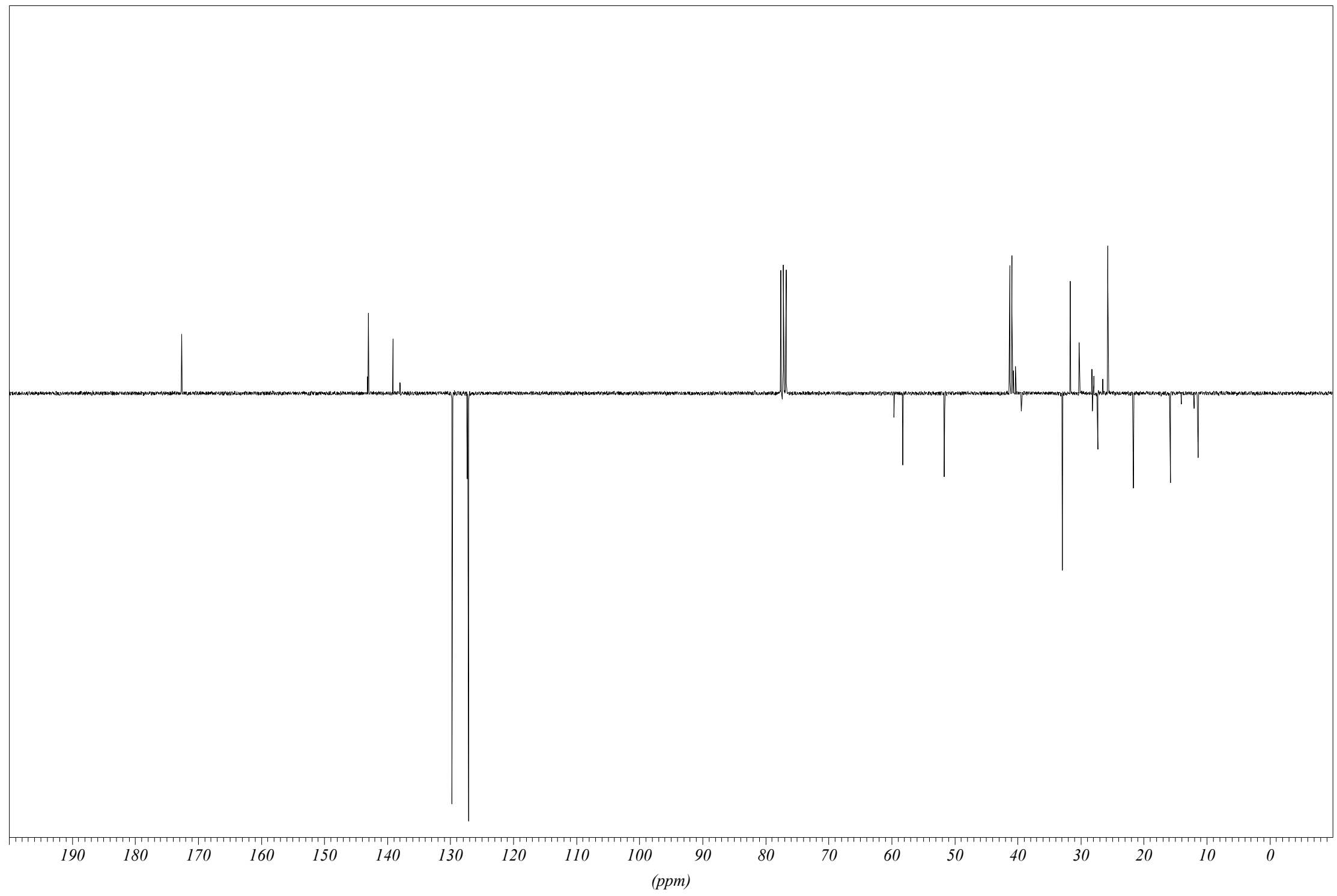

${ }^{13} \mathrm{C}$ NMR Spectrum $(75 \mathrm{MHz})$ of $\mathbf{1 6 i}$ and $\mathbf{1 7} \mathbf{i}(85: 15)$ in $\mathrm{CDCl}_{3}$ 


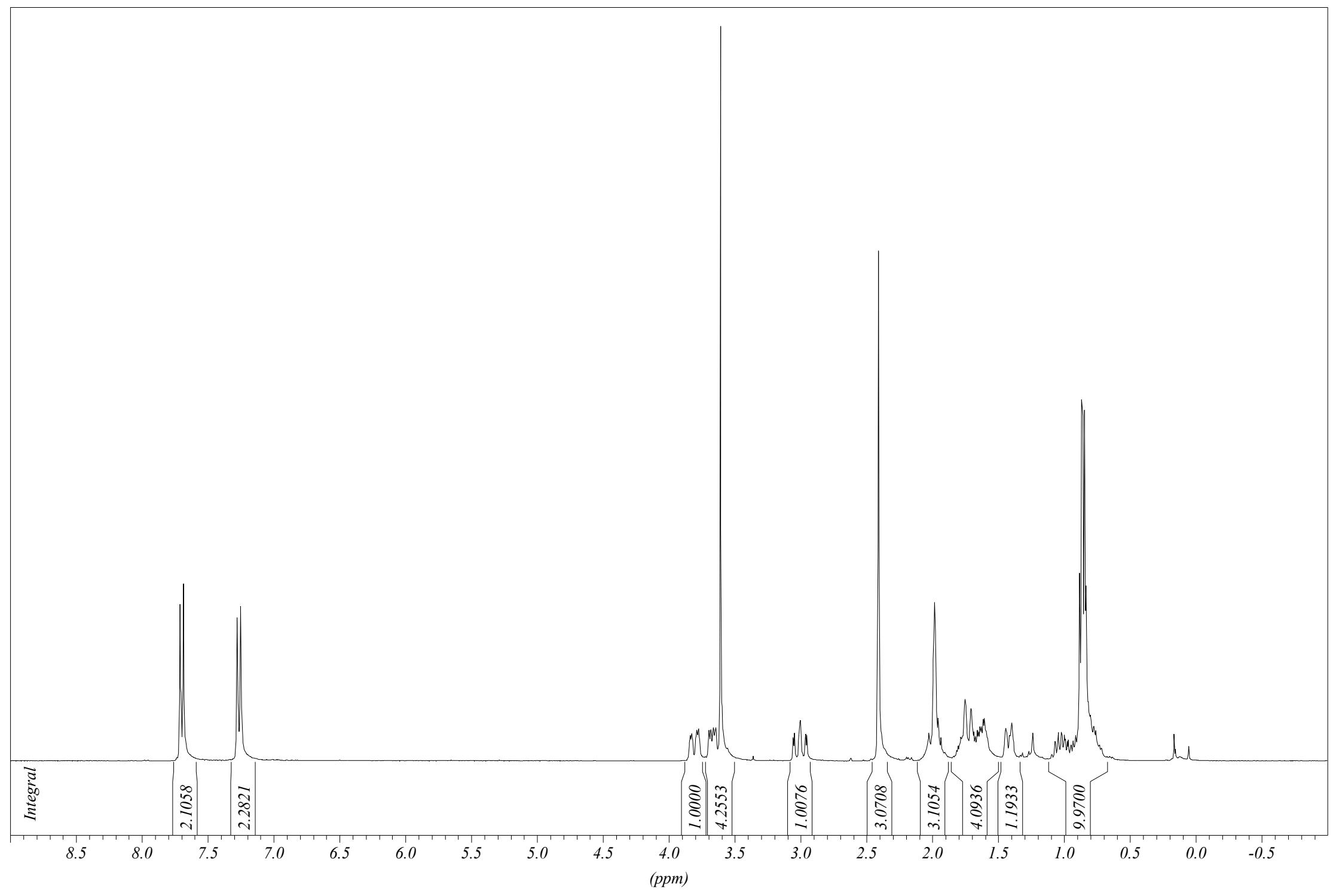

${ }^{1} \mathrm{H}$ NMR Spectrum (300 MHz) of $\mathbf{1 6} \mathbf{i}$ in $\mathrm{CDCl}_{3}$ 


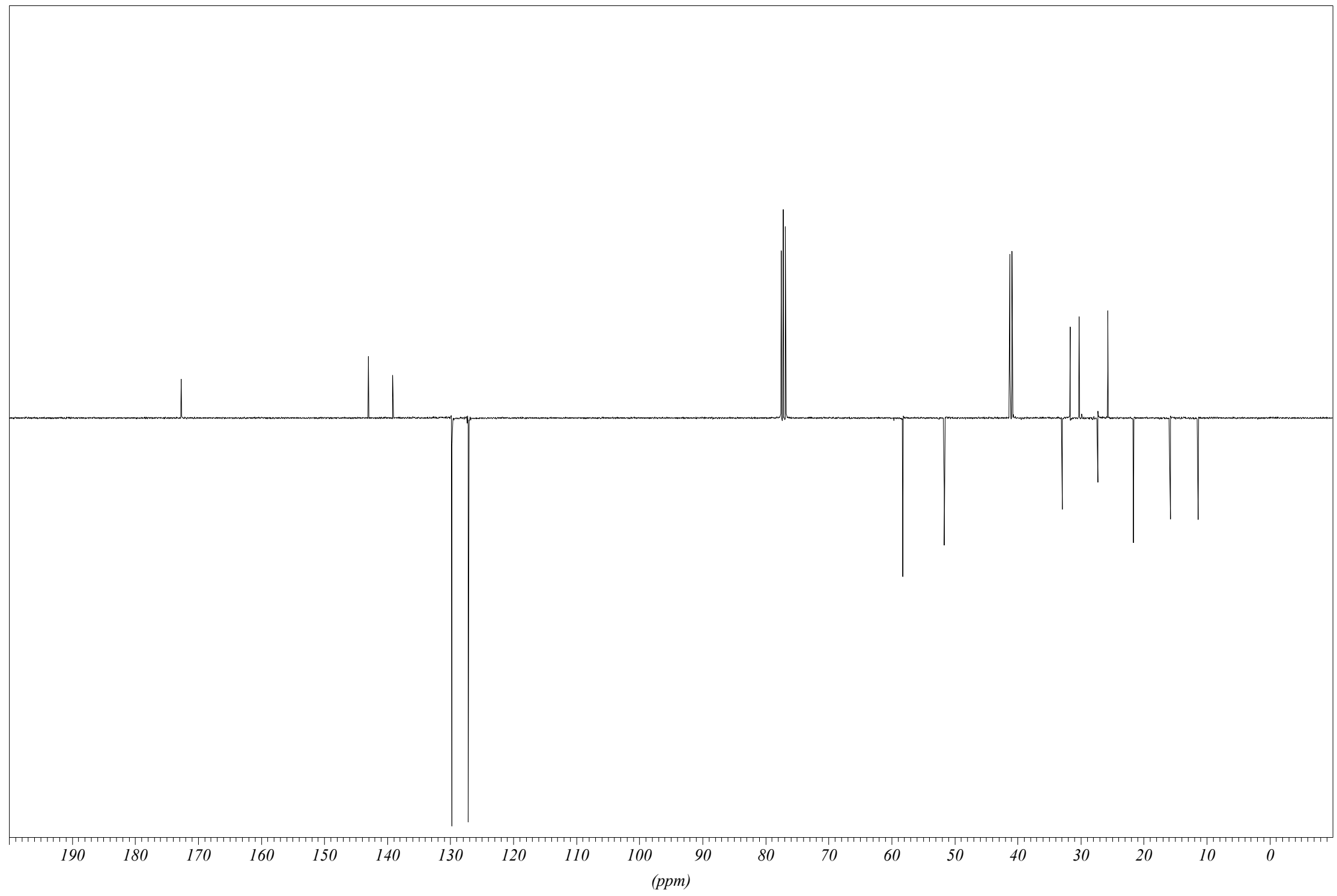

${ }^{13} \mathrm{C}$ NMR Spectrum (75 MHz) of $\mathbf{1 6} \mathbf{i}$ in $\mathrm{CDCl}_{3}$ 


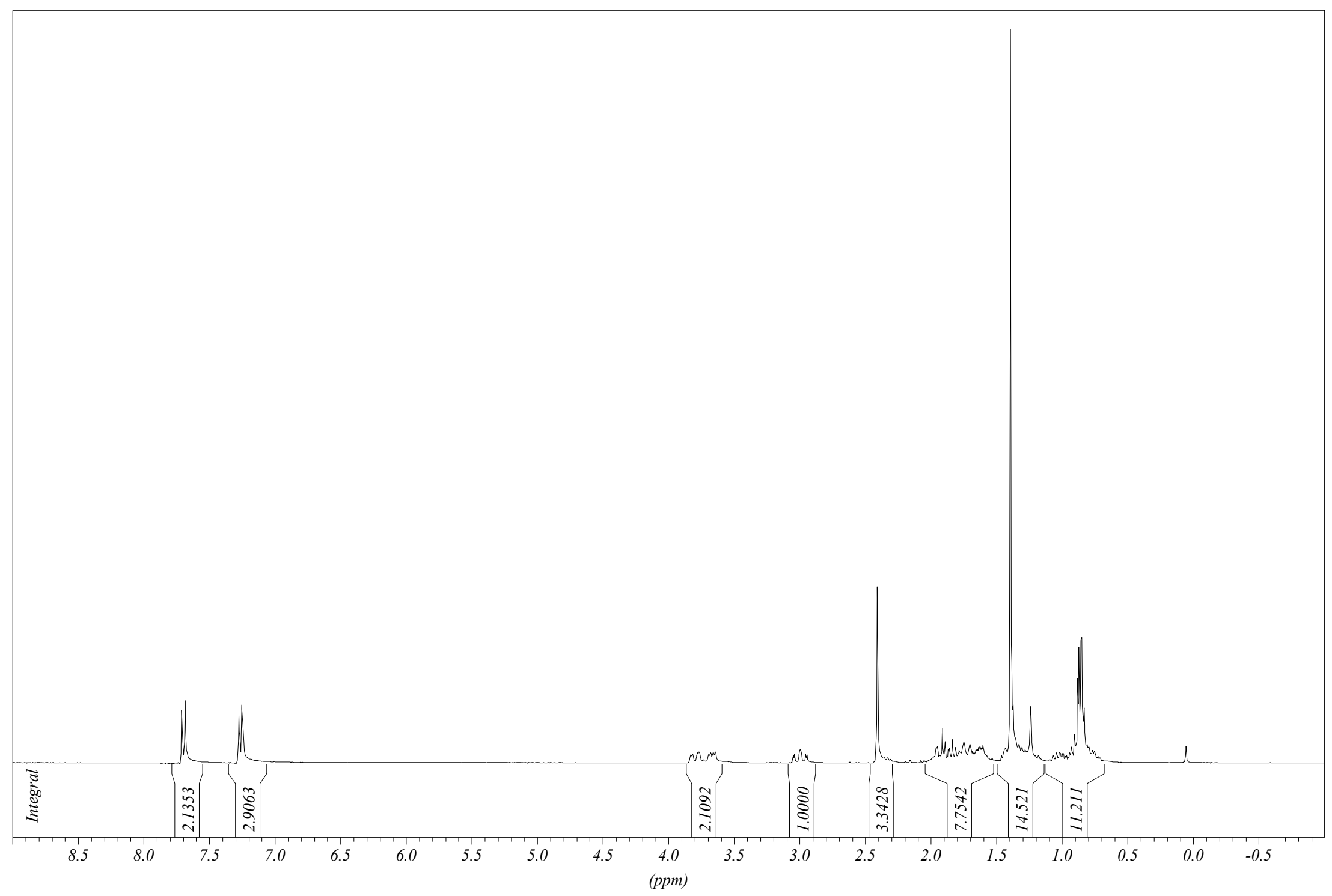

${ }^{1} \mathrm{H}$ NMR Spectrum (300 MHz) of $\mathbf{1 6} \mathbf{j}$ and $\mathbf{1 7} \mathbf{j}$ (97:3) in $\mathrm{CDCl}_{3}$ 


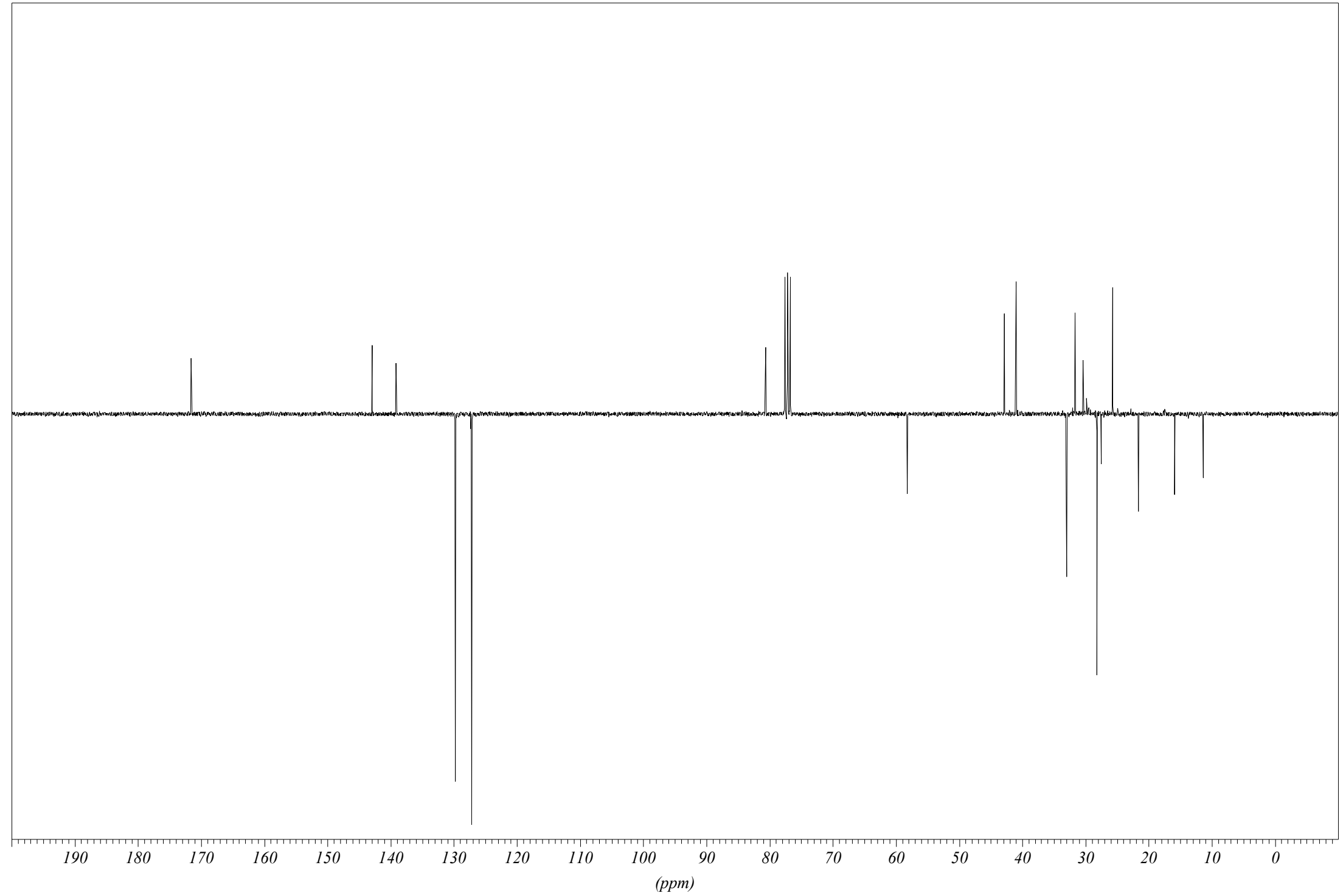

${ }^{13} \mathrm{C}$ NMR Spectrum (75 MHz) of $\mathbf{1 6} \mathbf{j}$ and $\mathbf{1 7} \mathbf{j}(97: 3)$ in $\mathrm{CDCl}_{3}$ 


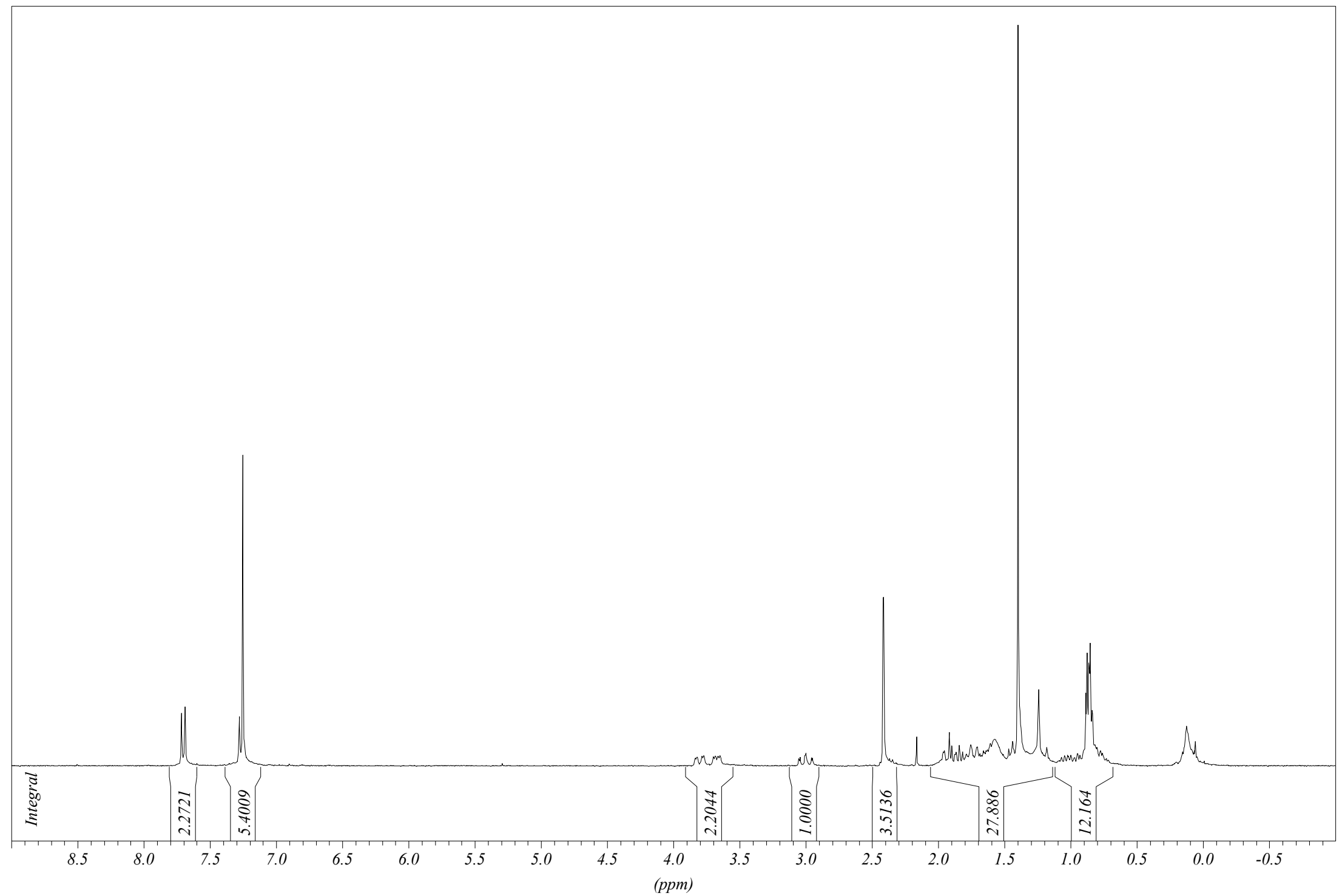

${ }^{1} \mathrm{H}$ NMR Spectrum (300 MHz) of $\mathbf{1 6} \mathbf{j}$ from TTMSS cyclization in $\mathrm{CDCl}_{3}$ 


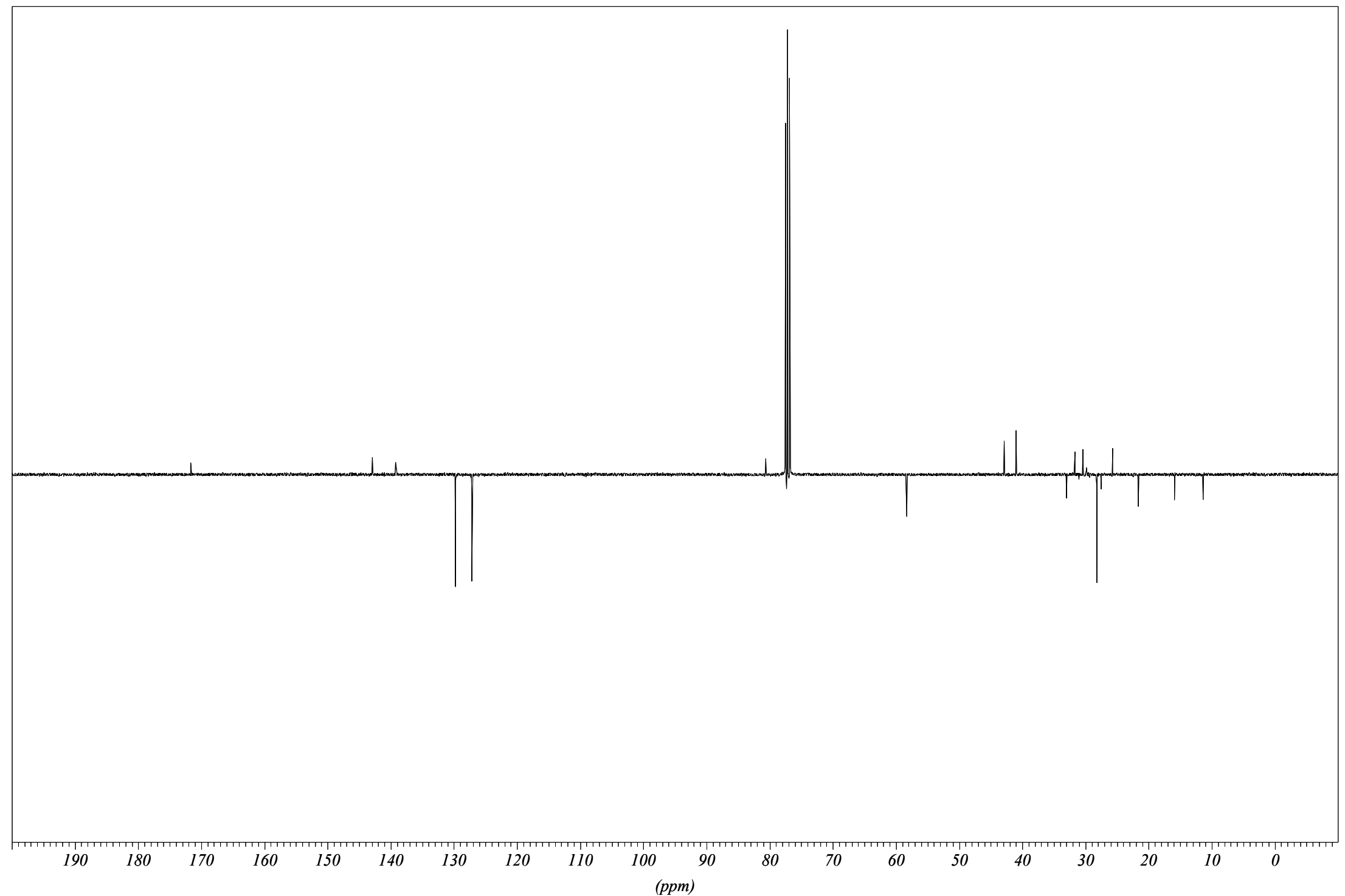

${ }^{13} \mathrm{C}$ NMR Spectrum (75 MHz) of $\mathbf{1 6} \mathbf{j}$ from TTMSS cyclization in $\mathrm{CDCl}_{3}$ 


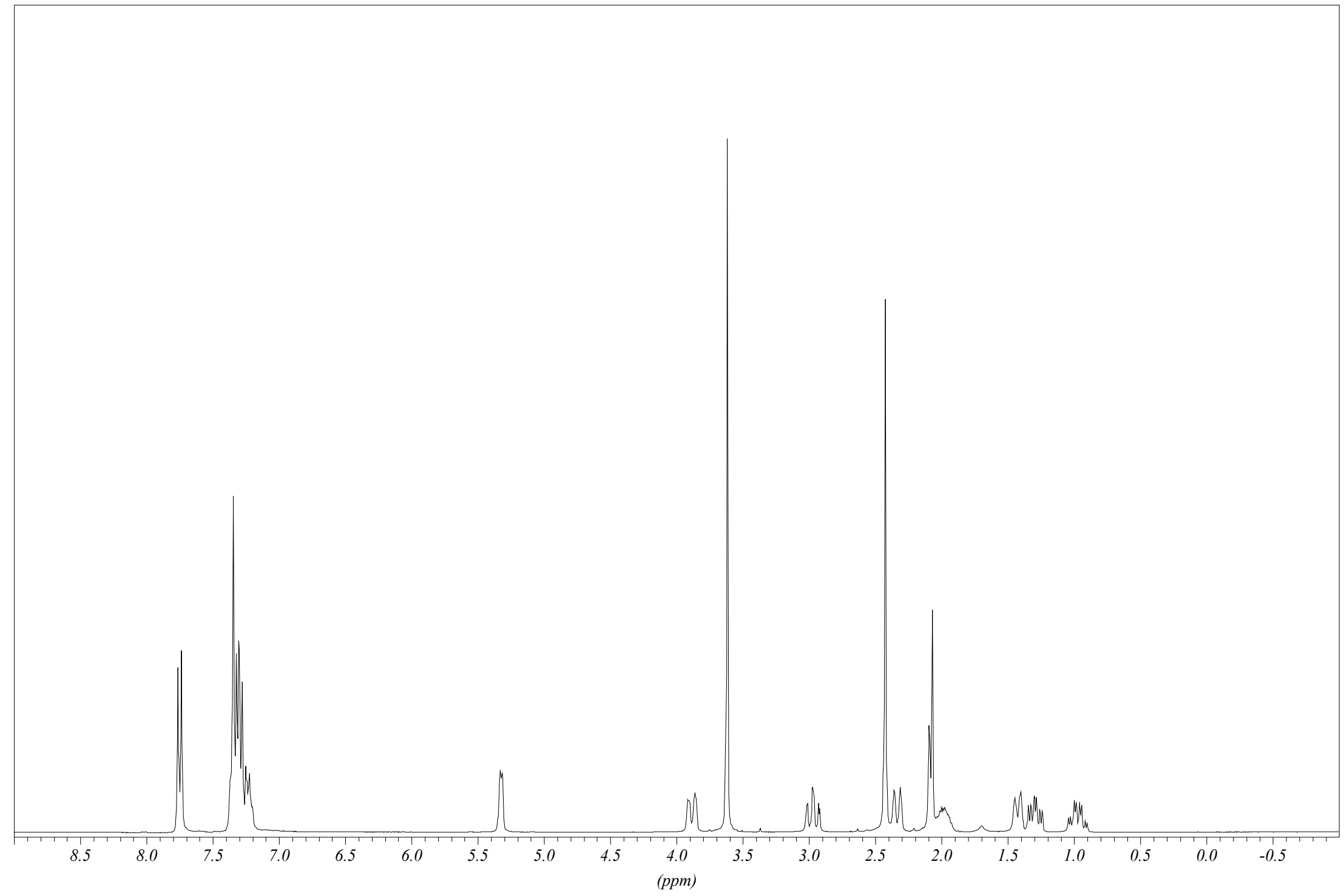

${ }^{1} \mathrm{H}$ NMR Spectrum (300 MHz) of $\mathbf{1 6 k}$ in $\mathrm{CDCl}_{3}$ 


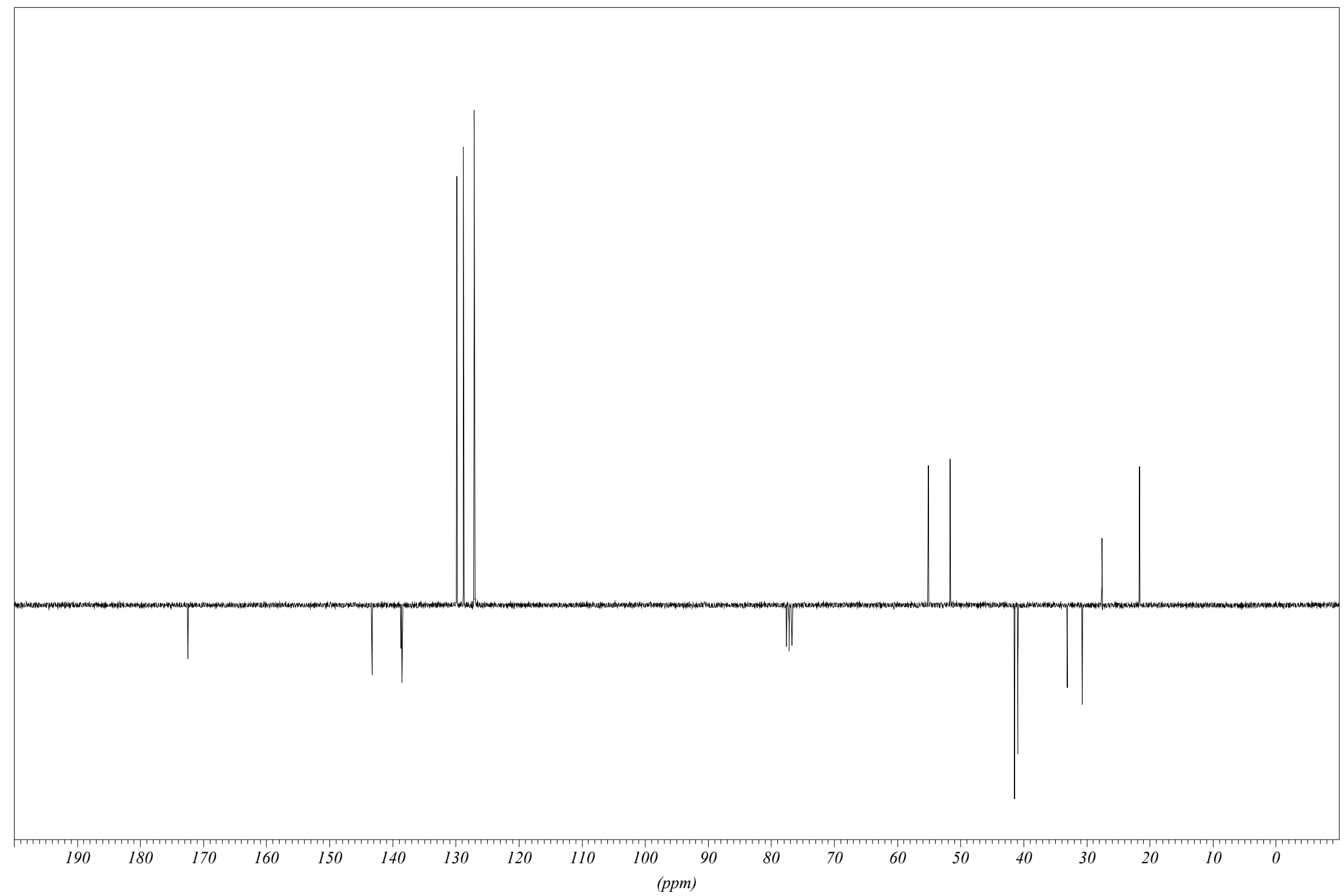

${ }^{13} \mathrm{C}$ NMR Spectrum $(75 \mathrm{MHz})$ of $\mathbf{1 6} \mathbf{k}$ in $\mathrm{CDCl}_{3}$ 


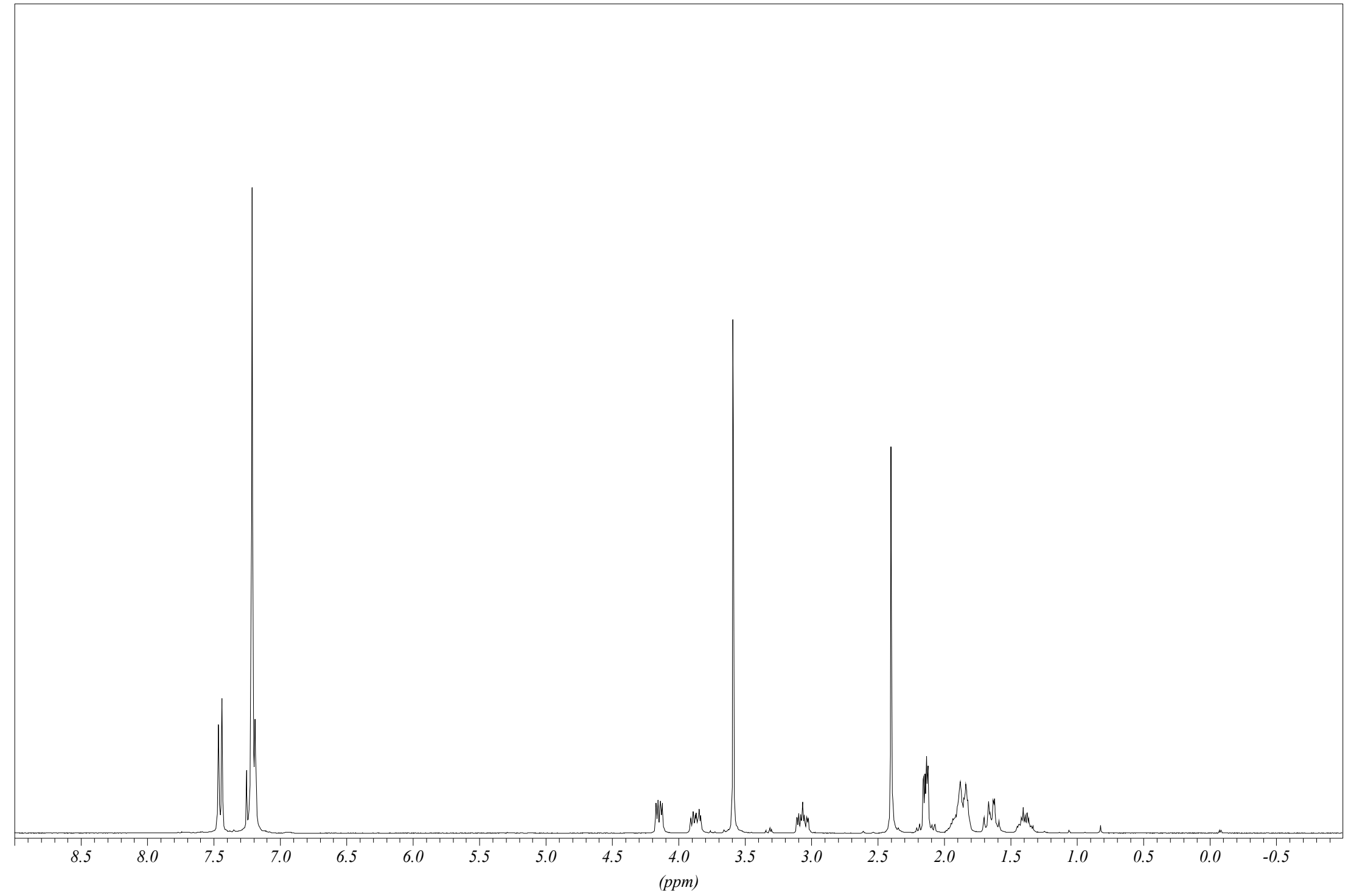

${ }^{1} \mathrm{H}$ NMR Spectrum (300 MHz) of $\mathbf{1 7} \mathbf{k}$ in $\mathrm{CDCl}_{3}$ 


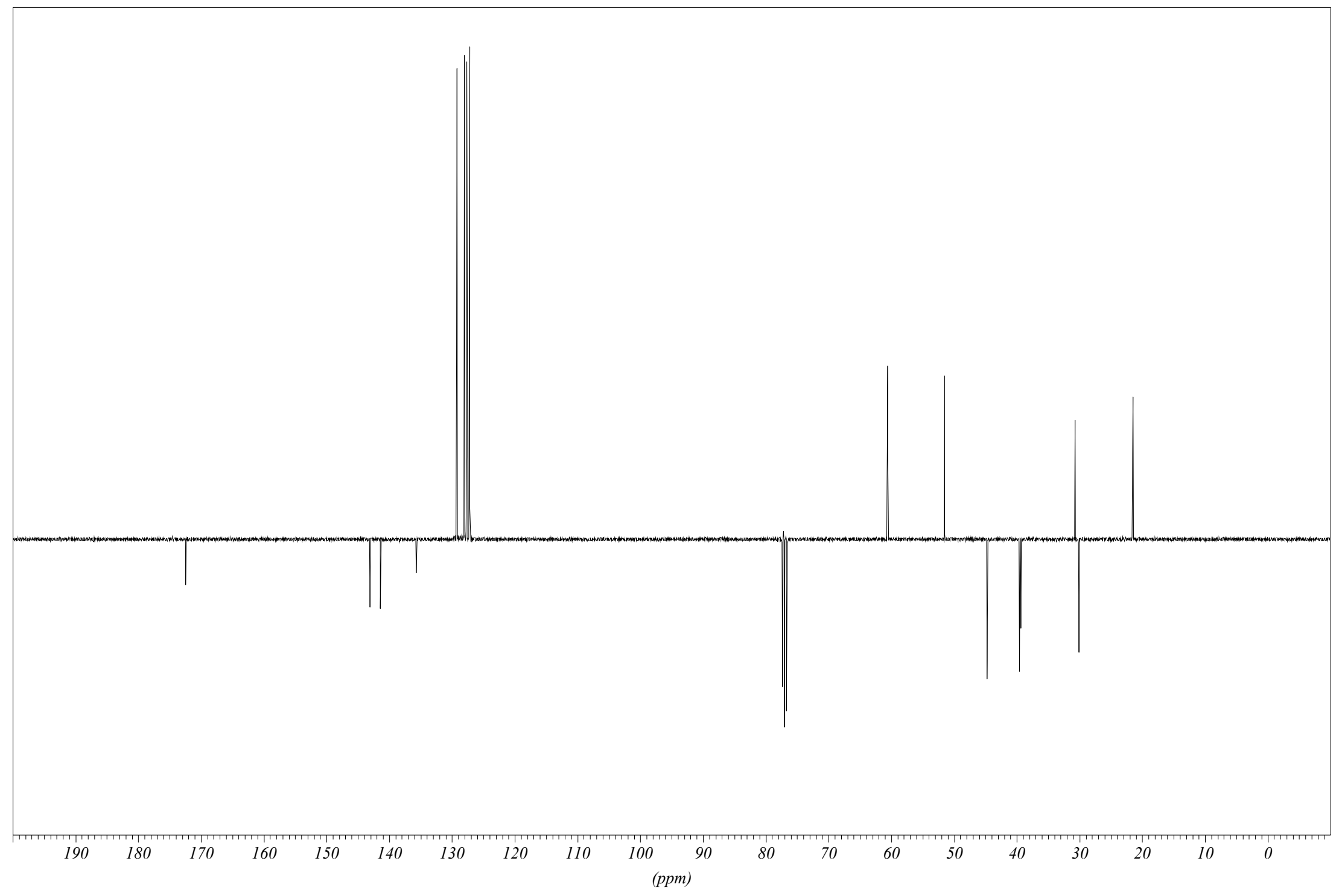

${ }^{13} \mathrm{C}$ NMR Spectrum $(100 \mathrm{MHz})$ of $\mathbf{1 7} \mathbf{k}$ in $\mathrm{CDCl}_{3}$ 


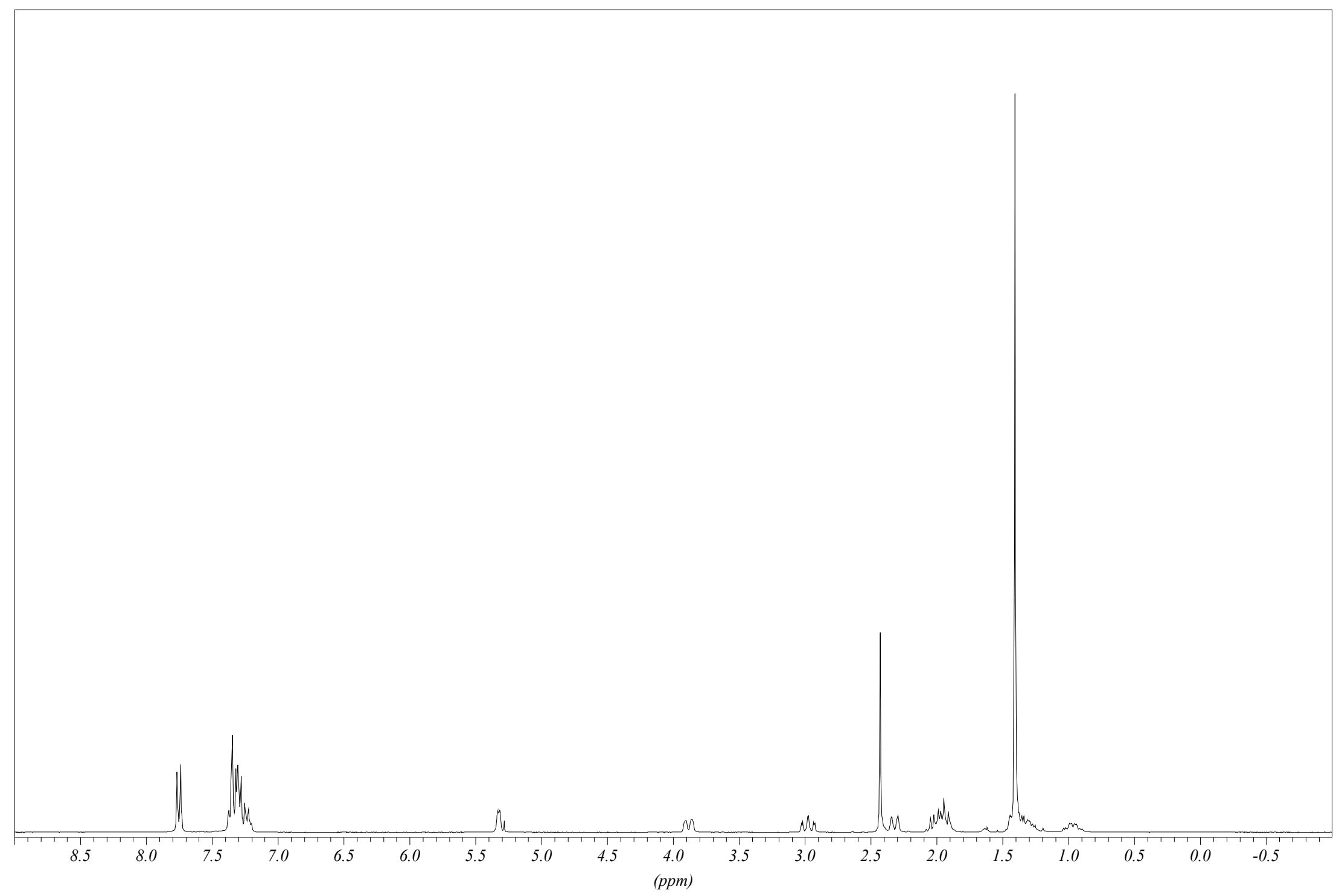

${ }^{1} \mathrm{H}$ NMR Spectrum (300 MHz) of $\mathbf{1 6 1}$ in $\mathrm{CDCl}_{3}$ 


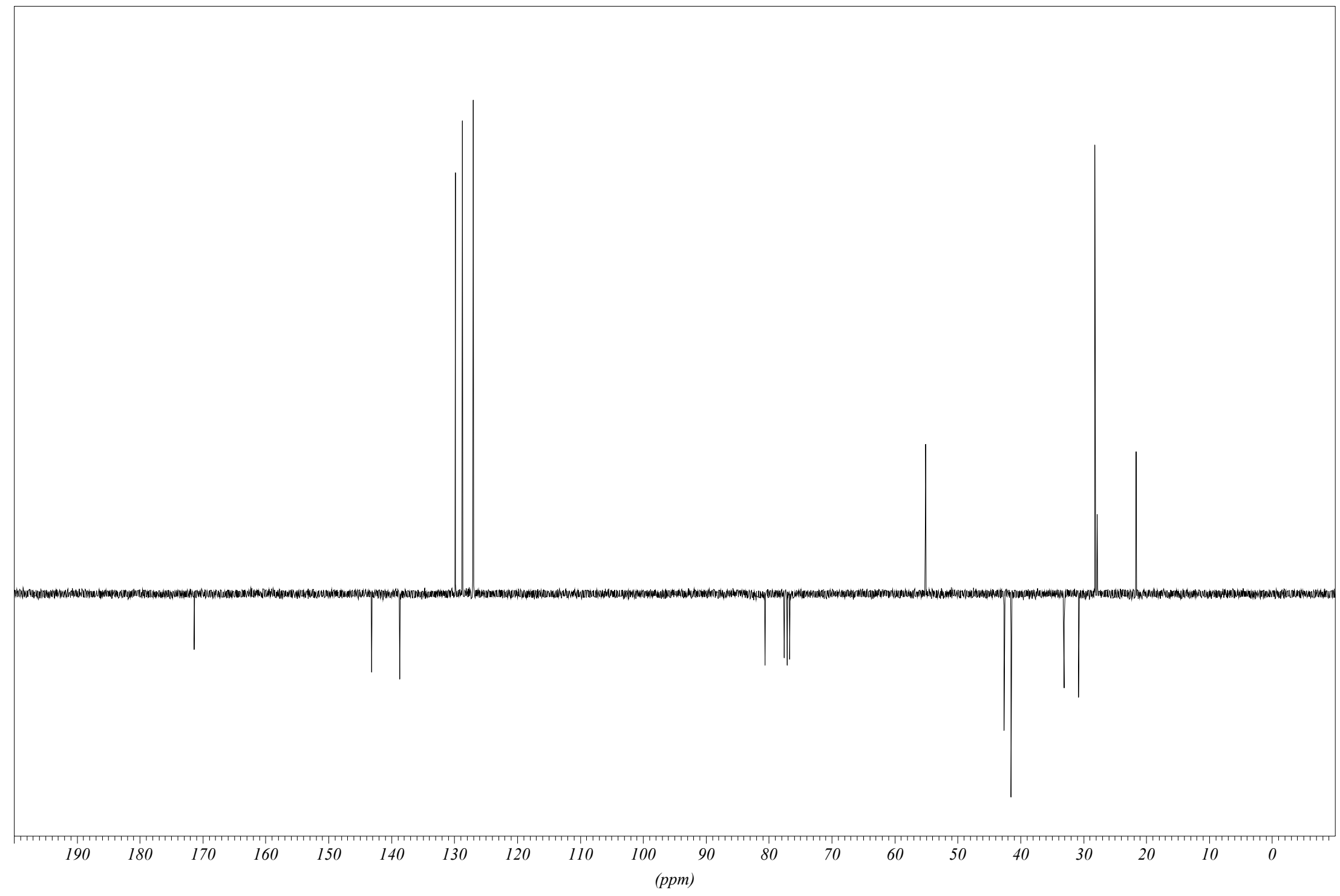

${ }^{13} \mathrm{C}$ NMR Spectrum $\left(75 \mathrm{MHz}\right.$ ) of $\mathbf{1 6 1}$ in $\mathrm{CDCl}_{3}$ 


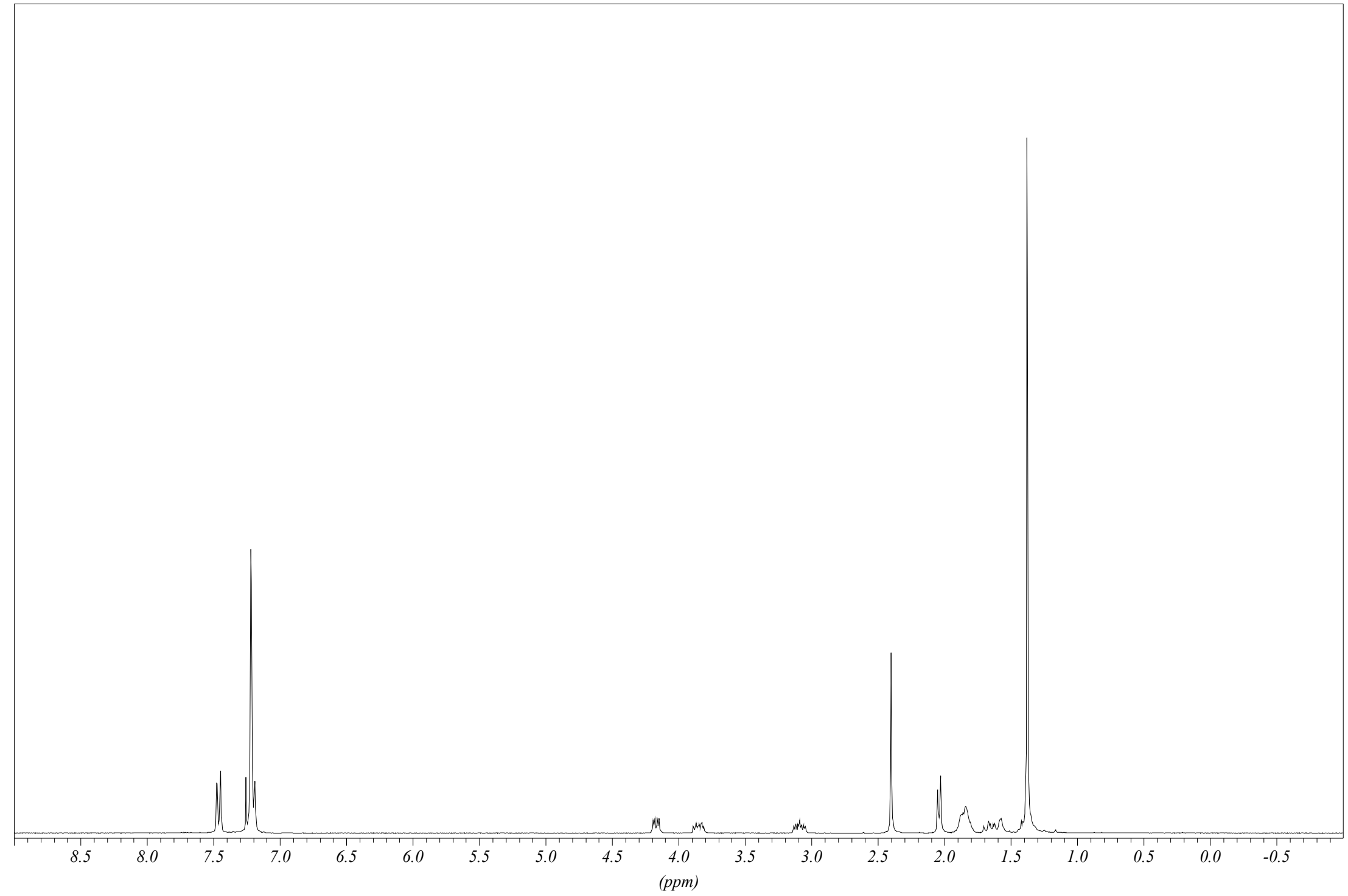

${ }^{1} \mathrm{H}$ NMR Spectrum (300 MHz) of $\mathbf{1 7 l}$ in $\mathrm{CDCl}_{3}$ 


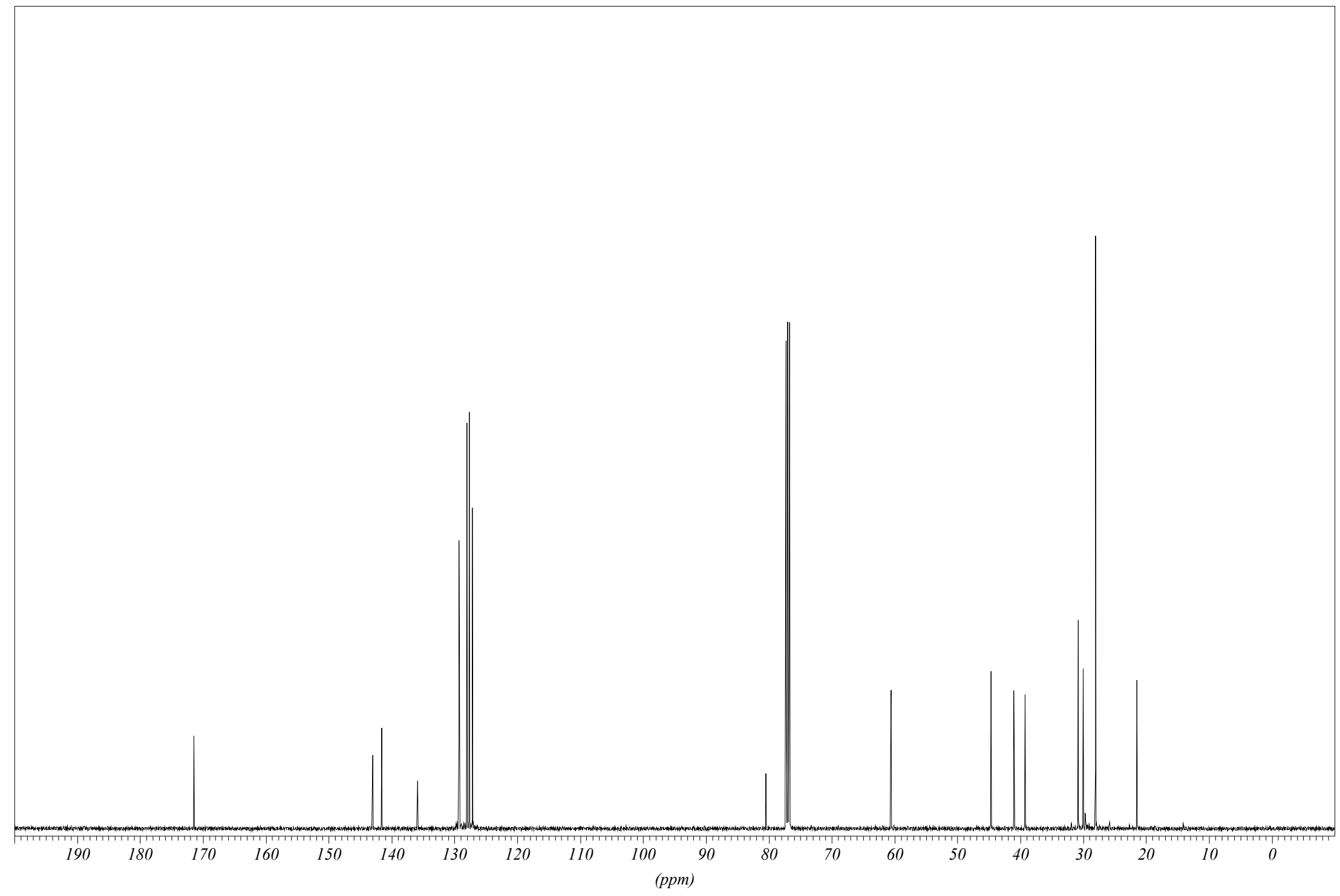

${ }^{13} \mathrm{C}$ NMR Spectrum $(125 \mathrm{MHz})$ of $\mathbf{1 7 l}$ in $\mathrm{CDCl}_{3}$ 


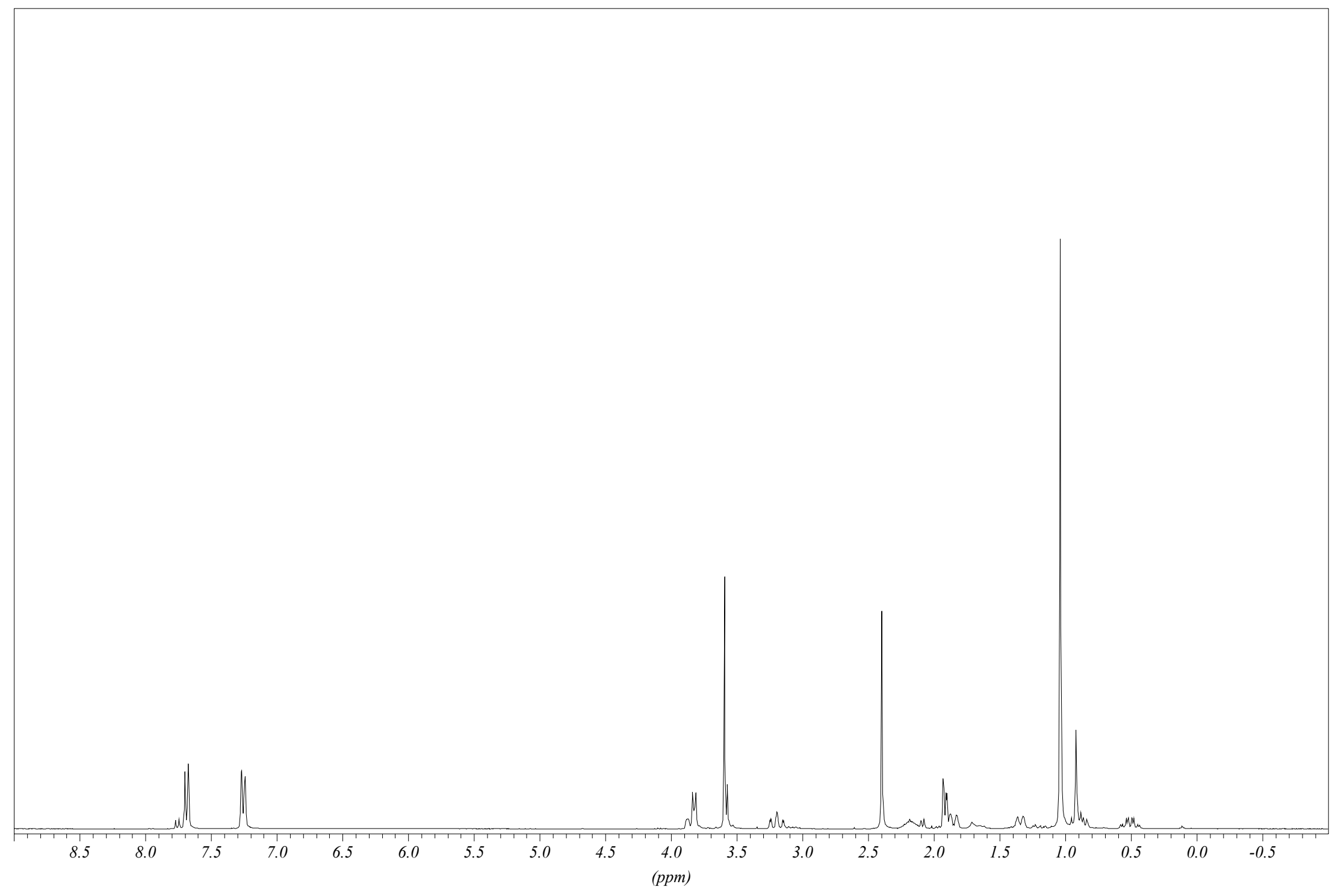

${ }^{1} \mathrm{H}$ NMR Spectrum $\left(300 \mathrm{MHz}\right.$ ) of $\mathbf{1 6} \mathbf{m}$ and $\mathbf{1 7} \mathbf{m}$ in $\mathrm{CDCl}_{3}$ 


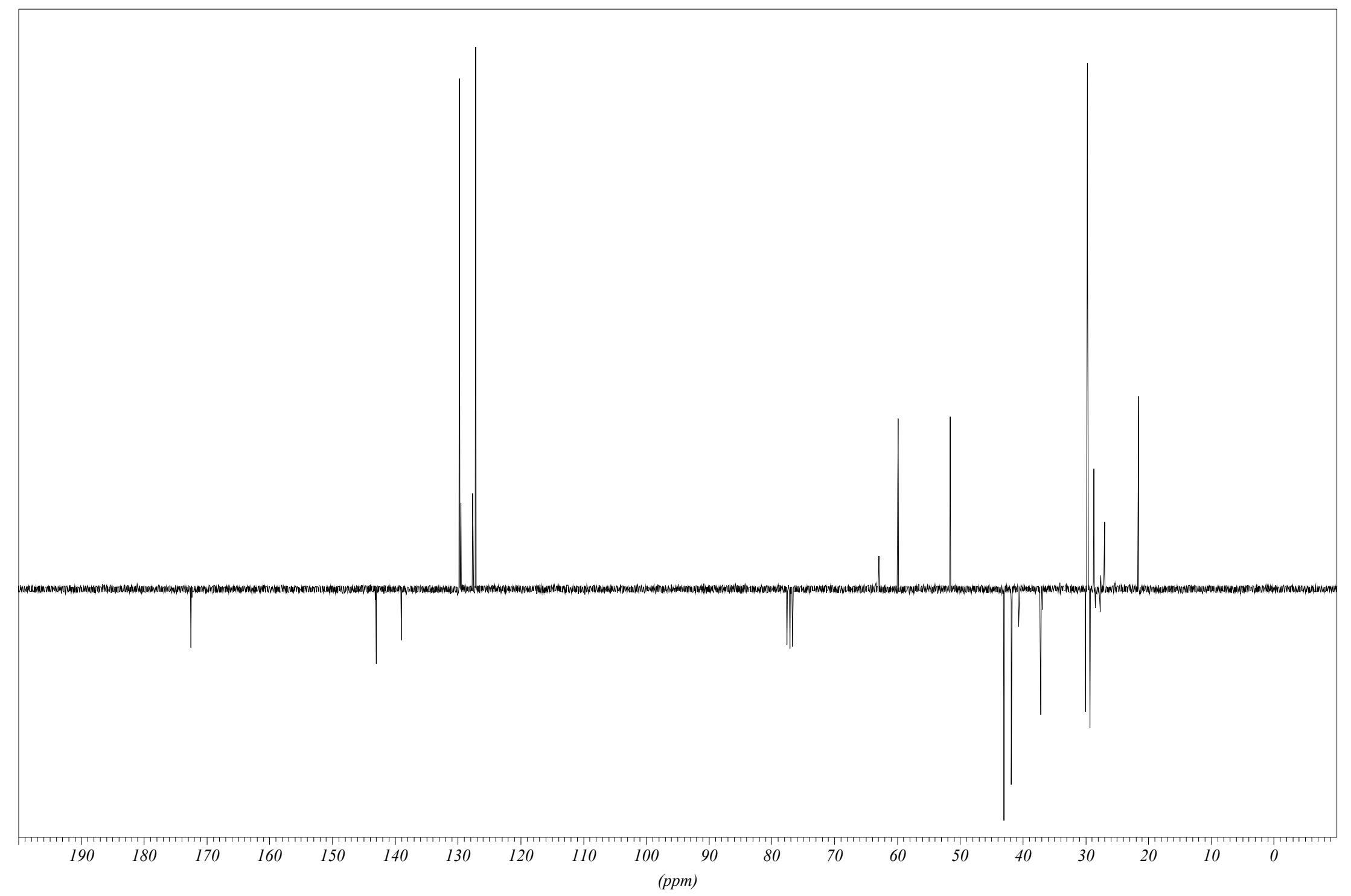

${ }^{13} \mathrm{C}$ NMR Spectrum $\left(75 \mathrm{MHz}\right.$ ) of $\mathbf{1 6} \mathbf{m}$ and $\mathbf{1 7} \mathbf{m}$ in $\mathrm{CDCl}_{3}$ 


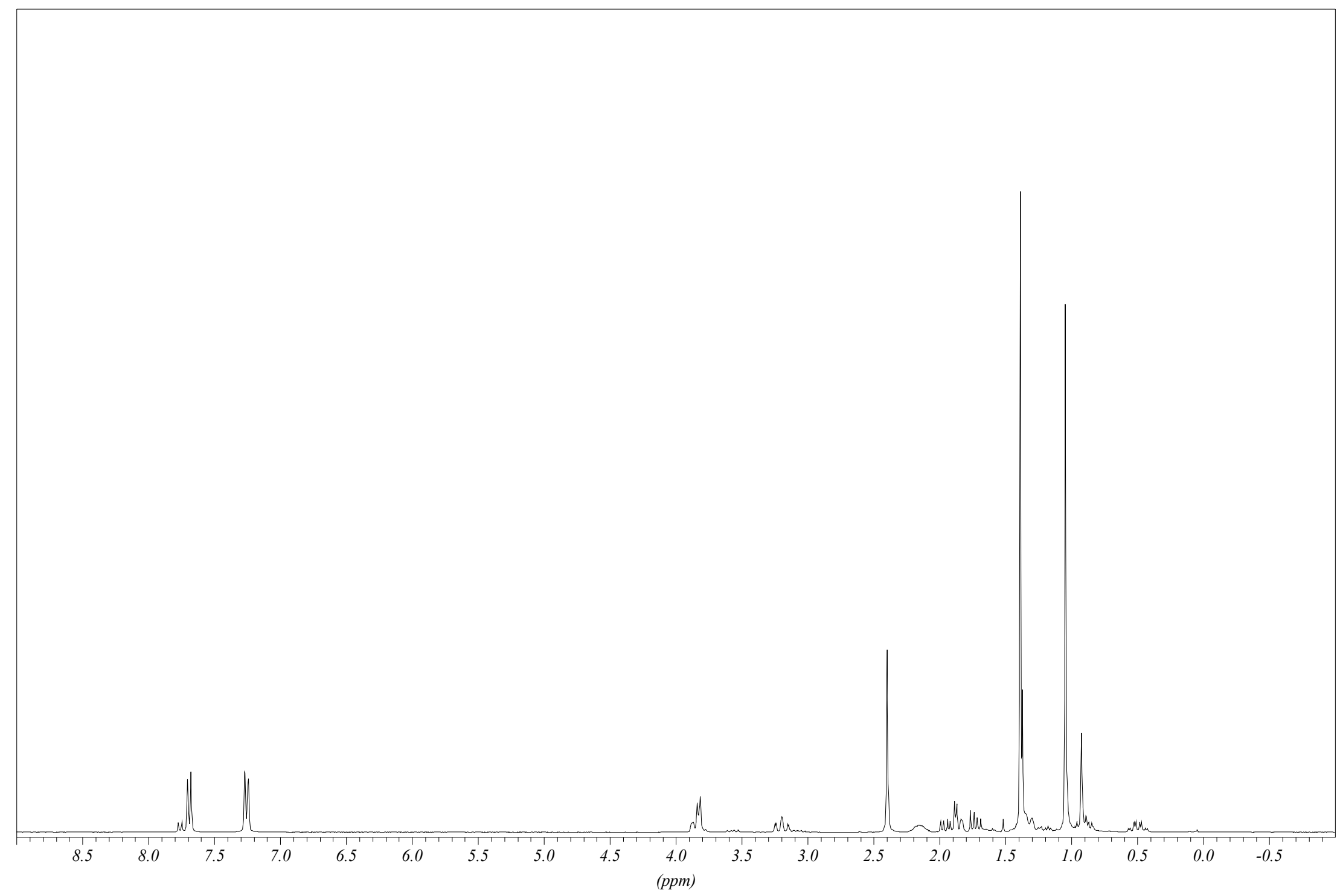

${ }^{1} \mathrm{H}$ NMR Spectrum $(300 \mathrm{MHz})$ of $\mathbf{1 6 n}$ and $\mathbf{1 7 n}$ in $\mathrm{CDCl}_{3}$ 


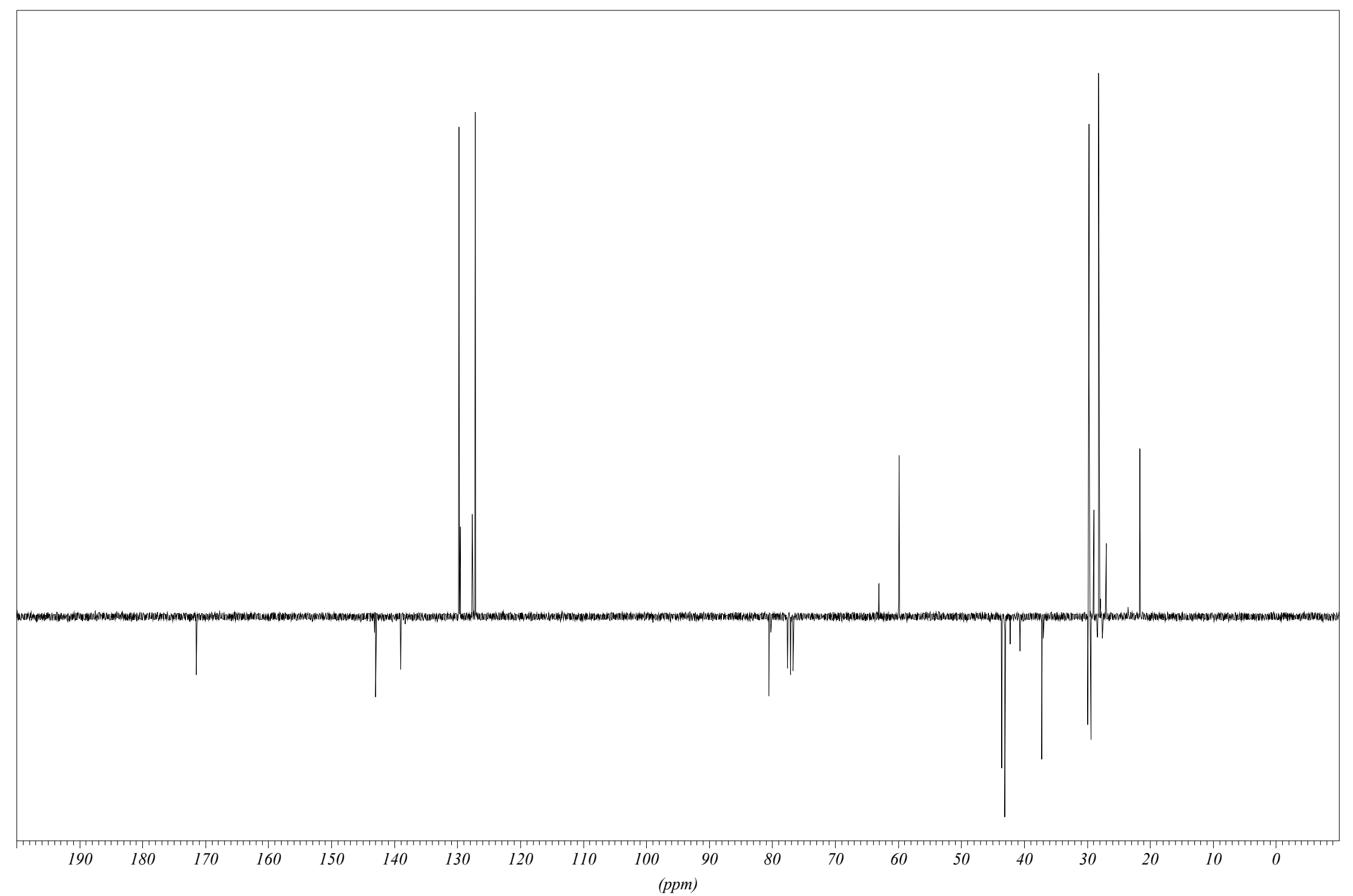

${ }^{13} \mathrm{C}$ NMR Spectrum $(75 \mathrm{MHz})$ of $\mathbf{1 6} \mathbf{n}$ and $\mathbf{1 7} \mathbf{n}$ in $\mathrm{CDCl}_{3}$ 


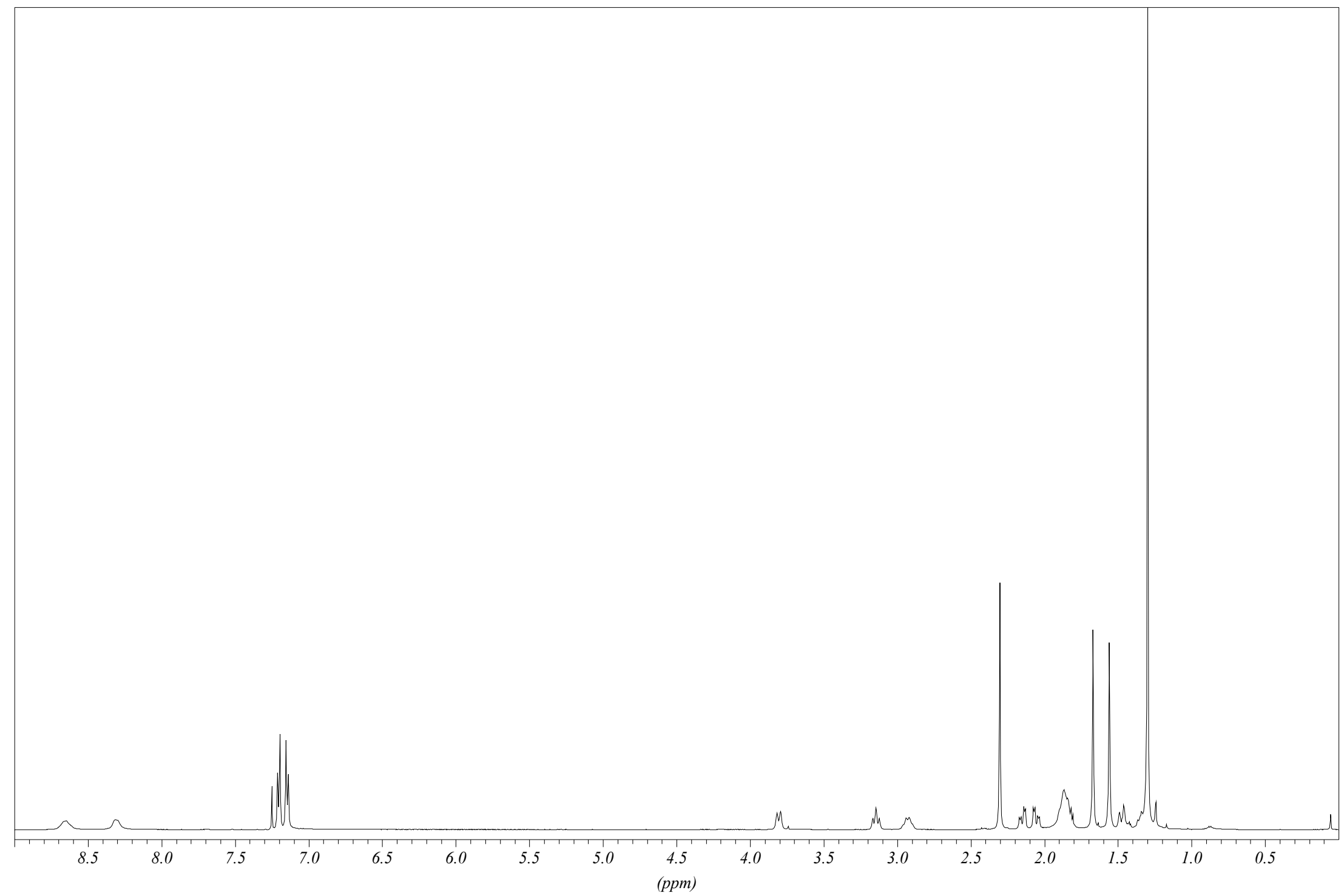

${ }^{1} \mathrm{H}$ NMR Spectrum $(500 \mathrm{MHz})$ of $\mathbf{2 4} \mathbf{f}$ in $\mathrm{CDCl}_{3}$ 


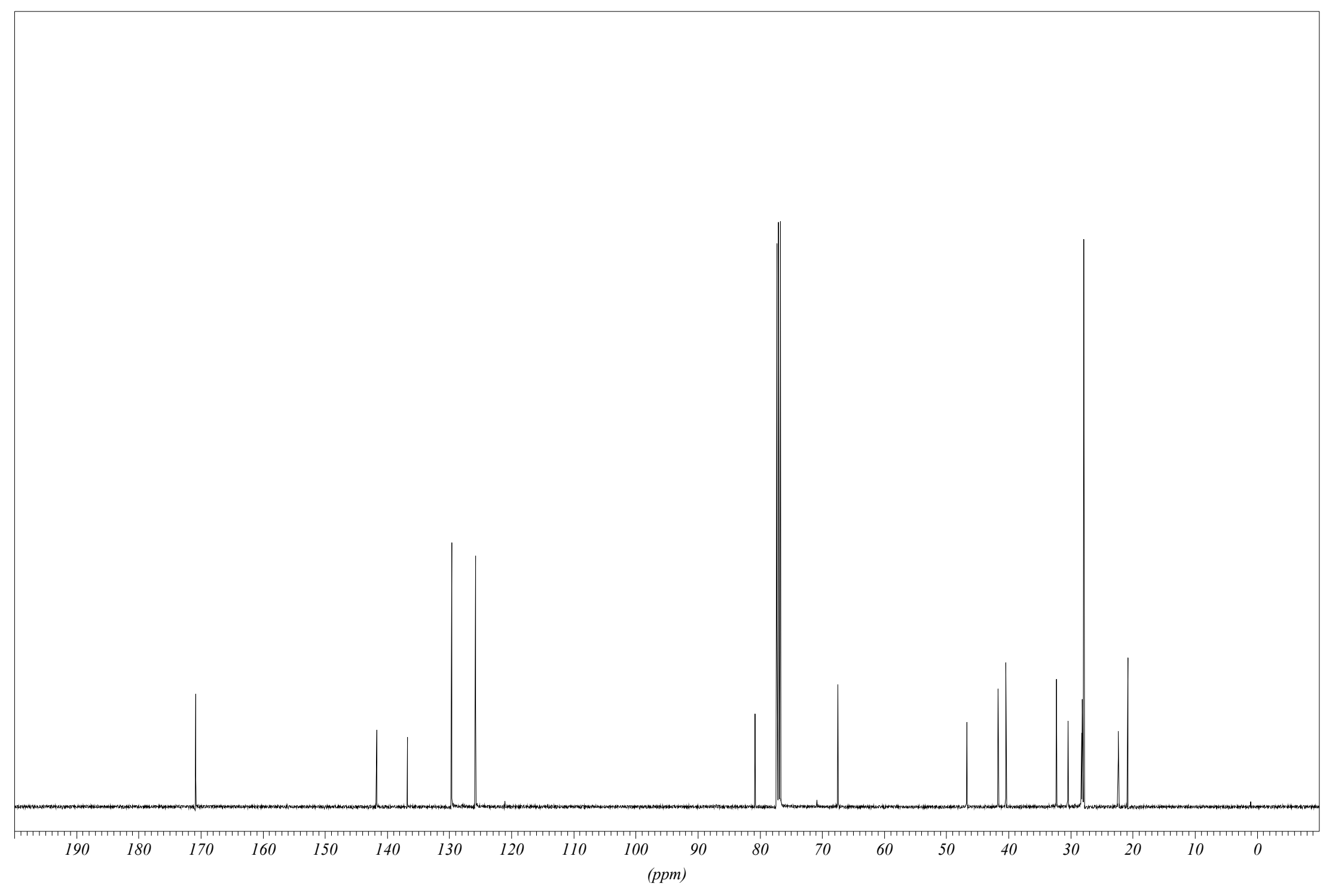

${ }^{13} \mathrm{C}$ NMR Spectrum (125 MHz) of $\mathbf{2 4 f}$ in $\mathrm{CDCl}_{3}$ 


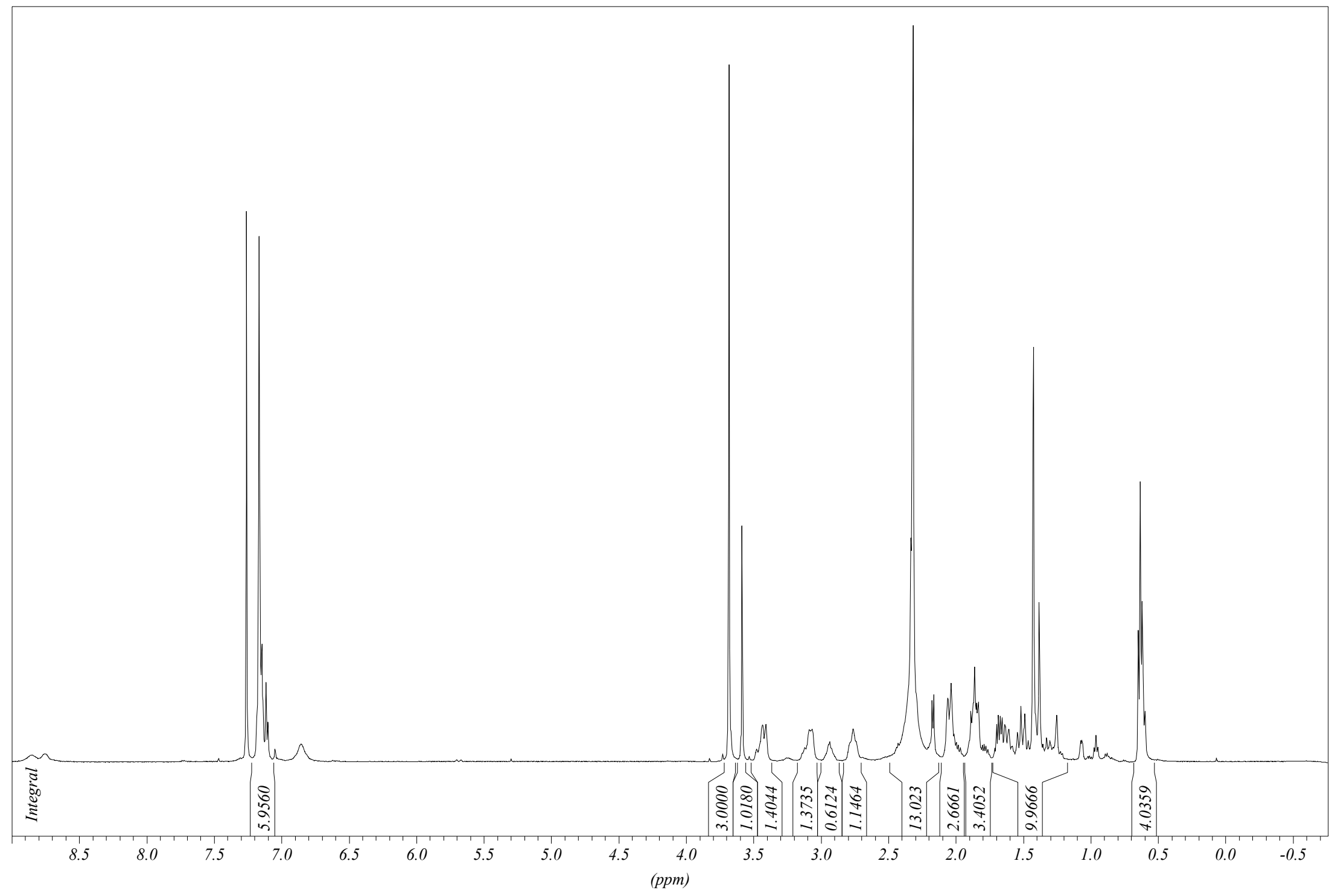

${ }^{1} \mathrm{H}$ NMR Spectrum (300 MHz) of $\mathbf{2 4 i}$ in $\mathrm{CDCl}_{3}$ 


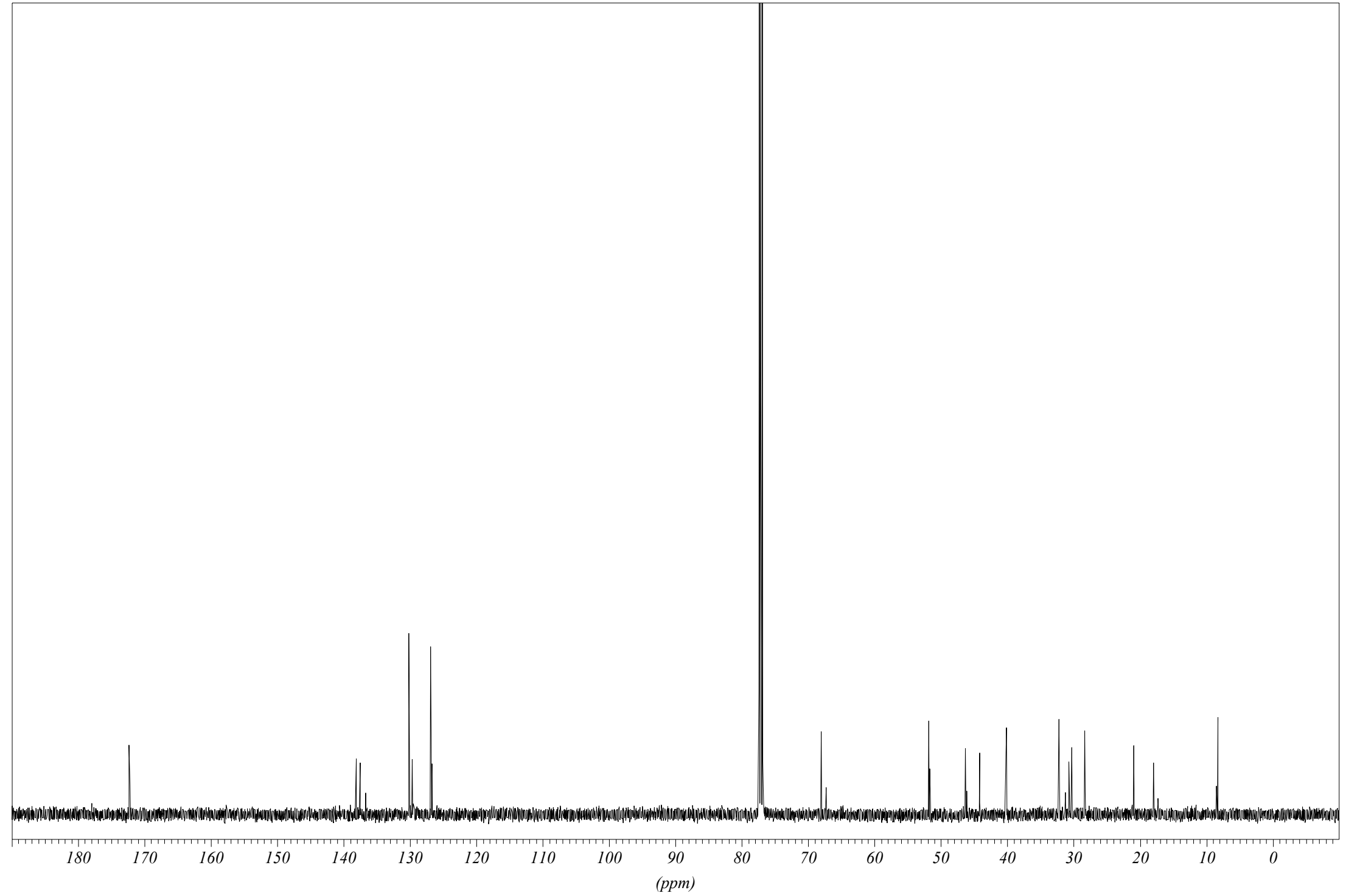

${ }^{13} \mathrm{C}$ NMR Spectrum (75 MHz) of 24i in $\mathrm{CDCl}_{3}$ 


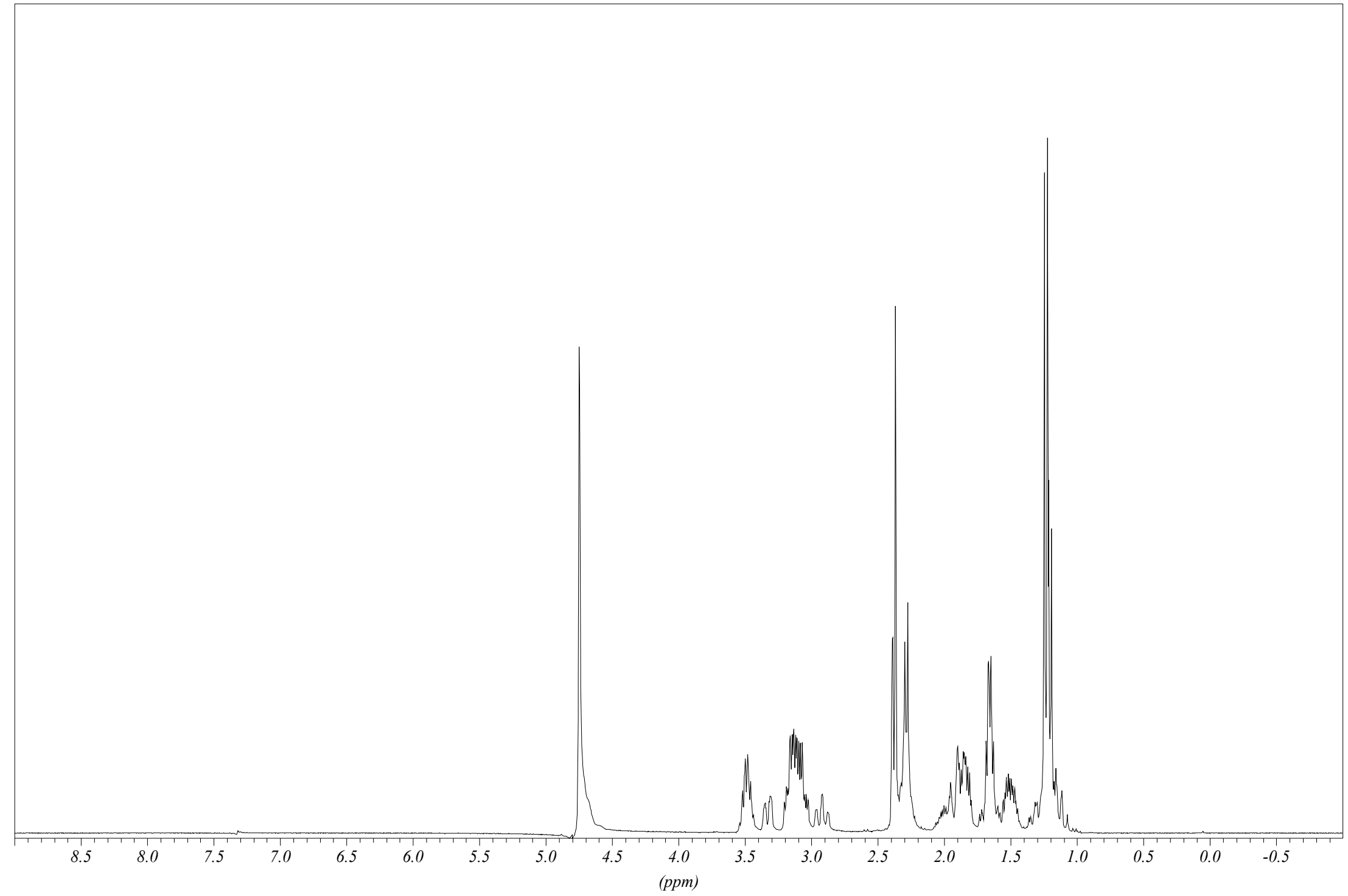

${ }^{1} \mathrm{H}$ NMR Spectrum $(300 \mathrm{MHz})$ of $25 \mathbf{a}$ in $\mathrm{D}_{2} \mathrm{O}$ 


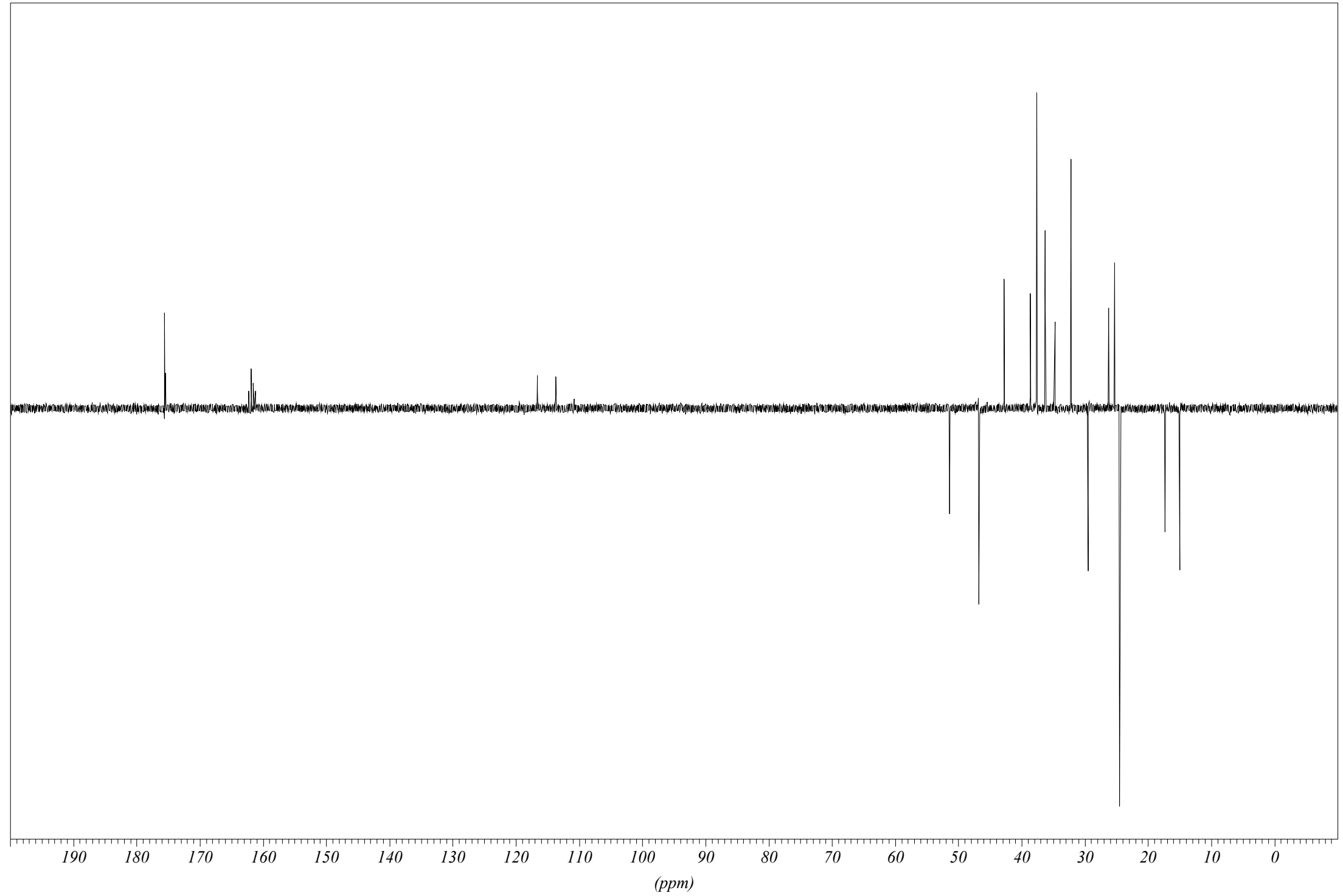

${ }^{13} \mathrm{C}$ NMR Spectrum $(100 \mathrm{MHz})$ of $\mathbf{2 5 a}$ in $\mathrm{D}_{2} \mathrm{O}$ NB trifluoroacetate counterion peaks also visible 


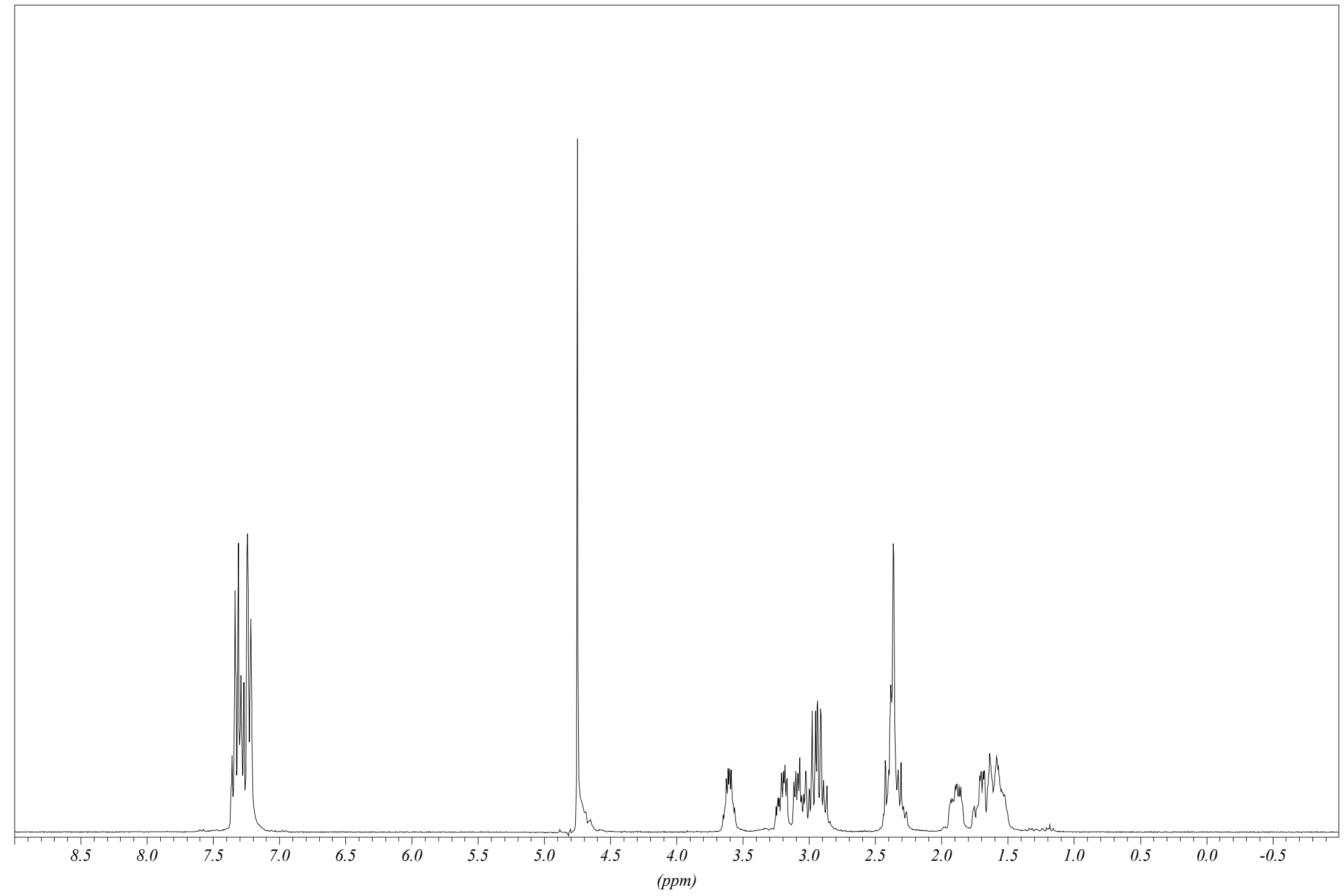

${ }^{1} \mathrm{H}$ NMR Spectrum $(300 \mathrm{MHz})$ of $\mathbf{2 5 b}$ in $\mathrm{D}_{2} \mathrm{O}$ 


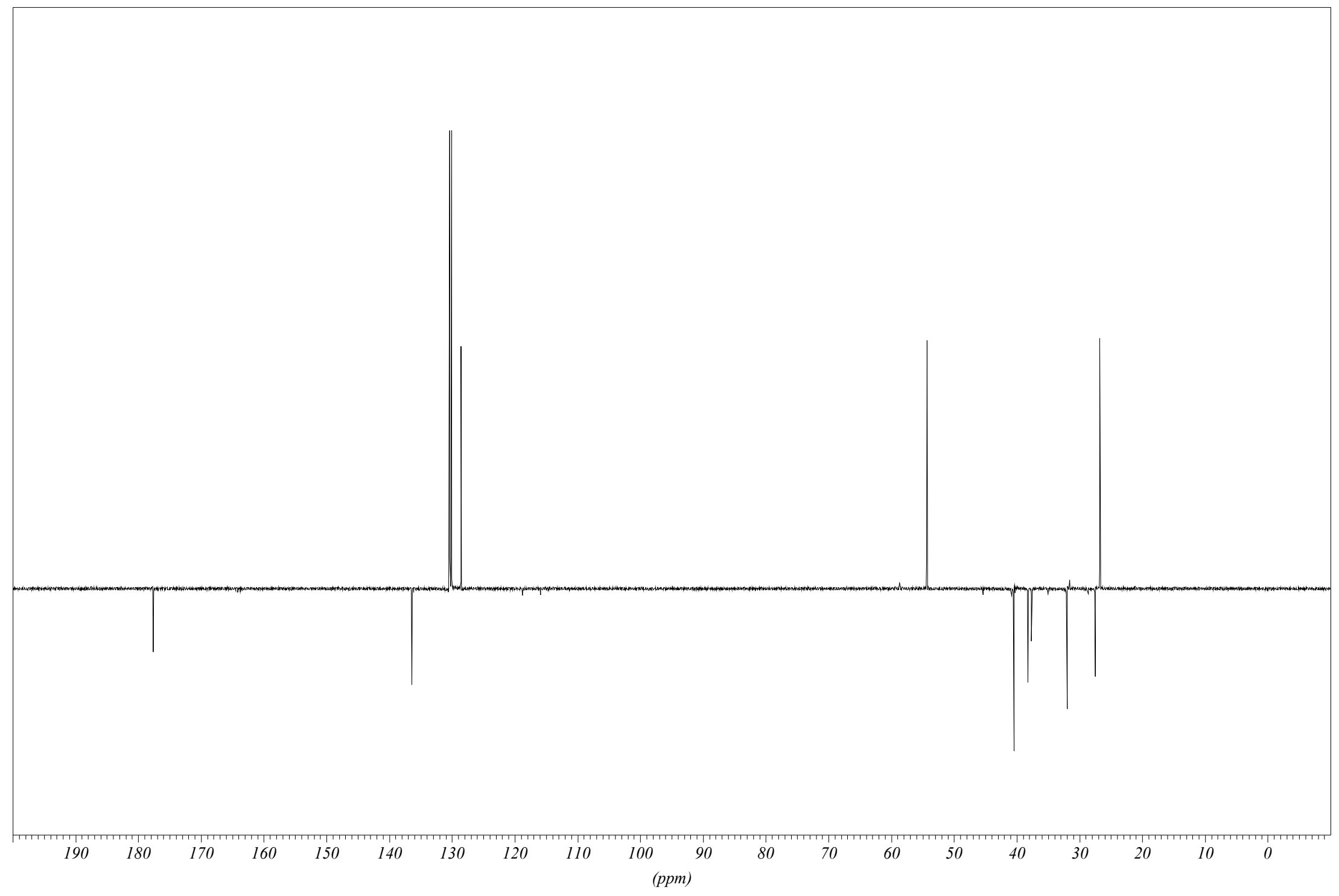

${ }^{13} \mathrm{C}$ NMR Spectrum $(100 \mathrm{MHz})$ of $\mathbf{2 5 b}$ in $\mathrm{D}_{2} \mathrm{O}$ 


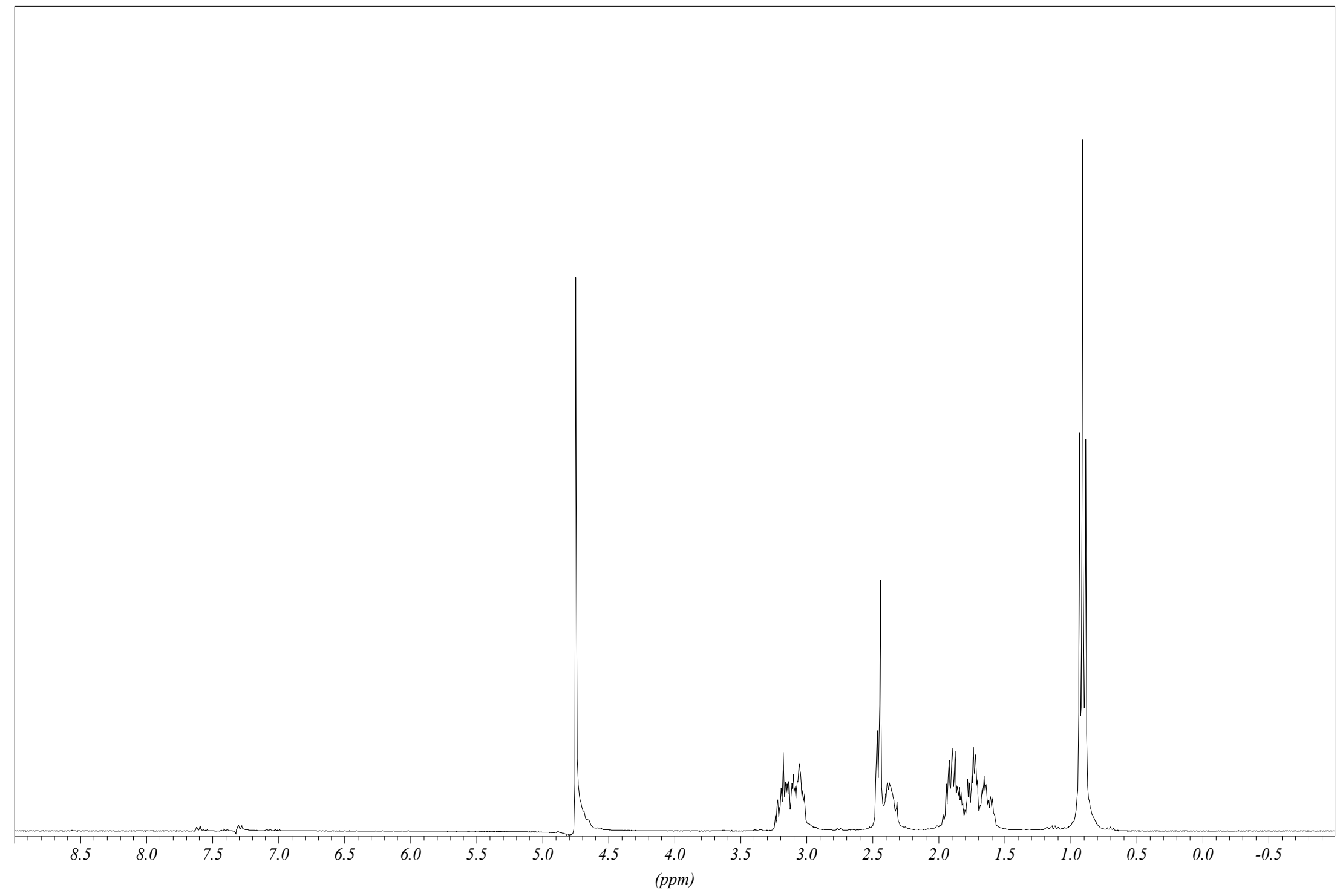

${ }^{1} \mathrm{H}$ NMR Spectrum $(300 \mathrm{MHz})$ of $\mathbf{2 5 c}$ in $\mathrm{D}_{2} \mathrm{O}$ 


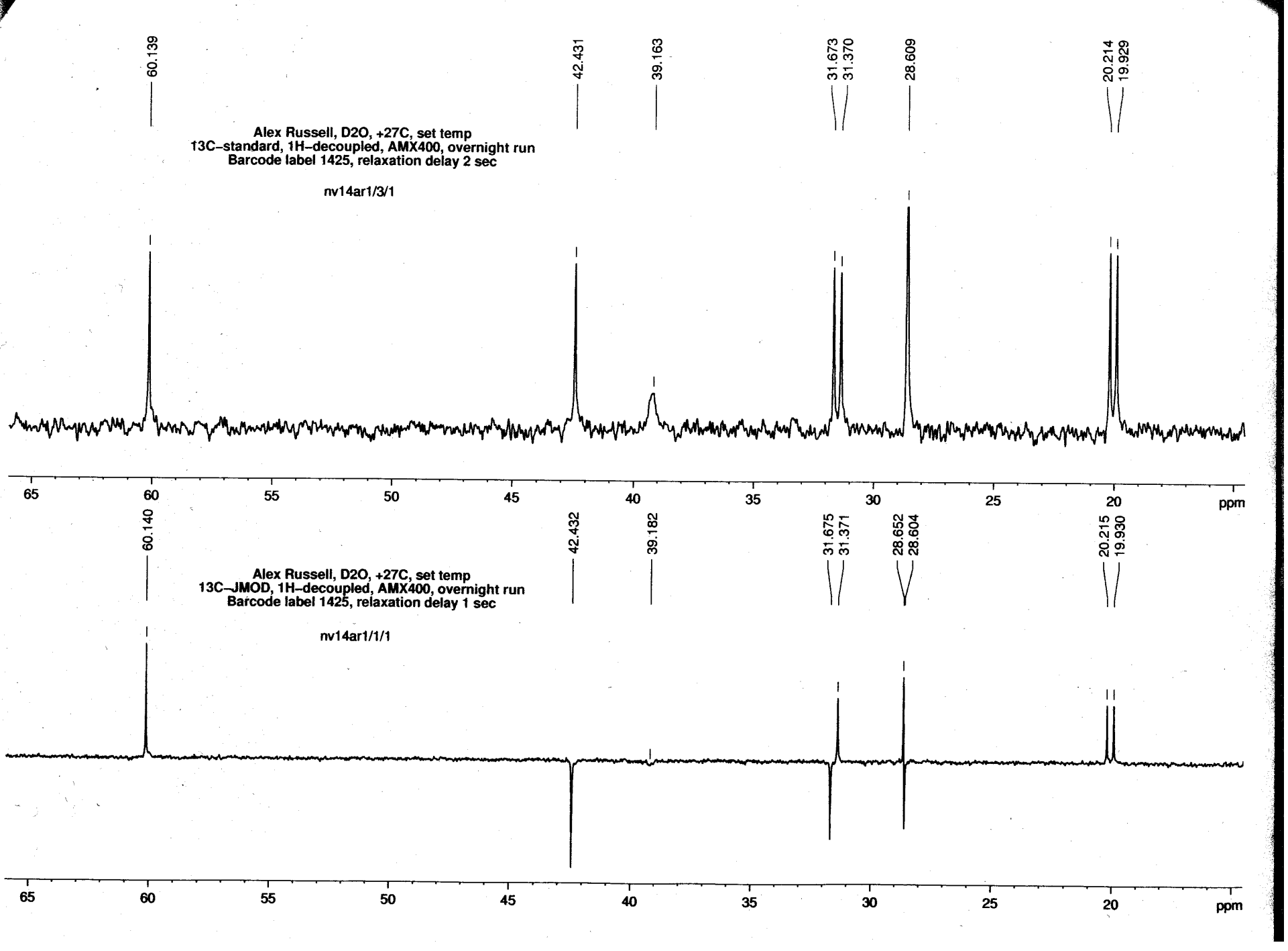

${ }^{13} \mathrm{C}$ NMR Spectrum (100 MHz) of $\mathbf{2 5 c}$ in $\mathrm{D}_{2} \mathrm{O}$ (2 second relaxation delay) 
Alex Russell, D2O, 27C, set temp
13C-JMOD, $1 \mathrm{H}-$ decoupled, AMM400, overnight run
Barcode label 1425, relaxation delay 1 sec
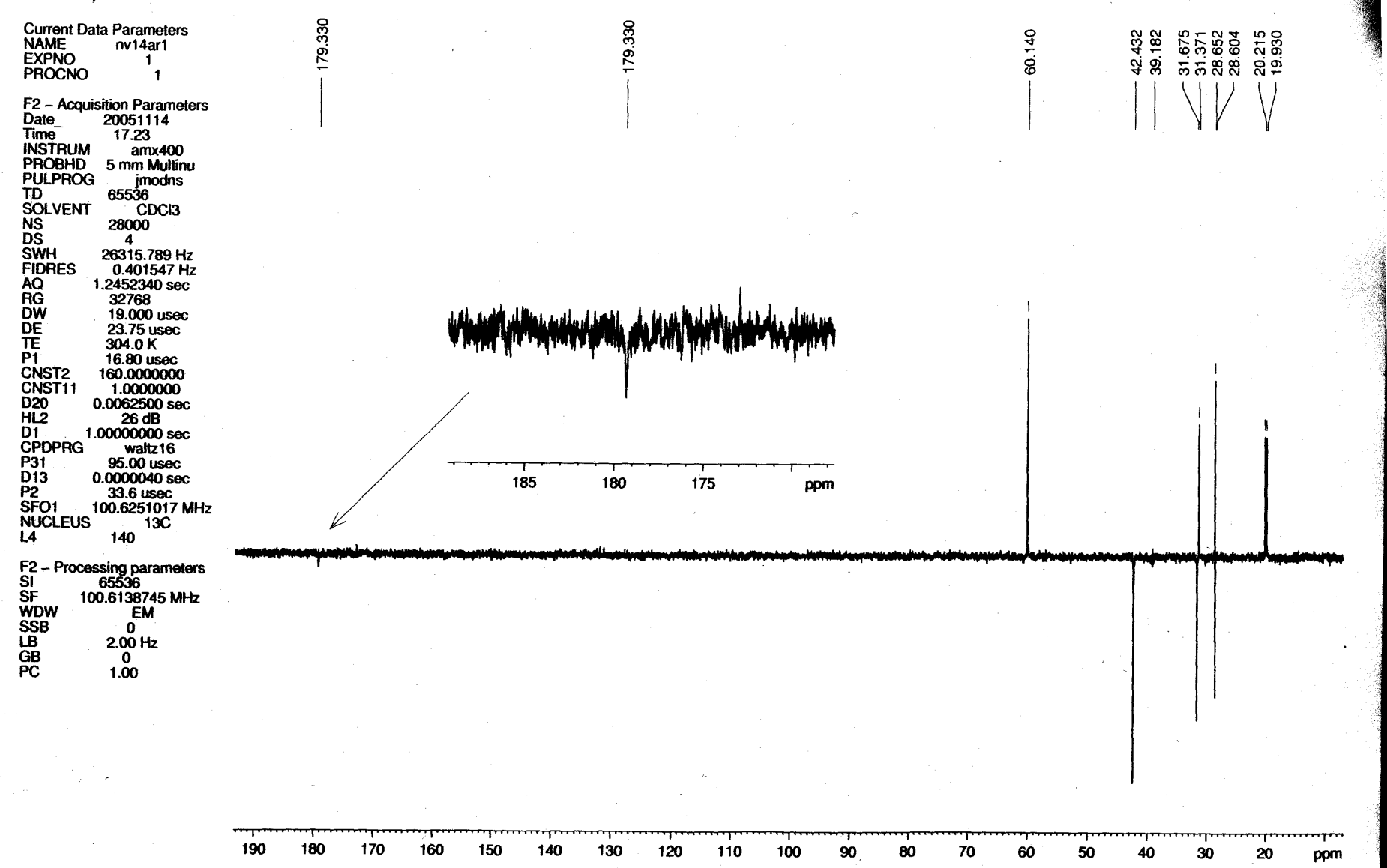

${ }^{13} \mathrm{C}$ NMR Spectrum $(100 \mathrm{MHz})$ of $25 \mathrm{c}$ in $\mathrm{D}_{2} \mathrm{O}$ (1 second relaxation delay) 


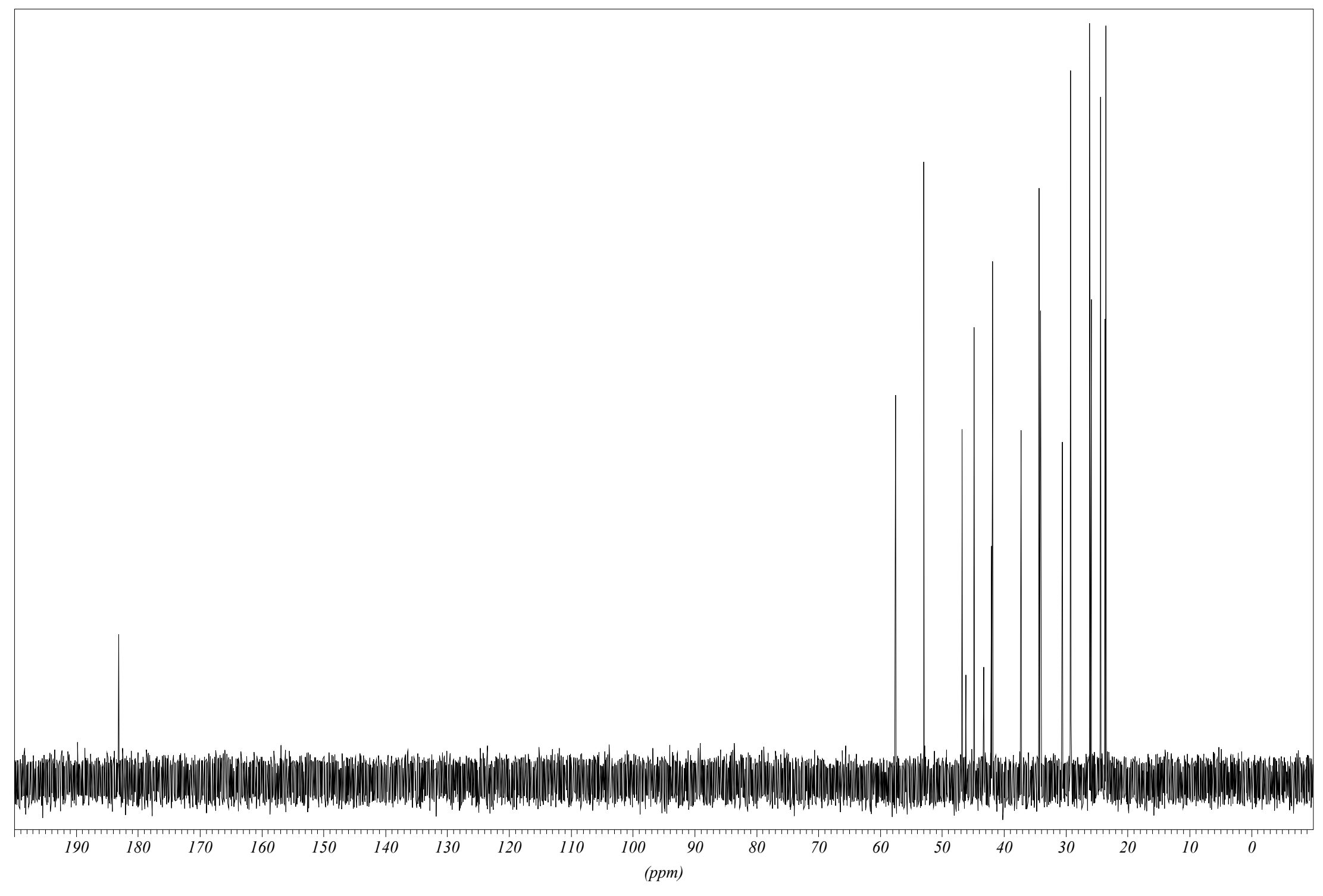

${ }^{13} \mathrm{C}$ NMR Spectrum $\left(75 \mathrm{MHz}\right.$ ) of 25d in $\mathrm{D}_{2} \mathrm{O}$ 


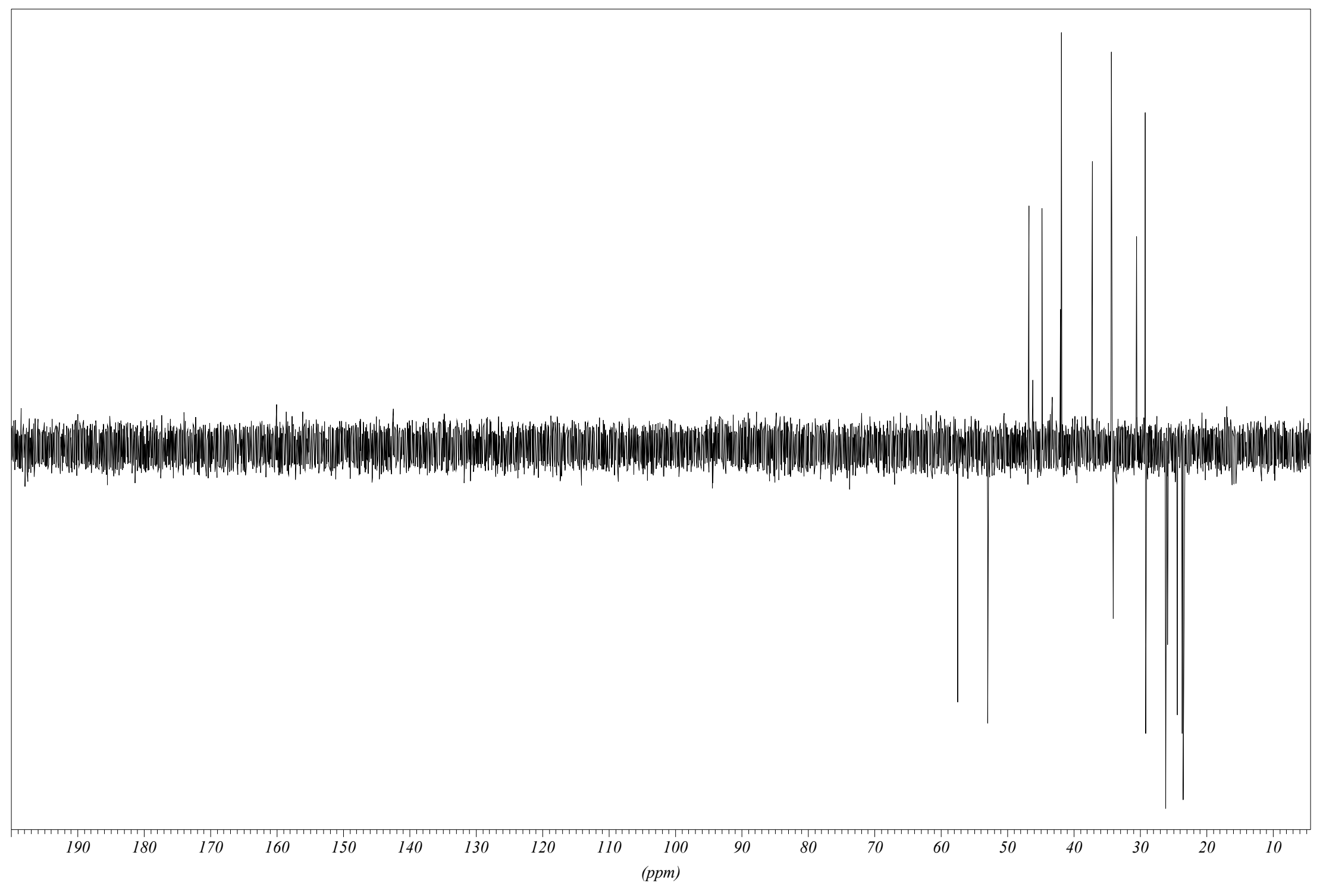

${ }^{13} \mathrm{C}$ NMR Spectrum $\left(75 \mathrm{MHz}\right.$ ) of 25d in $\mathrm{D}_{2} \mathrm{O}$ 